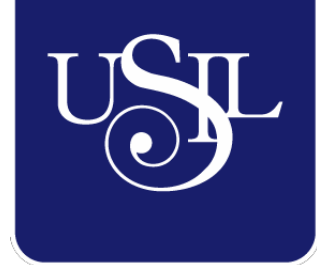

UNIVERSIDAD

SAN IGNACIO

DE LOYOLA

ESCUELA DE POSTGRADO

\title{
PLAN DE NEGOCIO PARA COMERCIALIZACIÓN DE LONCHERAS SALUDABLES EN COLEGIOS PARTICULARES DE EDUCACIÓN INICIAL Y PRIMARIA
}

Trabajo de Investigación para optar el grado de:

CARLOS ENRIQUE CUEVA ROMERO

Maestro en Ciencias Empresariales con Mención en Gestión de Proyectos

NORMA ROCIO SALAS YCHOCAN

Maestro en Ciencias Empresariales con Mención en Gestión de Proyectos

SUSANA ELENA VALVERDE GARAY

Maestro en Ciencias Empresariales con Mención en Gestión de Proyectos

RENE FERNANDO ZAVALAGA RABORG

Maestro en Ciencias Empresariales con Mención en Gestión de Proyectos

Asesor:

Dra. Nidia Ruth Vilchez Yucra

Lima - Perú

2020 


\section{RESUMEN}

La obesidad y sobrepeso son problemas que se han ido acentuando en las últimas generaciones y ello debido al estilo de vida cada vez más acelerado que conlleva al consumo de los bien llamados alimentos chatarra.

Los niños obesos o con sobrepeso tienden a continuar siendo obesos durante su adolescencia y adultez y ello tiene como consecuencias problemas de salud como enfermedades cardiovasculares e incluso la diabetes, sumado a problemas de baja autoestima.

El objetivo del presente proyecto de negocio es brindar una alternativa de alimentación saludable a los padres de familia con niños en edad escolar de educación inicial y primaria con opciones de loncheras que puedan ser agradables al paladar y a la vez nutritivas y saludables para su organismo.

Teniendo en cuenta esta problemática es que la propuesta inicial se realizará en colegios particulares de educación inicial y primaria ubicados en los distritos de Santa Anita, Ate y la Molina.

\section{Palabras clave:}

Obesidad, sobrepeso, alimentación saludable, niños y adolescentes 


\begin{abstract}
Obesity and overweight are problems that have been developing further in the last generations and this is due of to the increasingly accelerated lifestyle that leads to the aptly named junky food comsuption.

Children who are obese or with overweight problems, usually stay that way through their teenage and adult years carrying on many health problems as heart diseases, diabetes and even low self esteem issues.

The main goal of this business project is to bring healthy eating alternatives to the parents whose children are still in Pre or Elementary school, offering them several options for lunch breaks that could be not only pleasant and tasty but healthy and with nutrional content at the same time.

In view of the difficulties sorrounding this topic, the initial proposal will be applied for Pre and Elementary private schools located in Santa Anita, Ate and La Molina áreas.
\end{abstract}

Keywords:

Obesity, overweight, healthy eating, children and teenagers 


\section{Tabla de Contenidos}

Lista de tablas

Lista de figuras .xvii

Lista de anexos XX

Resumen ejecutivo 1

Introducción 3

Capítulo I. Generalidades 6

1.1. Antecedentes 6

1.2. Determinación del problema u oportunidad 12

1.3. Justificación del proyecto 16

1.4. Objetivos generales y específicos 17

1.5. Alcances y limitaciones de la investigación 18

Capítulo II. Estructura económica del sector 19

2.1. Descripción del estado actual de la industria

2.1.1. Segmentación de la industria

2.1.2. Empresas que la conforman

2.2. Tendencias de la industria .26

2.3. Análisis estructural del sector industrial .... .28

2.3.1. Rivalidad entre competidores actuales. .29

2.3.2. Amenaza de entrada de nuevos competidores 31

2.3.3. Poder de negociación de los proveedores 32

2.3.4. Poder de negociación de los clientes 34 


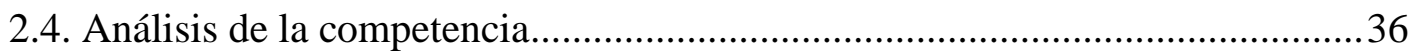

2.4.1. Empresas que ofrecen el mismo producto o servicio..................................36

2.4.2. Participación de mercado de cada uno de ellos ........................................40

2.4.3. Matriz de perfil competitivo …................................................................. 41

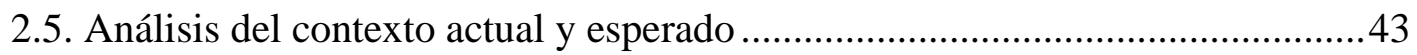

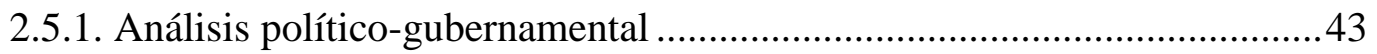

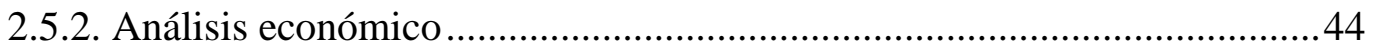

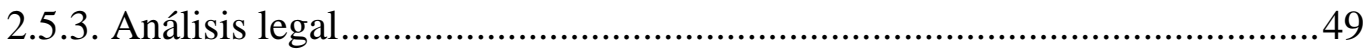

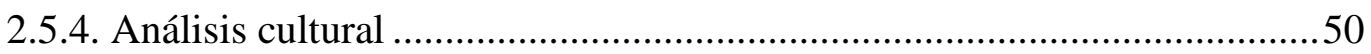

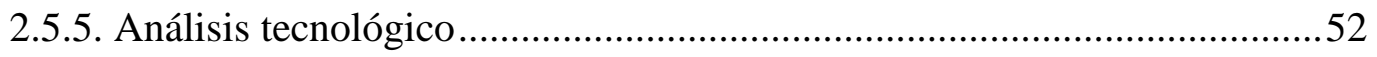

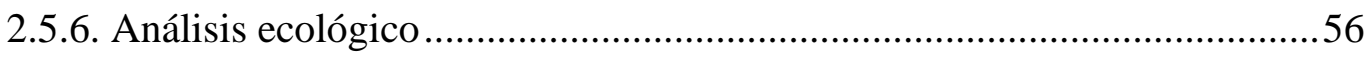

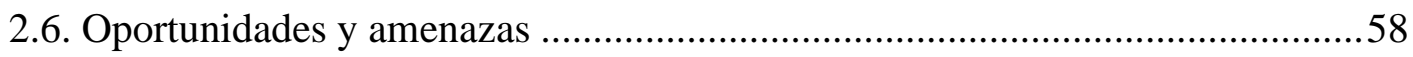

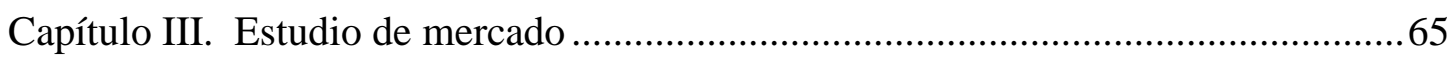

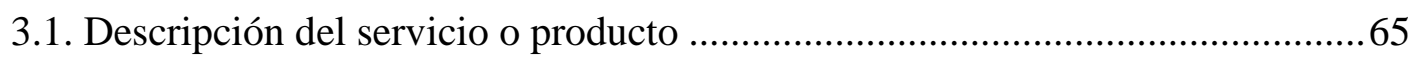

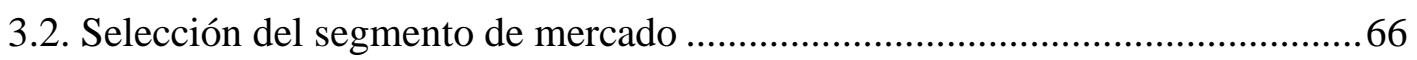

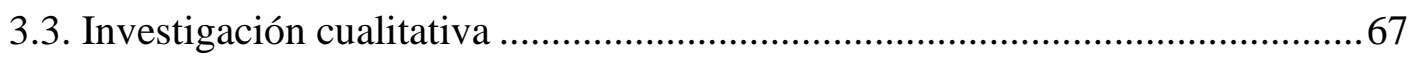

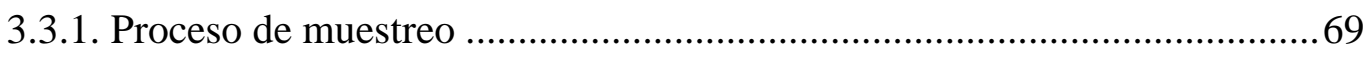

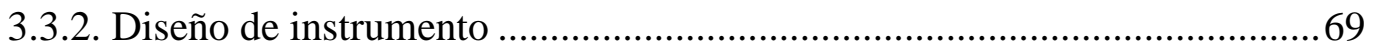

3.3.3. Análisis y procesamiento de datos ...................................................... 70

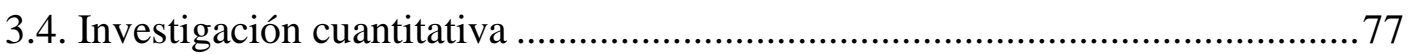


3.4.2. Diseño de instrumento .81

3.4.3. Análisis y procesamiento de datos .82

3.5. Conclusiones y recomendaciones del estudio cualitativo y cuantitativo .93

Capítulo IV. Proyección del mercado objetivo .95

4.1. El ámbito de la proyección .95

4.2. Selección del método de proyección. .96

4.2.1. Mercado potencial 101

4.2.2. Mercado disponible 105

4.2.3. Mercado efectivo 108

4.2.4. Mercado objetivo 112

4.3. Pronóstico de ventas 115

4.4. Aspectos críticos que impactan el pronóstico de ventas. 118

Capítulo V. Ingeniería del proyecto.

5.1. Estudio de ingeniería.

5.1.1. Modelamiento y selección de procesos productivos.

5.1.2. Selección del equipamiento

5.1.3. Layout

5.1.4. Distribución de equipos y maquinarias

5.2. Determinación del tamaño 132

5.2.1. Proyección de crecimiento 133 
5.2.4. Flexibilidad

5.2.5. Selección del tamaño ideal

5.3. Estudio de localización 136

5.3.1. Definición de factores locacionales 136

5.3.2. Consideraciones legales.

5.4. Determinación de la localización óptima

6.1.1. Visión

6.1.2. Misión

6.1.3. Principios

6.2. Formulación de estrategias del negocio

6.3. Determinación de las ventajas competitivas criticas 156

6.4. Diseño de la estructura organizacional deseada. 158

6.5. Diseño de los perfiles de puestos clave.

6.6. Remuneraciones compensaciones e incentivos 166

6.7. Política de recursos humanos 169

Capítulo VII. Plan de marketing 170

7.1. Estrategias de marketing. 170 
7.1.1. Estrategia de producto

7.1.2. Estrategia de precio

7.1.3. Estrategia de distribución 176

7.1.4. Estrategia de promoción y publicidad. 179

7.2. Estrategia de ventas 181

7.2.1. Plan de ventas 183

7.2.2. Políticas de servicios y garantías 185

Capítulo VIII. Planificación financiera 188

8.1. La inversión 188

8.1.1. Inversión pre-operativa 188

8.1.2. Inversión en capital de trabajo 189

8.1.3. Costo del proyecto 192

8.1.4. Inversiones futuras 192

8.2. Financiamiento 193

8.2.1. Endeudamiento y condiciones 193

8.2.2. Capital y costo de oportunidad 196

8.2.3. Costo de capital promedio ponderado. 200

8.3. Presupuestos base. 201

8.3.1. Presupuesto de ventas 201

8.3.2. Presupuesto de costos y producción 204

8.3.3. Presupuesto de compras. 207 
8.4.3. Flujo de caja proyectado

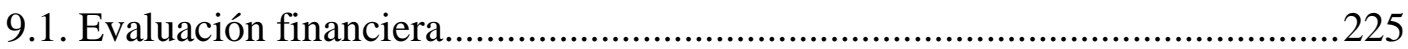

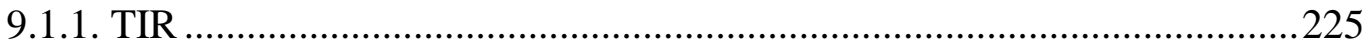

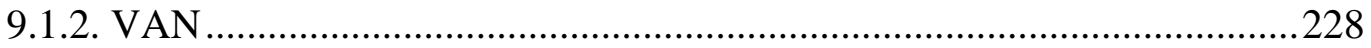

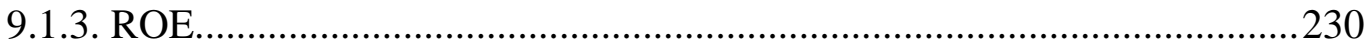

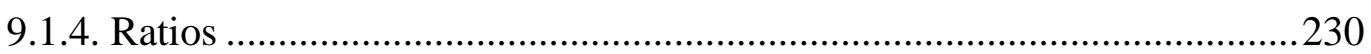

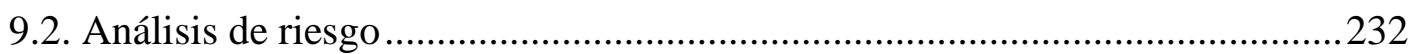

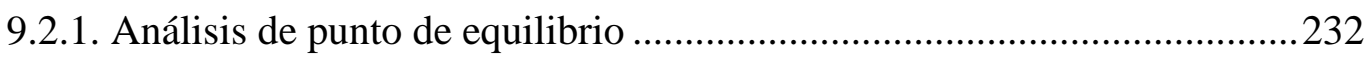

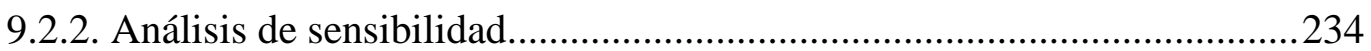

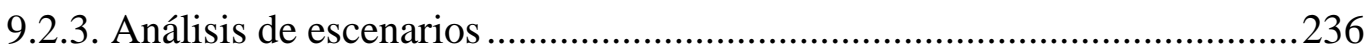

9.2.4. Matriz de riesgos y plan de mitigación ...................................................2236

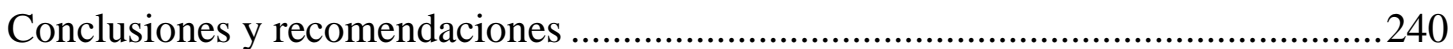

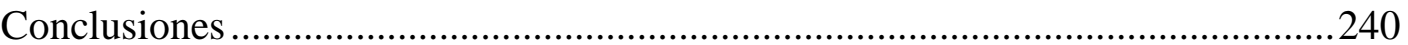




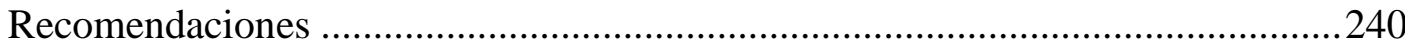

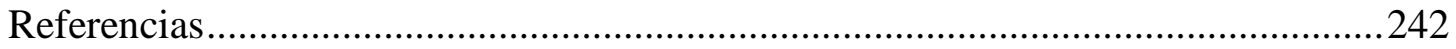

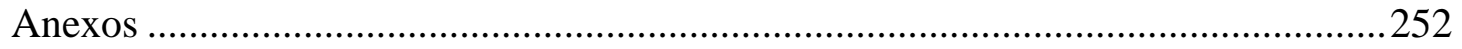




\section{Lista de Tablas}

Tabla 1.Número y proporción de casos con diagnóstico nutricional según indicador P/T por provincias 1 de enero de 2018 - 31 de diciembre de 2018 (Lima) ........................................

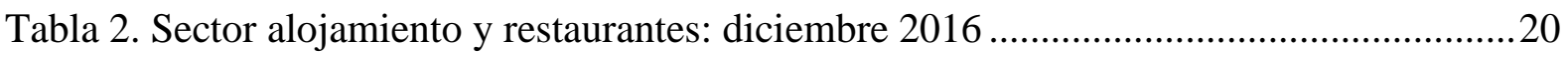

Tabla 3. Perú: Densidad Empresarial, según Actividad Económica, 2013 ............................22

Tabla 4. Lima Metropolitana: Densidad Empresarial, según Actividad Económica, 2013.....23

Tabla 5. Perú: Mipymes formales por estrato empresarial, según sección CIIU, 2015..........25

Tabla 6. Matriz de atractividad rivalidad entre competidores. .............................................. 30

Tabla 7. Matriz de atractividad amenaza de nuevos competidores. ...................................... 32

Tabla 8. Matriz de atractividad de poder de negociación de los proveedores. ........................33

Tabla 9. Matriz de atractividad poder de negociación de los clientes. ..................................34

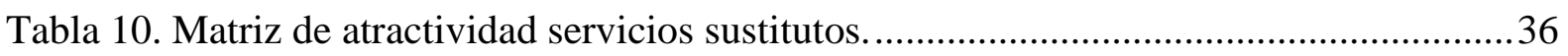

Tabla 11. Matriz del perfil competitivo .......................................................................... 42

Tabla 12. Perú: Política de inversión pública en ciencia, tecnología e investigación. .............53

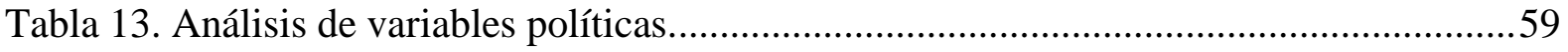

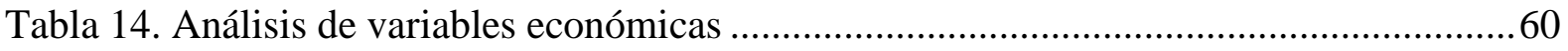

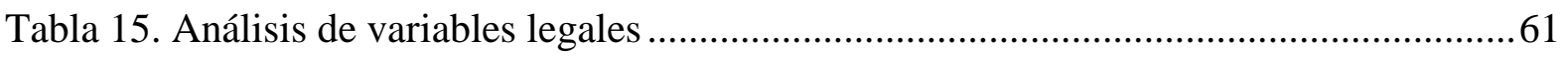

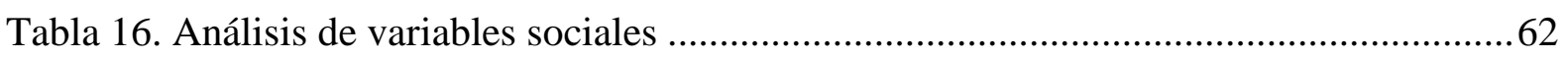

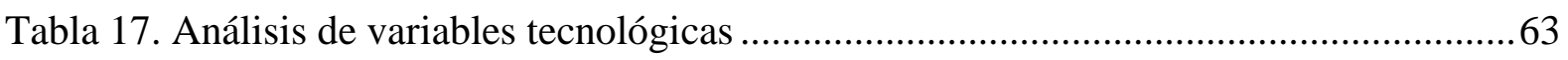

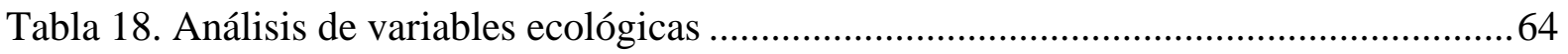

Tabla 19. Cantidad de colegios por tipo de gestión/dependencia, distritos Ate, La Molina y

Santa Anita. .66

Tabla 20. Cuotas por distrito según nivel de los distritos Ate La Molina y Santa Anita.........80

Tabla 21. Tipo y número de preguntas de la encuesta..................................................... 82

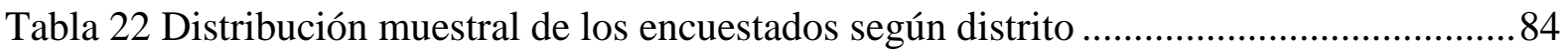


Tabla 23. ¿Qué opción de alimentos predomina en la lonchera de sus hijos? .85

Tabla 24. ¿Cuál es la principal razón por la que su hijo debería consumir una lonchera

saludable?

Tabla 25. ¿Conoce alguna empresa que brinde servicio de loncheras saludables estándar para niños de educación inicial o primaria? .86

Tabla 26. Basándose en la descripción del producto, ¿Le parece interesante esta propuesta? 86

Tabla 27. ¿Qué opción de bebidas le gustaría encontrar en la lonchera saludable? .87

Tabla 28. ¿Qué opción de sándwich le gustaría encontrar dentro de las loncheras saludables?

Tabla 29. ¿Qué opción de frutas le gustaría encontrar dentro de las opciones de loncheras saludables? .88

Tabla 30.¿Cuánto estaría dispuesto a pagar por una lonchera saludable que incluye refresco,

Tabla 31. ¿Estaría dispuesto a comprar la lonchera saludable?

Tabla 32. ¿Qué paquete de lonchera saludable compraría usted?

Tabla 33. ¿Con qué frecuencia estaría dispuesto a consumir el programa de loncheras 90

Tabla 34. ¿Cómo preferiría realizar el pago de las loncheras saludables?

Tabla 35. ¿Le gustaría recibir tips sobre temas de nutrición de manera gratuita a su correo? 91

Tabla 36. ¿Recomendaría estas loncheras saludables con sus amistades? 91

Tabla 37. ¿Qué promoción le gustaría recibir eventualmente? .92

Tabla 38. ¿Cuál sería un nombre adecuado para este proyecto? .92

Tabla 39. ¿Cómo desearía que se realice la comunicación con usted? 93

Tabla 40. Alumnos de educación inicial y primaria en colegios del sector privado

Tabla 41. Matrícula en el sistema educativo privado por distrito y nivel educativo (2008-

2016) 97 
Tabla 42.. Población proyectada Ate (cantidad de alumnos). .99

Tabla 43.Población proyectada La Molina (cantidad de alumnos) ....................................... 100

Tabla 44. Población proyectada Santa Anita (cantidad de alumnos) .................................... 101

Tabla 45. Población por distrito proyectada 2017 - 2022 (cantidad de alumnos) .................. 102

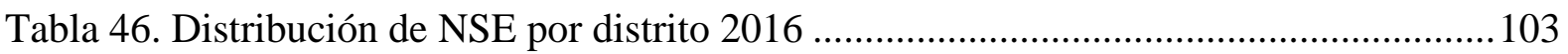

Tabla 47. Mercado potencial proyectado 2017-2022 (cantidad de alumnos) ........................ 104

Tabla 48. ¿Basándose en la descripción del producto, ¿Le parece interesante esta propuesta?

Tabla 49. Factor de mercado disponible por nivel educativo ........................................... 106

Tabla 50. Mercado disponible proyectado 2017-2022 (cantidad de alumnos) ...................... 107

Tabla 51. ¿Cuál es el rango de precios que estaría dispuesto a pagar por una lonchera........ 108

Tabla 52. ¿Estaría dispuesto a comprar una lonchera saludable? ........................................ 109

Tabla 53. Factor disposición compra por distrito y nivel educativo.................................... 109

Tabla 54. Factor disposición compra por distrito y nivel educativo corregido .....................110

Tabla 55. Factor mercado efectivo por distrito y nivel educativo .......................................110

Tabla 56. Mercado efectivo proyectado 2017-2022 (cantidad de alumnos).........................111

Tabla 57. Guía de aproximaciones de porcentaje de participación de mercado ..................... 113

Tabla 58. Producto bruto interno por sectores productivos (variaciones porcentuales) ........ 114

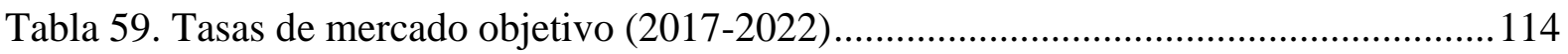

Tabla 60. Mercado objetivo proyectado 2017-2022 (cantidad de alumnos) .........................115

Tabla 61. Del Periodo escolar ¿Con qué frecuencia estaría dispuesto a consumir el programa de loncheras saludables? 115

Tabla 62. Cuadro resumen ventas por año (cantidad de loncheras) .................................... 116

Tabla 63. Precio de paquetes semanales por año ......................................................... 116

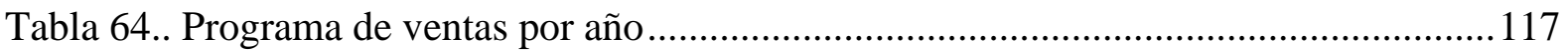


Tabla 65. Ventas por año (cantidad de loncheras)

Tabla 66. Tamaño óptimo de Lunch Kids

Tabla 67. Cuadro del método cualitativo por puntos ......................................................... 148

Tabla 68. Matriz para determinar la ventaja competitiva .................................................. 157

Tabla 69. Descripción de puesto - Administrador ................................................................ 160

Tabla 70. Descripción de puesto - Asistente Administrativo................................................161

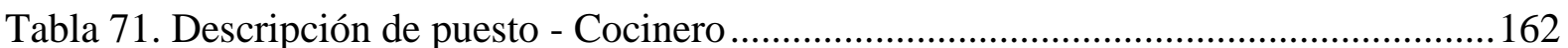

Tabla 72. Descripción de puesto - Ayudante de cocina ..................................................... 163

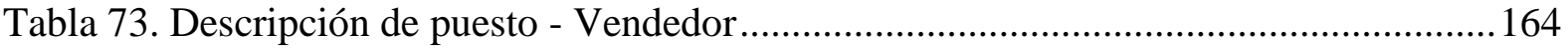

Tabla 74. Descripción de puesto - Repartidor ..................................................................... 165

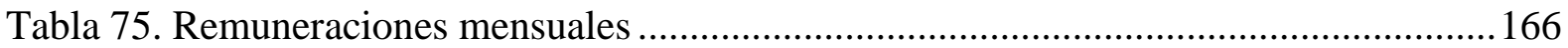

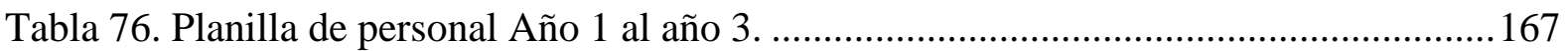

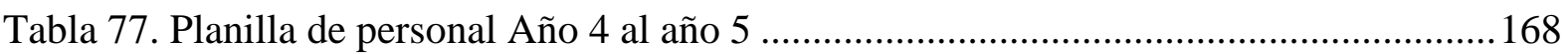

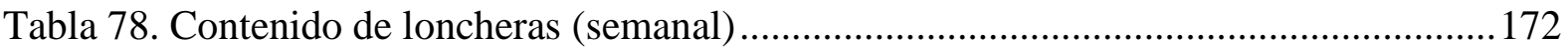

Tabla 79. Resultado de encuesta - Rango de precio........................................................... 174

Tabla 80.. Costos de producción de una lonchera ............................................................. 175

Tabla 81. Descuento por compras-precio por paquetes .................................................... 176

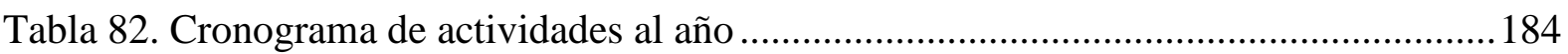

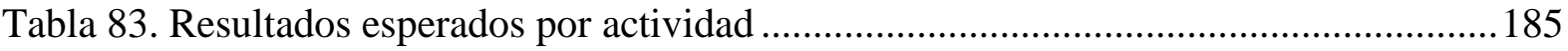

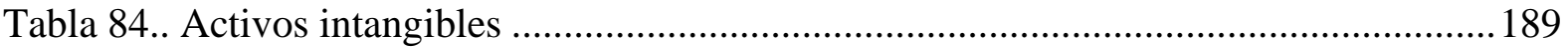

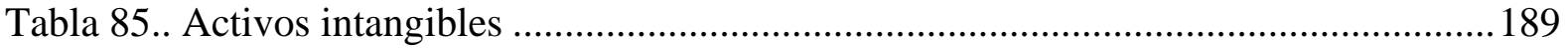

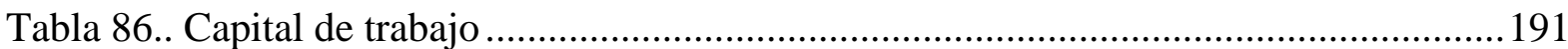

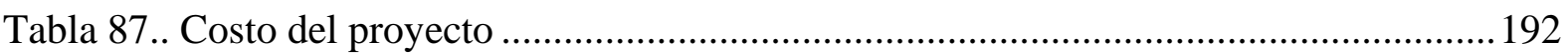

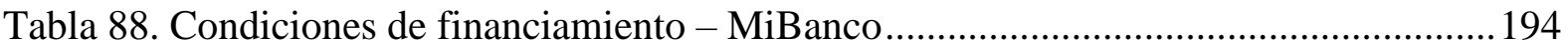

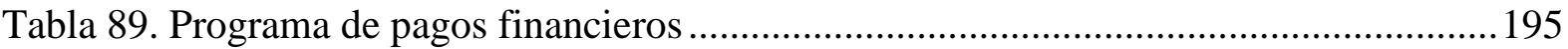


Tabla 90. Inversión total y capital de trabajo

Tabla 91. Cálculo de Beta apalancado

Tabla 92. Rendimientos de 1986 al 2016 - promedio aritmético 198

Tabla 93. Fórmula para la determinación de COK PERU .....................................................2200

Tabla 94. Fórmula para la determinación de WACC …......................................................201

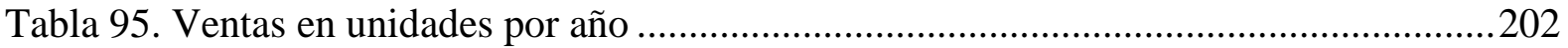

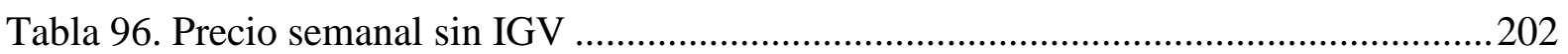

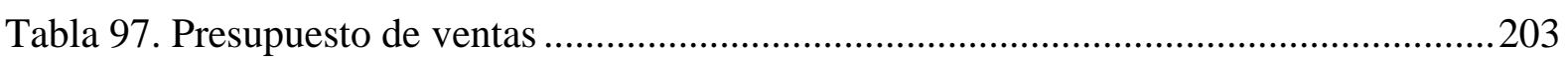

Tabla 98. Presupuesto de costos de producción unitario ........................................................205

Tabla 99. Presupuesto de costos de producción.....................................................................206

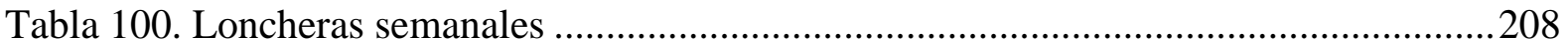

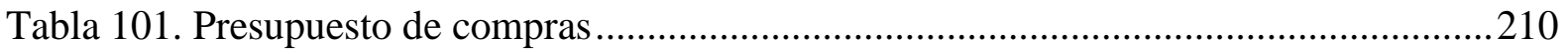

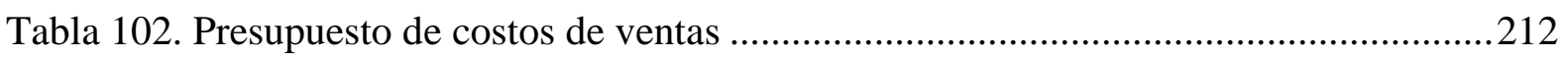

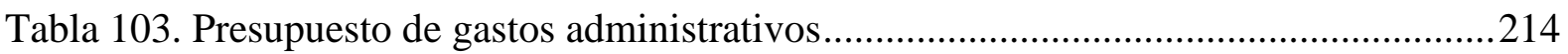

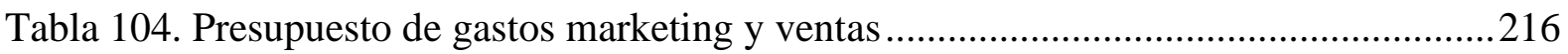

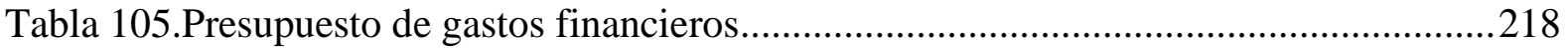

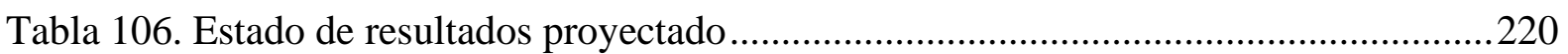

Tabla 107. Estado de situación financiera proyectado........................................................222

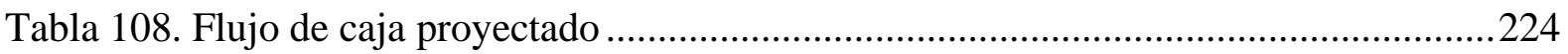

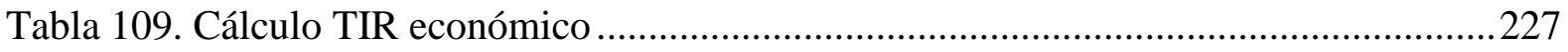

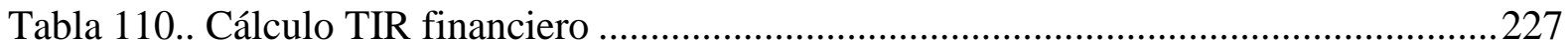

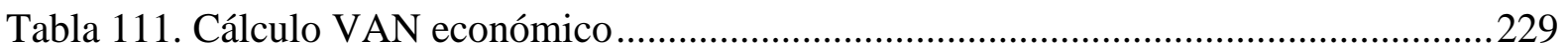

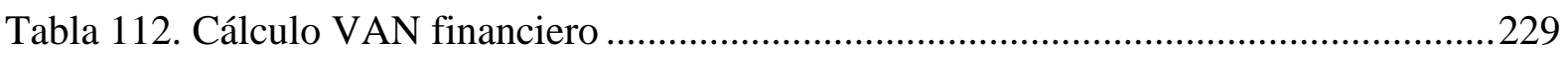

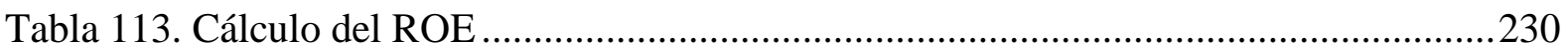

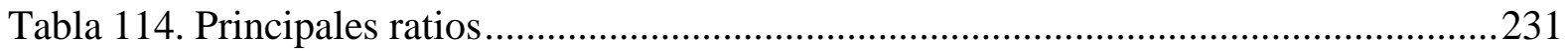


Tabla 115. Punto de equilibrio (en cantidad)

Tabla 116. Punto de equilibrio (en soles)

Tabla 117. Sensibilidad y escenarios con variación de la participación 235

Tabla 118. Sensibilidad y escenarios con variación del precio 235

Tabla 119. Análisis de riesgos 237

Tabla 120. Matriz de riesgos probabilidades e impacto 238

Tabla 121. Plan de respuesta de riesgos 239 


\section{Lista de figuras}

Figura 1. Ventas al menudeo anuales per cápita de alimentos y bebidas ultraprocesados en 13

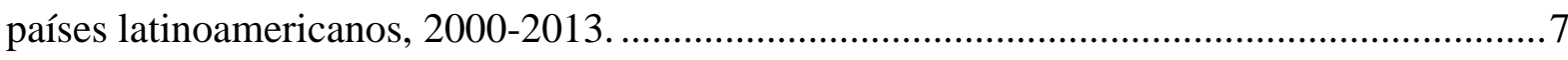

Figura 2. Prevalencia de sobrepeso y obesidad según grupos etáreos, Perú 2011 ..................8

Figura 3. Distribución porcentual del sobrepeso y obesidad en niños menores de 3 años (OMS) atendidos en Ministerio de Salud del Perú I-Sem 2012 ......................................... 8

Figura 4. Tendencia del sobrepeso y obesidad en niñas y niños de 5 a 9 años. Perú 20082014

Figura 5. Distribución del tipo de lonchera en escolares de instituciones Educativas de nivel primario. Perú, 2013. (Porcentaje)

Figura 6. Distribución del tipo de lonchera en escolares de instituciones educativas de nivel primario. Perú, 2013. (Porcentaje).

Figura 7. Distribución del tipo de lonchera en escolares de instituciones educativas de nivel

primario. Perú, 2013. (Porcentaje).

Figura 8. Alojamiento y restaurantes: diciembre 2016.

Figura 9. Evolución mensual de la actividad Restaurantes: 2013-2016.

Figura 10. Modelo de competencia de las cinco fuerzas de Porter. Fuente: Conceptos de

administración estratégica por David (2013, p. 76)

Figura 11. Distribución de la procedencia de bebidas en escolares de instituciones educativas de nivel primario. Perú, 2013. (Porcentaje) .38

Figura 12. Distribución de la procedencia de complemento en escolares de instituciones educativas de nivel primario. Perú, 2013. (Porcentaje). .39

Figura 13. PBI por sectores económicos .46

Figura 14. Tasas de Interés en Moneda Nacional como en Moneda Extranjera. .47

Figura 15. Inflación promedio y desviación estándar. .48 
Figura 16. Índices de morosidad de los créditos.

Figura 17. Pirámide de la población peruana, 1950, 2015 y 2015. .50

Figura 18. Estructura de la población peruana por grandes grupos de edad, 1950-2050........51

Figura 19. ¿Cuánto se preocupa Ud. por seguir una dieta saludable? .52

Figura 20. Penetración (\%) de internet fijo. Perú 2015......................................................54

Figura 21. Servicio de conexión a internet al 2015 (fijo y móvil)........................................55

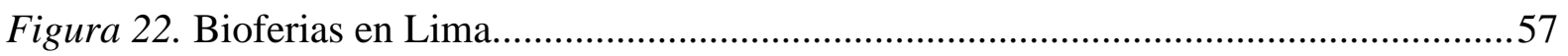

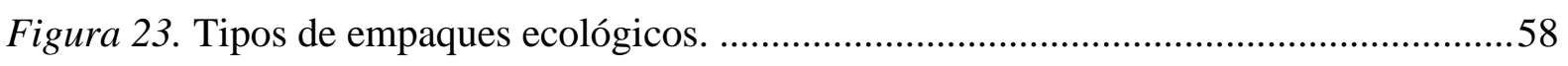

Figura 24. Regresión Lineal Ate Inicial........................................................................ 98

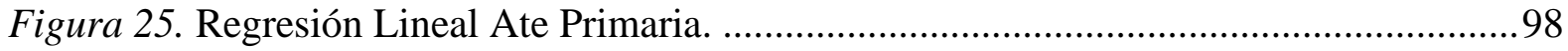

Figura 26. Regresión Lineal La Molina Inicial................................................................99

Figura 27. Regresión Lineal La Molina Primaria.. .................................................................99

Figura 28. Regresión Lineal Santa Anita Inicial.............................................................. 100

Figura 29. Regresión Lineal Santa Anita Primaria. ........................................................ 100

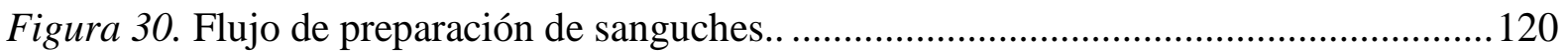

Figura 31. Flujo de preparación de jugos y/o refrescos.. .................................................... 121

Figura 32. Flujo de preparación de postre y/o ensalada de fruta.........................................121

Figura 33. Calendario de estacionalidad de frutas a nivel nacional................................... 122

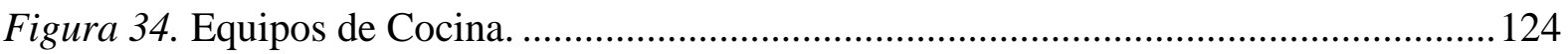

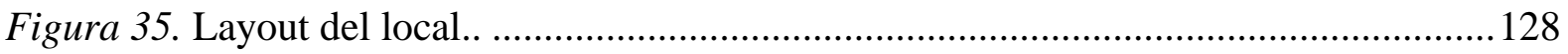

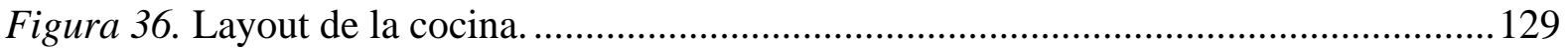

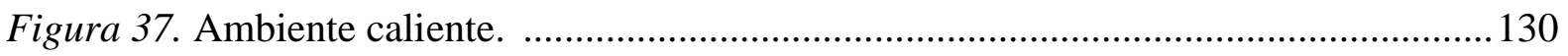

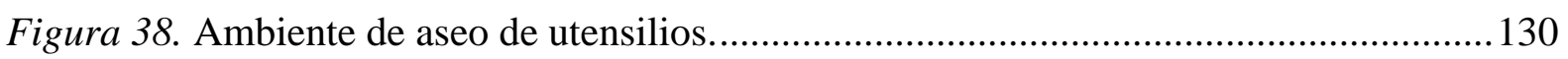

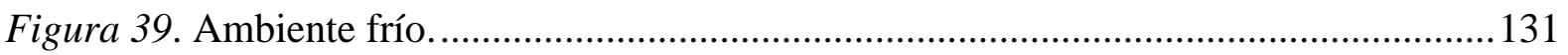

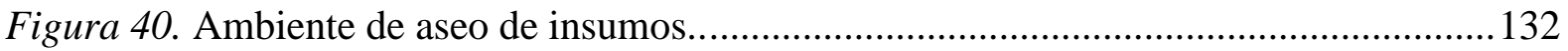


Figura 41. Locales evaluados.

Figura 42. Mapa de los locales evaluados

Figura 43. Resumen de costos de procedimientos administrativos y servicios prestados en exclusividad.

Figura 44. Resumen de costos de procedimientos administrativos y servicios prestados en exclusividad.

Figura 45. Reserva de denominación o razón social.

Figura 46. Registra tu Mype de manera más fácil, rápida y segura. 144

Figura 47. Facilidades para el registro de marca. 145

Figura 48. Facilidades para el registro de patente. 146

Figura 49. Mapa de local elegido. 149

Figura 50. Estrategias de negocios 154

Figura 51. Organigrama del proyecto. 158

Figura 52. Logo "Lunch kids" 171

Figura 53. Empaque. 173

Figura 54. Canal de Distribución. 177

Figura 55. Proceso de Distribución. 178 


\section{Lista de anexos}

Anexo 1. Ficha técnica de la investigación cualitativa Focus Group (dirigido a padres)......252

Anexo 2. Ficha técnica de investigación cualitativa Focus Group (dirigida a docentes) ......256

Anexo 3. Ficha técnica de la entrevista a profundidad Expertos del Sector: Nutrición ........260

Anexo 4: Ficha técnica de la entrevista a profundidad Expertos del sector: Restaurantes....263

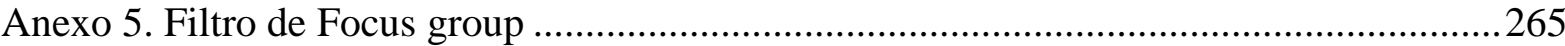

Anexo 6. Acta de la primera sesión del focus group (padres de familia) ..............................266

Anexo 7. Acta de la segunda sesión del focus group (padres de familia) ............................2273

Anexo 8. Acta de la primera sesión del focus group (docentes nivel inicial - primaria) ......286

Anexo 9. Acta de la segunda sesión del focus group (docentes nivel primaria) ...................292

Anexo 10: Primera entrevista a profundidad expertos del sector restaurante........................300

Anexo 11 Segunda entrevista a profundidad con expertos del sector restaurante .................303

Anexo 12. Segunda entrevista a profundidad con expertos del sector: Nutrición ..................308

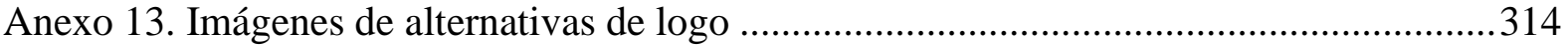

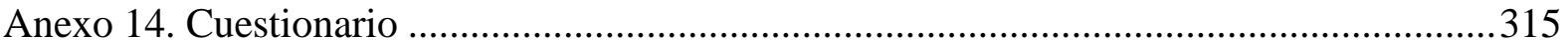

Anexo 15. Preguntas de control- perfil general de los niveles socioeconómicos ...................319

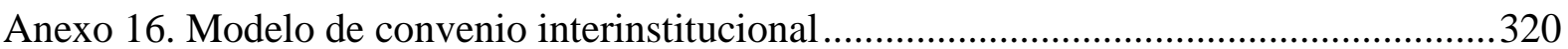

Anexo 17. Cartilla de lonchera saludable para educación primaria.......................................323

Anexo 18: Cartilla de lonchera saludable para Educación Inicial .........................................324

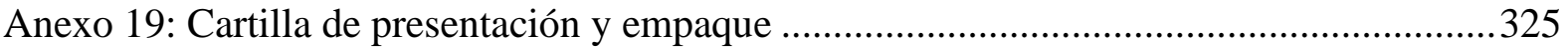




\section{Resumen ejecutivo}

Uno de los problemas de salud que se ha acentuado en el Perú es la obesidad en la etapa de la niñez, cuyas consecuencias se perciben no solo en la adolescencia, sino también en la adultez en la que se puede llegar a desarrollar otras enfermedades. Actualmente existe una preocupación por los niños que se encuentran entre los 5 y 9 años, pues se ha detectado qué de cada 10 niños, 3 sufren de sobrepeso y/u obesidad, y los principales factores que han desencadenado este alarmante incremento son los hábitos alimenticios que se forman desde el hogar.

En la actualidad, gran parte de los padres y madres de familia deben trabajar para obtener ingresos que cubran las necesidades del hogar, motivo por el cual buscan opciones fáciles y rápidas en la preparación de la lonchera de sus hijos, acudiendo muchos de ellos a comprar alimentos procesados y de poco valor nutricional, tales como bebidas azucaradas, bizcochos, galletas, golosinas, entre otros.

La presente idea de negocio, busca aprovechar la tendencia creciente por una alimentación saludable y satisfacer la necesidad de este nicho desatendido ofreciendo alternativas de loncheras saludables para niños en edad escolar del nivel inicial y primaria, utilizando el formato de venta por delivery, ello permitirá a los padres delegar la elaboración de dichas loncheras y tener la seguridad que sus hijos recibirán de forma oportuna una lonchera escolar que cumpla con el valor nutricional necesario para el buen desarrollo y desempeño en su día de clases.

La inversión inicial ha sido calculada en S/.172,239.06 y será cubierta por préstamo bancario en un $23 \%$ y el $77 \%$ restante será cubierto por los socios emprendedores, en porcentaje equivalente del $25 \%$ cada uno.

El proyecto tiene un periodo de evaluación de cinco años y considerando un escenario conservador, con una participación de mercado de $2.5 \%$, el TIR y la VAN serían positivos, por 
lo tanto, el proyecto sería viable, siendo el periodo de recuperación económica de 1.81 y periodo de recuperación financiero de 1.59 años.

Los impulsores del proyecto son:

Enrique Cueva Romero, administrador de profesión, candidato a Máster en Administración con especialización en Gestión de Proyectos, con experiencia en gestión académica.

Rocio Salas Ychocan, administradora de profesión, candidata a Máster en Administración con especialización en Gestión de Proyectos, con experiencia en gestión académica.

Susana Valverde Garay, administradora de profesión, candidata a Máster en Administración con especialización en Gestión de Proyectos, con experiencia en gestión administrativa.

Rene Zavalaga Raborg, administrador de profesión, candidato a Máster en Administración con especialización en Gestión de Proyectos, con experiencia en gestión financiera. 


\section{Introducción}

En el presente proyecto se propone la comercialización de loncheras saludables para niños de educación inicial y primaria de colegios de gestión privada.

El objetivo es llegar a los padres con una propuesta económica y saludable para la lonchera de sus hijos, la cual les ahorrará tiempo que podrán dedicar a otras actividades familiares sin descuidar brindar a sus hijos una alimentación nutritiva, variada, sencilla, con la cantidad adecuada y sobre todo agradable al paladar de sus hijos.

A continuación, se brinda un resumen de lo investigado en cada capítulo del presente plan de negocios:

En el capítulo I se describe la oportunidad de negocio referente a la comercialización de loncheras saludables. Incluye antecedentes, objetivos, justificación y limitaciones de la investigación.

En el capítulo II se analiza la estructura económica del sector de servicios al cual pertenece el negocio propuesto, de la misma forma muestra las tendencias globales y la competencia.

En el capítulo III se define el producto y la investigación cualitativa y cuantitativa para la identificación del perfil del potencial cliente.

En el capítulo IV se determina la proyección del mercado objetivo y tendencias de compra para la proyección de ventas. Así mismo, en el capítulo V se realiza la ingeniería del proyecto determinando el tamaño de la empresa, evaluación de la ubicación y definición de la tecnología a utilizar.

En el capítulo VI se definen los aspectos organizacionales y la determinación de la fuerza laboral y cultura organizacional. Además, en el capítulo VII se determinan las estrategias de marketing, de ventas, plan de ventas y políticas de servicios y garantías.

En el capítulo VIII se planifica la gestión financiera, así como la evaluación de la inversión inicial y determinación de financiamiento. 
Finalmente, en el capítulo IX se analizan los resultados financieros para evaluar la viabilidad del proyecto.

La empresa estará conformada por un capital social de S/. 172,239.06 siendo el 77\% (S/. 132,239.06) producto del aporte de los socios y $23 \%$ (S/. 40, 000) se obtendrá mediante financiamiento bancario. La inversión es necesaria y requerida a fin de iniciar las operaciones con lo indispensable para el correcto funcionamiento de la empresa.

Luego del análisis realizado se obtuvo un VAN financiero de S/306,286.95 y un VAN económico de S/306,932.25 es así que, al ser ambos indicadores positivos, se determinó que el proyecto es viable financiera y económicamente.333

La TIR económica es $62 \%$ y es mayor al COK (14.78\%), por lo tanto, el proyecto es rentable.

El período de recuperación económico y financiero de la inversión es de 1.81 años y 1.59 años respectivamente. En el quinto año, el flujo de caja económico es de S/272,383.39 y el flujo de caja financiero es de S/260,634.98.

Sin duda, nadie podía prever una pandemia para el 2020, pero es algo que ocurrió y la actual coyuntura ha puesto a miles de empresas frente a un escenario de incertidumbre que ha traído consigo un replanteamiento en la forma de trabajar y en los objetivos de las empresas, por ello surge la necesidad de evolucionar y evaluar alternativas que ayuden a mantener a flote el proyecto ante esta situación imprevista, entre las que se podría evaluar:

- El servicio de loncheras saludables a domicilio, dado que muchos padres se encuentran desarrollando trabajo remoto al igual que los niños estudiando desde casa y necesitan la merienda de media mañana que los ayude a mantener las energías hasta la hora de su almuerzo.

- Implementar el servicio de bocaditos saludables para compartir en casa en ocasiones especiales familiares. 
- Implementar el servicio de delivery para la compra de frutas y verduras.

Una última alternativa a evaluar podría ser diferir el inicio del proyecto, y ello involucraría una nueva evaluación del entorno y estudio de mercado. 


\section{Capítulo I. Generalidades}

\subsection{Antecedentes}

A fin de desarrollar el presente proyecto, se analizará la tendencia alimenticia mundial, así como las consecuencias de una alimentación no saludable.

En el 2013, la Asamblea Mundial de la Salud, como máximo órgano de decisión de la OMS, publicó el "Plan de acción mundial de la OMS para la prevención y el control de las enfermedades no transmisibles 2013-2020" que, entre otras nueve metas mundiales, proporcionaba información para detener el incremento de la diabetes y obesidad, así como reducir en 30\% de la ingesta de sal al 2025 en sus 193 estados miembros (Organización Mundial de la Salud [OMS], 2015).

Desde el año 2012 la Agencia de Normas Alimentarias Británica reglamentó que todos los alimentos cuenten con un semáforo nutricional en sus etiquetas (rojo, verde y amarillo), iniciativa que posteriormente fue adoptada por Ecuador y Bolivia en América del Sur. Posteriormente en el 2016, Chile publicó la Ley de Composición Nutricional de los Alimentos, seguida por el Perú con la conocida "Ley de la Comida Chatarra". (El Comercio, 2017).

Entre todos los países latinoamericanos, el Perú presenta un incremento del 107\% en el consumo de gaseosas y alimentos procesados entre el 2000 y el 2013, el detalle indica que en el 2000 se vendían 40.2 kilos de alimentos por cada persona y al 2013 se incrementó a 83.2 kilos de alimento por cada persona. Aun así, el Perú registra el menor incremento entre los países del sector, como se muestra en la figura 1. 


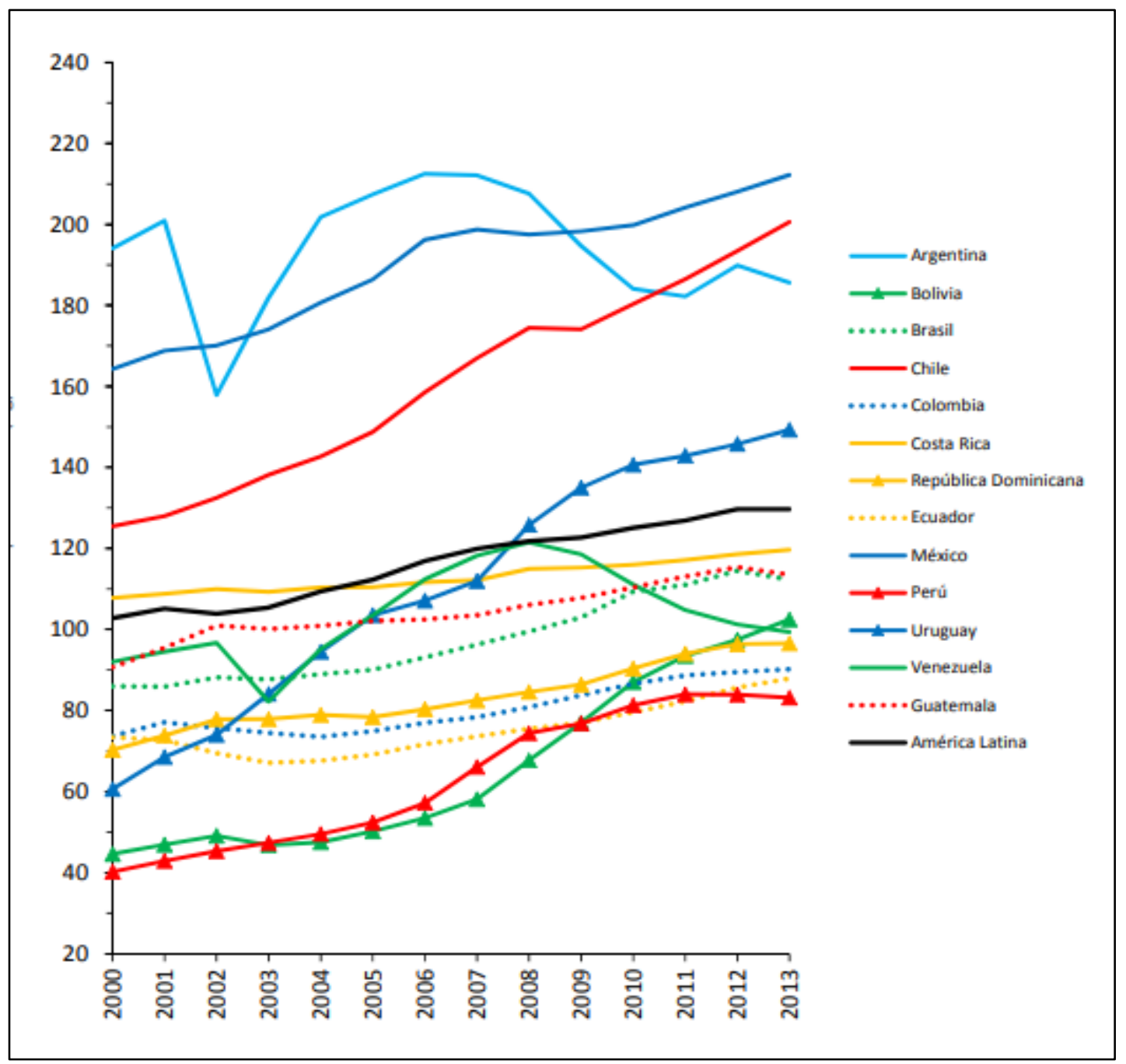

Figura 1. Ventas al menudeo anuales per cápita de alimentos y bebidas ultraprocesados en 13 países latinoamericanos, 2000-2013.Fuente: Alimentos y bebidas ultraprocesados en América latina: tendencias, efecto sobre la obesidad e implicaciones para las políticas públicas por OMS, 2015, p. 21. Recuperado de http://iris.paho.org/xmlui/bitstream/handle/123456789/7698/9789275318645_esp.pdf

El artículo de “Andina del Perú para el mundo” del 2014 refiere lo siguiente:

Según la Organización Mundial de la Salud (OMS), el Perú ocupa el octavo lugar en el ranking mundial de países con mayor obesidad infantil, con más de 480 mil niños menores de cinco años que sufren de este mal. El Instituto Nacional de Estadística e Informática (INEI) refiere que el sobrepeso en la población escolar suele ser más frecuente en las zonas urbanas $(16 \%)$ que en las zonas rurales $(7 \%)$. 


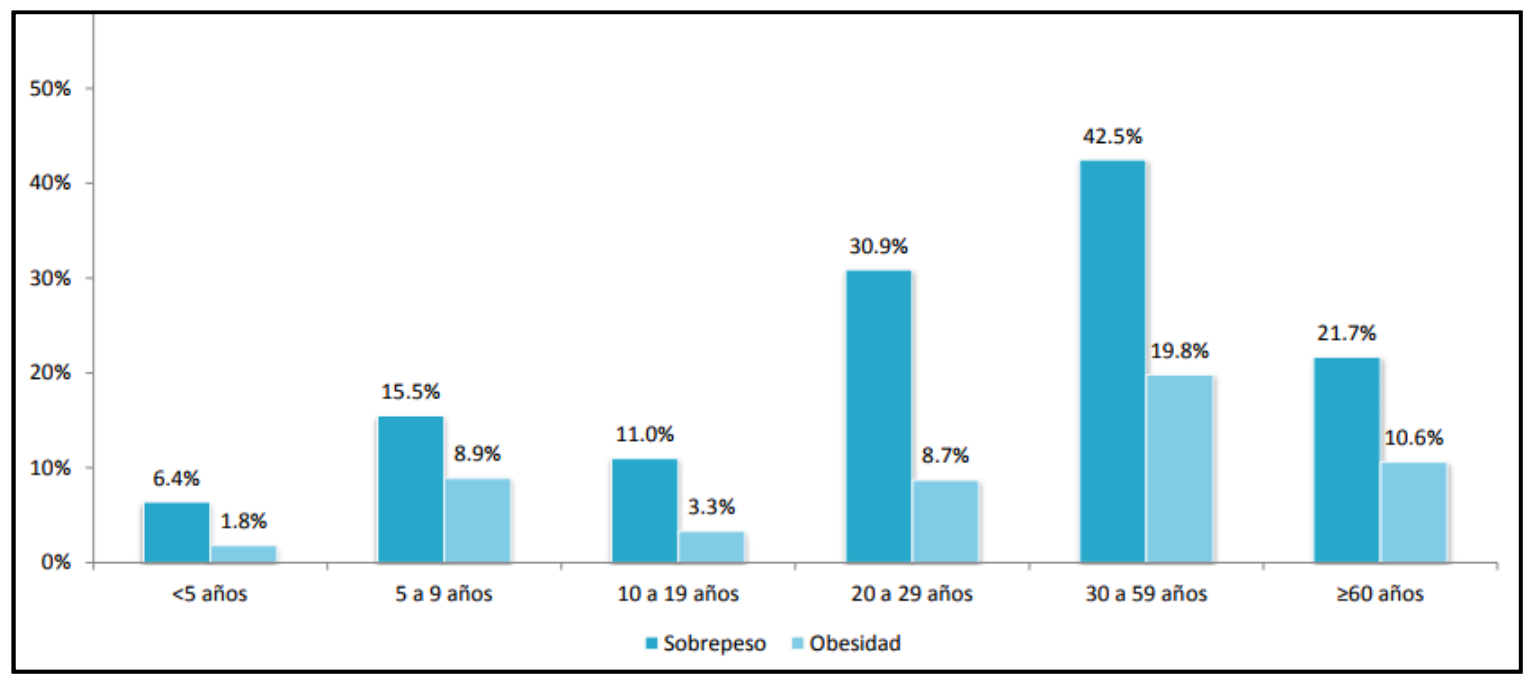

Figura 2. Prevalencia de sobrepeso y obesidad según grupos etáreos, Perú 2011. Fuente: Sala situacional Sobrepeso y obesidad por Instituto Nacional de Salud, 2013, p.5. Recuperado de https://web.ins.gob.pe/sites/default/files/Archivos/cenan/van/sala_nutricional/sala_3/01_Sala_Situacional_Ali mentaria_Nutricional_5_Sobrepeso_y_obesidad.pdf

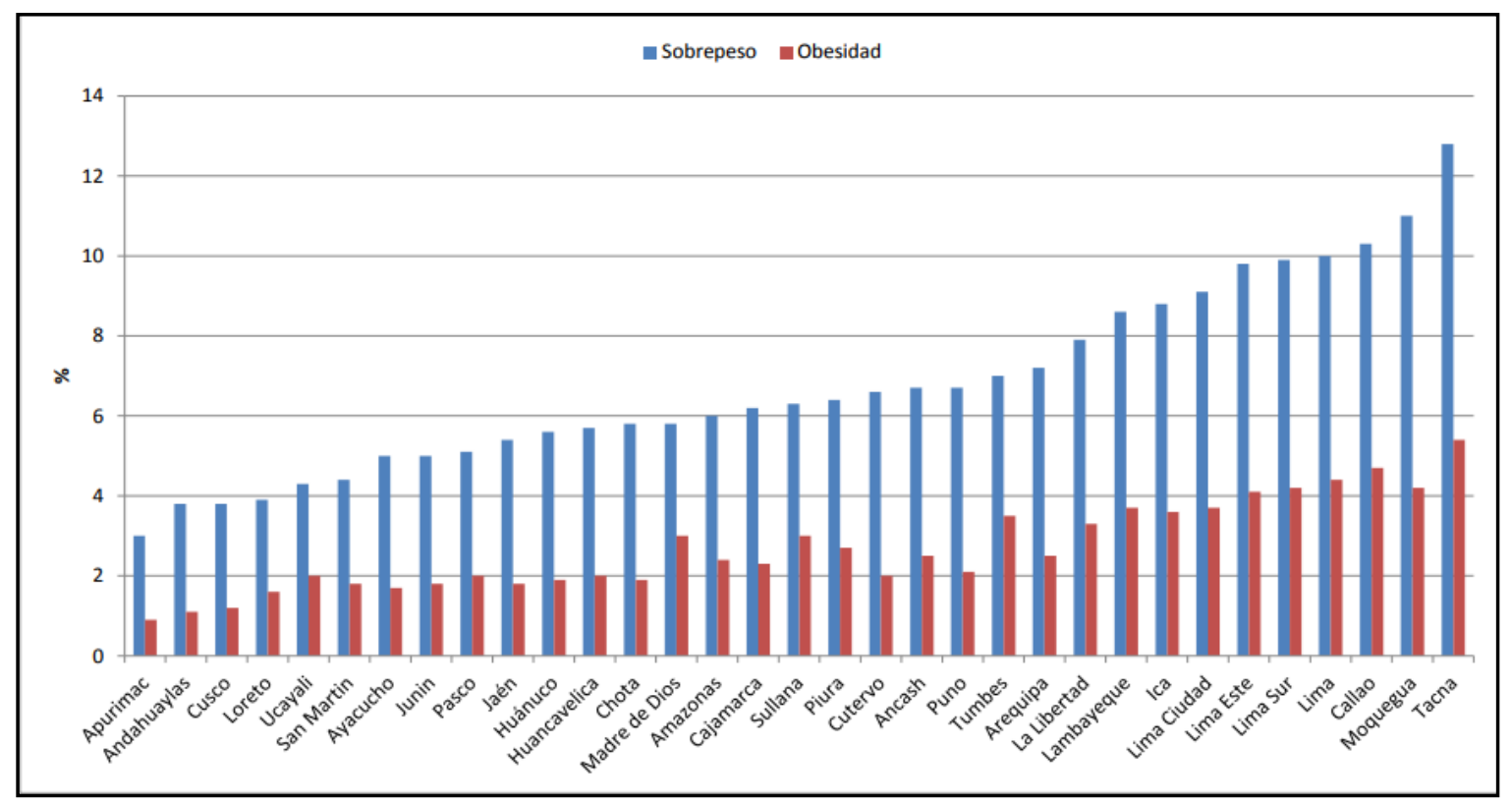

Figura 3. Distribución porcentual del sobrepeso y obesidad en niños menores de 3 años (OMS) atendidos en Ministerio de Salud del Perú I-Sem 2012. Fuente: Sala situacional Sobrepeso y obesidad por Instituto Nacional de Salud, 2013, p.12. Recuperado de https://web.ins.gob.pe/sites/default/ files/Archivos/cenan/van/sala_nutricional/sala_3/01_Sala_Situacional_Alimentaria_Nutricional_5_Sobrepeso _y_obesidad.pdf 
Lima Metropolitana no es ajena al problema de obesidad y sobrepeso de los niños, pues al 31 de marzo del 2018 el 9.1\% sufría de sobrepeso, el 2.4\% tenía problemas de obesidad, mientras que el 1.0\% mostraban desnutrición aguda. Es decir, el 11.5\% de los niños de Lima Metropolitana ya presentaban problemas de nutrición.

Tabla 1.

Número y proporción de casos con diagnóstico nutricional según indicador P/T por provincias 1 de enero de 2018 - 31 de diciembre de 2018 (Lima)

\begin{tabular}{|c|c|c|c|c|c|}
\hline Descripción & $\begin{array}{r}\text { Desnutrido } \\
\text { agudo }\end{array}$ & Sobrepeso & Obesidad & Normales & Total \\
\hline LIMA & $3015(1,0 \%)$ & $\begin{array}{r}31821 \\
(10,4 \%)\end{array}$ & $\begin{array}{r}7340 \\
(2,4 \%)\end{array}$ & $\begin{array}{l}264064 \\
(86,2 \%)\end{array}$ & $\begin{array}{r}306240 \\
(100 \%)\end{array}$ \\
\hline HUARAL & $526(0,9 \%)$ & $\begin{array}{r}6647 \\
(11,1 \%)\end{array}$ & $\begin{array}{r}1924 \\
(3,2 \%)\end{array}$ & $\begin{array}{r}50844 \\
(84,8 \%)\end{array}$ & $\begin{array}{l}59941 \\
(100 \%)\end{array}$ \\
\hline HUAURA & $520(0,9 \%)$ & $\begin{array}{r}6221 \\
(11,0 \%)\end{array}$ & $\begin{array}{r}1711 \\
(3,0 \%)\end{array}$ & $\begin{array}{r}47848 \\
(85,0 \%)\end{array}$ & $\begin{array}{l}56300 \\
(100 \%)\end{array}$ \\
\hline CAÑETE & $591(1,1 \%)$ & $\begin{array}{r}5767 \\
(10,5 \%)\end{array}$ & $\begin{array}{r}1444 \\
(2,6 \%)\end{array}$ & $\begin{array}{r}46994 \\
(85,8 \%)\end{array}$ & $\begin{array}{l}54796 \\
(100 \%)\end{array}$ \\
\hline BARRANCA & $305(0,8 \%)$ & $\begin{array}{r}4469 \\
(11,2 \%)\end{array}$ & $\begin{array}{r}1196 \\
(3,0 \%)\end{array}$ & $\begin{array}{r}33944 \\
(85,0 \%)\end{array}$ & $\begin{array}{l}39914 \\
(100 \%)\end{array}$ \\
\hline HUAROCHIRI & $304(1,1 \%)$ & $\begin{array}{r}2222 \\
(8,2 \%)\end{array}$ & $\begin{array}{r}499 \\
(1,8 \%)\end{array}$ & $\begin{array}{r}24184 \\
(88,9 \%)\end{array}$ & $\begin{array}{l}27209 \\
(100 \%)\end{array}$ \\
\hline CANTA & $54(0,9 \%)$ & $469(7.5 \%)$ & $90(1,4 \%)$ & $\begin{array}{r}5631 \\
(90,2 \%)\end{array}$ & $\begin{array}{r}6244 \\
(100 \%)\end{array}$ \\
\hline YAUYOS & $64(1,1 \%)$ & $456(7,6 \%)$ & $\begin{array}{r}124 \\
(2,1 \%)\end{array}$ & $\begin{array}{r}5392 \\
(89,3 \%)\end{array}$ & $\begin{array}{r}6036 \\
(100 \%)\end{array}$ \\
\hline OYON & $46(1,0 \%)$ & $296(6,4 \%)$ & $40(0,9 \%)$ & $\begin{array}{r}4254 \\
(91,8 \% 6)\end{array}$ & $\begin{array}{r}4636 \\
(100 \%)\end{array}$ \\
\hline CAJATAMBO & $22(0,9 \%)$ & $93(3,8 \%)$ & $14(0,6 \%)$ & $\begin{array}{r}2289 \\
(94,7 \%)\end{array}$ & $\begin{array}{r}2418 \\
(100 \%)\end{array}$ \\
\hline
\end{tabular}

Nota: Tablero de mando por Instituto Nacional de Salud, 2018. Recuperado de https://tablerodemando. ins.gob.pe/desnutricion/aguda/departamentos 
Por ello, hoy en día ya muchos de los distritos de Lima Metropolitana han tomado acciones concretas para combatir ésta problemática y están realizando algunas campañas para promover una alimentación saludable en sus distritos, es así que, por ejemplo, se tiene municipalidades como la de Miraflores que, desde el año 2012, cuenta con el programa "Punto saludable", el cual está dirigido a escolares tanto de primaria como de secundaria y una de sus actividades es la capacitación en nutrición saludable a brigadieres escolares, profesores y padres de familia. También se tiene el caso de la Municipalidad de Lima Metropolitana que, desde el año 2014, cuenta con el programa "Escuelas saludables", cuyo principal objetivo es capacitar a los padres, tutores y profesores sobre hábitos saludables en los niños como son el consumo de alimentos sanos, la actividad física, y la importancia del consumo de agua. La MML, primero realiza un diagnóstico en cuatro instituciones educativas en las que identifica el grupo de niños con problema de sobrepeso y obesidad, a ellos y a sus padres se les brinda una supervisión de calidad nutricional de las loncheras con el fin de educarlos en el consumo de frutas y verduras, y finalmente realizan un monitoreo del avance de este grupo para determinar si está funcionando el programa y lograron reducir el porcentaje de casos. A estas dos municipalidades, se han sumado algunas otras con programas similares como son la Municipalidad de Barranco, Jesús María, Pachacamac, San Borja, San Martín de Porres, entre otras; sin embargo, aún no se tiene al $100 \%$ de los municipios con programas similares, por lo que aún hay una oportunidad para continuar concientizando a los padres sobre los riesgos de estas enfermedades y la importancia de poner mayor atención a la alimentación de los niños, los cuales son los más vulnerables dado que muchas veces ellos no deciden sobre su alimentación, no son conscientes de qué es bueno o del daño que les está ocasionando los alimentos que llevan en su lonchera (Observa T- Perú, s.f.).

En el marco de velar por la salud de los niños, el Congreso de la República aprobó el 10 de mayo del 2013 la Ley 30021 Ley de promoción de la alimentación saludable para niños, niñas 
y adolescentes, así mismo en junio del 2017 se aprobó el reglamento de dicha ley, mediante esta norma se fijan los parámetros técnicos sobre los alimentos y las bebidas no alcohólicas relacionadas al alto contenido de azúcar, sodio y grasas saturadas, a su vez también se regula los productos que se comercializan en los quioscos escolares (Decreto Supremo N $017-2017$ SA, Reglamento de la Ley $\left.\mathrm{N}^{\circ} 30021,2017\right)$.

El Ministerio de Educación en conjunto con el Ministerio de Salud son los encargados de promover la educación nutricional, incluyendo en el diseño curricular nacional programas de promoción de hábitos alimentarios, a través de acciones de difusión y promoción de la alimentación saludable.

Los responsables de fiscalizar y establecer las sanciones correspondientes son la Comisión de Fiscalización de la competencia desleal del Instituto Nacional de Defensa de la Competencia y de la Protección de la Propiedad Intelectual (INDECOPI), el Ministerio de Educación, las Unidades de Gestión Educativa Local (UGEL) y los gobiernos regionales de acuerdo con su ámbito de competencia (Ley 30021, 2013).

Estudios realizados por Cabrera (2015), indican que el implementar un programa educativo incrementa de manera significativa los conocimientos sobre nutrición, asimismo menciona que a nivel internacional no hay una preocupación verdadera de los profesores por mejorar la salud de los estudiantes y esto se comprueba con el consumo diario de golosinas, gaseosas y por la poca costumbre de consumir verduras y/o frutas; siendo precisamente por ello que se genera la necesidad de articular estrategias que generen una adquisición de hábitos alimenticios saludables.

Dado el gran incremento que han presentado en los últimos años el número de niños con problemas de sobrepeso y obesidad, siendo las causas principales la mala alimentación, cambios en el estilo de vida, hoy más sedentarios, poco tiempo que tienen los padres para involucrarse más en la alimentación de sus hijos, la facilidad que tienen los niños por adquirir 
productos altos en grasa y azúcares, etc.; es que se identifica la oportunidad de brindar una solución a los padres de familia y facilitarles opciones de loncheras saludables para sus niños, garantizando una alimentación balanceada, disminuyendo considerablemente los niveles de grasa y azúcares, y de esta manera apoyando al cuidado de su salud.

\subsection{Determinación del problema u oportunidad}

La obesidad en la etapa de la niñez afecta a la salud y sus consecuencias se perciben no solo en la adolescencia, sino también en la adultez, afectando de manera negativa la economía de un país, ya que aumentan la posibilidad de las enfermedades crónicas en sus habitantes, incrementando los gastos públicos de salud.

En el Perú, donde todavía no se ha solucionado el problema de la desnutrición, ya se observa una alta tasa de obesidad infantil (10\% en niños menores de cinco años), encontrándose así entre los países latinoamericanos con mayor incremento. La etapa de la niñez y adolescencia son muy importantes ya que en ellas se adquieren hábitos alimentarios y de actividad física que regirán el estilo de vida en la adultez; por ello, es importante prevenir el sobrepeso y la obesidad infantil y adolescente, buscando como resultado la mejora en las condiciones de salud del país (Liria, 2012).

Actualmente existe una preocupación por los niños que se encuentran entre los 5 y 9 años de edad, pues se ha encontrado que, en este grupo de cada 10 niños, 3 sufren de sobrepeso y/u obesidad, y los principales factores que han desencadenado este alarmante incremento son los hábitos alimenticios que se forman desde el hogar, por ejemplo, uno de los errores más comunes es añadir azúcar a la leche, acostumbrar a los niños al consumo de alimentos altos en azúcares, en sal, entre otros. Otra de las causas se da en la escuela, por la alimentación que llevan los niños en las loncheras o por la variedad de alimentos nada saludables que son ofrecidos en los kioscos y/o comedores de los colegios. (INS, 2016). 


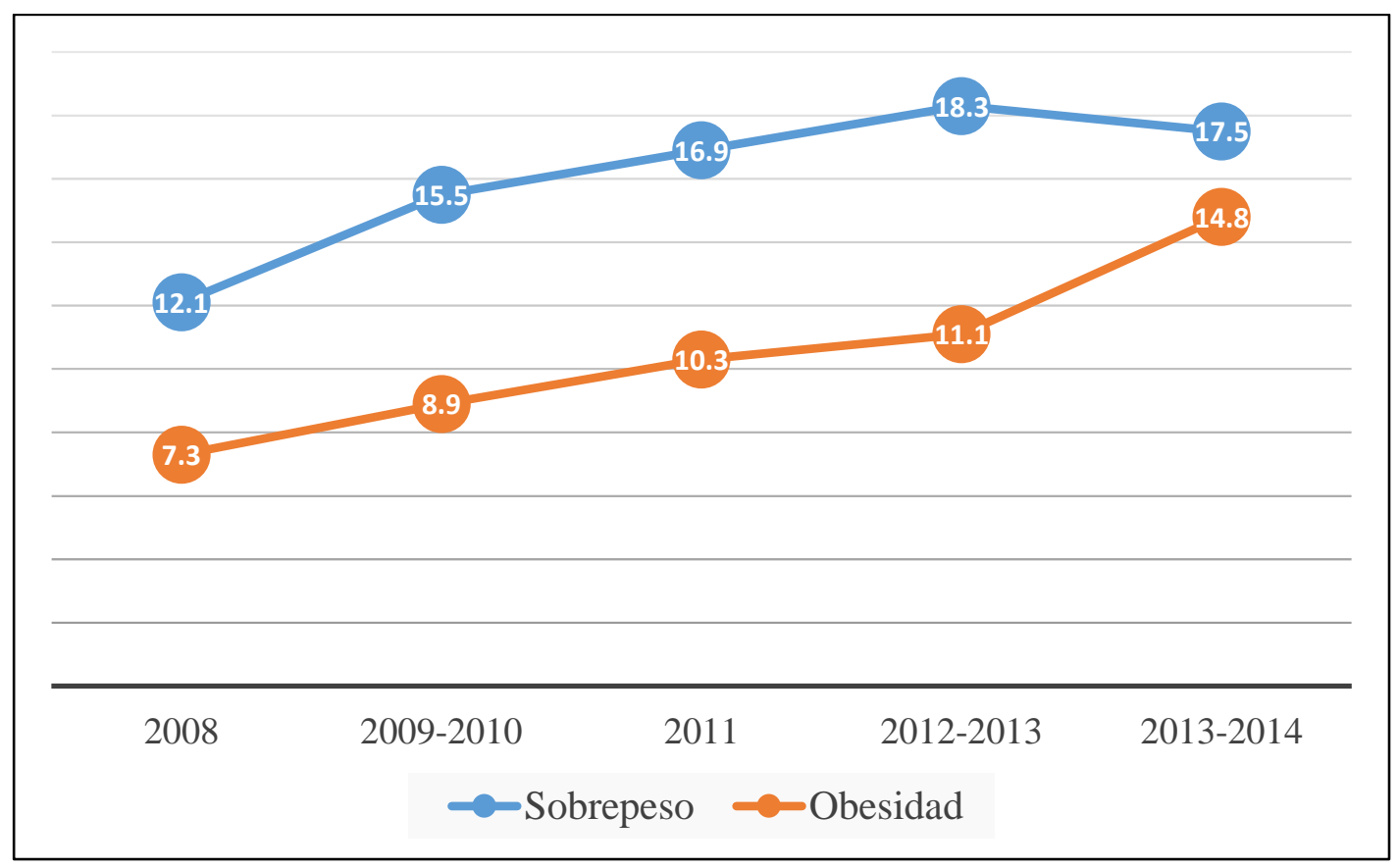

Figura 4. Tendencia del sobrepeso y obesidad en niñas y niños de 5 a 9 años. Perú 2008-2014. Fuente: “La obesidad en el mundo" por Malo, M., Castillo, N. \& Pajita, D., 2017, An Fac med., 78 (2), 67-72. Recuperado de https://www.researchgate.net/publication/318480868_La_ obesidad_en_el_mundo

De acuerdo con el Ministerio de Salud (2015), gran parte de los padres de familia deben trabajar para obtener ingresos que cubran las necesidades del hogar, motivo por lo cual buscan opciones fáciles en la preparación de la lonchera de sus hijos, acudiendo muchos de ellos a comprar alimentos altos en calorías, pero con poco valor nutricional tales como bebidas azucaradas, golosinas, snacks, entre otros.

Asimismo, los padres por comodidad y falta de tiempo cuando sus hijos comienzan a ser independientes, optan por entregarle una propina para comprar en los quioscos escolares, dejando que ellos elijan lo que van a comprar, siendo esta una problemática ya que los niños no tienen la capacidad de poder distinguir entre los alimentos saludables o no saludables (RPP noticias, 2015). 
De acuerdo con el Informe técnico: Lonchera Escolar en Estudiantes de Nivel Primario, Perú 2013 (INS, 2015), solo el 5,4\% de los alumnos llevan o adquieren una lonchera saludable, y el 94,6\% de alumnos llevan loncheras no saludables. Así mismo, en Lima Metropolitana solo el $8,1 \%$, llevan loncheras saludables, mientras que en los colegios privados este número alcanza el 10,0\%, lo que significa que solo 1 de cada 10 alumnos lleva una lonchera saludable, siendo esta una oportunidad de negocio potencial.

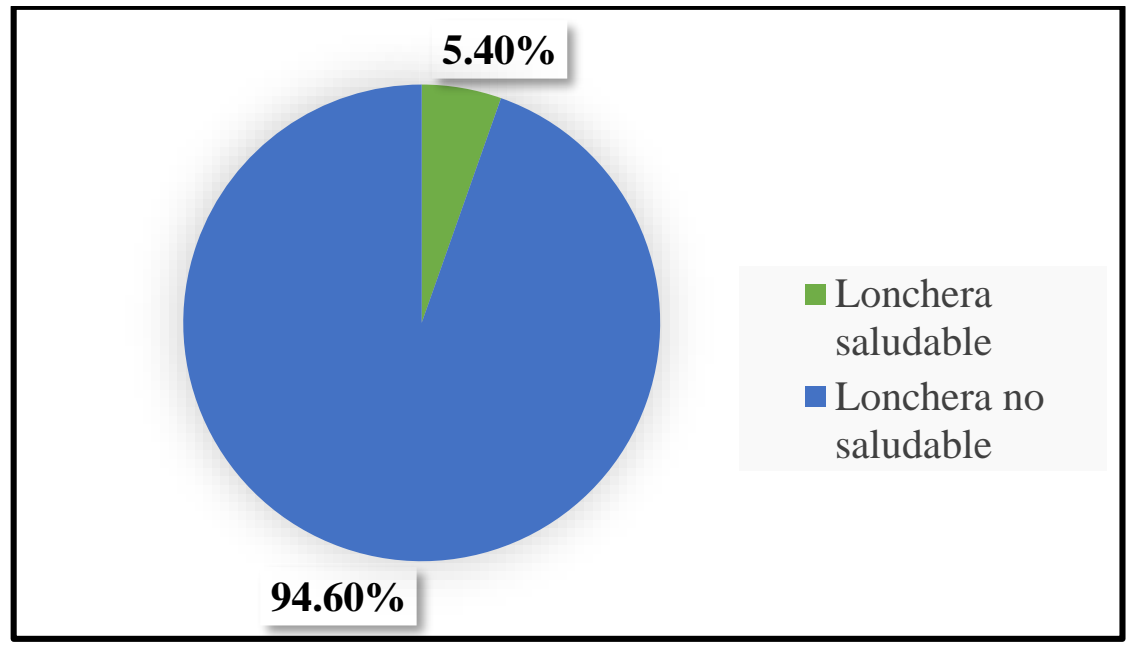

Figura 5. Distribución del tipo de lonchera en escolares de instituciones Educativas de nivel primario. Perú, 2013. (Porcentaje). Fuente: “Informe Técnico: Lonchera Escolar en Estudiantes de Nivel Primario, Perú 2013”, por Instituto Nacional de Salud, 2015, p. 24. Recuperado de http://www.portal.ins.gob.pe/en/component /rsfiles/preview?path=cenan $\% 252 \mathrm{FV}$ igilancia\%2BAlimentaria\%2By\%2BNutricional $\% 252$ FPeru\%2BLonchera\%2BEscolar\%2Bprimaria\%2B2013.pdf 


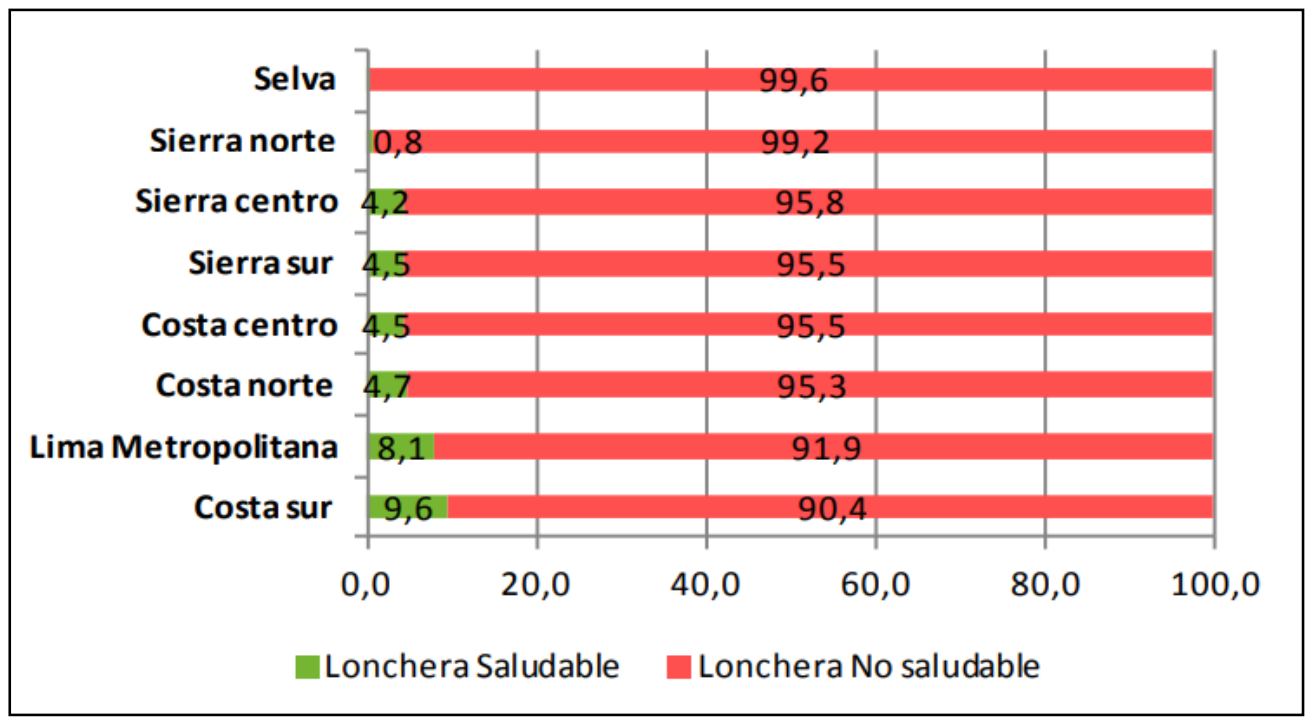

Figura 6. Distribución del tipo de lonchera en escolares de instituciones educativas de nivel primario. Perú, 2013. (Porcentaje). Fuente: “Informe Técnico: Lonchera Escolar en Estudiantes de Nivel Primario, Perú 2013", por Instituto Nacional de Salud, 2015, p. 25. Recuperado dehttp://www.portal.ins.gob.pe/en/component/rsfiles/preview?path=cenan\%252FVigilancia\%2BAlimentar ia\%2By\%2BNutricional\%252FPeru\%2BLonchera\%2BEscolar\%2Bprimaria\%2B2013.pdf

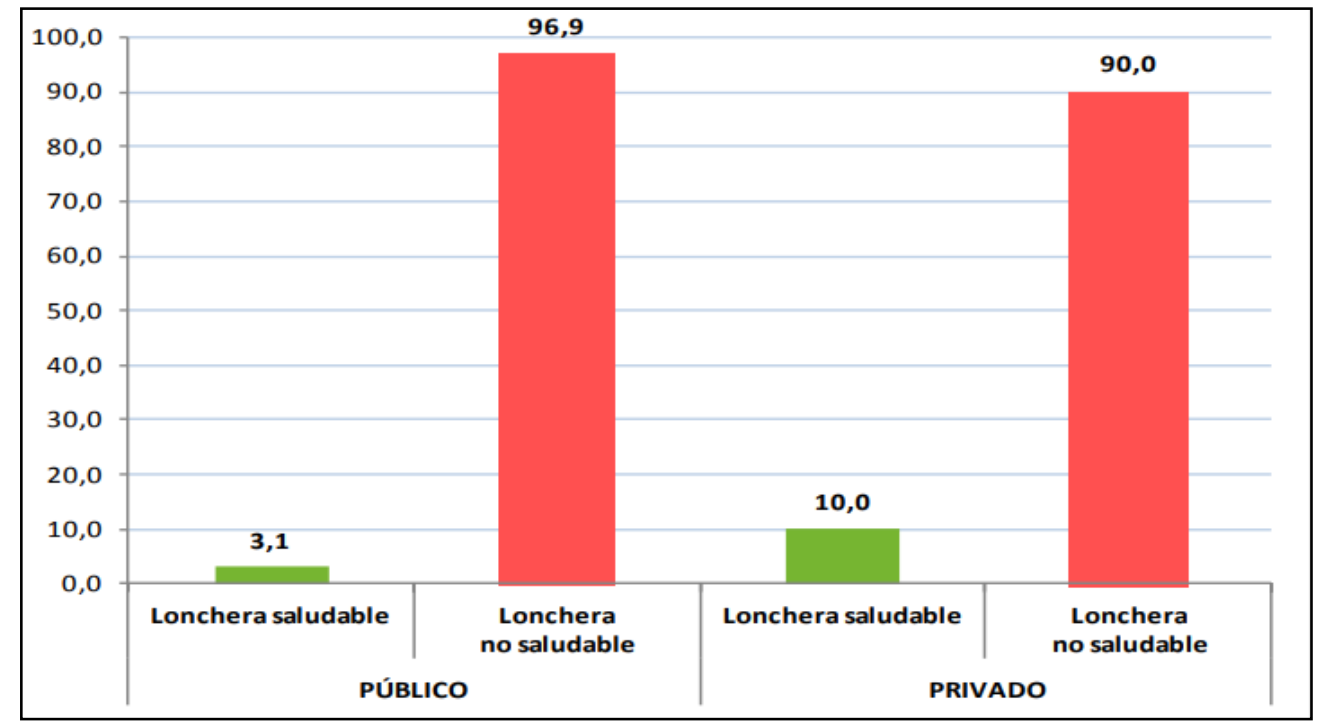

Figura 7. Distribución del tipo de lonchera en escolares de instituciones educativas de nivel primario. Perú, 2013. (Porcentaje). Fuente: “Informe Técnico: Lonchera Escolar en Estudiantes de Nivel Primario, Perú 2013", por Instituto Nacional de Salud, 2015, p. 25. Recuperado de http://www.portal.ins.gob.pe/en/component/rsfiles/preview?path=cenan\%252FVigilancia\%2BAlimentaria \%2By\%2BNutricional\%252FPeru\%2BLonchera\%2BEscolar\%2Bprimaria\%2B2013.pdf 
Es importante mencionar que el refrigerio cubre las necesidades de energía del alumno, aportando a un correcto rendimiento físico y mental durante el horario de clases, éste debe contribuir entre 10 y $15 \%$ de los requerimientos de energía que el estudiante necesita diariamente. Si bien el desayuno es uno de los alimentos más importantes, ya que ayuda a tener un buen rendimiento académico, este no debe ser sustituido por el refrigerio, pero si se elimina uno de ellos, los estudiantes mostrarán agotamiento durante el horario que permanecen en el colegio. (INS, 2012).

Por lo tanto, identificando la problemática del incremento de la obesidad y el sobrepeso en los niños, reconociendo la importancia del refrigerio ya que aporta entre el $10 \%$ y $15 \%$ de los requerimientos de energía que los niños necesitan diariamente y teniendo en cuenta que los padres de familia cada vez tienen menos tiempo para preparar las loncheras de sus hijos; se considera que ésta propuesta será una excelente alternativa, cómoda y conveniente, dado que no tendrán que preocuparse en su preparación, ahorrando tiempo y sobre todo brindando a sus hijos una alimentación saludable.

\subsection{Justificación del proyecto}

Dado el acelerado ritmo de vida por el que se atraviesa actualmente a nivel mundial, que no prioriza el desarrollo de actividades físicas y facilita el consumo de alimentos industrializados ricos en grasas saturadas, principalmente en la población urbana, el índice de sobrepeso y obesidad ha venido incrementándose principalmente en niños en edad escolar, los cuales llegan a la adultez con una alta tendencia a la diabetes y enfermedades cardiovasculares.

El Perú no es ajeno a ello y, según lo demostrado en la determinación del problema y oportunidades del presente plan de negocio, el gobierno peruano viene promoviendo campañas de nutrición, no solamente enfocada en adultos, sino principalmente en los niños a fin de crear hábitos de alimentación saludable. Lamentablemente, en un alto porcentaje de familias urbanas 
trabajan tanto el padre como la madre, principalmente en Lima Metropolitana, y cuentan con tiempo limitado para la preparación de la lonchera escolar de sus pequeños, por lo que deben recurrir a bebidas y bizcochos industrializados que pueden llenar el estómago, pero no ofrecen los nutrientes necesarios para la buena alimentación de sus hijos.

Es por ello que el presente proyecto de negocio, busca satisfacer la necesidad de este nicho desatendido, ofreciendo alternativas de loncheras saludables para niños en edad escolar de inicial y primaria, en formato de venta por delivery, ello permitirá a los padres delegar la elaboración de las mismas y tener la seguridad que sus hijos recibirán en forma oportuna una lonchera escolar que cumpla con las calorías, proteínas y minerales balanceados para el buen desarrollo y desempeño en su día de clase, éstas serán recomendadas por un médico nutricionista y tendrán la opción de elegir su alternativa con una semana de anticipación.

\subsection{Objetivos generales y específicos}

El objetivo general del proyecto es evaluar la viabilidad de un plan de negocio que ofrezca opciones de loncheras saludables en los colegios particulares de distritos de Lima Metropolitana.

Entre los objetivos específicos se pueden citar:

a. Realizar un análisis del entorno de la empresa para la implementación del plan de negocio.

b. Realizar un estudio de mercado para determinar la tendencia alimenticia saludable de los clientes que radican en los distritos de Ate, Santa Anita y La Molina.

c. Identificar el mercado objetivo y su poder adquisitivo.

d. Determinar los recursos humanos y materiales necesarios para poner en marcha el proyecto.

e. Diseñar el plan de marketing y de ventas.

f. Analizar la viabilidad económica y/o financiera para la implementación del negocio. 


\subsection{Alcances y limitaciones de la investigación}

El presente proyecto de negocio tiene como alcance los colegios particulares de educación inicial y primaria ubicados en Lima Metropolitana, en los distritos de Ate, La Molina y Santa Anita. El público objetivo estará conformado principalmente por familias con estilo de vida sofisticado, progresista y moderno, con tendencia a brindar alimentación saludable a sus hijos en edad escolar, pero que no cuentan con el tiempo de elaborar loncheras cada mañana.

Las principales limitaciones son:

a. Poca o nula información sobre proyectos particulares similares en el Perú.

b. Limitado acceso a los colegios particulares para establecer contacto con la Asociación de Padres de Familia.

c. Información no actualizada del sector. 


\section{Capítulo II. Estructura económica del sector}

El presente capítulo desarrolla el análisis realizado a empresas dedicadas a los servicios de alimentación saludable considerando el estado actual de la industria, las tendencias del mercado, los clientes y otros elementos de relevancia para la propuesta del plan de negocio.

\subsection{Descripción del estado actual de la industria}

Según el Instituto Nacional de Estadística e Informática (2010), el sector de Hoteles y restaurantes cuenta con la siguiente clasificación industrial uniforme de las actividades económicas:

Sección $\quad$ : I (Actividades de alojamiento y de servicio de comidas)

División : : $56 \quad$ (Actividades de servicio de comidas y bebidas)

Grupo : 561 (Actividades de restaurantes y de servicio móvil de comidas)

Clase $\quad$ : 5610 (Actividades de restaurantes y de servicio móvil de comidas)

La Clasificación Industrial Internacional Uniforme (CIIU) tiene como principal propósito ofrecer un conjunto de categorías de las actividades productivas, de tal manera que facilite el estudio del comportamiento de las diferentes entidades económicas.

El sector de Hoteles y Restaurantes cuenta con el subsector de restaurantes, el cual comprende la actividad de servicios de delivery. En el año 2016 el grupo de restaurantes creció 2,08\%, mientras que en el 2015 su crecimiento fue de 3,05\%. (ver Tabla 2) 
Tabla 2.

Sector alojamiento y restaurantes: diciembre 2016

\begin{tabular}{lrrr}
\hline \multicolumn{1}{c}{ Sector } & \multicolumn{2}{c}{ Variación porcentual } \\
& Ponderación & Diciembre & $\begin{array}{c}\text { Enero- } \\
\text { Diciembre }\end{array}$ \\
\hline Sector alojamiento y restaurantes & $100.0 \%$ & 2.44 & 2.57 \\
Alojamiento & $13.6 \%$ & 3.55 & 3.68 \\
Restaurantes & $86.4 \%$ & 2.29 & 2.40 \\
\hline
\end{tabular}

Nota: Elaboración propia.

En el mes de diciembre del 2016, el subsector Restaurantes registró un total de 2,29\%, como resultado de las actividades que desarrolla, las cuales son: negocios de restaurantes $(2,08 \%)$ y otras actividades de servicios de comidas $(3,75 \%)$; también se consideran las actividades de servicios de bebidas (1,87\%). (ver Figura 8).

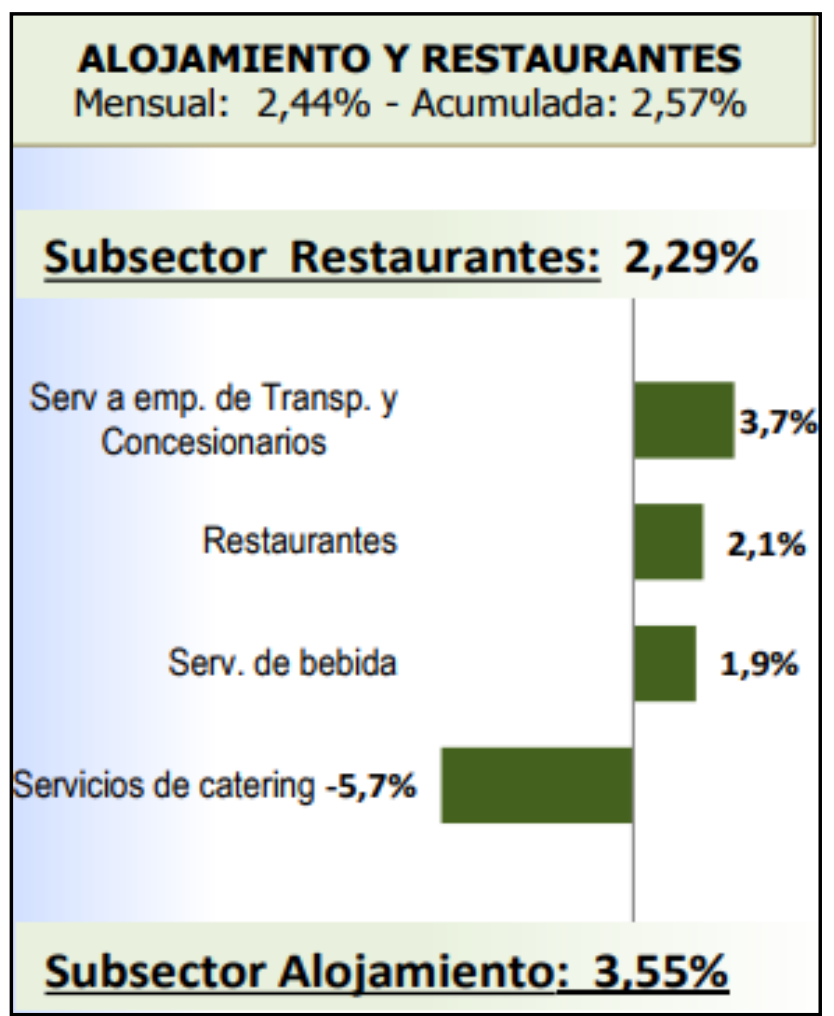

Figura 8. Alojamiento y restaurantes: diciembre 2016. Fuente: Informe técnico N²: Producción nacional por INEI (2017, p.7). Recuperado de https://www.inei.gob.pe/ media/principales_indicadores/02-informe-tecnico-n02_produccion-nacional-dic2016.pdf 
Para el 2013, a nivel nacional existieron 142, 579 empresas dedicadas al sector de Actividades de alojamiento y de servicio de comidas, según el análisis de la densidad empresarial. INEI (2013). 
Tabla 3

Perú: Densidad empresarial, según actividad económica, 2013

\begin{tabular}{|c|c|c|c|}
\hline Actividad Económica Perú & $\begin{array}{c}\text { Total empresas } \\
2013\end{array}$ & $\begin{array}{c}\text { Estructura } \\
\text { porcentual } 2013\end{array}$ & $\begin{array}{c}\text { Densidad } \\
\text { empresarial (Emp } \\
\text { / mil hab) }\end{array}$ \\
\hline Agricultura, ganadería, silvicultura y pesca & $35,723.0$ & 2.0 & 1.2 \\
\hline Explotación de minas y canteras & $9,897.0$ & 0.6 & 0.3 \\
\hline Industrias manufactureras & $157,001.0$ & 8.8 & 5.2 \\
\hline Electricidad, gas y agua & $4,237.0$ & 0.2 & 0.1 \\
\hline Construcción & $48,745.0$ & 2.7 & 1.6 \\
\hline Comercio y reparación de vehículos automotores y motocicletas & $824,742.0$ & 46.4 & 27.1 \\
\hline Transporte y almacenamiento & $86,283.0$ & 4.9 & 2.8 \\
\hline Actividades de alojamiento de servicio y comidas & $142,579.0$ & 8.0 & 4.7 \\
\hline Información y comunicaciones & $52,839.0$ & 3.0 & 1.7 \\
\hline Servicios profesionales técnicos y de apoyo empresarial & $179,006.0$ & 10.1 & 5.9 \\
\hline Otros servicios & $237,325.0$ & 13.3 & 7.8 \\
\hline Total & $1,778,377.0$ & 100.0 & 58.4 \\
\hline
\end{tabular}

1/ Incluye financieras, seguros, inmobiliarias, administración pública, enseñanza, salud, artísticas, entretenimiento y otros servicios.

Nota: Adaptado de "Perú: estructura empresarial" por INEI (2014, p.109). Recuperado de https://www.inei.gob.pe/media/MenuRecursivo/publicaciones_digitales/Est/

Lib1178/index.html 
Tabla 4

Lima metropolitana: densidad empresarial, según actividad económica, 2013.

\begin{tabular}{|c|c|c|c|c|}
\hline Actividad Económica Lima Metropolitana & $\begin{array}{c}\text { Total } \\
\text { empresas } \\
2013\end{array}$ & $\begin{array}{l}\text { Estructura } \\
\text { porcentual } \\
\quad 2013\end{array}$ & $\begin{array}{c}\text { Densidad } \\
\text { empresarial } \\
\text { (Emp / mil hab) }\end{array}$ & $\begin{array}{c}\text { Densidad } \\
\text { empresarial } \\
\text { (Emp / km2) }\end{array}$ \\
\hline Agricultura, ganadería, silvicultura y pesca & 4333 & 0.5 & 0.5 & 1.5 \\
\hline Explotación de minas y canteras & 3139 & 0.4 & 0.3 & 1.1 \\
\hline Industrias manufactureras & 86636 & 10.3 & 9 & 30.8 \\
\hline Electricidad, gas y agua & 2532 & 0.3 & 0.3 & 0.9 \\
\hline Construcción & 18102 & 2.2 & 1.9 & 6.4 \\
\hline $\begin{array}{l}\text { Comercio y reparación de vehículos automotores y } \\
\text { motocicletas }\end{array}$ & 386556 & 45.9 & 40.3 & 137.2 \\
\hline Transporte y almacenamiento & 34317 & 4.1 & 3.6 & 12.2 \\
\hline Actividades de alojamiento de servicio y comidas & 51162 & 6.1 & 5.3 & 18.2 \\
\hline Información y comunicaciones & 27229 & 3.2 & 2.8 & 9.7 \\
\hline Servicios profesionales técnicos y de apoyo empresarial & 97484 & 11.6 & 10.2 & 34.6 \\
\hline Otros servicios & 131032 & 15.6 & 13.6 & 46.5 \\
\hline Total & 842522 & 100.0 & 87.8 & 299.1 \\
\hline
\end{tabular}

1/ Incluye financieras, seguros, inmobiliarias, administración pública, enseñanza, salud, artísticas, entretenimiento y otros servicios.

Nota: Adaptado de "Perú: estructura empresarial" por INEI (2014, p.116). Recuperado de https://www.inei.gob.pe/media/MenuRecursivo/publicaciones_digitales/Est/

Lib1178/index.html 


\subsubsection{Segmentación de la industria}

El sector de alojamiento de restaurantes lo integran los siguientes servicios:

a. Subsector Restaurantes

- Servicio a empresa de transporte y concesionarios

- Restaurantes (comidas rápidas, restaurantes, restaurantes turísticos, cebicherías, carnes y parrillas y heladerías, por la extensión de cadenas a nivel nacional, alianzas comerciales, servicio de delivery, cenas buffet bailable de año nuevo, acondicionamiento de áreas para la organización de eventos y reuniones de camaradería.)

- Servicios de bebidas

- Servicios de catering

b. Subsector alojamiento

El plan de negocios propuesto se encuentra dentro del subsector de servicios de restaurantes y en el grupo de servicio delivery. (INEI, 2010).

\subsubsection{Empresas que la conforman}

En el año 2015, el 6,9\% de las empresas formales a nivel nacional, es decir 118,110 establecimientos, pertenecían a la sección " $\mathrm{H}$ " correspondiente al sector de hoteles y restaurantes. (ver Tabla 5) 
Tabla 5

Perú: Mipymes formales por estrato empresarial, según sección CIIU, 2015

\begin{tabular}{|c|c|c|c|c|c|c|c|}
\hline \multirow[b]{2}{*}{ Sección } & \multirow[b]{2}{*}{ Descripción } & \multicolumn{4}{|c|}{ Numero de Mipyme } & \multirow[b]{2}{*}{$\begin{array}{c}\text { Gran } \\
\text { empresa }\end{array}$} & \multirow[b]{2}{*}{$\begin{array}{c}\text { Total } \\
\text { empresas }\end{array}$} \\
\hline & & $\begin{array}{l}\text { Micro } \\
\text { empresa }\end{array}$ & $\begin{array}{l}\text { Pequeña } \\
\text { empresa }\end{array}$ & $\begin{array}{l}\text { Mediana } \\
\text { empresa }\end{array}$ & $\begin{array}{c}\text { Toral } \\
\text { mipyme }\end{array}$ & & \\
\hline G & Comercio al por mayor y menor & 715,500 & 28,704 & 1,091 & 745,295 & 3,275 & 748,570 \\
\hline $\mathrm{K}$ & $\begin{array}{l}\text { Actividades inmobiliarias, empresariales y de alquiler } \\
\text { Otras actividades de servicio comunitarios, sociales y }\end{array}$ & 214,783 & 11,236 & 440 & 226,459 & 1,231 & 227,690 \\
\hline $\mathrm{O}$ & personales & 171,485 & 2,902 & 83 & 174,470 & 199 & 174,669 \\
\hline $\mathrm{D}$ & Industrias manufactureras & 140,908 & 7,531 & 293 & 148,732 & 1,327 & 150,059 \\
\hline I & Transporte, almacenamiento y comunicaciones & 121,751 & 8,680 & 292 & 130,723 & 933 & 131,656 \\
\hline $\mathrm{H}$ & Hoteles y restaurantes & 115,058 & 2,850 & 61 & 117,969 & 141 & 118,110 \\
\hline $\mathrm{F}$ & Construcción & 50,004 & 4,882 & 197 & 55,083 & 469 & 55,552 \\
\hline A & Agricultura, ganadería, caza y silvicultura & 22,165 & 1,926 & 93 & 24,184 & 341 & 24,525 \\
\hline $\mathrm{N}$ & Actividades de servicios sociales y de salud (privada) & 21,557 & 1,088 & 29 & 22,674 & 107 & 22,781 \\
\hline M & Enseñanza (privada) & 14,165 & 904 & 21 & 15,090 & 89 & 15,179 \\
\hline $\mathrm{C}$ & Explotación de minas y canteras & 12,767 & 843 & 59 & 13,669 & 349 & 14,018 \\
\hline $\mathrm{B}$ & Pesca & 2,813 & 663 & 21 & 3,497 & 75 & 3,572 \\
\hline $\mathrm{J}$ & Intermediación financiera & 3,037 & 326 & 20 & 3,383 & 156 & 3,539 \\
\hline \multirow[t]{2}{*}{$\mathrm{E}$} & Suministro de electricidad, gas y agua & 1,312 & 129 & 12 & 1,453 & 89 & 1,542 \\
\hline & $e_{1}$ & $1,607,305$ & 72,664 & 2,712 & $1,682,681$ & 8,781 & $1,691,462$ \\
\hline
\end{tabular}

Nota: Adaptado de “Anuario Estadístico Industrial, Mype y Comercio Interno, 2015,” por el Ministerio de la Producción, PRODUCE (2015, p. 120). Recuperado de http://www.produce.gob.pe/documentos/estadisticas/anuarios/anuario-estadistico-mype-2015.pdf

${ }^{a}$ El estrato empresarial es determinado de acuerdo con la Ley nro. 30056 


\subsection{Tendencias de la industria}

A finales del 2016, el número de empresas activas en el país ascendió a 2029,648 mayor en 7,8\% respecto al año anterior. Solo en el IV trimestre del 2015 se crearon 62,581 empresas a nivel nacional, de las cuales el 8,5\% $(5,304)$ correspondió a la actividad económica de hoteles y restaurantes, la cual registró una variación de 30,6\% respecto al año anterior. (INEI, 2010)

El subsector de restaurantes en el año 2015 presentó un crecimiento de 2,94\%, el cual muestra un resultado menor al 5,08\% obtenido en el año 2014. Si bien el sector muestras resultados de desaceleración, en comparación de la economía local y los mercados internacionales, este presenta crecimiento constante. (ver figura 9) 


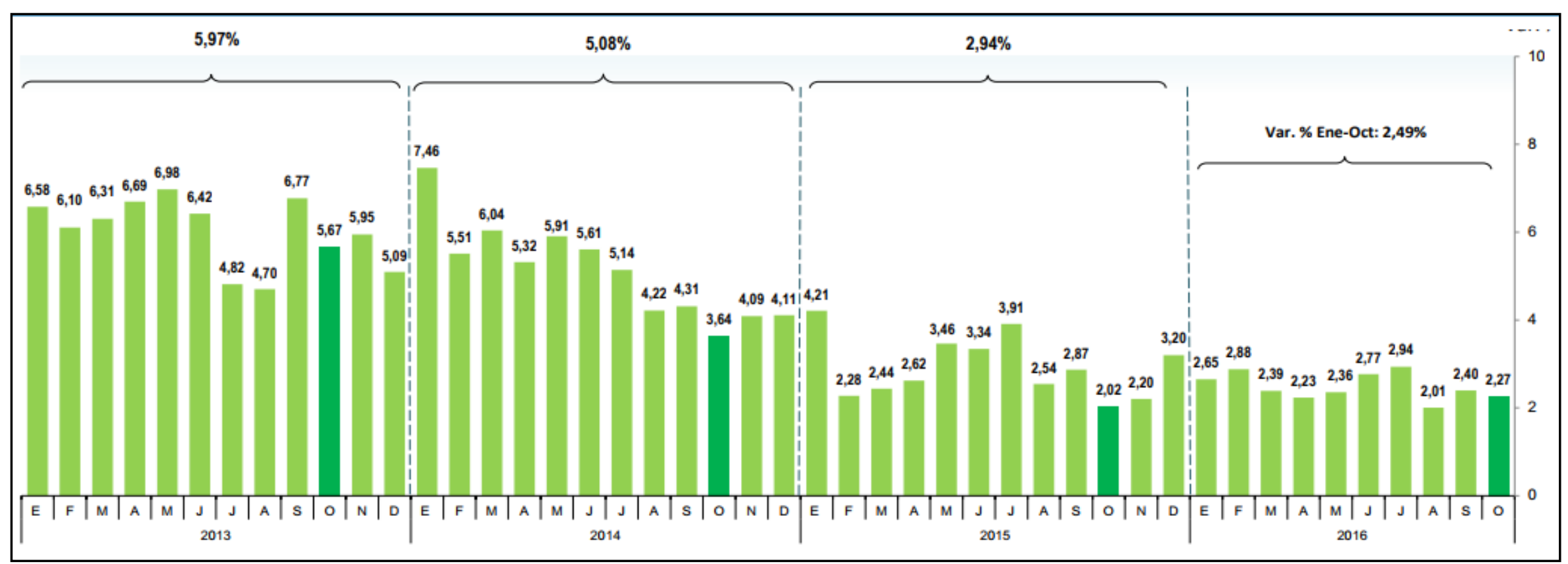

Figura 9. Evolución mensual de la actividad Restaurantes: 2013-2016. Fuente: Informe técnico º12: Producción nacional por INEI (2016, p.29). Recuperado de https://www.inei.gob.pe/media/MenuRecursivo/boletines/informe-tecnico-n12_produccion_oct2016.pdf 
En la actualidad la oferta en el mercado de productos naturales ha tomado mucha relevancia para los consumidores quienes buscan tener una vida saludable.

Según Gestión (2017), en los últimos años la empresa de Lima Orgánica ha crecido en la plataforma digital y también en cuanto a unidades de negocios, la comunidad tuvo en un comienzo, hace dos años, 12 marcas en la categoría de restaurantes y tiendas. Actualmente, cuenta con más de 100 marcas en distintas categorías.

\subsection{Análisis estructural del sector industrial}

Según David (2013), el microentorno del sector considera aquellos aspectos por los cuales las empresas interactúan de forma directa, son todas aquellas fuerzas que actúan alrededor de cualquier institución y que pueden influir en los resultados de estas.

Para determinar los diferentes aspectos de influencia del entorno directo, se utilizará el modelo de las 5 fuerzas de Porter, lo cual permitirá conocer el marco de análisis del sector de loncheras saludables en la zona de los distritos de Ate, La Molina y Santa Anita. (ver Figura 10)

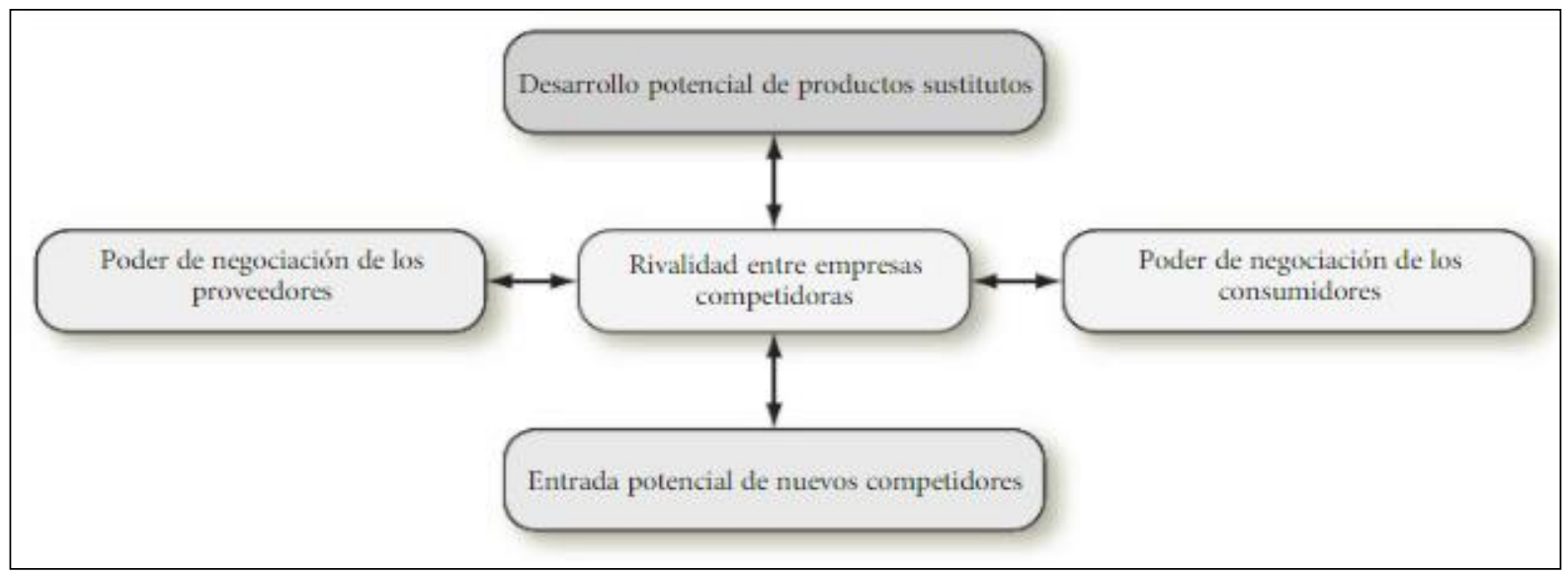

Figura 10. Modelo de competencia de las cinco fuerzas de Porter. Fuente: Conceptos de administración estratégica por David (2013, p. 76) 
Las cinco fuerzas de Porter buscan maximizar los recursos utilizados por la empresa y con ello marcar una alta diferencia con la competencia. Se realizá un análisis de la empresa, con el objetivo de conocer la actualidad de esta con relación a la competencia. En las siguientes matrices se han analizado cada una de las fuerzas, divididas en cinco rangos, siendo la calificación nuemro 1 la más baja y el numero 5 la más alta.

\subsubsection{Rivalidad entre competidores actuales}

"La rivalidad entre empresas competidoras suele ser la más poderosa de las cinco fuerzas competitivas". (David, 2013, p.76)

A mayor número de competidores en el sector esta fuerza competitiva toma relevancia, cuando las empresas cuentan con similares capacidades de operación el sector crece de manera paulatina y logran alcanzar también costos fijos elevados o sus barreras de salidas son altas. (David, 2013, p.77)

\section{a. Diversidad de los competidores}

En Lima no se tiene conocimiento de empresas que brinden los servicios de loncheras escolares saludables, pero si existen aquellas que ofrecen alimentación saludable para público en general y en un establecimiento donde los interesados puedan visitarlos. Calificación: Baja.

\section{b. Costos fijos elevados}

El presente modelo de negocio requiere una inversión inicial mediana en activos fijos, ya que es necesaria la compra de una cocina industrial, congeladoras y refrigeradoras para la conservación de alimentos, así como movilidad para poder trasladar los productos a los diferentes colegios. Calificación: Media. 


\section{c. Grupos Empresariales}

El sector no se encuentra representado por grupos empresariales debido a que es un nicho de mercado aún desatendido. Calificación: Baja.

d. Equilibrio entre capacidad y producción

Puede generar competencia en el sector, debido a la calidad, eficiencia y eficacia con la que se atienda al cliente. Calificación: Media.

e. Crecimiento de demanda

Favorecida por la creciente tendencia al consumo de loncheras escolares saludables para niños, las cuales no siempre pueden ser preparadas por los padres debido al estilo de vida agitado de estos tiempos. Calificación: Alta.

Tabla 6

Matriz de atractividad rivalidad entre competidores.

\begin{tabular}{|c|c|c|c|c|c|c|}
\hline $\begin{array}{l}\text { RIVALIDAD ENTRE COMPETIDORES } \\
\text { ACTUALES }\end{array}$ & 1 & 2 & 3 & 4 & 5 & Ponderado \\
\hline Diversidad de los competidores & $\mathrm{X}$ & & & & & \\
\hline Costos fijos elevados & & & & $\mathrm{X}$ & & \\
\hline Grupos empresariales & $X$ & & & & & 2.8 \\
\hline Equilibrio entre capacidad y producción & & & $\Lambda$ & & & \\
\hline Crecimiento de la demanda & & & & & $\mathrm{X}$ & \\
\hline
\end{tabular}

Nota. Adaptado de "Ejemplo de una matriz de perfil competitivo". Fuente: Conceptos de administración estratégica por David (2013, p. 83)

En la matriz de rivalidad entre competidores, se puede notar que, a pesar de que el crecimiento de la demanda es elevado, esta fuerza tiene factores muy bajos como la diversidad de competidores y la nula representación de grupos empresariales. Calificación media-baja. 


\subsubsection{Amenaza de entrada de nuevos competidores}

La intensidad de la competencia tiende a incrementarse cuando existe un mínimo grado de dificultad para que los competidores potenciales ingresen a un sector; sin embargo, la existencia de barreras de entradas podría obstaculizar el ingreso de nuevos competidores. (David, 2013, p.77)

Este proyecto de negocio presenta el siguiente análisis:

a. Diversidad de los competidores

Dado que es un nuevo nicho de mercado, existen pocas empresas que ofrecen servicios de loncheras saludables. Calificación: Baja.

b. Barreras a la entrada

Actualmente no existen barreras de entrada al mercado de servicios de comida saludable. Calificación: Baja.

c. Política gubernamental

Se puede presentar una reforma a la Ley de promoción de la alimentación saludable a solicitud del Gobierno de turno. Calificación: Media.

d. Desventaja en costes independientemente de la escala

Las empresas que lideran el mercado de consumo masivo de alimentos presentan mayor inversión en tecnología. Calificación: Alta.

e. Inversiones de capital

El rubro no maneja altos importes en lo que se refiere al capital inicial, lo que da ventaja a nuevos competidores. Calificación: Alta.

f. Economías de escala

La base de datos de padres de familia es el recurso principal debido a que no estamos presentes dentro de los colegios. Calificación: Alta. 
Tabla 7.

Matriz de atractividad amenaza de nuevos competidores.

\begin{tabular}{|c|c|c|c|c|c|c|}
\hline $\begin{array}{l}\text { AMENAZA DE NUEVOS } \\
\text { COMPETIDORES }\end{array}$ & \multicolumn{5}{|c|}{ AMENAZA DE NUEVOS } & Ponderado \\
\hline Diversidad de los competidores & $\mathrm{X}$ & & & & & \\
\hline Barreras de entrada & $\mathrm{X}$ & & & & & \\
\hline Política Gubernamental & & $\mathrm{X}$ & & & & 3.0 \\
\hline Desventaja en costes independie & & & & & $\mathrm{X}$ & \\
\hline Inversión de capital & & & & $\mathrm{X}$ & & \\
\hline Economías de escala & & & & & $\mathrm{X}$ & \\
\hline
\end{tabular}

Nota. Adaptado de "Ejemplo de una matriz de perfil competitivo". Fuente: Conceptos de administración estratégica por David (2013, p. 83)

En conclusión, el proyecto de negocio no contiene barreras de ingreso, ya que es de fácil implementación.

\subsubsection{Poder de negociación de los proveedores}

Al contar con un menor número de proveedores el poder de negociación de estos incrementa. La búsqueda de mejores condiciones de precios, pagos, así como presentar una postura de menor flexibilidad de las exigencias del comprador. (David, 2013, p.78)

Los proveedores que van a contribuir con el funcionamiento del negocio son seleccionados por: los productos que nos brindarán o el servicio de calidad que desarrollarán en la implementación del negocio.

a. Cantidad de proveedores

En el mercado se encuentra una gran diversidad de proveedores pudiendo conseguir una alta calidad de productos o servicios y precios acorde con lo planificado en el proyecto. Calificación: Baja.

b. Poder de decisión en el precio por parte del proveedor 
El mercado ofrece diversos precios, los cuales están en relación con la calidad de la oferta de proveedores, por lo que le permite tener poder de decisión en el precio. Calificación: Media.

c. Nivel de organización de los proveedores

Los precios por sus servicios se encuentran dentro de un rango, por ello podemos definir que los proveedores se encuentran organizados. Calificación: Media.

d. Impacto de insumos

Los servicios ofrecidos por nuestros proveedores tienen relación con la operativa del negocio. Calificación: Media.

Tabla 8

Matriz de atractividad de poder de negociación de los proveedores.

\begin{tabular}{lllllll}
\hline PODER DE NEGOCIACION DE LOS & & & & & & \\
PROVEEDORES & 1 & 2 & 3 & 4 & 5 & Ponderado \\
\hline Cantidad de proveedores en la industria & $\mathrm{X}$ & & & & & \\
Poder de decisión en el precio por parte del & & & & & & 2.5 \\
proveedor & & $\mathrm{X}$ & & \\
Nivel de organización de los proveedores & & $\mathrm{X}$ & & \\
Impacto de insumos & & $\mathrm{X}$ & & \\
\hline
\end{tabular}

Nota. Adaptado de "Ejemplo de una matriz de perfil competitivo". Fuente: Conceptos de administración estratégica por David (2013, p. 83)

En esta matriz podemos apreciar que la fuerza de poder de negociación de los proveedores es baja y no tiene efecto negativo en el proyecto de negocio. 


\subsubsection{Poder de negociación de los clientes}

La competencia en un sector industrial, se define en cierto grado, por el poder de negociación que tienen los clientes con las empresas que producen el bien o servicio. (David, 2013, p.78)

a. Productos sustitutos

El mercado brinda una gran variedad de productos sustitutos, no necesariamente en el formato delivery, pero el servicio se brinda en lugares que el público puede visitar. Calificación: Alta.

b. Diferenciación

Servicio personalizado, pero carece de identificación con la marca por ser nueva en el mercado. Calificación: Media.

c. Volumen de compra

Es calculado teniendo en cuenta los márgenes de ingresos de los potenciales clientes. Calificación: Alta

d. Concentración de clientes

El número estará definido por el número de alumnos en colegios y nidos en los distritos donde se ofrecerá el producto. Calificación: Alta

Tabla 9.

Matriz de atractividad poder de negociación de los clientes.

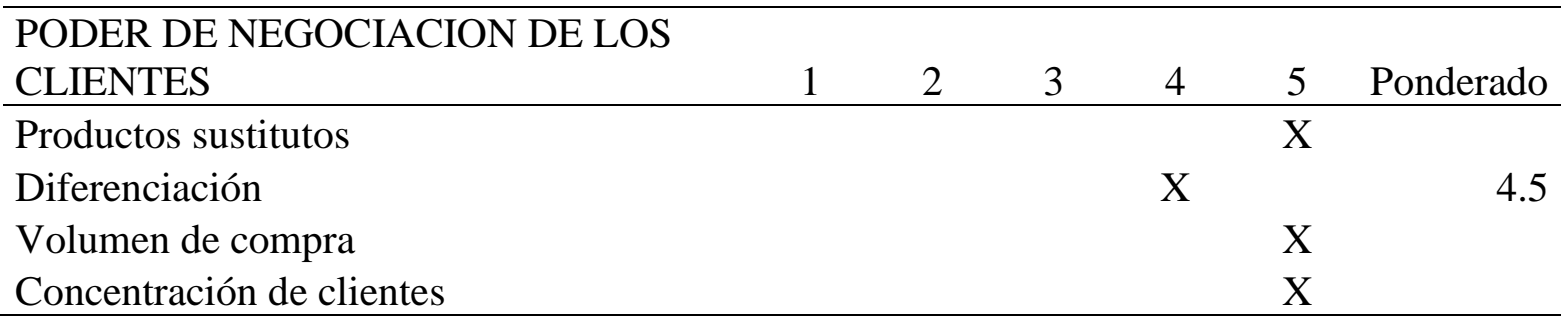

Nota. Adaptado de "Ejemplo de una matriz de perfil competitivo". Fuente: Conceptos de administración estratégica por David (2013, p. 83) 
La matriz de atractividad del poder de negociación de los clientes, tiene una calificación alta, ya que, si bien este negocio es nuevo, es fácil de replicar pero al ser una marca nueva aún carece de identificación.

\subsubsection{Amenaza de productos sustitutos}

Las presiones competitivas que surgen por los productos sustitutos aumentan a medida que el precio relativo de estos disminuye, y conforme el costo en el que incurren los consumidores por cambiar a ellos también se reduce. (David, 2013, p.77)

a. Disponibilidad de sustitutos cercanos

Los quioscos escolares dentro de los colegios son espacios donde se ofrecen alimentos a los alumnos de los niveles preescolar y escolar, y son regulados mediante Ley 30021, Ley de promoción de la alimentación saludable para niños, niñas y adolescentes, que promueven los “Quioscos y comedores escolares saludables", por lo tanto, de cumplir con las regulaciones exigidas, se encontrarían en la capacidad de ofrecer una diversidad de productos sustitutos a las loncheras saludables. Calificación: Alta.

b. Nivel percibido de diferenciación de producto o servicio

No registra el mercado un modelo de negocio similar, pero es de fácil imitación. Calificación: Media.

c. Coste o facilidad del comprador

Al mejorar la oferta el cliente puede cambiar de proveedor. Calificación: Alta.

d. Propensión del comprador a sustituir

El servicio y los precios no son suficientes para contar con la fidelidad del cliente. Calificación: Alta. 
Tabla 10

Matriz de atractividad servicios sustitutos.

\begin{tabular}{|c|c|c|c|c|c|c|}
\hline AMENAZA DE PRODUCTOS & & & & & & \\
\hline SUSTITUTOS & 1 & 2 & 3 & 4 & 5 & Ponderado \\
\hline Disponibilidad de sustitutos cercanos & & & & & $\mathrm{X}$ & \\
\hline $\begin{array}{l}\text { Nivel percibido de diferenciación de } \\
\text { producto o servicio }\end{array}$ & & & $X$ & & & 4.5 \\
\hline Coste o facilidad del comprador & & & & & $\mathrm{X}$ & \\
\hline Propensión del comprador a sustituir & & & & & $X$ & \\
\hline
\end{tabular}

Nota. Adaptado de "Ejemplo de una matriz de perfil competitivo". Fuente: Conceptos de administración estratégica por David (2013, p. 83)

Esta matriz sobre los servicios sustitutos tiene una calificación alta, esto debido a que, si bien no existen empresas que den el mismo servicio, los quioscos de los colegios tienen la capacidad de poder implementarlo.

\subsection{Análisis de la competencia}

El presente plan de negocio ofrece la comercialización de loncheras saludables a niños de colegios particulares en el nivel inicial y primario, con alimentos variados y nutritivos recomendados por un médico nutricionista según la edad del niño.

En Lima, se tiene poco conocimiento de competidores directos particulares, pero, dada la reglamentación de la nueva Ley 30021 se puede considerar como competencia indirecta a los quioscos y cafeterías que funcionan dentro de los colegios, asimismo también se considera la venta de alimentos en tiendas cercanas a los colegios.

\subsubsection{Empresas que ofrecen el mismo producto o servicio}

Si bien es cierto no existen muchas empresas que ofrezcan el mismo producto, se ha encontrado las siguientes empresas que ofrecen el mismo servicio: 


\section{a. Competencia directa.}

\section{- Loncheras escolares "PowerLunch"}

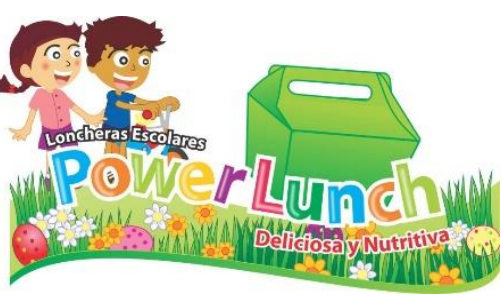

Es una empresa dirigida por nutricionistas colegiadas, que ofrece loncheras nutritivas variadas, caseras, de bajo costo y elaboradas con alimentos peruanos, además ofrece servicio de concesionario, quioscos saludables, evaluación y consulta nutricional para escolares, sesiones educativas y demostrativas.

\section{- ColiLunch, Delivery Loncheras Nutritivas}

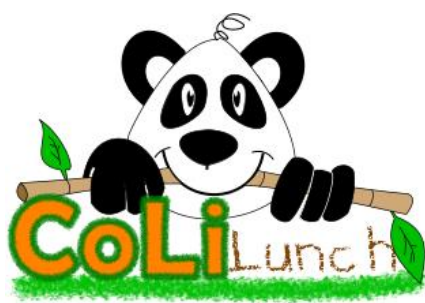

Ofrece servicio de loncheras delivery para niños de 3 a

5 años, siguiendo las recomendaciones del Ministerio de Salud y la Gerencia de Desarrollo Social de la Municipalidad de Lima. Ofrecen el valor nutricional adecuado a cada una de las etapas de desarrollo del niño, considerando alimentos constructores reguladores y formadores.

\section{- DeliLunch}

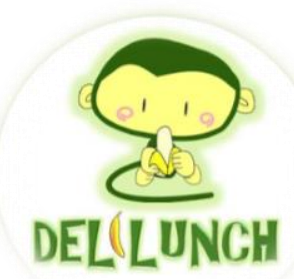

Es una empresa que ofrece el servicio de delivery de loncheras escolares nutritivas y saludables, su objetivo es solucionar las necesidades de los padres de familia, permitiéndoles cubrir las necesidades nutricionales de los niños al facilitar una lonchera 
rápida y deliciosa. Brinda tres tipos de loncheras: básica, light y loncheras especialmente preparadas según el gusto del cliente.

\section{b. Competencia indirecta:}

Se categorizará la competencia indirecta según la procedencia de alimentos de la lonchera escolar, los enviados desde casa y los comprados en la institución educativa (quioscos y/o cafeterías) para ello se tomó como referencia las estadísticas mostradas en el Informe Técnico: Lonchera escolar en estudiantes de nivel primario. Perú 2013 (INS, 2015)

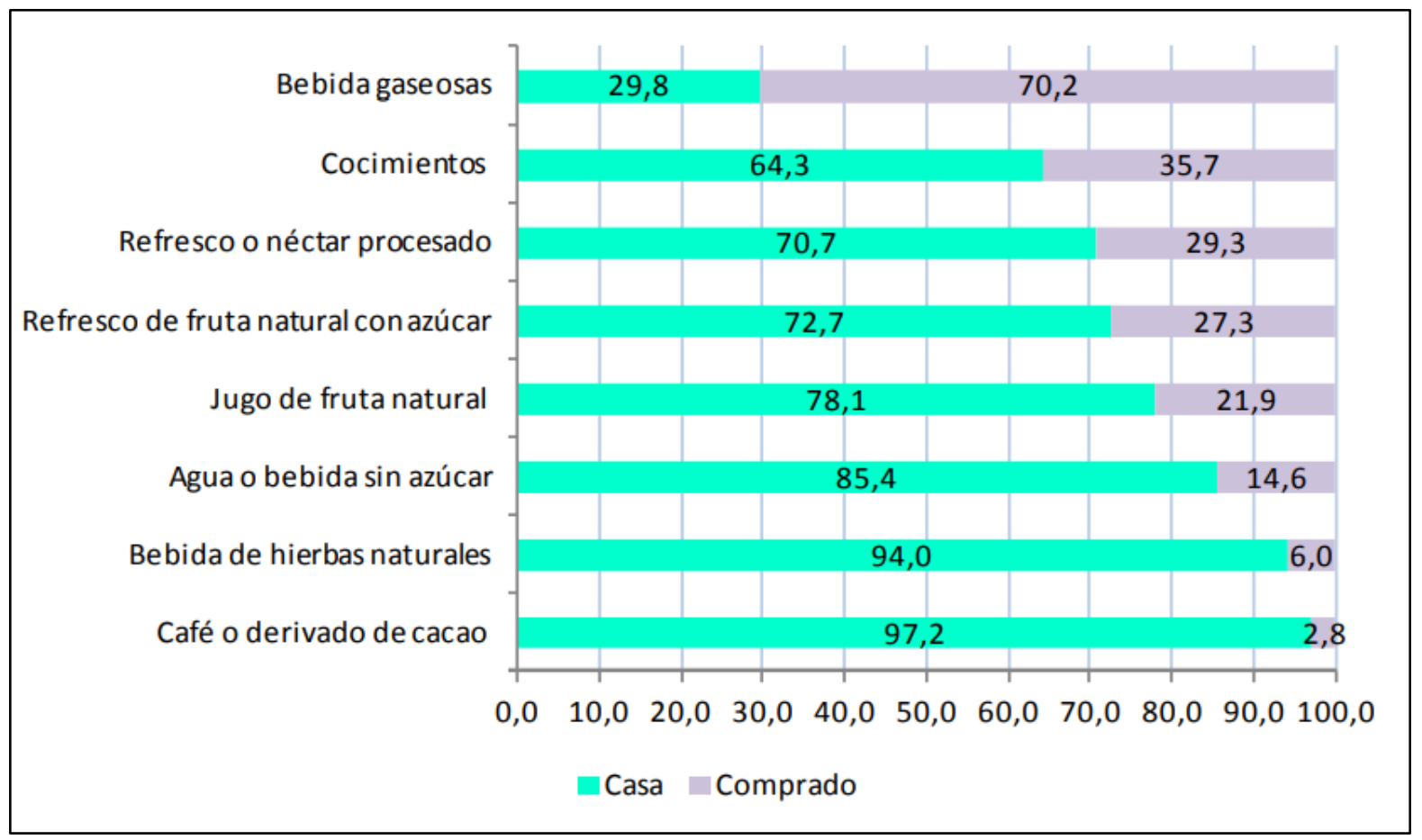

Figura 11. Distribución de la procedencia de bebidas en escolares de instituciones educativas de nivel primario. Perú, 2013. (Porcentaje). Fuente: "Informe Técnico: Lonchera Escolar en Estudiantes de Nivel Primario, Perú 2013", por Instituto Nacional de Salud, 2015, p. 27. Recuperado de http://www.portal.ins.gob.pe/en/component/rsfiles/preview?path=cenan\%252FVigilancia\%2BAlimentaria\%2By \%2BNutricional\%252FPeru\%2BLonchera\%2BEscolar\%2Bprimaria\%2B2013.pdf 


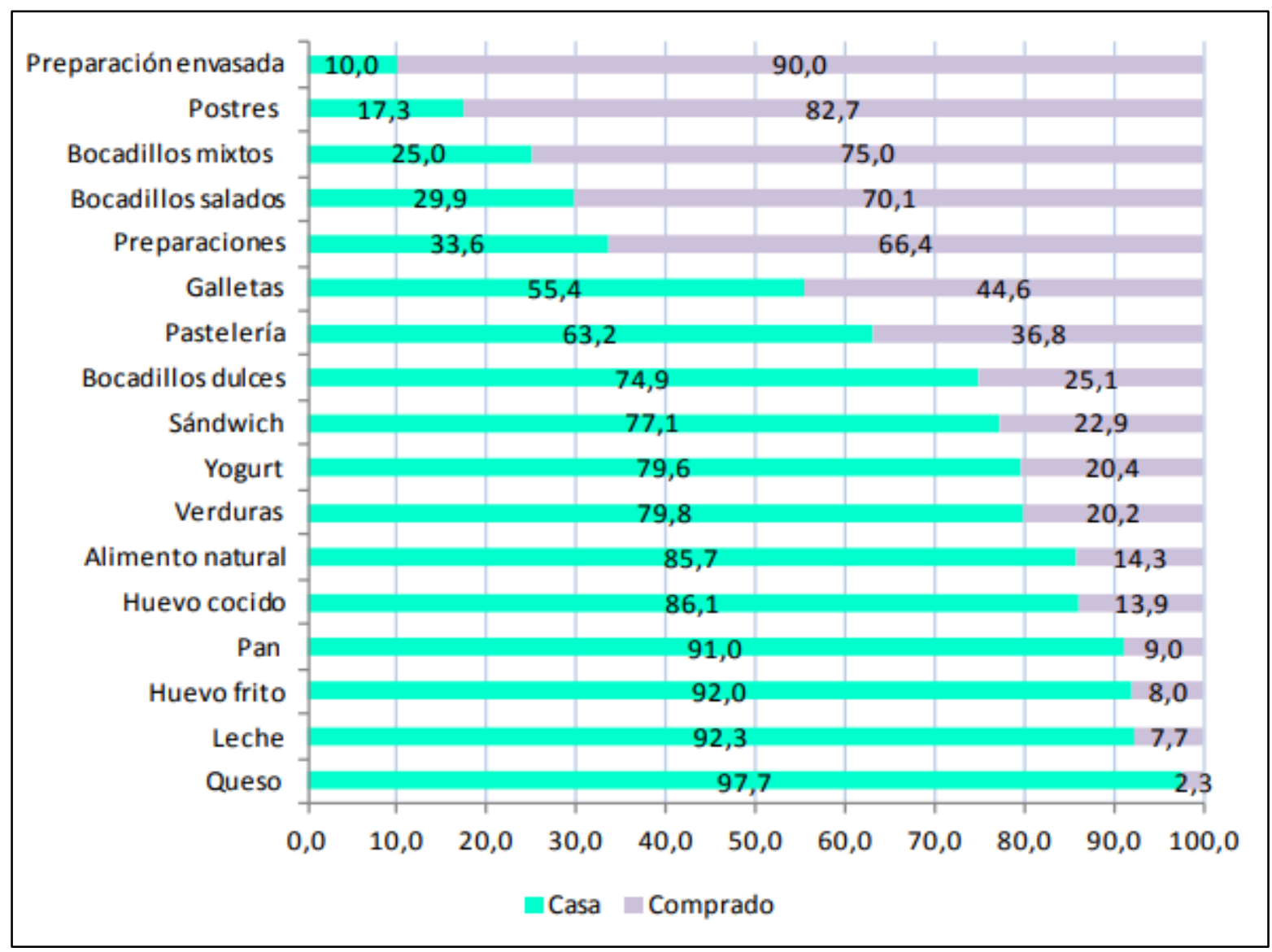

Figura 12. Distribución de la procedencia de complemento en escolares de instituciones educativas de nivel primario. Perú, 2013. (Porcentaje). Fuente "Informe Técnico: Lonchera Escolar en Estudiantes de Nivel Primario, Perú 2013”, por Instituto Nacional de Salud, 2015, p. 28. Recuperado de http://www.portal.ins.gob.pe/en/component/rsfiles/preview?path=cenan\%252FVigilancia\%2BAlimentaria\%2By \%2BNutricional\%252FPeru\%2BLonchera\%2BEscolar\%2Bprimaria\%2B2013.pdf

Procedencia enviada desde casa.

En esta categoría se encuentran las loncheras preparadas por los padres de familia, asimismo también están los productos envasados comprados en mercados y/o supermercados como Plaza Vea, Metro, Wong, etc. 
Procedencia comprados en la institución educativa.

En esta categoría se encuentran los productos comprados en los quioscos y/o cafeterías de los colegios.

En la figura 11 se muestra la distribución de las bebidas de acuerdo a su lugar de procedencia: de casa o comprado en el colegio. Se observa que casi el $30 \%$ de las bebidas gaseosas consumidas por los escolares son enviadas desde el hogar del niño y el $70 \%$ de ellas son compradas en el colegio, alrededor del $70 \%$ de las bebidas, como refrescos naturales y procesados, son enviadas desde casa y el $30 \%$ son comprados en el colegio, casi el $80 \%$ de jugos naturales son enviados desde casa, asimismo, el $85 \%$ de agua es enviada desde casa.

Asimismo, el complemento de las loncheras, muestra que la mayor parte de alimentos procesados (galletas, bocaditos), postres y preparaciones son comprados en los colegios (ver Figura 12).

Mediante estos datos se puede observar que hace falta la implementación de quioscos saludables de acuerdo con las recomendaciones del Ministerio de Salud para mejorar la alimentación de los escolares.

\subsubsection{Participación de mercado de cada uno de ellos}

Actualmente no existe información disponible sobre la participación de mercado de este tipo de negocio debido a que la competencia son empresas nuevas que recién se están posicionando. 


\subsubsection{Matriz de perfil competitivo}

Para elaborar la matriz MCP se identificará los factores claves de éxito y se realizará la calificación propuesta, comparando con los posibles competidores para finalmente lograr una puntuación total que mostrará la competitividad de la empresa. 
Tabla 11.

Matriz del perfil competitivo

\begin{tabular}{|c|c|c|c|c|c|c|c|c|c|c|}
\hline \multirow{2}{*}{ Nro. } & \multirow{2}{*}{$\begin{array}{c}\text { Factores Críticos de } \\
\text { Éxito }\end{array}$} & \multirow{2}{*}{ Peso } & & & \multicolumn{2}{|c|}{ POWERLUNCH } & \multicolumn{2}{|c|}{ COLILUNCH } & \multicolumn{2}{|c|}{ DELILUNCH } \\
\hline & & & & & Calificación & Total & Calificación & Total & Calificación & Total \\
\hline 2 & $\begin{array}{l}\text { Personal calificado } \\
\text { (Nutricionista) }\end{array}$ & 0.20 & 3 & 0.6 & 3 & 0.6 & 4 & 0.8 & 3 & 0.6 \\
\hline 3 & $\begin{array}{l}\text { Alianzas estratégicas } \\
\text { con colegios. }\end{array}$ & 0.20 & 3 & 0.6 & 2 & 0.4 & 4 & 0.8 & 2 & 0.4 \\
\hline 4 & $\begin{array}{l}\text { Presencia en redes } \\
\text { sociales }\end{array}$ & 0.15 & 4 & 0.6 & 2 & 0.3 & 4 & 0.6 & 2 & 0.3 \\
\hline 6 & Ahorro de tiempo & 0.05 & 4 & 0.2 & 4 & 0.2 & 3 & 0.15 & 2 & 0.1 \\
\hline 7 & $\begin{array}{l}\text { Servicios adicionales } \\
\text { (consultas nutricionales) }\end{array}$ & $\begin{array}{c}0.05 \\
1\end{array}$ & 4 & 0.2 & 4 & $\begin{array}{l}0.2 \\
\mathbf{2 . 9}\end{array}$ & 4 & $\begin{array}{l}0.2 \\
\mathbf{3 . 3}\end{array}$ & 4 & $\begin{array}{c}0.2 \\
\mathbf{3}\end{array}$ \\
\hline
\end{tabular}

Nota: Elaboración propia.

${ }^{a}$ El número 1 indica debilidad principal, el número 2 indica debilidad menor, el número 3 indica fortaleza menor y el número 4 es fortaleza principal. 


\subsection{Análisis del contexto actual y esperado}

Para analizar el macroentorno del presente plan de negocio se utilizó el análisis PESTEL que considera los ambientes político, económico, social, tecnológico, ecológico y legal.

\subsubsection{Análisis político-gubernamental}

La Ley 30021, también conocida como la ley contra la comida chatarra, fue promulgada el 16 de mayo del 2013, y en el año 2017 mediante Decreto Supremo Nro.017-2017-SA, se aprobaron los parámetros técnicos de su aplicación.

La Ley en mención ha generado mucho debate por su contenido, ocasionando que algunas asociaciones levanten su voz de protesta contra esta ley al considerarla perjudicial para sus negocios. (Romainville, 2017).

Según Montaño (2017), actualmente en el Perú hay más de 50 leyes que no se aplican por falta de reglamento, las cuales han sido publicadas desde el año 2005 hasta el 20 de marzo de 2018, y la mayor parte de estas pertenecen al sector salud, que es justamente uno de los sectores que presenta más reclamos. Esto ocasiona que dichas leyes no puedan ser ejecutadas puesto que, al no tener una reglamentación, tienen un vacío legal, las cuales quedan expuestas a una mala interpretación. Por ejemplo, el año pasado el Congreso de la República aprobó y publicó 125 leyes, de estas solo 14 necesitaban reglamentación, de las cuales se cumplió con completar seis, pero ocho quedaron al aire.

Diferentes municipios de los distritos de Lima cuentan hoy con programas de salud con los cuales buscan combatir el problema de obesidad y sobrepeso en los niños, estos programas son variados y consisten en realizar un acompañamiento a un grupo de niños que ya han sido identificados con estas enfermedades brindándoles un apoyo a los padres y capacitándolos sobre la nutrición que deben tener sus hijos, y son evaluados 
en su colegio por personal que la municipalidad ha dispuesto. En otros distritos, se ha creado puntos saludables que están dirigidos a escolares tanto de primaria como de secundaria y en el cual se busca solo ofrecerles alimentos saludables. (Instituto Nacional de Salud, 2017)

Como otra iniciativa del Estado, tenemos que el Ministerio de Salud dio a conocer una relación de alimentos que no son saludables para la población, esta relación de alimentos debe cumplir con la normativa que regula sobre el contenido de sal, azúcar, grasa saturada, que contienen los alimentos y deberá estar basada en las recomendaciones dadas por la Organización Mundial de la Salud (OMS) y la Organización Panamericana de la Salud (OPS).

Según López (2016), se hablaba sobre la posibilidad de ejercer algún tipo de política fiscal sobre los alimentos no saludables que tengan alto contenido de azúcar y/o grasa saturada, sin embargo se ha podido indagar que esta clase de política se dio ya en algunos países a nivel mundial sin tener buenos resultados, por ejemplo, se realizó en el año 2011 en Dinamarca en dónde se estableció un impuesto, el cual finalmente fue retirado por el nivel de desempleo que generó en la industria, el contrabando y la inflación. En el 2012 se realizó una política parecida en Francia y tampoco tuvo éxito, esto fue analizado por la Comunidad Europea y en el año 2014 fue adoptada por México y tampoco funcionó, la obesidad disminuyó muy poco, y las personas con menores recursos cambiaron las bebidas industrializadas por bebidas alternas con niveles similares de azúcar, pero sin controles de impuesto, ni controles sanitarios.

\subsubsection{Análisis económico}

El 23 de agosto del 2017 fue aprobado en sesión de Consejo de Ministros el Marco Macroeconómico Multianual 2018-2021, en dicho documento se menciona que la 
economía del país se encuentra en un proceso de recuperación y se espera que este año el PBI crezca 2.8\%, mientras que en el año 2018 se espera un crecimiento de $4.0 \%$ y para los siguientes tres años se esperaría un crecimiento de cerca del $5.0 \%$. La recuperación de la economía del Perú para el año 2018 estará básicamente centrada en la inversión pública dado el proceso de reconstrucción del último fenómeno del niño, y además de las obras de construcción de los Juegos Panamericanos que se llevarán a cabo en nuestro país en el año 2018. Otro de los puntos que ayudarán a activar la economía es el mayor impulso fiscal que generaría oportunidades de negocio. (Ministerio de Economía y Finanzas, 2017)

La economía peruana, a pesar de los problemas que se presentaron, lideró el crecimiento económico de América Latina en el primer semestre del 2017, el bloque de América Latina registró un crecimiento de 1\%, mientras que Perú registra un crecimiento de 2.3\% (Ministerio de Economía y Finanzas, 2017)

El PBI del sector comercio y servicio en los meses de mayo y junio presentaron una recuperación después que se disipó los efectos del niño costero, con esto se espera que pase de $2.8 \%$ a 3.5\% (Banco Central de Reserva del Perú, 2017) 


\begin{tabular}{|c|c|c|c|c|c|c|c|c|}
\hline \multicolumn{9}{|c|}{$\begin{array}{l}\text { PBI POR SECTORES ECONÓMICOS } \\
\text { (Variaciones porcentuales reales) }\end{array}$} \\
\hline & \multirow{2}{*}{2015} & \multirow{2}{*}{2016} & \multirow{2}{*}{$\begin{array}{l}\text { I Sem. } \\
2017\end{array}$} & \multicolumn{2}{|c|}{$2017^{*}$} & \multicolumn{2}{|c|}{$2018^{*}$} & \multirow{2}{*}{$\frac{2019^{*}}{\text { RI Set.17 }}$} \\
\hline & & & & RI Jun.17 & RI Set.17 & RI Jun.17 & RI Set.17 & \\
\hline Agropecuario & 3,5 & 2,3 & 0,3 & 2,2 & 2,5 & 4,6 & 4,5 & 4,4 \\
\hline Agricola & 2,3 & 1,2 & $-0,5$ & 1,3 & 2,9 & 4,8 & 4,6 & 4,5 \\
\hline Pecuario & 5,2 & 4,0 & 1,8 & 3,5 & 1,9 & 4,2 & 4,2 & 4,4 \\
\hline Pesca & 15,9 & $-10,1$ & 82,9 & 34,0 & 30,2 & 5,5 & 7.2 & 2,9 \\
\hline Mineria e hidrocarburos & 9,5 & 16,3 & 2,9 & 4,3 & 3,5 & 7,1 & 5,3 & 2,0 \\
\hline Mineria metálica & 15,7 & 21,2 & 3,7 & 4,5 & 4,1 & 6,5 & 4,6 & 2,4 \\
\hline Hidrocarburos & $-11,5$ & $-5,1$ & $-1,3$ & 3,5 & 0,5 & 9,8 & 10,6 & 0,0 \\
\hline Manufactura & $-1,5$ & $-1,4$ & 2,7 & 2,3 & 1,6 & 3,2 & 3,6 & 4,1 \\
\hline Recursos primarios & 1,8 & $-0,6$ & 21,0 & 11,8 & 11,2 & 4,0 & 4,6 & 4,7 \\
\hline Manufactura no primaria & $-2,6$ & $-1,7$ & $-3,0$ & $-0,9$ & $-1,5$ & 3,0 & 3,3 & 3,7 \\
\hline Electricidad y agua & 5,9 & 7,3 & 1,3 & 3,1 & 2,2 & 4,5 & 4,5 & 4,5 \\
\hline Construcción & $-5,8$ & $-3,1$ & $-4,1$ & $-0,7$ & 0,9 & 8,0 & 8,0 & 9,5 \\
\hline Comercio & 3,9 & 1,8 & 0,5 & 1,7 & 1,8 & 3,5 & 3,5 & 3,8 \\
\hline Servicios & 4,1 & 4,0 & 2,9 & 2,9 & 3,1 & 3,4 & 3,6 & 4,3 \\
\hline PRODUCTO BRUTO INTERNO & 3,3 & 4,0 & 2,3 & 2,8 & 2,8 & 4,2 & 4,2 & 4,2 \\
\hline \multicolumn{9}{|l|}{ Nota: } \\
\hline PBI primario & 6,9 & 9,9 & 5,4 & 5,3 & 4.7 & 6,1 & 5,1 & 2,9 \\
\hline PBI no primario & 2,4 & 2,4 & 1,4 & 2,0 & 2,2 & 3,7 & 3,9 & 4,6 \\
\hline
\end{tabular}

Figura 13. PBI por sectores económicos. Fuente: Reporte de inflación, setiembre 2017 por BCRP (2017, p. 53). Recuperado de http://www.bcrp.gob.pe/docs/Publicaciones/Reporte-Inflacion/2017/setiembre/reporte-deinflacion-setiembre-2017.pdf

Las tasas de interés no han sufrido cambios significativos en moneda nacional y en moneda extranjera los cambios han sido menores a las variaciones internacionales, se adjunta un cuadro comparativo tanto en soles como en dólares de las tasas pasivas y activas. (Banco Central de Reserva del Perú, 2017) 


\begin{tabular}{|c|c|c|c|c|c|c|}
\hline \multicolumn{7}{|c|}{$\begin{array}{l}\text { TASAS DE INTERÉs EN MONEDA NACIONAL } \\
\text { (En porcentajes) }\end{array}$} \\
\hline & & Set.15 & Dic.15 & Set.16 & Dic.16 & Feb.17 \\
\hline \multirow{3}{*}{ Pasivas } & Depósitos hasta 30 dias & 4,12 & 4,01 & 4,03 & 4,29 & 4,27 \\
\hline & Depósitos a plazo de 31 a 180 dias & 4,41 & 4,67 & 4,98 & 4,77 & 4,81 \\
\hline & Depositos a plazo de 181 a 360 dias & 4,41 & 4,74 & 5,20 & 5,04 & 5,01 \\
\hline \multirow{6}{*}{ Activas } & Corporativos & 5,87 & 6,18 & 6,07 & 5,88 & 6,04 \\
\hline & Grandes Empresas & 7,16 & 7,12 & 7,23 & 7,12 & 7,39 \\
\hline & Medianas Empresas & 10,19 & 10,23 & 10,74 & 10,39 & 10,54 \\
\hline & Pequefias Empresas & 20,36 & 20,45 & 21,59 & 21,65 & 21,60 \\
\hline & Consumo & 42,4 & 44,03 & 44,01 & 46,77 & 44,84 \\
\hline & Hipotecario & 8,59 & 8,95 & 8,82 & 8,52 & 8,71 \\
\hline
\end{tabular}

\begin{tabular}{|c|c|c|c|c|c|c|}
\hline \multicolumn{7}{|c|}{$\begin{array}{l}\text { TASAS DE INTERÉS EN MONEDA EXTRANJERA } \\
\text { (En porcentajes) }\end{array}$} \\
\hline & & Set.15 & Dic.15 & Set.16 & Dic.16 & Feb.17 \\
\hline \multirow{3}{*}{ Pasivas } & Depósitos hasta 30 dias & 0,15 & 0,23 & 0,28 & 0,29 & 0,49 \\
\hline & Depósitos a plazo de 31 a 180 dias & 0,31 & 0,45 & 0,56 & 0,55 & 0,60 \\
\hline & Depósitos a plazo de 181 a 360 dias & 0,60 & 0,57 & 0,55 & 0,55 & 0,65 \\
\hline \multirow{6}{*}{ Activas } & Corporativos & 1,94 & 2,33 & 3,00 & 2,47 & 2,30 \\
\hline & Grandes Empresas & 5,55 & 5,54 & 5,18 & 5,02 & 5,16 \\
\hline & Medianas Empresas & 8,48 & 8,06 & 7,37 & 6,91 & 7,21 \\
\hline & Pequeñas Empresas & 12,82 & 11,26 & 10,00 & 10,67 & 10,85 \\
\hline & Consumo & 32,4 & 32,07 & 32,38 & 32,08 & 33,36 \\
\hline & Hipotecario & 6,81 & 6,71 & 6,46 & 6,14 & 6,33 \\
\hline
\end{tabular}

Figura 14. Tasas de Interés en Moneda Nacional como en Moneda Extranjera. Fuente: Reporte de inflación, marzo 2017 por BCRP (2017, p.76). Recuperado de http://www.bcrp.gob.pe/docs/Publicaciones/Reporte-Inflacion/2017/marzo/reporte-de-inflacion-marzo2017.pdf

La inflación se espera que para el 2018 regrese al rango meta y esté entre el 2\% y el $2.2 \%$ de la variación actual que coloca la inflación por encima del rango meta (4.25\%) esto se explica por la variación de los precios de algunos alimentos perecibles que fueron afectados por el fenómeno del niño que se presentó este año. (Banco Central de Reserva del Perú, 2017) 
NOTA: Los datos son calculados para el periodo $2003-2016$, periodo a partir del cual la inflación ecuatoriana se estabilzó.

Figura 15. Inflación promedio y desviación estándar. Fuente: Reporte de inflación por BCRP (2017, p.94). Recuperado de http://www.bcrp.gob.pe/docs/Publicaciones/Reporte-Inflacion/2017/setiembre/reporte-deinflacion-setiembre-2017.pdf

La tasa de desempleo sufrió una variación considerable a febrero del 2017, al ubicarse en 7.7\% que, a comparación del mismo mes del año 2016, se tiene que la tasa de desempleo fue de $6.9 \%$, es decir la variación fue de $14.2 \%$ (Banco Central de Reserva del Perú, 2017)

La morosidad sufrió una ligera tendencia al alta registrando $3.31 \%$ en febrero vs el 3,09\% que registro en diciembre. (Banco Central de Reserva del Perú, 2017)

\begin{tabular}{|c|c|c|c|c|c|}
\hline & \multicolumn{5}{|c|}{ Porcentajes } \\
\hline & Dic.14 & Dic.15 & Dic.16 & Ene.17 & Feb.17 \\
\hline Crédito a empresas & 3,14 & 4,65 & 5,04 & 5,24 & 5,29 \\
\hline Corporativo y grandes empresas & 0,37 & 0,47 & 0,41 & 0,48 & 0,47 \\
\hline Medianas empresas & 4,79 & 5,28 & 6,10 & 6,76 & 6,82 \\
\hline Micro y pequeñas empresas & 7,82 & 7,46 & 7,16 & 7,31 & 7,53 \\
\hline Crédito a personas & 2,46 & 2,65 & 3,05 & 3,17 & 3,19 \\
\hline Consumo & 3,34 & 3,32 & 3,66 & 3,84 & 3,84 \\
\hline Tarjetas de crédito & 4,23 & 4,10 & 4,86 & 5,16 & 5,26 \\
\hline Vehicular & 4,25 & 4,41 & 5,60 & 5,75 & 5,71 \\
\hline Hipotecario & 1,44 & 1,84 & 2,28 & 2,33 & 2,39 \\
\hline PROMEDIO & 2,91 & 2,87 & 3,09 & 3,26 & 3,31 \\
\hline
\end{tabular}

Figura 16. Índices de morosidad de los créditos. Recuperado de http://www.bcrp.gob.pe/docs/Publicaciones/Reporte-Inflacion/2017/marzo/reporte-deinflacion-marzo-2017.pdf 
El tipo de cambio ha registrado una apreciación a marzo del 2018, pasando el tipo de cambio de S/ 3.357 a S/ 3.291 por dólar. La variación se explica principalmente por el cambio de algunos comodities, por ejemplo, el caso de Cobre. (Banco Central de Reserva del Perú, 2017).

\subsubsection{Análisis legal}

La manipulación de alimentos exige cumplir con normas sanitarias que son exigidas por el Ministerio de Salud, el incumplimiento de una de estas normas genera sanciones que pueden ir desde el cierre de local, el cual puede ser definitivo o temporal, incautación de los implementos hasta decomisar los alimentos. Por lo que es sumamente importante cumplir con las pautas y adecuación de la norma, esto se establece en el Título IX artículo 123 (Decreto Supremo Nº 007-98-SA, 1998).

El reglamento sobre Vigilancia y Control Sanitario de Alimentos y Bebidas fue aprobado el 24 de setiembre de 1998, y en éste se encuentra las normas generales de higiene que deben cumplirse para la elaboración, transporte y almacenamiento, entre otros puntos, para garantizar la inocuidad de los alimentos. Se consideran también las condiciones y requisitos para obtener el registro sanitario y la descripción de infracciones y sanciones aplicables. (Decreto Supremo Nº07-98-SA, 1998).

También se debe tener en cuenta la Ley N 29571 que corresponde al Código de Protección y Defensa del Consumidor, que establece los derechos que tienen los consumidores dentro del marco del artículo 65 de la Constitución del Perú. (Instituto Nacional de Defensa de la Competencia y de la Protección de la Propiedad Intelectual, 2010) 
El Ministerio de Salud (2015), establece que los municipios son los encargados de cumplir la función de vigilancia sanitaria de los restaurantes y/o establecimientos a fines, con el fin de garantizar la inocuidad en la preparación de los alimentos.

\subsubsection{Análisis cultural}

En cuanto a lo demográfico, como señala el INEI (2015), a mitad del año 2015 la población del Perú alcanzó a ser 31 millones 151 mil 643 habitantes, y la composición de edades demuestra una modificación en el comportamiento social y económico al comparar las pirámides poblacionales entre los años 1950 y 2015 con una proyección al 2025. (ver Figura 17)

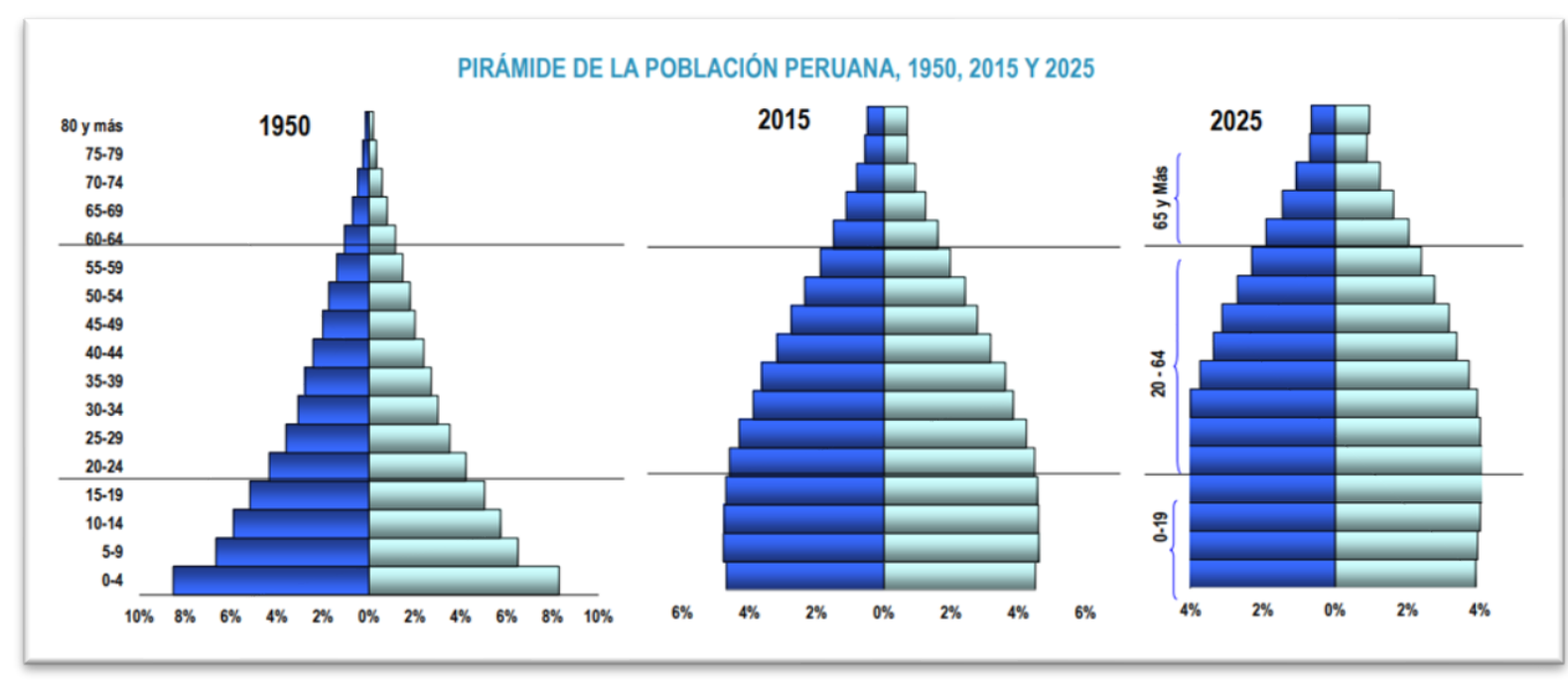

Figura 17. Pirámide de la población peruana, 1950, 2015 y 2015. Fuente: Estado de la Población Peruana 2015 por INEI (2015, p.6). Recuperado de http://www.inei.gob.pe/media/MenuRecursivo/ publicaciones_digitales/Est/Lib1251/Libro.pdf

Asimismo, según INEI (2017), el Censo del presente año permitirá identificar la proporción real de los menores de cinco años y mayores de 64 años y la relación de dependencia con las personas potencialmente productivas (15 a 64 años) la cual está 
disminuyendo en porcentajes históricos, lo que tiene influencia en lo económico ya que motiva la posibilidad de ahorro e inversión de la población. (ver Figura 18)

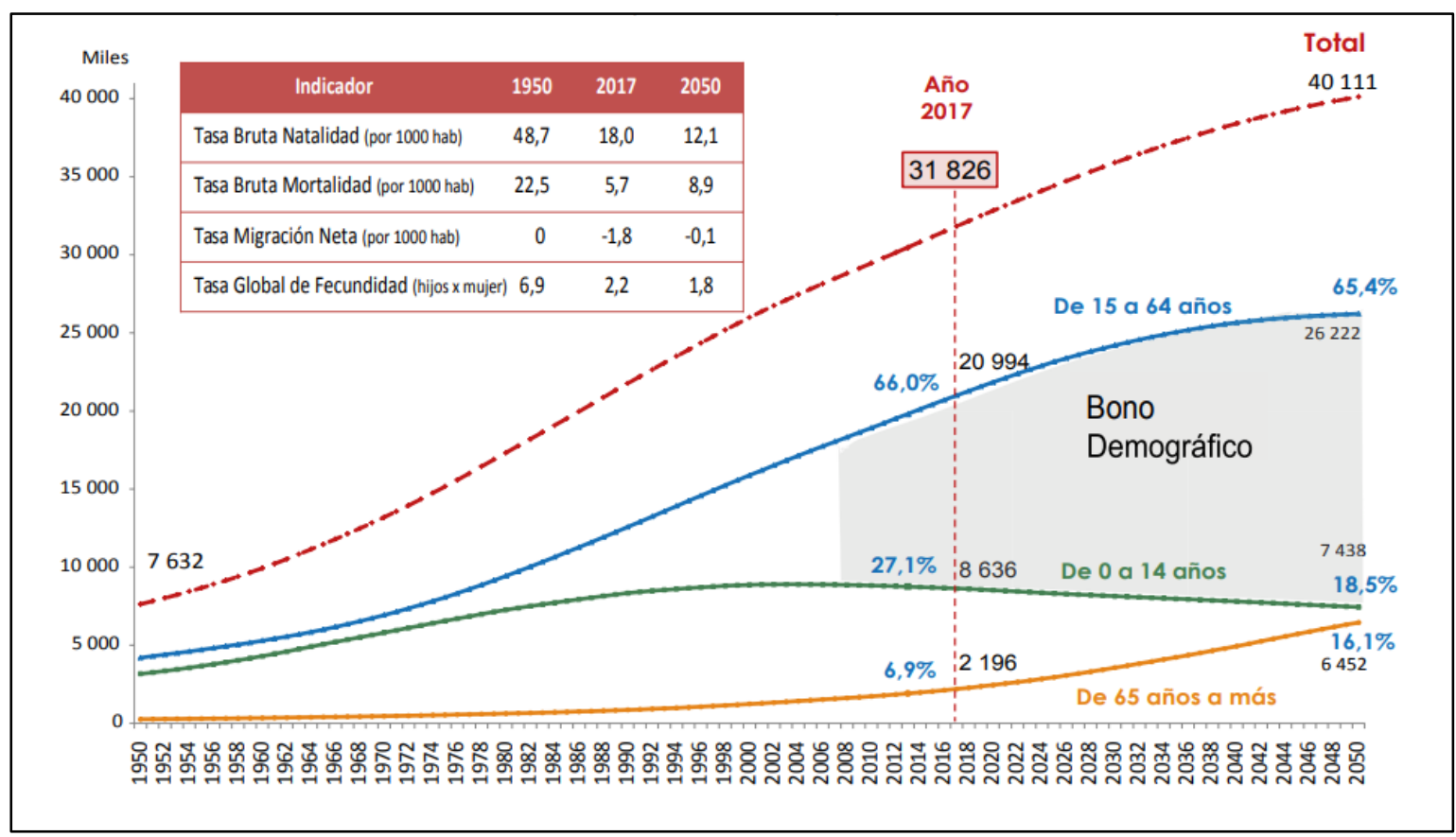

Figura 18. Estructura de la población peruana por grandes grupos de edad, 1950-2050. Fuente: Boletín Censos Nacionales 2017: XII de población y VII de vivienda y III de Comunidades indígenas, 2017, p.41. Recuperado de https://www.inei.gob.pe/media/MenuRecursivo/ publicaciones_digitales/Est/Lib1437/libro.pdf

Aníbal Sánchez, jefe del INEI, declaró a Gestión que, en base a las proyecciones del último censo nacional realizado en el año 2007, la tasa de crecimiento poblacional al 2017 vendría demostrando una disminución de $0.5 \%$ debido a las menores tasas de fecundidad de los últimos años. (Gestión, 2016)

Según investigación realizada por Datum Internacional (2013), el 40\% de la población adulta peruana encuestada se encuentra preocupada por seguir una alimentación saludable, esta tendencia se muestra en mayor porcentaje en las mujeres y personas mayores desde los 25 años. (Ver Figura 19). 


\section{MAS DE LA MITAD DE LA POBLACION NO SE PREOCUPA POR SEGUIR UNA DIETA}

SALUDABLE

¿Cuánto se preocupa Ud. por seguir una dieta saludable?

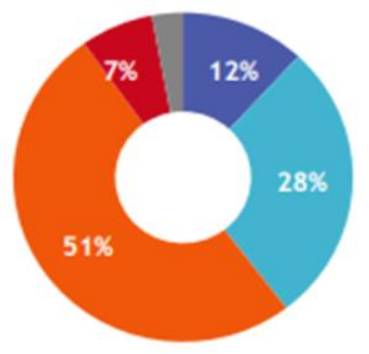

Mucho

- Bastante

Exoco

- Nada

ass $/ \mathrm{Nc}$

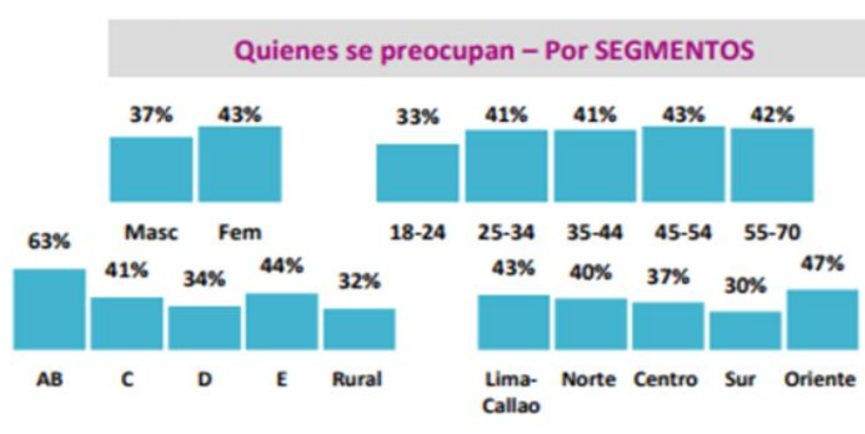

Figura 19. ¿Cuánto se preocupa Ud. por seguir una dieta saludable? Fuente: Los peruanos no cuentan con la información nutricional necesaria para seguir una dieta saludable por Datum Internacional, 2013. Recuperado de http://www.datum.com.pe/new_web_files/files/pdf/HAS.pdf

La tendencia a una adecuada alimentación implica el consumo de productos orgánicos, funcionales, integrales y/o light, ello gracias a la promoción de políticas estatales para un estilo de vida saludable a las cuales se adaptaron también empresas del sector privado. (El Comercio, 2017)

Dentro de esta tendencia de vivir sano, los millennials encabezan la lista de los más exigentes pues no sólo buscan insumos no industrializados, conocer la procedencia de los alimentos y que sean ricos al paladar, sino que además sea fácil de preparar y que no tome mucho tiempo en la cocina”. (Rengifo, 2017).

\subsubsection{Análisis tecnológico}

Según el Ministerio de Economía y Finanzas (MEF), la inversión en Ciencia, Tecnología e Investigación (CTI) tiene una marcada influencia en el crecimiento económico, educativo y social del país y se identifican tres objetivos necesarios que 
lograrán incrementar, en el mediano y largo plazo, la competitividad y productividad del país. (ver Tabla 12)

Tabla 12

Perú: Política de inversión pública en ciencia, tecnología e investigación.

\begin{tabular}{cl}
\hline OBJETIVOS & \multicolumn{1}{c}{ LINEAMIENTOS GENERALES } \\
\hline $\begin{array}{c}\text { Mayor acceso, absorción y } \\
\text { uso de conocimientos y } \\
\text { tecnologías }\end{array}$ & $\begin{array}{l}\text { Mejora de las capacidades de absorción tecnológica } \\
\text { Apoyo para facilitar el acceso y uso de nuevos } \\
\text { conocimientos y tecnologías }\end{array}$ \\
Mejora de los vínculos entre los generadores de \\
$\begin{array}{c}\text { Mayor transferencia y } \\
\text { difusión de conocimientos y y } \\
\text { tecnologías }\end{array}$ \\
Mejora de la difusión de innovaciones tecnológicas \\
Apoyo financiero para la transferencia de tecnología \\
Mejora del capital humano para la investigación, \\
desarrollo tecnológico e innovación \\
conocimientos y tecnología \\
$\begin{array}{l}\text { Impulsar inversiones para renovar y complementar la } \\
\text { infraestructura y equipamiento en materia de CTI } \\
\text { Fortalecimiento de la actividad innovadora de } \\
\text { empresas }\end{array}$ \\
Aumento de la inversión privada
\end{tabular}

Nota: Adaptado de "Perú: política de inversión pública en ciencia, tecnología e innovación. Prioridades, 20132020” por Ministerio de Economía y Finanzas, 2012. Recuperado de https://www.mef.gob.pe/contenidos/inv_publica/docs/novedades/2013/agosto/Lineamientos_CTI.pdf

Desde hace más de una década, el Perú ha mostrado un constante crecimiento económico, pero ello no será sostenible en el largo plazo si no cimienta su modelo económico en la inversión en tecnología que potencie las actividades industriales y de negocios. MEF (2012). 
El Perú se encuentra en el puesto 100 de 177 países con acceso a Internet y Lima tiene el mayor porcentaje de penetración de internet fijo al 2015. La penetración de Internet en el país demuestra ausencia en las regiones, por lo que el Ministro de Transportes y Comunicaciones Martín Alberto Vizcarra Cornejo (julio 2016-mayo 2017) anunció un proyecto para la creación del Viceministerio de las TIC. (La República, 2017). (ver Figura 20 y 21).

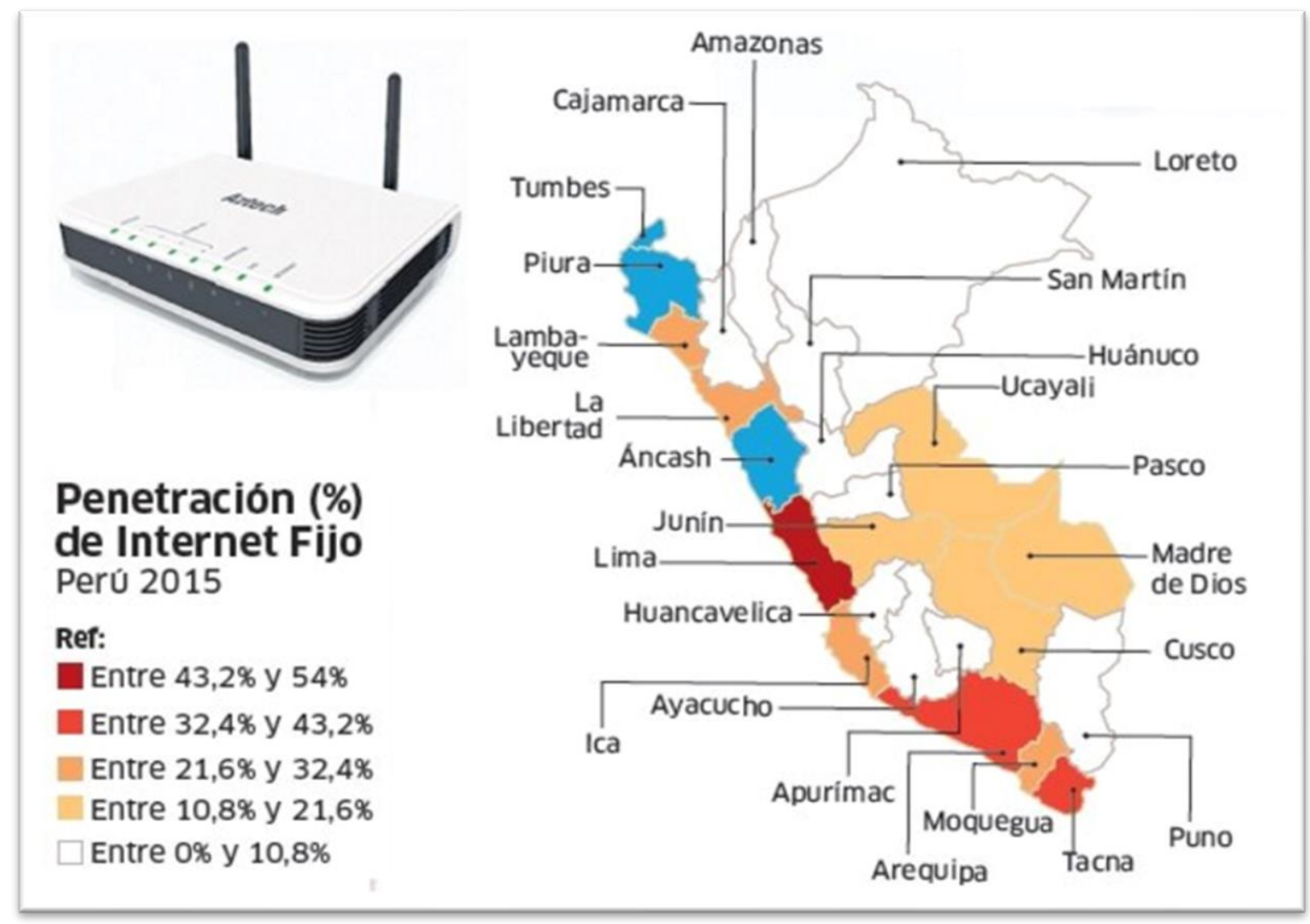

Figura 20. Penetración (\%) de internet fijo. Perú 2015. Fuente: "Perú: datos de telecomunicaciones" por Reyes, F. (2016). Recuperado de http://telecomunicaciones-peru.blogspot.com/2016/03/peru-datos-detelecomunicaciones.html 


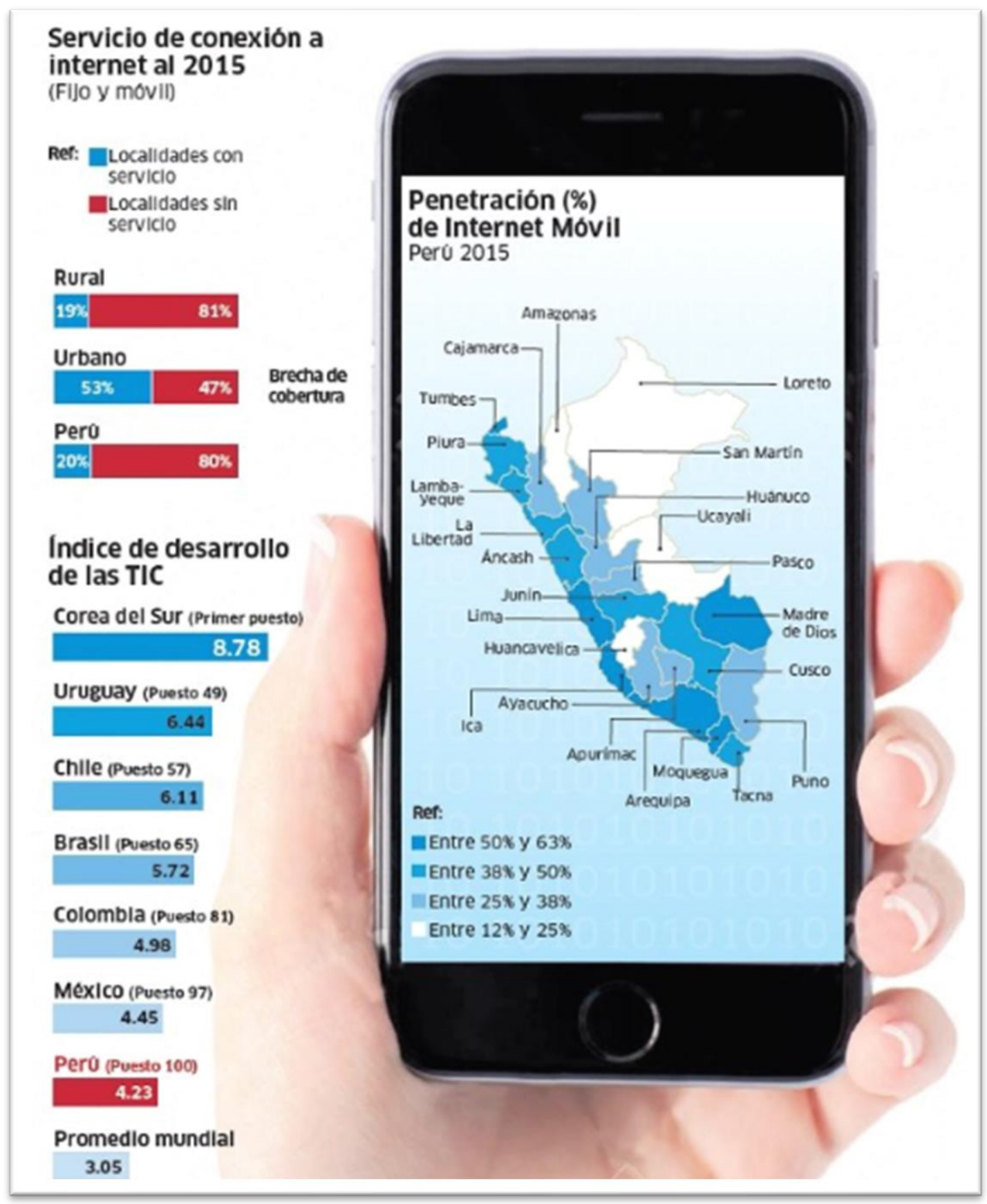

Figura 21. Servicio de conexión a internet al 2015 (fijo y móvil). Fuente: "Perú: datos de telecomunicaciones" por Reyes, F. (2016). Recuperado de http://telecomunicacionesperu.blogspot.com/2016/03/peru-datos-de-telecomunicaciones.html

A fin de desarrollar soluciones tecnológicas y mejorar el sistema de salud del Perú, más de 100 personas participan del "Hackaton Minsa 2017" en la Pontificia 
Universidad Católica del Perú (PUCP) diseñando prototipos para dispositivos móviles o programas informáticos.

La médica cirujana Liliana Frida Má Cardenas, Directora General de Telesalud, Referencias y Urgencias, manifestó a MINSA:

Tenemos mucha expectativa de los prototipos que se puedan elaborar para mejorar los servicios de salud en nuestro país. Han llegado jóvenes profesionales y estudiantes, formados en diferentes especialidades, con todas las ganas de aportar soluciones a las necesidades que ellos mismos tienen como usuarios de los servicios de salud. (MINSA, 2017)

En el Perú se evalúa el uso de la plataforma virtual Watson Health que podría ayudar a mejorar el servicio de salud, de forma que los médicos puedan reducir el tiempo en la revisión de historias clínicas de sus pacientes, a fin de que se detecte enfermedades en tiempo récord e indicar el tratamiento adecuado. Esta plataforma se viene utilizando en países como Estados Unidos, Chile, Colombia, México y Brasil. (El Peruano, 2016).

\subsubsection{Análisis ecológico}

Según el estudio de impacto ecológico en ciudades de América Latina, realizado por Economist Intelligence Unit y patrocinado por Siemens, Lima y Montevideo son las ciudades latinoamericanas con menor impacto ecológico al proteger las áreas verdes, pero no en la construcción de edificios ecológicos. (Radio Programas del Perú, 2017).

Asimismo, se indica que, en el Perú el consumo de productos orgánicos no es ajeno a la tendencia mundial pues en los últimos 10 años, ha tenido un incremento del $70 \%$. En la actualidad existen 20 bioferias en el Perú, de las cuales 7 se encuentran en Lima. (ver Figura 22) 


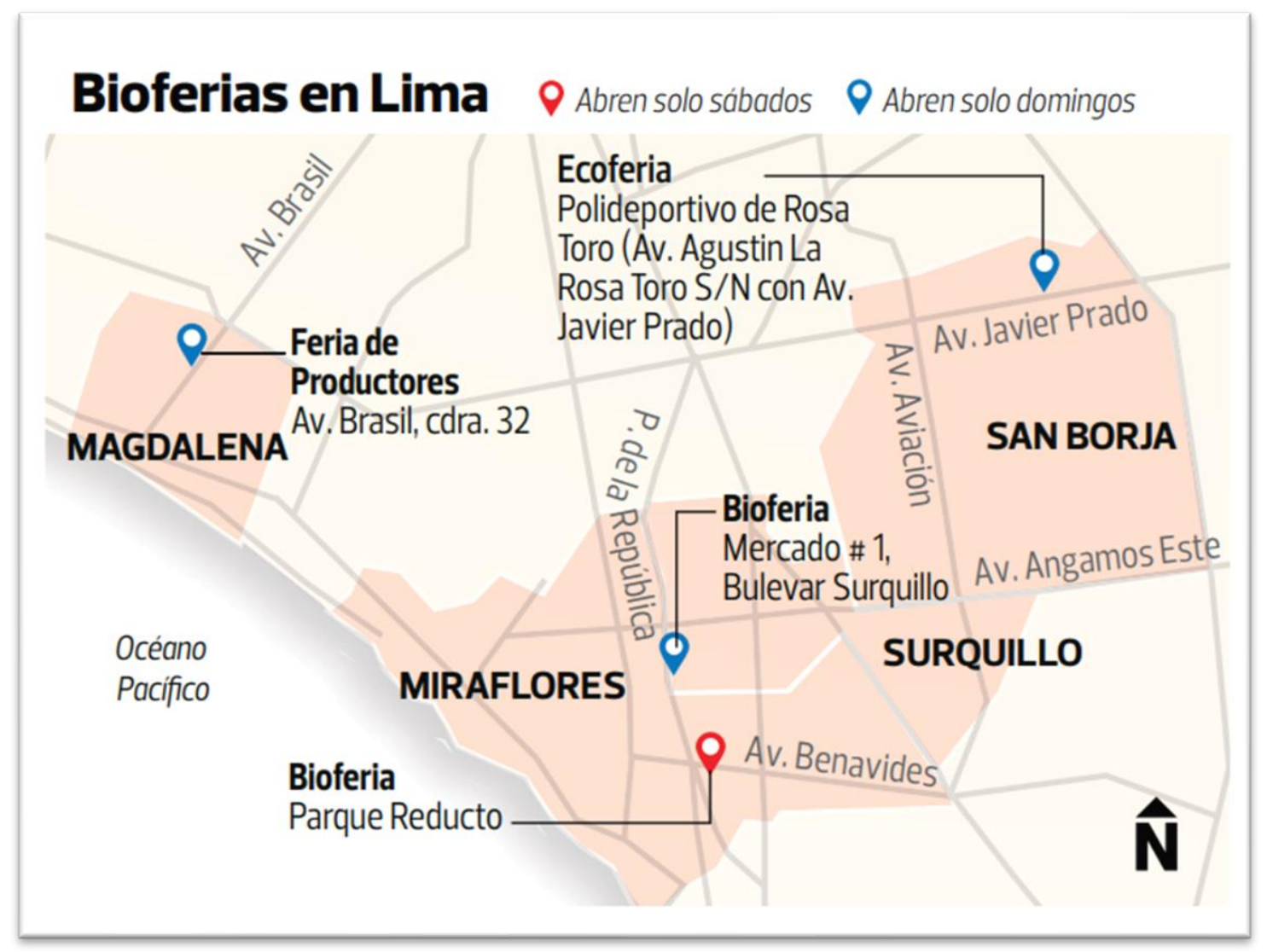

Figura 22. Bioferias en Lima. Fuente: El consumo de productos orgánicos crece entre los peruanos por Soto, F., 2015, A12. Recuperado de http://www.actualidadambiental.pe/wpcontent/uploads/2015/03/ elcomercio_2015-03-19_p12.pdf

El antropólogo Carlos Aramburú publicó en su columna de El Comercio, que el consumo de alimentos saludables en el Perú aún se concentra en estratos altos pero la tendencia indica que se extenderá hasta los sectores populares. (El Comercio, 2015)

En el Perú, empresas como Ecoempaques han desarrollado una línea de productos comprometidos con el medio ambiente, $100 \%$ reciclables y según la necesidad de sus clientes, para fomentar la cultura de reciclaje. (ver Figura 23) 


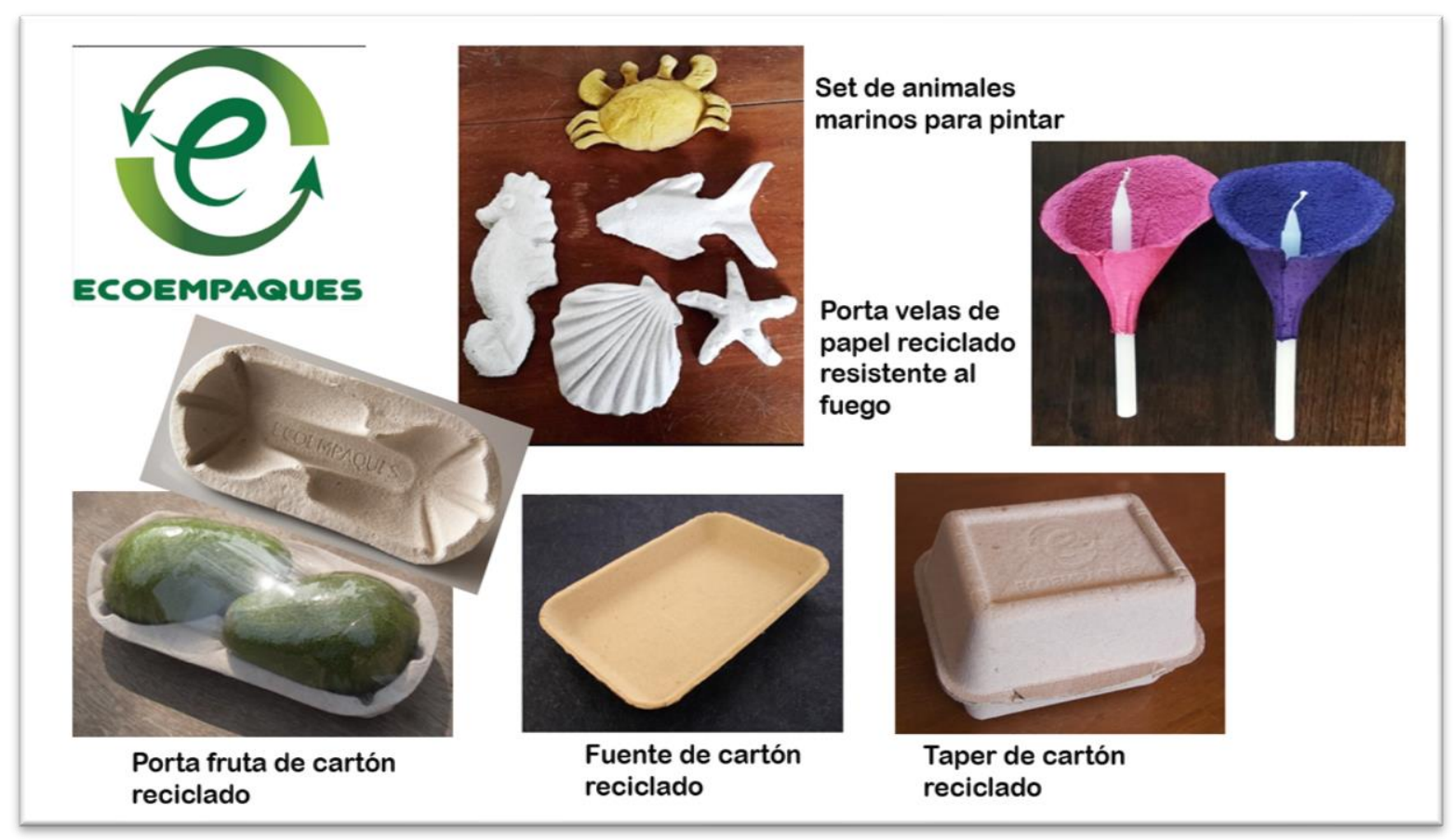

Figura 23. Tipos de empaques ecológicos. Fuente: Página en Facebook Ecoempaques. Recuperado de https://www.facebook.com/ecoempaques

Cada vez más las empresas se encuentran comprometidas con el desarrollo social y ecológico en el sector en que operan, principalmente contaminando menos mediante la reducción de residuos e involucrándose con programas educativos y sociales. Empresas como Pepsico han desarrollado en México un programa de capacitación para la producción de girasol con el fin de obtener una fuente confiable de aceite, logrando una relación de gana-gana. (Gestión, 2016)

\subsection{Oportunidades y amenazas}

A fin de tener un mejor panorama sobre las oportunidades y amenazas del presente proyecto de negocio, se ha procedido a analizar diferentes variables como se muestra a continuación. 
Tabla 13

Análisis de variables políticas

\begin{tabular}{llll}
\hline \multicolumn{1}{c}{ Var. Política } & \multicolumn{1}{c}{ Tendencia } & $\begin{array}{c}\text { Escenario } \\
\text { esperado }\end{array}$ & Amenaza/oportunidad \\
\hline $\begin{array}{l}\text { Ley 30021, mayo } \\
2013\end{array}$ & $\begin{array}{l}\text { Evitar consumo } \\
\text { de comida } \\
\text { chatarra }\end{array}$ & $\begin{array}{l}\text { Optar por } \\
\text { alimentos } \\
\text { saludables }\end{array}$ & Oportunidad \\
$\begin{array}{l}\text { Demora en la } \\
\text { aprobación de } \\
\text { reglamentación de } \\
\text { leyes }\end{array}$ & $\begin{array}{l}\text { Interpretación a } \\
\text { conveniencia }\end{array}$ & Vacío Legal & Amenaza \\
$\begin{array}{l}\text { Involucramiento de } \\
\text { Municipios en } \\
\text { alimentación } \\
\text { saludable }\end{array}$ & $\begin{array}{l}\text { Campañas de } \\
\text { sobre nutrición }\end{array}$ & $\begin{array}{l}\text { Población } \\
\text { informada }\end{array}$ & Oportunidad \\
$\begin{array}{l}\text { Involucramiento de } \\
\text { Ministerio de Salud }\end{array}$ & $\begin{array}{l}\text { Campañas sobre } \\
\text { alimentos no } \\
\text { recomendados } \\
\text { (chatarra) }\end{array}$ & $\begin{array}{l}\text { Población } \\
\text { informada }\end{array}$ & Oportunidad \\
\hline
\end{tabular}

Nota: Elaboración propia.

En cuanto a la variable política podemos apreciar que, tanto el Estado como diferentes entidades públicas demuestran preocupación por incentivar la tendencia hacia una alimentación saludable, no solo con charlas y campañas sino también con Leyes que puedan supervisar principalmente los establecimientos de alimentos que comercializan dentro de los colegios. Ello representa una oportunidad para el presente proyecto de negocio. 
Tabla 14

Análisis de variables económicas

\begin{tabular}{|c|c|c|c|}
\hline Var. Económica & Tendencia & $\begin{array}{c}\text { Escenario } \\
\text { esperado }\end{array}$ & Amenaza/oportunidad \\
\hline $\begin{array}{l}\text { Marco } \\
\text { Macroeconómico } \\
\text { Multianual 2018-2021 }\end{array}$ & $\begin{array}{l}\text { Crecimiento } \\
\text { económico }\end{array}$ & $\begin{array}{l}\text { Inversión } \\
\text { pública }\end{array}$ & Oportunidad \\
\hline Tasa de desempleo & $\begin{array}{l}\text { Incremento en } \\
1.2 \%\end{array}$ & $\begin{array}{l}\text { Menor poder } \\
\text { adquisitivo }\end{array}$ & Amenaza \\
\hline Tasa de morosidad & $\begin{array}{l}\text { Incremento en } \\
0.22 \%\end{array}$ & $\begin{array}{l}\text { Riesgo } \\
\text { financiero }\end{array}$ & Amenaza \\
\hline Tipo de cambio & Estable & $\begin{array}{l}\text { Propicia } \\
\text { inversión } \\
\text { privada }\end{array}$ & Oportunidad \\
\hline
\end{tabular}

Nota: Elaboración propia.

En cuanto a la variable económica podemos apreciar que, si bien es cierto que el país ha tenido crecimiento económico sostenido y un tipo de cambio estable en los últimos años, las tasas de desempleo y endeudamiento también han demostrado un ligero incremento, lo cual nos demuestra que la elección de colegios particulares para seleccionar su público objetivo sería uno de los filtros que reduciría el riesgo de morosidad a fin de lograr la rentabilidad esperada. 
Tabla 15

Análisis de variables legales

\begin{tabular}{|c|c|c|c|}
\hline Var. Legal & Tendencia & Escenario esperado & Amenaza/oportunidad \\
\hline $\begin{array}{l}\text { Normas Sanitarias } \\
\text { Decreto Supremo No } 007- \\
\text { 98-SA, } 1998\end{array}$ & $\begin{array}{l}\text { Cumplimiento } \\
\text { estricto }\end{array}$ & $\begin{array}{l}\text { Exigencia del } \\
\text { Ministerio de Salud }\end{array}$ & Amenaza \\
\hline $\begin{array}{l}\text { Ley } \mathrm{N}^{\circ} 29571 \text {, protección } \\
\text { y defensa del consumidor }\end{array}$ & $\begin{array}{l}\text { Cumplimiento } \\
\text { estricto }\end{array}$ & $\begin{array}{l}\text { Respetar los derechos } \\
\text { del consumidor }\end{array}$ & Amenaza \\
\hline Vigilancia Sanitaria & $\begin{array}{l}\text { Supervisada por } \\
\text { municipios }\end{array}$ & $\begin{array}{l}\text { Correcta } \\
\text { manipulación de } \\
\text { alimentos }\end{array}$ & Oportunidad \\
\hline
\end{tabular}

Nota: Elaboración propia.

En cuanto a la variable legal podemos apreciar que tanto el Estado como entidades públicas velan por el cumplimiento de normas sanitarias respaldadas por decretos supremos, así como también por los derechos del consumidor, lo cual indicaría que las empresas del rubro alimentos están constantemente auditadas, pero también sería una oportunidad para demostrar al público que la empresa cumple con todos los requisitos exigidos por las entidades reguladoras. 
Tabla 16

Análisis de variables sociales

\begin{tabular}{|c|c|c|c|}
\hline Var. Social & Tendencia & Escenario esperado & Amenaza/oportunidad \\
\hline $\begin{array}{l}\text { Pirámide } \\
\text { poblacional } 2017\end{array}$ & $\begin{array}{l}\text { Reducción de } \\
\text { tasa de } \\
\text { fecundidad y } \\
\text { mortalidad }\end{array}$ & $\begin{array}{l}\text { Crecimiento de } \\
\text { población } \\
\text { económicamente activa }\end{array}$ & Oportunidad \\
\hline $\begin{array}{l}\text { Políticas estatales } \\
\text { para estilo de vida } \\
\text { saludable }\end{array}$ & $\begin{array}{l}\text { Campañas } \\
\text { estatales y } \\
\text { privadas }\end{array}$ & $\begin{array}{l}\text { Concientización para } \\
\text { una alimentación } \\
\text { saludable }\end{array}$ & Oportunidad \\
\hline $\begin{array}{l}\text { Alimentación } \\
\text { saludable }\end{array}$ & $\begin{array}{l}\text { Interés por una } \\
\text { dieta saludable }\end{array}$ & Información limitada & Oportunidad \\
\hline Millennials & $\begin{array}{l}\text { Ritmo de vida } \\
\text { acelerado }\end{array}$ & $\begin{array}{l}\text { PEA, clientes } \\
\text { potenciales }\end{array}$ & Oportunidad \\
\hline
\end{tabular}

Nota: Elaboración propia.

En cuanto a la variable social podemos apreciar que existe un crecimiento en la tendencia del consumo de alimentos saludables, principalmente por la preocupación de los padres por informarse sobre la adecuada combinación de alimentos que favorezcan la adecuada nutrición de sus hijos.

Asimismo, dado que generalmente trabajan ambos padres, el tiempo para preparar este tipo de loncheras cada vez es más reducido por lo que se considera que es una potencial oportunidad de negocio. 
Tabla 17.

Análisis de variables tecnológicas

Var. Tecnológica Tendencia Escenario esperado Amenaza/oportunidad

Inversión en

Ciencia,

Impulso a la

Crecimiento

Tecnología e

investigación de

económico y mejora

empresarial

Oportunidad

Investigación desarrollo

(CTI)

El Perú se

encuentra en

Acceso a Acceso a mejor

puesto 100 de 177 comunicación

servicio educativo, de

Oportunidad

países con acceso global

a Internet

salud y comunicación

Convocatoria

Hackaton Minsa ciudadana para la solución de

Concientización para

2017

problemas de salud

Oportunidad salud

Plataforma virtual Watson Health

Inversión en Salud

Reducir tasas de mortalidad

Oportunidad

Nota: Elaboración propia.

En cuanto a la variable tecnológica podemos apreciar que el Perú cuenta con una banda de internet que le permite tener acceso a comunicación global, ello permite a los usuarios no solo a poder investigar sobre temas de interés sino también a la empresa a publicitar sus ofertas en línea y tener mayor llegada a su público objetivo. Ello es considerado una oportunidad de negocio. 
Tabla 18.

Análisis de variables ecológicas

\begin{tabular}{|c|c|c|c|}
\hline Var. Ecológica & Tendencia & Escenario esperado & Amenaza/oportunidad \\
\hline $\begin{array}{l}\text { Lima, ciudad } \\
\text { latina con menor } \\
\text { impacto } \\
\text { ecológico }\end{array}$ & $\begin{array}{l}\text { Cuidado } \\
\text { ambiental }\end{array}$ & $\begin{array}{l}\text { Concientización a la } \\
\text { preservación del } \\
\text { medio ambiente }\end{array}$ & Oportunidad \\
\hline $\begin{array}{l}\text { Incremento de } \\
\text { bioferias en Lima }\end{array}$ & $\begin{array}{l}\text { Alimentación } \\
\text { saludable }\end{array}$ & $\begin{array}{l}\text { Preferencia por } \\
\text { consumo de } \\
\text { productos orgánicos }\end{array}$ & Oportunidad \\
\hline $\begin{array}{l}\text { Compromiso con } \\
\text { el medio } \\
\text { ambiente }\end{array}$ & $\begin{array}{l}\text { Empresas } \\
\text { preocupadas por } \\
\text { el eco ambiente }\end{array}$ & $\begin{array}{l}\text { Reducir la } \\
\text { contaminación } \\
\text { ambiental }\end{array}$ & Oportunidad \\
\hline
\end{tabular}

Nota: Elaboración propia.

En cuanto a las variables ecológicas podemos apreciar que las personas demuestran no solo tendencia hacia una alimentación saludable sino también interés por el cuidado del medio ambiente, ello puede ser aprovechado por el presente proyecto de negocio que utilizaría empaques de papel para reducir la contaminación ambiental y mejorar su imagen antes sus clientes. 


\section{Capítulo III. Estudio de mercado}

En este capítulo se realizó el estudio de mercado para el nuevo servicio de comercialización de Loncheras Escolares Saludables, a través de una investigación cualitativa y cuantitativa.

Según Malhotra (2008), “la investigación de mercado es la identificación, recopilación, análisis, difusión y uso sistemático y objetivo de la información, con el propósito de mejorar la toma decisiones relacionadas con la identificación y solución de problemas y oportunidades de marketing" (p. 7).

\subsection{Descripción del servicio o producto}

El servicio brindado será la venta de loncheras escolares saludables para niños de nivel inicial (grupo de 3-5 años) y primario (grupo de 6- 11 años), con un contenido basado en los requerimientos nutricionales de dichos estudiantes.

El servicio radica en llevar las loncheras a los colegios y nidos a la hora del refrigerio, a su vez los padres tendrán a su disposición en la página web de la empresa, un catálogo en el que podrán consultar el contenido nutricional de cada lonchera y donde podrán escoger la que más se adecue de acuerdo con la edad y gustos de su niño.

Para facilitar la labor de los padres, las loncheras escolares estarán clasificadas por edades (3-5 años, 6-8 años, 9-11 años) y tendrán opciones por semana y día, asimismo se contará con tipos de loncheras (lonchera económica, lonchera estándar, lonchera premium).

Los precios que se ofrecerán varían en función del tipo de lonchera, asimismo el pago por la compra de la lonchera podrá ser realizado a través de la página web o mediante depósito bancario a la cuenta corriente a nombre de la empresa. Los gastos de envío serán gratuitos.

La propuesta de negocio constituye una alternativa innovadora debido a que, en el mercado, existen pocas empresas que brindan un servicio como el que se propone, que ayudará a 
combatir la obesidad de los niños en etapa escolar y fomentar en los clientes hábitos alimenticios saludables.

\subsection{Selección del segmento de mercado}

Como menciona Kotler (2013), no hay una forma única para segmentar un mercado de consumo, existen varias variables de segmentación, solas y combinadas para encontrar la manera más adecuada de establecer la estructura del mercado, las variables son geográfica, demográfica, psicográfica y conductuales.

Según las variables geográficas se eligió a los distritos Ate, Santa Anita y La Molina, debido a que, en los distritos mencionados existen una mayor cantidad de centros educativos de inicial y primaria de gestión privada que pública. (ver Tabla 19)

Tabla 19.

Cantidad de colegios por tipo de gestión/dependencia, distritos Ate, La Molina y Santa Anita

\begin{tabular}{|c|c|c|c|}
\hline \multicolumn{4}{|c|}{ Gestión / Dependencia } \\
\hline Distrito & Publica & $\begin{array}{l}\text { Privada - } \\
\text { Particular }\end{array}$ & Total \\
\hline Ate & 282 & 624 & 906 \\
\hline La Molina & 19 & 169 & 182 \\
\hline Santa Anita & 69 & 192 & 261 \\
\hline \multicolumn{4}{|c|}{ Nota: Adaptado de "Padrón de Instituciones Educativas y Programas que gestiona la Unidad de Estadística del } \\
\hline Ministerio de Educa & , por Minist & ación, Unidad & cativa (ESCALE), 2016. \\
\hline
\end{tabular}

Según las variables demográficas se eligió a padres de familia con niños en edad escolar, debido a que como menciona INEI (2015), los grupos de 3-5 años y 6- 11 años en edad escolar estimada y proyectada, según sexo y edad simple, ocupa el $41 \%$ del total de la población escolar que se encuentra en este rango. 
Según la variable psicográfica se eligió al nivel socioeconómico B y $\mathrm{C}$, ya que como se menciona en el Informe de Niveles Socioeconómicos 2016, el $62.9 \%$ de hogares en Lima Metropolitana pertenece al nivel socioeconómico B y C. (APEIM, 2016).

Además, según los estilos de vida de Arellano, se seleccionó a las Modernas, ya que son mujeres que trabajan y/o estudian, que buscan su realización personal y como madres, además compran productos de marca y que les faciliten las tareas del hogar, están en todos los niveles socioeconómicos.

Según las variables conductuales, como señaló el Estudio de Opinión Pública sobre nutrición y hábitos de alimentación saludable, el $40 \%$ de peruanos se preocupa por mantener una alimentación sana, asimismo se observa que la preocupación por seguir una dieta sana es mayor entre las mujeres (43\% vs $37 \%$ entre los hombres) y crece en los NSE A y B con un $63 \%$ y $41 \%$ en el NSE C. (Datum Internacional, 2013).

En conclusión, el mercado seleccionado está compuesto por padres de familia con hijos en edad escolar de educación inicial y/o primaria de gestión particular, que viven en los distritos de Ate, Santa Anita y La Molina y que son del nivel socioeconómico B y C.

\subsection{Investigación cualitativa}

La investigación cualitativa es una actividad que localiza al observador en el mundo. Consiste en un conjunto de prácticas interpretativas que hacen al mundo visible. Estas prácticas transforman el mundo, lo convierten en una serie de representaciones, que incluyen las notas de campo, las entrevistas, conversaciones, fotografías, registros y memorias. En este nivel, la investigación cualitativa implica una aproximación interpretativa y naturalista del mundo. Esto significa que los investigadores cualitativos estudian las cosas en su contexto natural, intentando dar sentido o interpretar los fenómenos en 
función de los significados que las personas le dan. (Rodriguez y Valldeoriola, 2012, p. 46)

Para realizar el estudio cualitativo se utilizaron dos técnicas, la primera fue el focus group, con la que se busca recoger información de primera mano de las personas que están más involucradas con las loncheras de los niños, como son sus padres y los profesores. Ambos juegan un papel muy importante ya que los padres se encargan de la elaboración o la compra de los insumos, mientras que los profesores son aliados, ya que pueden brindar información sobre las costumbres alimenticias que observan en el día a día.

Como menciona Kotler y Armstrong (2017) los focus group se han convertido en una herramienta importante de la investigación cualitativa, ya que permite conocer de manera directa las opiniones y los sentimientos de los consumidores. Hoy los investigadores no solo realizan esto, sino que también pueden analizar sus expresiones corporales, movimientos y la participación del grupo. Se recomienda utilizar muestras pequeñas para ser más eficiente en el uso de los tiempos y la participación de grupo.

Por su parte, Malhotra (2008) menciona que una de las principales características de las sesiones de grupo o focus group es que deben desarrollarse generalmente con la participación entre 8 y 12 personas, el también menciona que los grupos con menos de ocho participantes podrían no producir el ímpetu y la dinámica de grupo deseada para estos casos.

Por ello se realizaron cuatro focus group que contaron con la participación entre 8 y 12 personas cada uno, dos focus group se realizaron con padres que tienen hijos en inicial y/o primaria, un focus group con docentes de educación primaria y un último focus group con docentes de educación inicial.

También se realizaron tres entrevistas a profundidad, la primera con una reconocida nutricionistas del sector educativo, básicamente para recoger su impresión sobre la problemática actual del crecimiento abrupto que se ha tenido en los últimos años del número 
de niños con sobrepeso y obesidad, así como recibir las recomendaciones de cómo debe ser una lonchera saludable, que porcentajes de proteínas, grasas, azúcares debe tener, el número adecuado de calorías que debe tener para niños en edad inicial y/o primaria teniendo en cuenta las diferentes actividades que realizan. Y las dos últimas entrevistas con expertos del sector para conocer la gestión interna en este tipo de negocios, así como las recomendaciones necesarias.

Para Malhotra (2008) las entrevistas en profundidad son otro método para obtener datos cualitativos, son de una forma no estructurada y directa para obtener datos, sin embargo, a diferencia de las entrevistas en grupo o focus Group esta se realiza a una sola persona por la que el entrevistador debe estar altamente capacitado en el tema con la finalidad de conocer sobre las motivaciones, actitudes y creencias sobre un tema. La entrevista a profundidad se recomienda que tengan una duración entre 30 minutos a una hora.

\subsubsection{Proceso de muestreo}

Para el estudio cualitativo, en primer lugar, se optó por la técnica del focus group, que demostró la tendencia a una alimentación saludable y las necesidades de los padres de familia que cada vez cuentan con menos tiempo.

En segundo lugar, se utilizaron las entrevistas a expertos para tener mayor conocimiento sobre la gestión de este tipo de negocios. Con estos resultados se tuvieron las bases para la elaboración de la encuesta cuantitativa.

\subsubsection{Diseño de instrumento}

Focus groups

Se realizaron un total de cuatro focus group, dos a padres de familia y dos a docentes de educación inicial y primaria. Asimismo, para elegir a los asistentes que cumplan con 
el segmento seleccionado, se aplicó un cuestionario con preguntas filtro (ver anexo 5). Todos los focus fueron moderados por los integrantes del grupo. Con la guía de pautas se buscó determinar la aceptación del producto ofrecido y captar las recomendaciones de cada grupo.

Entrevistas a profundidad

Se realizaron un total de tres entrevistas, la primera a una profesional Nutricionista con la finalidad de orientarnos con la combinación y porciones adecuadas de alimentos y dos a administradores de restaurantes para tener información sobre la logística de gestión y almacenamiento de productos perecibles. Todas las entrevistas fueron realizadas por los integrantes de grupo.

\subsubsection{Análisis y procesamiento de datos}

\section{Focus Group.}

Los focus group contaron con las siguientes fases:

Fase de presentación, en la cual cada miembro se presentó indicando su nombre y edad, así se logró que los participantes rompieran el hielo, a partir de esto se va aterrizando la idea del porque han sido convocados. Luego se realizó la fase de calentamiento en la que se ahonda un poco sobre algunos datos importantes de los participantes, como familia, lugar de residencia, y finalmente la fase de profundidad la cual se adjunta en los anexos como guía de pautas. (Ver anexo 1 y anexo 2)

Con estos Focus Group se buscó conocer lo siguiente:

- Antecedentes

- Hábitos de preparación de loncheras

- Conceptos de nutrición

- Evaluación de la propuesta de negocio 
- Presentación del producto

- Contraste entre concepto y producto

Se realizó dos focus group con la participación de padres de familia con hijos en educación inicial y/o en educación primaria. Todos los participantes cuentan con sus hijos en colegios de los distritos de Ate, Santa Anita ó La Molina. Para la realización de los focus group cada miembro del grupo asumió el rol de moderador en cada uno de ellos, los focus group se dividieron de la siguiente manera:

\section{Focus group de padres de familia con hijos en educación inicial y/o primaria}

- Focus group $\mathrm{N}^{\mathrm{o}}$ 1: Se contó con la participación de 11 padres de familia con hijos en educación inicial y/o primaria perteneciente a los distritos de Ate, Santa Anita ó La Molina.

- Focus group $\mathrm{N}^{\mathrm{o}}$ 2: Se contó con la participación de 09 padres de familia con hijos en educación inicial y/o primaria perteneciente a los distritos de Ate, Santa Anita ó La Molina

Focus group de profesores de educación inicial ó primaria de los distritos de Lima

\section{Metropolitana.}

- Focus group Nº1: Se contó con la participación de 10 docentes de educación inicial.

- Focus group N²: Se contó con la participación de 10 docentes de educación primaria.

\section{Análisis - Primer Focus Group Padres de Familia}

- Todos los participantes tienen hijos en educación inicial y/o primaria 
- Todos demuestran preocupación por incluir alimentos saludables en la lonchera escolar de sus hijos.

- 10 de 11 participantes indicaron no tener conocimiento exacto sobre la cantidad de vitaminas y proteínas que debe consumir diariamente su hijo.

- Todos los participantes indican que la lonchera se prepara el mismo día.

- 3 de 11 participantes indican tener ayuda de padres o empleadas del hogar que les ayudan en la preparación de las loncheras, pero con la supervisión directa de su contenido.

- 9 de 11 participantes indican que organizan su tiempo en las mañanas para poder preparar la lonchera.

- Se presentó el proyecto informando sobre las bondades del servicio y el tiempo que podrían ahorrar ya que no solo es la preparación de la lonchera sino también la compra de insumos cada semana.

- Todos los participantes desearían poder confiar la preparación de las loncheras a un tercero, pero, deben tener pleno conocimiento de lo que incluiría cada día y la forma de distribución (de preferencia a la entrada del colegio para evitar retrasos).

- Todos los participantes desearían recibir información periódica sobre la combinación adecuada de los alimentos para una balanceada dieta de sus hijos.

- 8 de 11 participantes indicó que también le gustaría un servicio similar para fiestas infantiles.

- Todos los participantes coincidieron en que no solo se debe convencer a los padres, sino también a los niños con presentaciones que llamen su atención.

- Todos los participantes demostraron su preocupación por el medio ambiente, y recomendaron presentaciones ecológicas con algo para pintar o un cuento.

- Todos los participantes están dispuestos a pagar entre 4 y 6 soles. 
- Se presentaron seis alternativas de logo y marca para su opinión, siendo la más preferida la nro. 6, cuyo nombre es Lunch Kids (ver anexo 12)

\section{Análisis - Segundo Focus Group Padres de Familia}

- Todos los participantes tienen hijos en educación inicial y/o primaria.

- Todos demuestran preocupación por la adecuada alimentación de sus hijos, eventualmente podrían proveerse de alimentos procesados.

- Algunos padres indican que las loncheras de sus hijos son supervisadas en el colegio y no les permiten llevar refrescos endulzados.

- Aproximadamente la mitad de los participantes tenían conocimiento sobre lo que debería contener una lonchera saludable (líquido, carbohidratos, proteínas y vitaminas)

- Consideran importantes las campañas de fidelización, como llevar una lonchera especial en el día de cumpleaños del niño o eventualmente al padre.

- Recomiendan personalizar los alimentos de la lonchera según necesidades de cada niño.

- Recomiendan proporcionar información sobre alimentación saludable mediante redes sociales.

- Recomiendan loncheras personalizadas, botellas con dibujos y su nombre.

- Sugieren empaques coloridos que llamen la atención.

- Los sanguches pueden tener siluetas de imágenes variadas.

- Se presenta el producto y describe beneficios del mismo.

- Demostraron interés en el producto siempre y cuando supervisaran el contenido y conozcan la distribución del mismo.

- Todos coincidieron en que el precio promedio a pagar seria entre 5 y 6 soles. 
- Se presentaron seis alternativas de logo y marca para su opinión. Eligieron la opción 6 (ver anexo 12).

\section{Análisis - Primer Focus Group docentes de educación inicial}

- Todas las participantes son docentes de educación inicial.

- Tienen empatía con los niños y disfrutan el ambiente rodeadas de niños.

- Consideran de suma importancia la alimentación del niño, ya que influye en su desarrollo intelectual y en las actividades que desarrolla durante el día.

- Indican que los padres demuestran preocupación por sus hijos en cuanto a su alimentación y procuran elaborar en casa la lonchera de los niños.

- Los alimentos más comunes en la lonchera son agua, agua de piña, jugo de frutas y sánguche de pollo, queso o jamón.

- Cada una tiene a cargo entre 7 y 5 niños.

- Solo una docente indica que tuvo un alumno con sobrepeso, pero era porque la abuela le consentía sus gustos.

- El horario de refrigerio es entre 10 y $11 \mathrm{am}$, y dura media hora.

- Las docentes les ayudan a alimentarse según como lo necesite cada niño.

- En uno de los colegios se incluye las loncheras saludables como parte del servicio.

- Procuran que los niños no consuman alimentos procesados.

- En los colegios de inicial no tienen kiosko, los alumnos llevan su lonchera.

- Después de conocer el producto, recomiendan elaborar loncheras variadas porque los niños se aburren rápido con los mismos alimentos.

- En cuanto al logo del proyecto eligieron el nro.5. 


\section{Análisis - Segundo Focus Group docentes de educación primaria}

- Todas las participantes son profesoras de educación primaria.

- Consideran de suma importancia la alimentación del niño, ya que influye en su desarrollo intelectual y en las actividades que desarrolla durante el día.

- Indican que los padres demuestran preocupación por sus hijos en cuanto a su alimentación y procuran elaborar en casa la lonchera de los niños.

- Los alimentos más comunes en la lonchera son agua, refresco de frutas y sánguches y frutas enteras.

- Cada una tiene a cargo entre 20 y 25 niños.

- Una docente indica que tiene un alumno que sigue una dieta alimenticia, pero puede ser por salud porque no llega a tener sobrepeso.

- El horario de refrigerio es a las 10:30 a.m. y dura entre 20 minutos a media hora.

- Procuran que los niños no consuman alimentos procesados, para ello conversan con los padres y eventualmente se dictan charlas en el colegio.

- Después de conocer el producto, recomiendan elaborar loncheras variadas porque los niños se aburren rápido con los mismos alimentos.

- En cuanto al logo del proyecto eligieron el nro.5

\section{Entrevistas a profundidad.}

Las entrevistas a profundidad se realizaron a una profesional en Nutrición y a dos Administradores de restaurantes de comida saludable, el objetivo principal para el caso de las nutricionistas es que brinden información de primera mano sobre la problemática actual que afecta a todos los niños del país, con este repentino aumento que muestran los indicadores de obesidad o sobrepeso. También se busca tener conocimiento sobre 
las porciones adecuadas que deben comer los niños, los valores nutricionales que deben consumir, entre otros puntos.

En el caso de los administradores de negocios de comida saludable se buscó que brinden una orientación sobre la gestión del negocio, los principales problemas a los que se enfrentan, algunos tips para tener en cuenta, e incluso indagar sobre la rentabilidad de este sector, conocer si hay alguna clase de estacionalidad y cómo se manejan.

Con estas entrevistas a profundidad se buscó conocer lo siguiente:

- Hábitos alimenticios

- Consecuencias de una mala alimentación

- Nociones básicas de una lonchera escolar saludable

- Recomendaciones generales

\section{Análisis - Entrevistas a expertos del Sector Restaurantes}

Luego de realizar la entrevista a los administradores de locales se concluye lo siguiente:

- Que en los últimos 5 años la demanda de comida saludable se ha incrementado considerablemente, esto debido a una nueva tendencia de los clientes por verse y sentirse mejor. Existe una preocupación por informarse qué tipo de productos consumen y cómo balancear su alimentación.

- En las barreras de entrada encontramos la falta de facilidades en realizar los trámites de implementación de locales, por lo que se contrata una empresa especializada. Otro dato importante, es el temor por parte de las personas por consumir productos nuevos, ya que relacionan comida saludable a la falta de sabor o gusto de los platos. 
- Los proveedores de insumos deben ser de evaluados, ya que es una pieza clave en el producto final.

- Los productos más perecederos son las frutas y los vegetales.

- El manejo de inventarios es parte importante de la gestión de los negocios.

- La temporada de verano es la de menor afluencia de público.

- La comunicación se realiza a través de redes, correo y referidos.

Entre las recomendaciones se puede mencionar:

- Que el mercado de loncheras saludables es una gran oportunidad de negocio y considerando la tendencia del mercado, es un buen momento de ingresar para poder posicionarse.

- La alimentación de los hijos es una preocupación constante de los padres que no necesariamente saben cómo elaborar una lonchera de manera adecuada.

\subsection{Investigación cuantitativa}

La investigación cuantitativa busca cuantificar los datos y suele, en la mayoría de los casos, aplicar un tipo de análisis estadístico. Se recomienda que cuando se trate de algún problema nuevo de investigación de mercado, esta investigación debería estar precedida de una investigación cualitativa (Malhotra, 2008).

\subsubsection{Procesos de muestreo}

De acuerdo con Malhotra (2008), el proceso de diseño del muestreo comprende cinco pasos: (a) definir la población meta, (b)determinar el marco de muestreo, (c)seleccionar la técnica de muestreo, (d) determinar el tamaño de la muestra, (e) llevar a cabo el proceso de muestreo, estos están relacionados entre sí y son muy importantes 
para todos los aspectos del proyecto de investigación de mercados, desde la definición del problema hasta la entrega de los resultados.

"La población meta, que es el conjunto de elementos u objetos que poseen la información buscada por el investigador y acerca del cual se harán inferencias" (Malhotra, 2008, p. 336).

En este proyecto se definió de la siguiente manera a la población meta:

Hombre o mujeres, padres de familia con hijos en edad escolar en nivel inicial y primario de instituciones educativas privadas de los distritos Ate, Santa Anita y La Molina.

Para este caso el marco de muestreo es la lista del Padrón de Instituciones Educativas y Programas que gestiona la Unidad de Estadística del Ministerio de Educación 2016 de los distritos Ate, Santa Anita y La Molina, de nivel inicial y primaria.

Para determinar el tamaño de la muestra representativa se consideró la fórmula para poblaciones finitas (Bernal, 2016, p.235):

$$
\mathrm{n}=\frac{Z^{2} \times P \times Q \times N}{E^{2}(\mathrm{~N}-1)+Z^{2} \times P \times Q}
$$

Donde:

Z: Nivel de confianza o margen de confiabilidad (95\%, es decir, $Z=1.96$ )

P: Probabilidad de ocurrencia, proporción de individuos que poseen la característica de la población.

Q: Probabilidad de fracaso (1-P)

E: Margen de error permitido

n: tamaño de la muestra

$\mathrm{N}$ : Número total de la población 
Según Hernández (2018) el nivel de confianza es el porcentaje o proporción de que tu muestra sea representativa de la población, además, según Bernal, C. (2016), en una investigación estadísticamente se suelen tomar valores para niveles de confianza igual o superior a $90 \%$. Para este estudio se ha seleccionado un nivel de confianza de $95 \%$, por lo que $Z=1,96$, ello significa que se busca que el $95 \%$ de la muestra cumpla con los criterios de inclusión requeridos, en consecuencia, se trabajará con un margen de error de 5\% (E), asimismo cuando no se tienen marcos de muestreos previos se usa un porcentaje estimado de 50\% (es decir, se asume que "P” y “Q” serán de 50\%).

De acuerdo con la lista del Padrón de Instituciones Educativas y Programas que gestiona la Unidad de Estadística del Ministerio de Educación 2016 de los distritos Ate, Santa Anita y La Molina, de nivel inicial y primaria se tomó el número total de la población (N) siendo 78,986.

De la fórmula se obtiene entonces:

$$
\mathrm{n}=\frac{1.96^{2} \times 0.5 \times 0.5 \times 78,986}{0.05^{2}(78,986-1)+1.96^{2} \times 0.5 \times 0.5}
$$

$$
\mathrm{n}=384
$$

En conclusión, con un nivel de confianza de 95\% y un error de estimación de 5\% para el total de padres de familia que cumplen con los criterios de inclusión y exclusión $(78,986)$, se requiere encuestar, por lo menos, 384 personas para conocer la percepción representativa de los padres de familia sobre las loncheras saludables.

Para facilitar la investigación cuantitativa del proyecto, se utilizó la técnica de muestreo no probabilístico, ya que como menciona Malhotra (2008), “es una técnica de muestreo que no usa procedimientos de selección al azar, sino que se basan en el juicio del investigador" (p.340). 
Asimismo, se utilizó el tipo de muestreo por cuotas como Malhotra (2008) lo establece, es por juicio restringido y consta de dos etapas, siendo la primera plantear categorías de control con características relevantes de los elementos de la población como por ejemplo sexo y edad, luego se determina de manera proporcional de acuerdo a las características de control. En la segunda etapa, se elige los elementos de la muestra por conveniencia o el juicio del investigador.

Para distribuir la muestra apropiadamente se tomó como base la lista del Padrón de Instituciones Educativas y Programas que gestiona la Unidad de Estadística del Ministerio de Educación 2016 de los distritos Ate, Santa Anita y La Molina, de nivel inicial y primaria, se filtró los colegios privados para luego hallar el porcentaje en forma proporcional por distrito, se usó ese factor para multiplicarlo por 384 que es el tamaño de la muestra, y así obtener la cuota por distrito. (Ver tabla 20)

Tabla 20.

Cuotas por distrito según nivel de los distritos Ate La Molina y Santa Anita

\begin{tabular}{clccc}
\hline \multirow{2}{*}{ Distrito } & \multicolumn{1}{c}{ Nivel } & Población & Proporción & Cuota por distrito \\
& Inicial & 14843 & $19 \%$ & 72 \\
Ate & Primaria & 32694 & $41 \%$ & 159 \\
& Inicial & 5440 & $7 \%$ & 26 \\
\multirow{3}{*}{ Lanta Anita } & Primaria & 10554 & $13 \%$ & 51 \\
& Inicial & 5264 & $7 \%$ & 26 \\
& Primaria & 10191 & $13 \%$ & 50 \\
& Total & 78986 & $100 \%$ & 384 \\
\hline
\end{tabular}

Nota: Adaptado de "Padrón de Instituciones Educativas y Programas que gestiona la Unidad de Estadística del Ministerio de Educación 2016”, por Ministerio de Educación, Unidad de Estadística Educativa (ESCALE), 2016. Recuperado de http://escale.minedu.gob.pe/padron-de-iiee

La muestra lo constituyen 384 padres de familia que cumplan con los siguientes criterios de inclusión y exclusión: 


\section{Criterios de inclusión:}

- Padres de familia cuyos niños estén matriculados en nivel inicial y primario.

- Padres de familia cuyos niños estén matriculados en una institución educativa privada.

- Padres de familia que envían regularmente lonchera a sus hijos.

- Padres de familia que pertenezcan al nivel socioeconómico B y C.

- Padres de familia que tengan a sus hijos en instituciones educativas dentro de los distritos de Ate, La Molina y Santa Anita.

- Padres de familia que acepten participar en el estudio.

- Padres de familia que vivan en otros distritos pero que pertenezcan al nivel socioeconómico B y C.

\section{Criterios de exclusión:}

- Personas a cargo de los niños con edad escolar (abuelo, tíos etc.)

- Padres de familia que tengan a sus hijos en instituciones educativas que incluyan las loncheras como un servicio.

\subsubsection{Diseño de instrumento}

Para la investigación cuantitativa se utilizó el tipo de encuesta directa estructurada, como menciona Malhotra (2008), es la técnica de recolección de datos más conocida que incluye la aplicación de un cuestionario formal donde las preguntas tienen un orden predeterminado, siendo estas básicamente de alternativa fija (Ver Anexo 13: Cuestionario).

La estructura del cuestionario consta de 8 preguntas filtro con las que se busca identificar el mercado potencial y 17 preguntas que permitan obtener la información necesaria para lograr el objetivo de la investigación cuantitativa, que es conocer la 
aceptación e intención de compra de las loncheras saludables para niños de centros educativos privados de inicial y primaria.

En la encuesta se utilizan preguntas de opción múltiple, dicotómicas, mixta y de escala. (Ver Tabla 21)

Tabla 21

Tipo y número de preguntas de la encuesta

\begin{tabular}{cc}
\hline Tipo de pregunta & Cantidad de preguntas \\
\hline Dicotómica & 2 \\
Opción Múltiple & 4 \\
Escala Nominal, Ordinal e Intervalo & 10 \\
Mixtas & 1 \\
\hline
\end{tabular}

Nota: Elaboración propia.

Asimismo, se utilizó unas cartillas de apoyo con imágenes de las loncheras saludables para facilitar la respuesta de la pregunta nro. 8. (ver anexo 15 y 16)

El tiempo promedio de la aplicación de la encuesta fue de 7 minutos aproximadamente. Además, se realizó una prueba piloto en una pequeña muestra de encuestados, la cual ayudó a corregir las preguntas del cuestionario final y hacerlas más claras para el encuestado.

\subsubsection{Análisis y procesamiento de datos}

La aplicación del cuestionario fue electrónica y se realizaron a través del correo electrónico e internet, para ello se utilizó Google Forms, herramienta que permite crear formularios personalizados, fáciles de compartir a través de correo electrónico o un vínculo a un sitio web, en este caso la publicación del enlace al cuestionario se realizó en redes sociales y por correo electrónico, teniendo en cuenta el mercado seleccionado, compuesto por padres de familia con hijos en edad escolar que estudian en los distritos 
de Ate, Santa Anita y La Molina y que son del Nivel socioeconómico B y C. (Ver Tabla 22) 
Tabla 22

Distribución muestral de los encuestados según distrito

\begin{tabular}{|c|c|c|c|c|c|c|c|c|c|c|c|c|c|c|c|}
\hline \multirow{2}{*}{ Distrito } & \multicolumn{4}{|c|}{ Sexo } & \multicolumn{6}{|c|}{ Edad } & \multicolumn{4}{|c|}{ NSE } & \multirow{2}{*}{ Total } \\
\hline & $\mathrm{M}$ & $\%$ & $\mathrm{~F}$ & $\%$ & $18-30$ & $\%$ & $31-45$ & $\%$ & $46-60$ & $\%$ & $\mathrm{~B}$ & $\%$ & $\mathrm{C}$ & $\%$ & \\
\hline \multicolumn{16}{|l|}{ Ate } \\
\hline Inicial & 25 & $35 \%$ & 47 & $65 \%$ & 30 & $42 \%$ & 39 & $54 \%$ & 3 & $4 \%$ & 27 & $38 \%$ & 45 & $63 \%$ & 72 \\
\hline Primaria & 72 & $45 \%$ & 87 & $55 \%$ & 57 & $36 \%$ & 98 & $62 \%$ & 4 & $3 \%$ & 49 & $31 \%$ & 110 & $69 \%$ & 159 \\
\hline \multicolumn{16}{|c|}{ Santa Anita } \\
\hline Inicial & 9 & $35 \%$ & 17 & $65 \%$ & 14 & $54 \%$ & 10 & $38 \%$ & 2 & $8 \%$ & 5 & $19 \%$ & 21 & $81 \%$ & 26 \\
\hline Primaria & 20 & $39 \%$ & 31 & $61 \%$ & 21 & $41 \%$ & 26 & $51 \%$ & 4 & $8 \%$ & 10 & $20 \%$ & 41 & $80 \%$ & 51 \\
\hline \multicolumn{16}{|c|}{ La Molina } \\
\hline Inicial & 2 & $8 \%$ & 24 & $92 \%$ & 9 & $35 \%$ & 12 & $46 \%$ & 5 & $19 \%$ & 16 & $62 \%$ & 10 & $38 \%$ & 26 \\
\hline Primaria & 4 & $8 \%$ & 46 & $92 \%$ & 19 & $38 \%$ & 26 & $52 \%$ & 5 & $10 \%$ & 36 & $72 \%$ & 14 & $28 \%$ & 50 \\
\hline Total & 132 & & 252 & & 150 & & 211 & & 23 & & 143 & & 241 & & 384 \\
\hline
\end{tabular}

Nota: Elaboración propia.

${ }^{a}$ Excluidos 36 encuestados que no cumplían con el perfil 
Se obtuvo los siguientes resultados del estudio cuantitativo:

Tabla 23.

Pregunta 1.- ¿Qué opción de alimentos predomina en la lonchera de sus hijos?

\begin{tabular}{lcc}
\hline \multicolumn{1}{c}{ Respuesta } & Cantidad & Porcentaje \\
\hline Galletas, snacks, chocolates, jugos procesados u otros similares & 118 & $31 \%$ \\
Embutidos, frituras u otros similares & 50 & $13 \%$ \\
Frutas frescas, frutos secos, verduras, agua & 216 & $56 \%$ \\
\multicolumn{1}{c}{ Total } & 384 & $100 \%$ \\
\hline
\end{tabular}

Nota: Elaboración propia.

Del 100\% de encuestados el 56\% indicó que en la lonchera de sus hijos predominaba el uso de Frutas frescas, frutos secos y verduras, sin embargo, hay un $44 \%$ donde aún predomina los Snacks y/o frituras.

Tabla 24.

Pregunta 2.- ¿Cuál es la principal razón por la que su hijo debería consumir una lonchera saludable?

\begin{tabular}{lcccc}
\hline \multicolumn{1}{c}{ Respuesta } & \multicolumn{3}{c}{ Porcentaje } \\
\hline & $\mathbf{1}$ & $\mathbf{2}$ & $\mathbf{3}$ & $\mathbf{4}$ \\
Ayuda al correcto crecimiento de los niños & $34 \%$ & $30 \%$ & $25 \%$ & $11 \%$ \\
Ayuda a prevenir enfermedades & $33 \%$ & $25 \%$ & $29 \%$ & $13 \%$ \\
Ayuda en el aprendizaje y desarrollo de actividades físicas & $17 \%$ & $22 \%$ & $31 \%$ & $30 \%$ \\
Evita la obesidad & $16 \%$ & $28 \%$ & $26 \%$ & $30 \%$ \\
\hline
\end{tabular}

Nota: Elaboración propia.

El 34\% de encuestados respondió que la principal razón para que sus hijos consuman una lonchera saludable es el correcto crecimiento de sus hijos y un 33\% para prevenir enfermedades. 
Tabla 25.

Pregunta 3.- ¿Conoce alguna empresa que brinde servicio de loncheras saludables estándar para niños de educación inicial o primaria?

\begin{tabular}{ccc}
\hline Respuesta & Cantidad & Porcentaje \\
\hline Si & 15 & $4 \%$ \\
No & 369 & $96 \%$ \\
Total & 384 & $100 \%$ \\
\hline
\end{tabular}

Nota: Elaboración propia.

El 96\% de los encuestados nos reafirma que no hay una empresa que se encargue de brindar este tipo de servicios.

Tabla 26.

Pregunta 4.- Basándose en la descripción del producto, ¿Le parece interesante esta propuesta?

\begin{tabular}{ccc}
\hline Respuesta & Cantidad & Porcentaje \\
\hline Si & 363 & $95 \%$ \\
No & 21 & $5 \%$ \\
Total & 384 & $100 \%$ \\
\hline
\end{tabular}

Nota: Elaboración propia.

La pregunta nos dio como resultado que al $95 \%$ de encuestados les parece una propuesta interesante. 
Tabla 27.

Pregunta 5.- ¿Qué opción de bebidas le gustaría encontrar en la lonchera saludable?

\begin{tabular}{cccccc}
\hline Respuesta & \multicolumn{3}{c}{ Porcentaje } \\
\hline & $\mathbf{1}$ & $\mathbf{2}$ & $\mathbf{3}$ & 4
\end{tabular}

Refrescos naturales (limonada, piña, maracuyá, manzana, emoliente u otros similares)

Infusiones (manzanilla, hierba luisa, anís u otros similares)

$\begin{array}{llll}13 \% & 35 \% & 30 \% & 22 \%\end{array}$

Jugos de fruta (naranja, piña, papaya, fresa u otros similares)

$26 \% \quad 25 \% \quad 24 \% \quad 25 \%$

Agua

$\begin{array}{lllll}6 \% & 32 \% & 34 \% & 28 \%\end{array}$ Nota: Elaboración propia.

La opción más solicitada por los encuestados fue la de refrescos naturales con un $55 \%$

Tabla 28.

Pregunta 6.- ¿Qué opción de sándwich le gustaría encontrar dentro de las loncheras saludables?

\begin{tabular}{ccccc}
\hline Respuesta & \multicolumn{3}{c}{ Porcentaje } \\
\hline & 1 & 2 & 3 & 4
\end{tabular}

Sándwich (pollo, atún, sangrecita, huevo, palta, queso, jamón de pavita u otros similares)

$55 \% \quad 29 \% \quad 11 \% \quad 5 \%$

Galletas (integrales, quinua, kiwicha u otros similares)

$\begin{array}{lllll}8 \% & 30 \% & 35 \% & 27 \%\end{array}$

Huevitos de codorniz, choclo con queso

$28 \% \quad 23 \% \quad 22 \% \quad 27 \%$

Tortillas de verduras (brócoli, berenjena u otros similares)

Nota: Elaboración propia.

El 55\% de los encuestados nos indicaron que la opción de sándwich que prefiere es la de pollo, huevo, palta, Etc. 
Tabla 29.

Pregunta 7.- ¿Qué opción de frutas le gustaría encontrar dentro de las opciones de loncheras saludables?

\begin{tabular}{lcccc}
\hline \multicolumn{1}{c}{ Respuesta } & \multicolumn{3}{c}{ Porcentaje } \\
\hline Naranja, pepino, piña, uva, kiwi & $\mathbf{1}$ & $\mathbf{2}$ & $\mathbf{3}$ & $\mathbf{4}$ \\
& $17 \%$ & $27 \%$ & $35 \%$ & $21 \%$ \\
Mandarina, granadilla, durazno, melocotón & $41 \%$ & $31 \%$ & $23 \%$ & $5 \%$ \\
Manzana, pera, melón, papaya, plátano, guayaba & & & & \\
Frutos secos & $34 \%$ & $23 \%$ & $22 \%$ & $27 \%$ \\
\hline
\end{tabular}

Nota: Elaboración propia.

Las frutas más solicitadas por los encuestado fueron las semi acidas con una $41 \%$

Tabla 30.

Pregunta 8.- ¿Cuánto estaría dispuesto a pagar por una lonchera saludable que incluye refresco, sanguche y fruta?

\begin{tabular}{lcc}
\hline \multicolumn{1}{c}{ Respuesta } & Cantidad & Porcentaje \\
\hline Menos de S/3 & 8 & $2 \%$ \\
De S/3 a menos de S/5 & 17 & $4 \%$ \\
De S/5 a menos de S/6 & 247 & $64 \%$ \\
De S/6 a menos de S/7 & 83 & $22 \%$ \\
De S/7 a menos de S/8 & 17 & $4 \%$ \\
De S/8 a menos de S/9 & 9 & $2 \%$ \\
Más de S/. 9 soles & 3 & $1 \%$ \\
\multicolumn{1}{c}{ Total } & 384 & $100 \%$ \\
\hline
\end{tabular}

Nota: Elaboración propia.

En cuanto al precio que están dispuestos a pagar, el mayor porcentaje lo obtuvimos en el rango de S/ 5.00 a S/ 6.00 soles con una $64 \%$ 
Tabla 31.

Pregunta 9.- ¿Estaría dispuesto a comprar la lonchera saludable?

\begin{tabular}{lccc}
\hline & Respuesta & Cantidad & Porcentaje \\
\hline Definitivamente $\mathrm{Si}$ & & 171 & $45 \%$ \\
Probablemente $\mathrm{Si}$ & & 176 & $46 \%$ \\
Me es indiferente & & 21 & $5 \%$ \\
Probablemente No & & 11 & $3 \%$ \\
Definitivamente No & Total & 5 & $1 \%$ \\
& & 384 & $100 \%$ \\
\hline
\end{tabular}

Nota: Elaboración propia.

En la pregunta 9 nos encontramos con un $45 \%$ de encuestados que definitivamente si están dispuestos a comprar una lonchera saludable para sus hijos, y un $46 \%$ que probablemente la adquiera.

Tabla 32.

Pregunta 10.- ¿Qué paquete de lonchera saludable compraría usted?

\begin{tabular}{lccc}
\hline & Respuesta & Cantidad & Porcentaje \\
\hline Semanal & & 227 & $59 \%$ \\
Quincenal & & 83 & $22 \%$ \\
Mensual & & 61 & $16 \%$ \\
Eventual & & 13 & $3 \%$ \\
& Total & 384 & $100 \%$ \\
\hline
\end{tabular}

Nota: Elaboración propia.

El paquete de lonchera que los encuestados prefieren es el semanal con un 59\% 
Tabla 33.

Pregunta 11.- Del periodo escolar ¿Con qué frecuencia estaría dispuesto a consumir el programa de loncheras saludables?

\begin{tabular}{lcc}
\hline Respuesta & Cantidad & Porcentaje \\
\hline Una vez al mes. & 3 & $1 \%$ \\
Una vez cada 15 días. & 9 & $2 \%$ \\
Una vez a la semana. & 11 & $3 \%$ \\
2 veces a la semana. & 27 & $7 \%$ \\
3 veces a la semana. & 28 & $7 \%$ \\
4 veces a la semana & 76 & $20 \%$ \\
5 veces a la semana. & 230 & $60 \%$ \\
Total & 384 & $100 \%$ \\
\hline
\end{tabular}

Nota: Elaboración propia.

El 60\% de encuestados respondió que la frecuencia con la que adquiriría la lonchera saludable es de 5 veces a la semana

Tabla 34.

Pregunta 12.- ¿Cómo preferiría realizar el pago de las loncheras saludables?

\begin{tabular}{lcccc}
\hline \multicolumn{1}{c}{ Respuesta } & \multicolumn{3}{c}{ Porcentaje } \\
\hline & $\mathbf{1}$ & $\mathbf{2}$ & $\mathbf{3}$ & $\mathbf{4}$ \\
Efectivo & $22 \%$ & $30 \%$ & $29 \%$ & $19 \%$ \\
Deposito/transferencia en cuenta & $52 \%$ & $15 \%$ & $5 \%$ & $28 \%$ \\
POS (tarjeta de crédito/debido) & $26 \%$ & $25 \%$ & $20 \%$ & $29 \%$ \\
Cargo automático en cuenta & $1 \%$ & $20 \%$ & $39 \%$ & $40 \%$ \\
\hline
\end{tabular}

Nota: Elaboración propia.

El medio de pago que los encuestados prefieren es el de depósito o transferencia en cuenta, con un $52 \%$. 
Tabla 35.

Pregunta 13.- ¿Le gustaría recibir tips sobre temas de nutrición de manera gratuita a su correo?

\begin{tabular}{ccc}
\hline Respuesta & Cantidad & Porcentaje \\
\hline Si & 364 & $95 \%$ \\
No & 20 & $5 \%$ \\
Total & 384 & $100 \%$ \\
\hline
\end{tabular}

Nota: Elaboración propia.

Al 95\% de encuestados les agradaría recibir tips sobre temas de nutrición de manera gratuita.

Tabla 36.

Pregunta 14.- ¿Recomendaría estas loncheras saludables con sus amistades?

\begin{tabular}{lccc}
\hline & Respuesta & Cantidad & Porcentaje \\
\hline Definitivamente si & 194 & $51 \%$ \\
Probablemente si & 176 & $46 \%$ \\
Me es indiferente & 11 & $3 \%$ \\
Probablemente no & 3 & $1 \%$ \\
Definitivamente no & 0 & $0 \%$ \\
Total & 384 & $100 \%$ \\
\hline Nota: Elaboración propia. & &
\end{tabular}

Nota: Elaboración propia.

En la pregunta 14 el $51 \%$ de los encuestados indicaron que definitivamente recomendaría las loncheras saludables a sus amistades. 
Tabla 37.

Pregunta 15.- ¿Qué promoción le gustaría recibir eventualmente?

\begin{tabular}{lcccc}
\hline \multicolumn{1}{c}{ Respuesta } & \multicolumn{4}{c}{ Porcentaje } \\
\hline & $\mathbf{1}$ & $\mathbf{2}$ & $\mathbf{3}$ & $\mathbf{4}$ \\
$\begin{array}{l}\text { Una lonchera especial para su hijo el día de } \\
\text { su cumpleaños }\end{array}$ & $67 \%$ & $15 \%$ & $13 \%$ & $5 \%$ \\
$\begin{array}{l}\text { Un descuento especial en la semana del } \\
\text { cumpleaños de su hijo }\end{array}$ & $21 \%$ & $20 \%$ & $30 \%$ & $29 \%$ \\
$\begin{array}{l}\text { Una lonchera gratuita para su hijo el día de } \\
\text { su cumpleaños }\end{array}$ & $9 \%$ & $50 \%$ & $15 \%$ & $26 \%$ \\
$\begin{array}{l}\text { Una lonchera gratuita para la mamá o el } \\
\text { papá }\end{array}$ & $3 \%$ & $24 \%$ & $35 \%$ & $38 \%$ \\
\hline
\end{tabular}

Nota: Elaboración propia.

El tipo de promoción que le gustaría recibir a los padres de familia eventualmente es el de una lonchera especial para sus hijos el día de su cumpleaños con un $67 \%$.

Tabla 38.

Pregunta 16.- ¿Cuál sería un nombre adecuado para este proyecto?

\begin{tabular}{lcccc}
\hline \multicolumn{1}{c}{ Respuesta } & \multicolumn{4}{c}{ Porcentaje } \\
\hline Nutribreak & $\mathbf{1}$ & $\mathbf{2}$ & $\mathbf{3}$ & $\mathbf{4}$ \\
LunchSchool & $16 \%$ & $20 \%$ & $19 \%$ & $45 \%$ \\
NutriLunch & $6 \%$ & $19 \%$ & $33 \%$ & $42 \%$ \\
LunchKids & $29 \%$ & $48 \%$ & $10 \%$ & $13 \%$ \\
Delirecreo & $31 \%$ & $30 \%$ & $15 \%$ & $24 \%$ \\
\hline
\end{tabular}

Nota: Elaboración propia.

El $31 \%$ de los encuestados recomendó el nombre LunchKids como el que debería llevar la empresa de loncheras saludables 
Tabla 39.

Pregunta 17.- ¿Cómo desearía que se realice la comunicación con usted?

\begin{tabular}{|c|c|c|c|c|}
\hline \multirow[t]{2}{*}{ Respuesta } & \multicolumn{4}{|c|}{ Porcentaje } \\
\hline & 1 & 2 & 3 & 4 \\
\hline Correo electrónico & $38 \%$ & $18 \%$ & $17 \%$ & $27 \%$ \\
\hline WhatsApp & $45 \%$ & $41 \%$ & $9 \%$ & $5 \%$ \\
\hline Facebook & $7 \%$ & $27 \%$ & $43 \%$ & $23 \%$ \\
\hline Teléfono & $10 \%$ & $33 \%$ & $21 \%$ & $36 \%$ \\
\hline
\end{tabular}

Nota: Elaboración propia.

El 45\% de los encuestados, nos indicó que preferirían usar el WhatsApp como medio de comunicación con nosotros.

\subsection{Conclusiones y recomendaciones del estudio cualitativo y cuantitativo}

Luego de realizar la investigación cualitativa y cuantitativa se concluye lo siguiente:

- Los padres de familia manifiestan una mayor preocupación por la alimentación de sus hijos, en consecuencia, se informan mucho más en cuanto al contenido de las loncheras de sus hijos, es por ello que la mayor parte de padres indicó que al menos uno de los alimentos esenciales dentro de la lonchera debe ser frutas y muy pocos indicaron que debería contener snacks, embutidos y/u otros similares.

- La mayoría de padres de familia son los encargados de preparar la lonchera de sus hijos, pero también afirman tener muy poco tiempo para dicha tarea.

- En cuanto al contenido de las loncheras la mayoría de padres de familia, indicó que debe contener un sánguche, una fruta y refresco natural (Limonada, piña, maracuyá, manzana, emoliente, etc.).

- En cuanto al lugar que desearían recibir las loncheras, la mayor parte indicó en el aula del niño. 
- LunchKids les parece un servicio nuevo e innovador que facilitaría a los padres en cuanto al tiempo de la preparación de las loncheras de sus hijos y a su vez garantizaría una alimentación nutritiva y variada, la mayor parte de padres de familia afirmaron que estarían dispuestos a comprar las loncheras saludables.

- El nombre elegido fue Lunch Kids y el slogan elegido fue "deliciosas y saludables"

- La mayor parte de los padres de familia consideran que sus hijos deberían consumir una lonchera saludable para sentirse bien y por una alimentación balanceada.

- Con relación al precio que estarían dispuestos a pagar, tanto en la investigación cualitativa y cuantitativa indicaron un rango de 5 a 6 soles.

Entre las recomendaciones se pueden mencionar:

- Que exista variedad en el menú de las loncheras y opciones a elegir semanalmente.

- Que la lonchera sea entregada en el aula del niño a la hora del recreo.

- Recomiendan que se debe proporcionar información sobre alimentación saludable mediante redes sociales, asimismo que los empaques sean coloridos con un personaje y/o dibujo preferido, para que llame la atención del niño. 


\section{Capítulo IV. Proyección del mercado objetivo}

Según Kotler y Keller (2012), “el pronóstico de mercado muestra la demanda de mercado prevista, no la demanda máxima de mercado" (p. 87).

Este capítulo permitió identificar el mercado al cual va dirigida la propuesta de valor del presente proyecto.

\subsection{El ámbito de la proyección}

Como mencionan Sapag y Sapag (2008):

Para que el producto resultante de la proyección permita su uso óptimo, la información deberá expresarse de la manera que sea más valiosa para el preparador del proyecto; por ejemplo, en algunos casos la información deberá expresarse desglosada por zona geográfica, o en función de algún atributo de los clientes, como sexo o edad. (p.90)

El ámbito de la proyección está limitado a Lima Metropolitana, específicamente los distritos de Ate, La Molina y Santa Anita, que concentran la mayor cantidad de centros educativos de educación inicial y primaria del sector privado. (ver Tabla 40)

Tabla 40.

Alumnos de educación inicial y primaria en colegios del sector privado

\begin{tabular}{|c|c|c|c|c|}
\hline Distrito & Nivel & Inicial & Nivel Primaria & Total \\
\hline Ate & & 14843 & 32694 & 47537 \\
\hline Santa Anita & & 5440 & 10554 & 15994 \\
\hline La Molina & & 5264 & 10191 & 15455 \\
\hline
\end{tabular}

Nota: Adaptado de "Padrón de Instituciones Educativas y Programas que gestiona la Unidad de Estadística del Ministerio de Educación 2016”, por Ministerio de Educación, Unidad de Estadística Educativa (ESCALE), 2016. Recuperado de http://escale.minedu.gob.pe/padron-de-iiee 


\subsection{Selección del método de proyección}

Se utilizaron los modelos de pronóstico causales de uso más frecuente como es el modelo de regresión lineal puesto que, como mencionan Sapag y Sapag (2008) los modelos causales proyectan el mercado sobre la base de antecedentes cuantitativos históricos, teniendo en cuenta que suponen que los factores condicionantes del comportamiento histórico de las variables del mercado permanecerán estables.

Para ello se utilizó los datos históricos del Padrón de Instituciones Educativas y Programas que gestiona la Unidad de Estadística del Ministerio de Educación 2008-2016, se filtró por distrito y nivel educativo con lo cual se proyectó la población (ver Tabla 41) 
Tabla 41

Matrícula en el sistema educativo privado por distrito y nivel educativo (2008-2016)

\begin{tabular}{|c|c|c|c|c|c|c|c|c|c|c|}
\hline Distrito & $\begin{array}{c}\text { Nivel } \\
\text { Educativo }\end{array}$ & 2008 & 2009 & 2010 & 2011 & 2012 & 2013 & 2014 & 2015 & 2016 \\
\hline \multirow{3}{*}{ Ate } & Inicial & 8,811 & 9,936 & 10,625 & 11,549 & 12,441 & 14,856 & 16,510 & 16,414 & 15,167 \\
\hline & Primaria & 22,599 & 23,984 & 26,775 & 27,986 & 28,753 & 31,258 & 32,953 & 33,584 & 33,279 \\
\hline & Inicial & 4,961 & 5,436 & 5,311 & 5,603 & 5,815 & 6,141 & 5,854 & 5,911 & 5,444 \\
\hline \multirow[t]{2}{*}{ La Molina } & Primaria & 9,853 & 10,086 & 10,126 & 10,691 & 10,734 & 10,707 & 10,583 & 10,719 & 10,342 \\
\hline & Inicial & 3,778 & 4,577 & 5,055 & 4,803 & 5,261 & 6,000 & 5,763 & 6,379 & 5,599 \\
\hline \multirow[t]{2}{*}{$\begin{array}{l}\text { Santa } \\
\text { Anita }\end{array}$} & Primaria & 9,127 & 9,630 & 10,229 & 10,424 & 10,623 & 11,165 & 10,766 & 10,885 & 10,749 \\
\hline & Total & 59,129 & 63,649 & 68,121 & 71,056 & 73,627 & 80,127 & 82,429 & 83,892 & 80,580 \\
\hline
\end{tabular}

Nota: Adaptado de "Magnitudes. Estadística online", por Ministerio de Educación, Unidad de estadística de la calidad educativa (ESCALE), 2016. Recuperado de http://escale.minedu.gob.pe/magnitudes 
Para determinar la precisión y confiabilidad de los resultados de la proyección se determinó el coeficiente de correlación $\mathrm{R}^{2}$, que indica qué tan correcto es el estimado de la ecuación de la regresión. Cuanto más alto sea el $\mathrm{R}^{2}$, más confianza se podrá tener en el estimado de la línea de regresión. Sapag y Sapag (2008)

La proyección de la población se realizó a partir del año 2017 hasta el año 2022, ya que se está evaluando el proyecto por un periodo de 5 años.

A continuación, se muestra la ecuación lineal utilizada para la proyección por cada distrito seleccionado y nivel educativo, así como la población proyectada a partir del 2017.

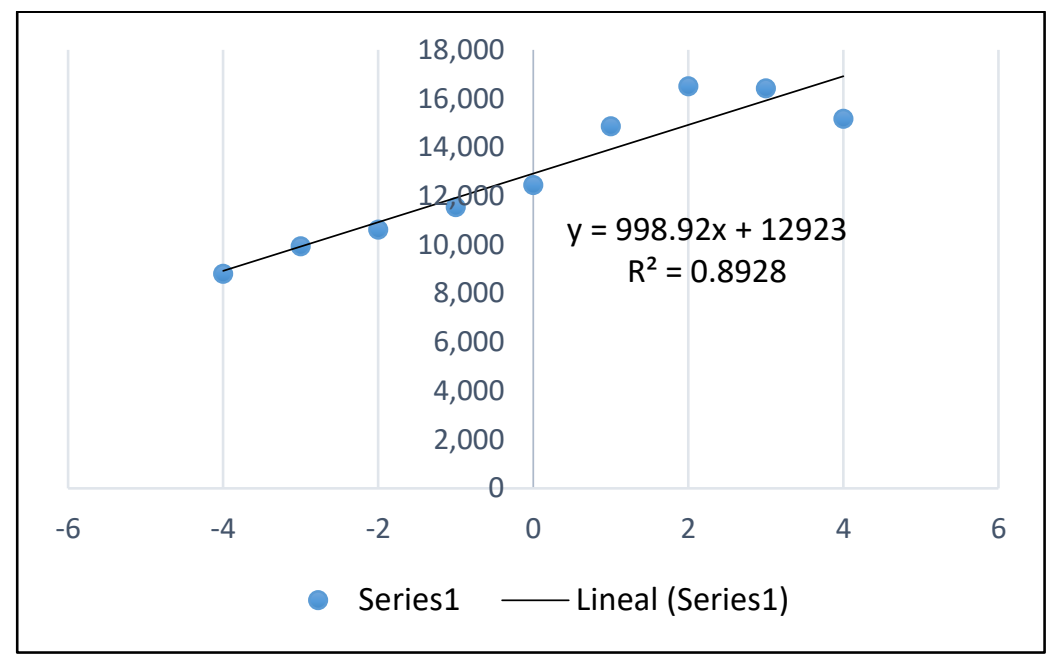

Figura 24. Regresión Lineal Ate Inicial. Elaboración propia.

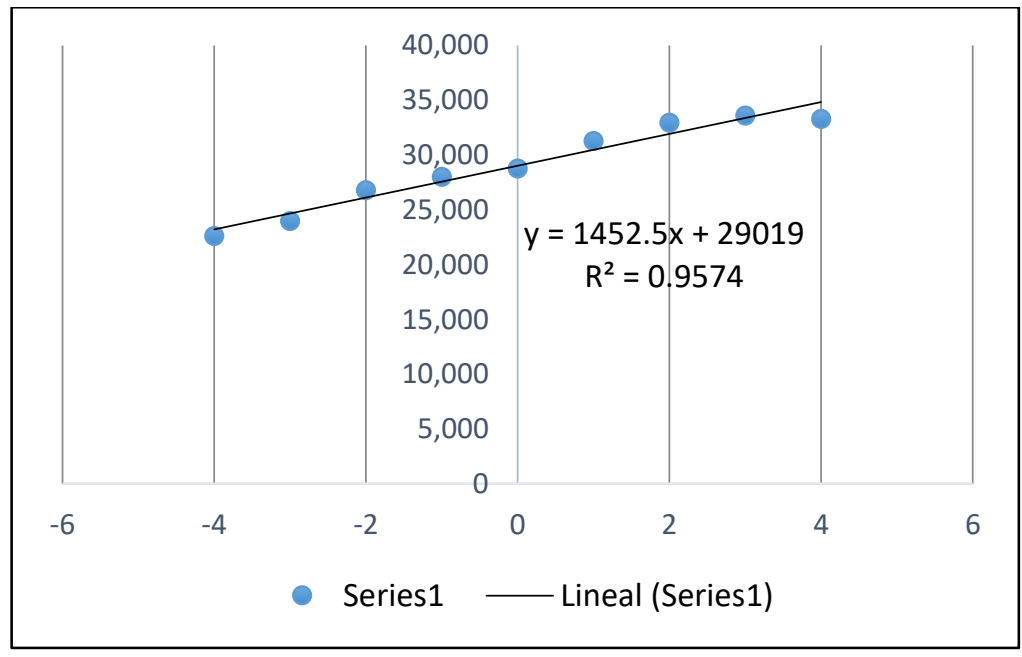

Figura 25. Regresión Lineal Ate Primaria. Elaboración propia 
Tabla 42.

Población proyectada Ate (cantidad de alumnos)

\begin{tabular}{ccc}
\hline Año & Inicial & Primaria \\
\hline 2017 & 17,918 & 36,282 \\
2018 & 18,917 & 37,734 \\
2019 & 19,915 & 39,187 \\
2020 & 20,914 & 40,639 \\
2021 & 21,913 & 42,092 \\
2022 & 22,912 & 43,544 \\
\hline
\end{tabular}

Nota: Adaptado de "Magnitudes. Estadística online", por Ministerio de Educación, Unidad de estadística de la calidad educativa (ESCALE), 2016. Recuperado de http://escale.minedu.gob.pe/magnitudes

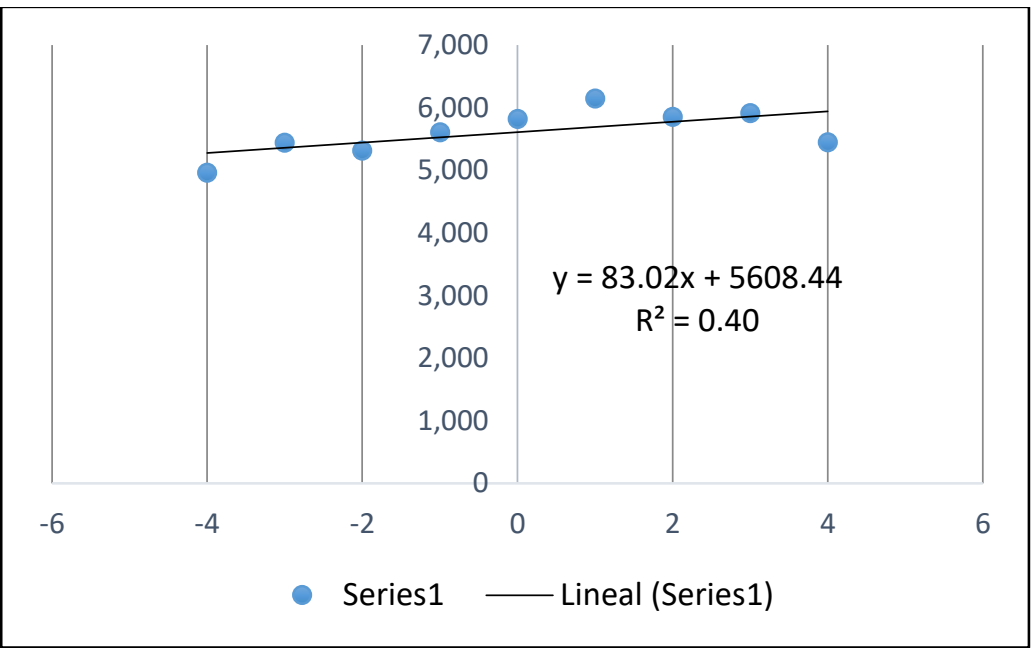

Figura 26. Regresión Lineal La Molina Inicial. Elaboración propia.

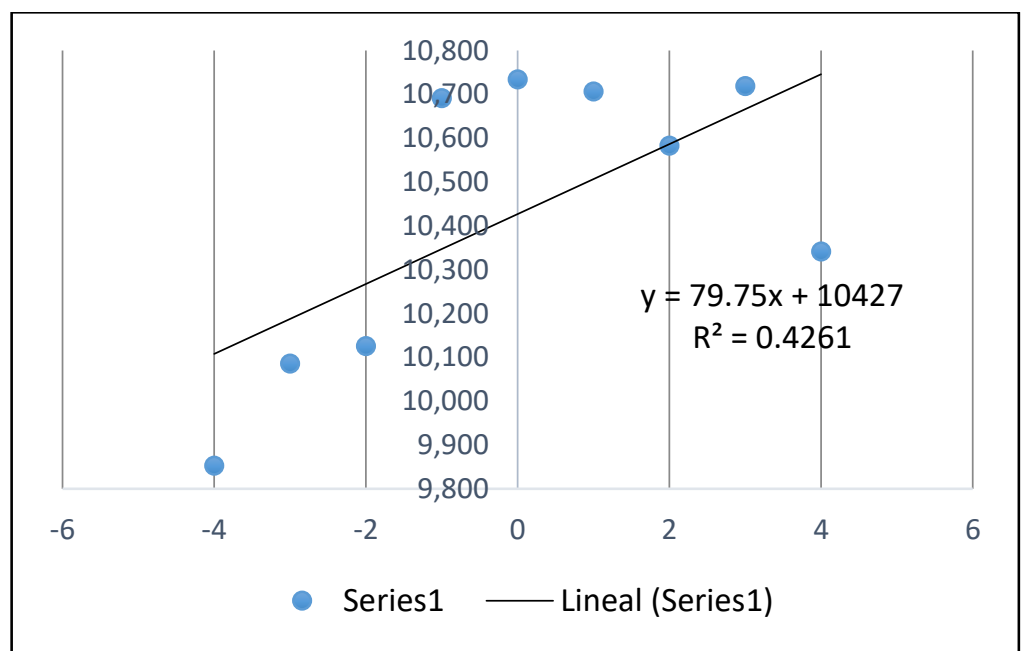

Figura 27. Regresión Lineal La Molina Primaria. Elaboración propia. 
Tabla 43.

Población proyectada La Molina (cantidad de alumnos)

\begin{tabular}{ccc}
\hline Año & Inicial & Primaria \\
\hline 2017 & 6,024 & 10,826 \\
2018 & 6,107 & 10,906 \\
2019 & 6,190 & 10,985 \\
2020 & 6,273 & 11,065 \\
2021 & 6,356 & 11,145 \\
2022 & 6,439 & 11,225 \\
\hline
\end{tabular}

Nota: Adaptado de "Magnitudes. Estadística online", por Ministerio de Educación, Unidad de estadística de la calidad educativa (ESCALE), 2016. Recuperado de http://escale.minedu.gob.pe/magnitudes

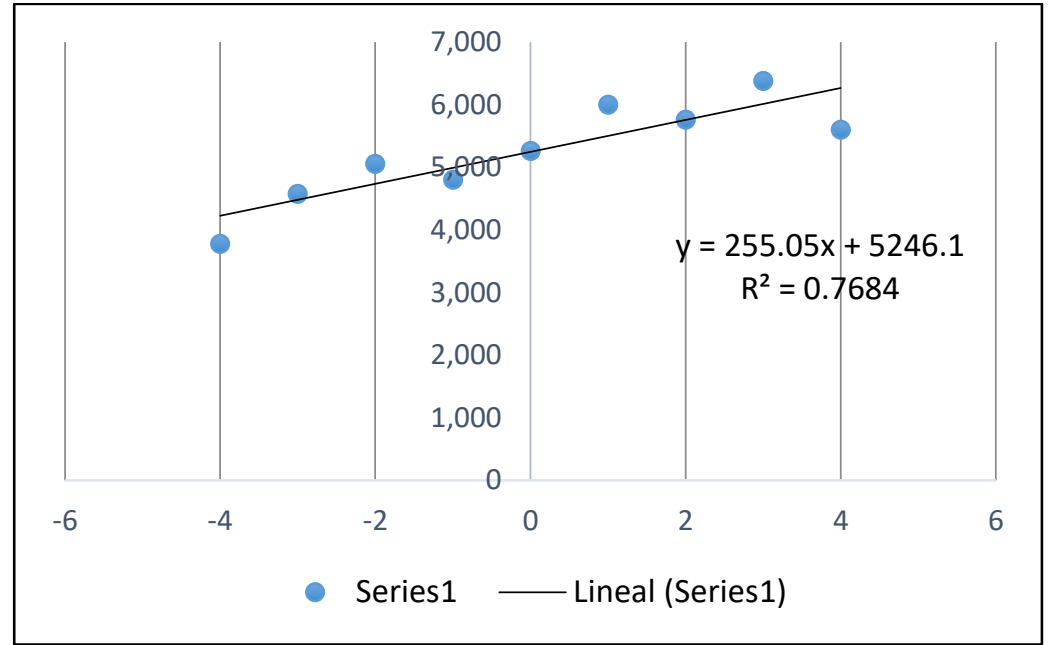

Figura 28. Regresión Lineal Santa Anita Inicial. Elaboración propia.

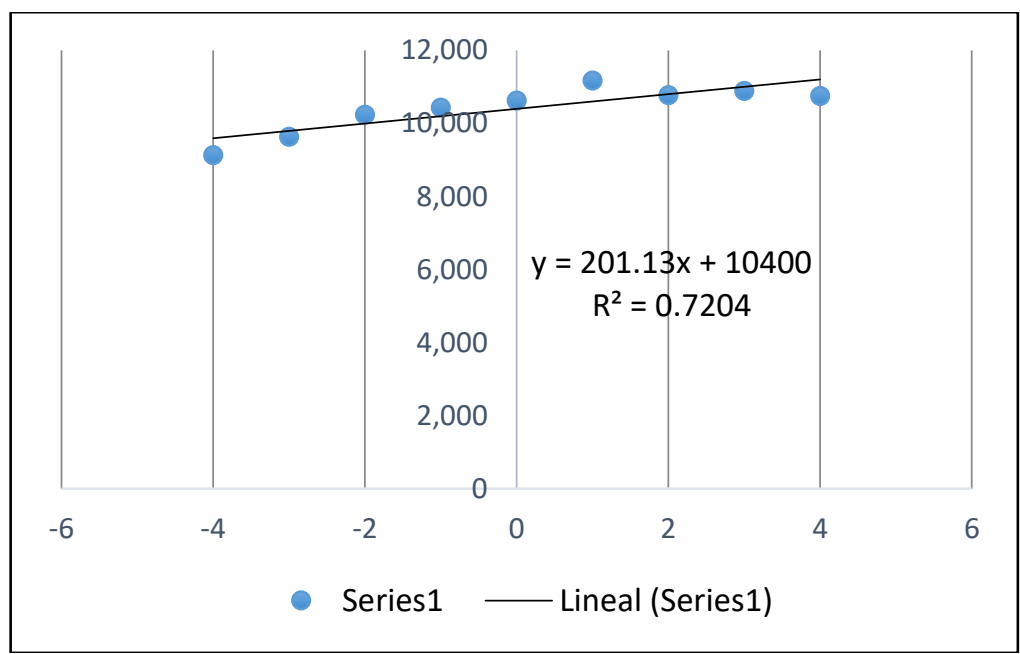

Figura 29. Regresión Lineal Santa Anita Primaria. Elaboración propia. 
Tabla 44.

Población proyectada Santa Anita (cantidad de alumnos)

\begin{tabular}{ccc}
\hline Año & Inicial & Primaria \\
\hline 2017 & 6,521 & 11,406 \\
2018 & 6,776 & 11,607 \\
2019 & 7,031 & 11,808 \\
2020 & 7,287 & 12,009 \\
2021 & 7,542 & 12,210 \\
2022 & 7,797 & 12,411 \\
\hline
\end{tabular}

Nota: Adaptado de "Magnitudes. Estadística online", por Ministerio de Educación, Unidad de estadística de la calidad educativa (ESCALE), 2016. Recuperado de http://escale.minedu.gob.pe/magnitudes

\subsubsection{Mercado potencial}

Según Kotler, P. (2016), el mercado potencial es el conjunto de consumidores que tiene un interés muy elevado por la oferta del mercado, no obstante, el interés no es suficiente para expresar con exactitud el mercado salvo que tenga también un ingreso suficiente y acceso al producto.

El mercado potencial del presente proyecto son los padres con hijos en edad escolar de educación inicial y/o primaria que residan en los distritos de Santa Anita, Ate y/o La Molina y que cuenten con los medios para adquirir el producto ofrecido por el presente proyecto, es decir que pertenezcan al nivel socioeconómico B y C. (Ver tabla 45) 
Tabla 45

Población por distrito proyectada 2017 - 2022 (cantidad de alumnos)

\begin{tabular}{|c|c|c|c|c|c|c|c|}
\hline Distrito & Nivel Educativo & 2017 & 2018 & 2019 & 2020 & 2021 & 2022 \\
\hline \multirow{2}{*}{ Ate } & Inicial & 17,918 & 18,917 & 19,915 & 20,914 & 21,913 & 22,912 \\
\hline & Primaria & 36,282 & 37,734 & 39,187 & 40,639 & 42,092 & 43,544 \\
\hline \multirow{2}{*}{ La Molina } & Inicial & 6,024 & 6,107 & 6,190 & 6,273 & 6,356 & 6,439 \\
\hline & Primaria & 10,826 & 10,906 & 10,985 & 11,065 & 11,145 & 11,225 \\
\hline \multirow[t]{3}{*}{ Santa Anita } & Inicial & 6,521 & 6,776 & 7,031 & 7,287 & 7,542 & 7,797 \\
\hline & Primaria & 11,406 & 11,607 & 11,808 & 12,009 & 12,210 & 12,411 \\
\hline & Total & 88,975 & 92,046 & 95,116 & 98,187 & 101,257 & 104,327 \\
\hline
\end{tabular}

Nota: Adaptado de "Padrón de Instituciones Educativas y Programas que gestiona la Unidad de Estadística del Ministerio de Educación 2016", por Ministerio de Educación,

Unidad de Estadística Educativa (ESCALE), 2016. Recuperado de http://escale.minedu.gob.pe/padron-de-iiee 
Se obtuvo la población escolar de educación inicial y primaria de colegios particulares de los distritos en mención, proyectada al 2022, luego se procedió a calcular el porcentaje de alumnos del NSE B y C, según información obtenida del INEI. (ver Tabla 46).

El mercado potencial $=$ Población proyectada* NSE en \%

Tabla 46.

NSE (\%) por distrito 2016

\begin{tabular}{lccc}
\hline \multicolumn{1}{r}{ Distrito } & NSE B & NSE C & NSE B+NSE C \\
\hline Ate & $11.1 \%$ & $25.70 \%$ & $36.80 \%$ \\
La Molina & $34.3 \%$ & $6.10 \%$ & $40.40 \%$ \\
Santa Anita & $11.1 \%$ & $53.10 \%$ & $64.20 \%$ \\
\hline
\end{tabular}

Nota. Adaptado de "Planos estratificados de Lima Metropolitana a nivel manzana 2016, según ingreso per cápita del hogar, según grupo de pobreza monetaria” por INEI, 2016. Recuperado de https://www.inei.gob.pe/media/MenuRecursivo/publicaciones_digitales/Est/Lib1403/libro.pdf 
Tabla 47.

Mercado potencial proyectado 2017-2022 (cantidad de alumnos)

\begin{tabular}{clcccccc}
\hline \multirow{2}{*}{ Distrito } & \multicolumn{1}{c}{$\begin{array}{c}\text { Nivel } \\
\text { Educativo }\end{array}$} & 2017 & 2018 & 2019 & 2020 & 2021 & 2022 \\
& Inicial & 6,594 & 6,961 & 7,329 & 7,696 & 8,064 & 8,432 \\
\multirow{2}{*}{ Ate } & Primaria & 13,352 & 13,886 & 14,421 & 14,955 & 15,490 & 16,024 \\
& Inicial & 2,434 & 3,505 & 3,553 & 3,600 & 3,648 & 3,696 \\
\multirow{2}{*}{ La Molina } & Primaria & 4,374 & 6,260 & 6,306 & 6,351 & 6,397 & 6,443 \\
& Inicial & 4,187 & 4,350 & 4,514 & 4,678 & 4,842 & 5,005 \\
& Primaria & 7,322 & 7,452 & 7,581 & 7,710 & 7,839 & 7,968 \\
& Total & 38,262 & 42,414 & 43,703 & 44,991 & 46,280 & 47,568 \\
\hline
\end{tabular}

Nota: Adaptado de "Magnitudes. Estadística online", por Ministerio de Educación, Unidad de estadística de la calidad educativa (ESCALE), 2016. Recuperado de http://escale.minedu.gob.pe/magnitudes 


\subsubsection{Mercado disponible}

"El mercado disponible es el conjunto de consumidores que tienen interés, ingresos y acceso a una oferta en particular” Kotler (2016).

Para hallar el mercado disponible se consideraron los resultados del cuestionario aplicado. Se utilizó el porcentaje de personas que, luego de mencionar el concepto del negocio, respondieron que le parece interesante la propuesta de loncheras saludables. La pregunta utilizada fue: Basándose en la descripción del producto ¿Le parece interesante esta propuesta? (ver Tabla 48).

Tabla 48 .

4. Basándose en la descripción del producto, ¿Le parece interesante esta propuesta?

\begin{tabular}{clccc}
\hline \multirow{2}{*}{ Distrito } & $\begin{array}{c}\text { Nivel } \\
\text { Educativo }\end{array}$ & SI & NO & Total \\
\hline \multirow{2}{*}{ Ate } & Inicial & 69 & 3 & 72 \\
& Primaria & 151 & 8 & 159 \\
\multirow{2}{*}{ La Molina } & Inicial & 24 & 2 & 26 \\
& Primaria & 48 & 3 & 51 \\
Santa Anita & Inicial & 24 & 2 & 26 \\
& Primaria & 47 & 3 & 50 \\
\hline
\end{tabular}

Nota: Elaboración propia.

Con lo cual se realizó el cálculo para obtener el factor mercado disponible

Mercado Disponible $=$ Mercado Potencial $*$ Factor mercado disponible

Se tomó como factor de mercado disponible al porcentaje de personas que si les parece interesante la propuesta de negocio. (ver Tabla 49). 
Tabla 49.

Factor de mercado disponible por nivel educativo

\begin{tabular}{clc}
\hline Distrito & Nivel Educativo & $\begin{array}{c}\text { Factor de mercado } \\
\text { disponible }\end{array}$ \\
\hline \multirow{2}{*}{ Ate } & Inicial & $96 \%$ \\
& Primaria & $95 \%$ \\
La Molina & Inicial & $92 \%$ \\
& Primaria & $94 \%$ \\
Santa Anita & Inicial & $92 \%$ \\
& Primaria & $94 \%$ \\
\hline
\end{tabular}

Nota: Elaboración propia. 
Tabla 50

Mercado disponible proyectado 2017-2022 (cantidad de alumnos)

\begin{tabular}{|c|c|c|c|c|c|c|c|}
\hline Distrito & Nivel Educativo & 2017 & 2018 & 2019 & 2020 & 2021 & 2022 \\
\hline \multirow{2}{*}{ Ate } & Inicial & 6,319 & 6,671 & 7,024 & 7,376 & 7,728 & 8,080 \\
\hline & Primaria & 12,680 & 13,187 & 13,695 & 14,203 & 14,710 & 15,218 \\
\hline \multirow{2}{*}{ La Molina } & Inicial & 2,246 & 3,236 & 3,280 & 3,324 & 3,368 & 3,411 \\
\hline & Primaria & 4,116 & 5,892 & 5,935 & 5,978 & 6,021 & 6,064 \\
\hline \multirow{3}{*}{ Santa Anita } & Inicial & 3,865 & 4,016 & 4,167 & 4,318 & 4,469 & 4,620 \\
\hline & Primaria & 6,883 & 7,004 & 7,126 & 7,247 & 7,369 & 7,490 \\
\hline & Total & 36,109 & 40,006 & 41,226 & 42,445 & 43,665 & 44,884 \\
\hline
\end{tabular}

Nota: Elaboración propia. 


\subsubsection{Mercado efectivo}

Para hallar el mercado efectivo se utilizó la pregunta número 8: ¿Cuánto estaría dispuesto a pagar por una lonchera saludable que incluye refresco, sanguche y fruta?, que es el factor precio y la disposición de compra ¿Estaría dispuesto a comprar la lonchera saludable? pregunta 9.

Mercado Efectivo= Mercado Disponible * Factor de mercado efectivo

Factor Mercado efectivo $=$ Factor de Precio*Factor de disposición de compra

Se tomó como factor precio al porcentaje de personas que respondieron que estarían dispuestos a pagar entre el rango 5 a 6 soles, 6 a 7 soles , 7 a 8 soles, 8 a 9 soles y más de 9 soles.

Se sumaron los valores de los porcentajes dando como factor precio 93\%. (Ver Tabla $51)$.

Tabla 51.

8. ¿Cuánto estaría dispuesto a pagar por una lonchera saludable que incluye refresco, sanguche y fruta?

\begin{tabular}{llcc}
\hline \multicolumn{1}{c}{ Respuesta } & Cantidad & Porcentaje \\
\hline a. & Menos de S/3 & 8 & $2 \%$ \\
b. & De S/3 a menos de S/5 & 17 & $4 \%$ \\
c. & De S/5 a menos de S/6 & 247 & $64 \%$ \\
d. & De S/6 a menos de S/7 & 83 & $22 \%$ \\
e. & De S/7 a menos de S/8 & 17 & $4 \%$ \\
f. & De S/8 a menos de S/9 & 9 & $2 \%$ \\
g. Más de S/. 9 soles & 3 & $1 \%$ \\
\multicolumn{2}{c}{ Total } & 384 & $100 \%$ \\
\hline
\end{tabular}

Nota: Elaboración propia. 
Luego se tomó como factor disposición de compra al porcentaje de personas que respondieron definitivamente sí y estarían dispuestos a comprar una lonchera saludable. (ver Tabla 52).

Se sumó los valores de los porcentajes dando como factor disposición compra. (ver Tabla 53).

Tabla 52

9. ¿Estaría dispuesto a comprar una lonchera saludable?

\begin{tabular}{ccccccc}
\hline \multirow{2}{*}{ Distrito } & Nivel Educativo & a. & b & c. & d. & e. \\
& & $\%$ & $\%$ & $\%$ & $\%$ & $\%$ \\
\hline \multirow{2}{*}{ Ate } & Inicial & $58 \%$ & $31 \%$ & $7 \%$ & $3 \%$ & $1 \%$ \\
& Primaria & $45 \%$ & $52 \%$ & $3 \%$ & $1 \%$ & $0 \%$ \\
La Molina & Inicial & $38 \%$ & $46 \%$ & $8 \%$ & $8 \%$ & $0 \%$ \\
& Primaria & $44 \%$ & $46 \%$ & $2 \%$ & $6 \%$ & $2 \%$ \\
& Inicial & $19 \%$ & $62 \%$ & $15 \%$ & $4 \%$ & $0 \%$ \\
& Primaria & $41 \%$ & $39 \%$ & $10 \%$ & $4 \%$ & $6 \%$ \\
& Total & $45 \%$ & $46 \%$ & $5 \%$ & $3 \%$ & $1 \%$ \\
\hline
\end{tabular}

Nota: Elaboración propia.

a Leyenda: a. Definitivamente si, b. Probablemente sí, c. Me es indiferente, d. Probablemente no, e. Definitivamente no.

Tabla 53

Factor disposición de compra por distrito y nivel educativo

\begin{tabular}{|c|c|c|}
\hline Distrito & Nivel Educativo & Factor disposición de compra \\
\hline \multirow{2}{*}{ Ate } & Inicial & $89 \%$ \\
\hline & Primaria & $97 \%$ \\
\hline \multirow{2}{*}{ La Molina } & Inicial & $85 \%$ \\
\hline & Primaria & $90 \%$ \\
\hline \multirow{2}{*}{ Santa Anita } & Inicial & $81 \%$ \\
\hline & Primaria & $80 \%$ \\
\hline
\end{tabular}

Nota: Elaboración propia. 
Sin embargo, para tener un cálculo más real y conservador, se empleó la escala de intención de compra de McDaniel C. y Gates R. (2016), donde toma un 70\% de los que "sin duda comprarán", 35\% de los que "probablemente comprarán", 10\% de los que “probablemente no comprarán” y $0 \%$ de los que "sin duda no comprarán.

\section{Tabla 54}

Factor disposición de compra por distrito y nivel educativo corregido

\begin{tabular}{|c|c|c|}
\hline Distrito & Nivel Educativo & Factor disposición de compra \\
\hline \multirow{2}{*}{ Ate } & Inicial & $52 \%$ \\
\hline & Primaria & $50 \%$ \\
\hline \multirow{2}{*}{ La Molina } & Inicial & $44 \%$ \\
\hline & Primaria & $48 \%$ \\
\hline \multirow{2}{*}{ Santa Anita } & Inicial & $35 \%$ \\
\hline & Primaria & $43 \%$ \\
\hline
\end{tabular}

Nota: Elaboración propia.

Luego se calculó el factor mercado efectivo

Factor Mercado efectivo $=$ Factor de Precio*Factor de disposición de compra

Tabla 55.

Factor mercado efectivo por distrito y nivel educativo

\begin{tabular}{clc}
\hline \multirow{2}{*}{ Distrito } & \multicolumn{1}{c}{$\begin{array}{c}\text { Nivel } \\
\text { Educativo }\end{array}$} & $\begin{array}{c}\text { Factor de mercado } \\
\text { Efectivo }\end{array}$ \\
& Inicial & $48 \%$ \\
\multirow{2}{*}{ Ate } & Primaria & $46 \%$ \\
& Inicial & $41 \%$ \\
\multirow{2}{*}{ La Molina } & Primaria & $44 \%$ \\
& Inicial & $33 \%$ \\
\multirow{2}{*}{ Santa Anita } & Primaria & $40 \%$ \\
\hline
\end{tabular}

Nota: Elaboración propia. 
Tabla 56.

Mercado efectivo proyectado 2017-2022 (Cantidad de alumnos)

\begin{tabular}{cccccccc}
\hline Distrito & Nivel Educativo & 2017 & 2018 & 2019 & 2020 & 2021 & 2022 \\
\hline \multirow{2}{*}{ Ate } & Inicial & 3,060 & 3,231 & 3,402 & 3,572 & 3,743 & 3,914 \\
& Primaria & 5,879 & 6,114 & 6,349 & 6,585 & 6,820 & 7,055 \\
\multirow{3}{*}{ La Molina } & Inicial & 921 & 1,326 & 1,344 & 1,362 & 1,380 & 1,398 \\
& Primaria & 1,828 & 2,616 & 2,635 & 2,655 & 2,674 & 2,693 \\
\multirow{2}{*}{ Santa Anita } & Inicial & 1,278 & 1,328 & 1,378 & 1,428 & 1,478 & 1,528 \\
& Primaria & 2,763 & 2,812 & 2,861 & 2,909 & 2,958 & 3,007 \\
& Total & 15,730 & 17,428 & 17,970 & 18,512 & 19,054 & 19,596 \\
\hline
\end{tabular}

Nota: Elaboración propia. 


\subsubsection{Mercado objetivo}

Según la guía de aproximaciones de porcentaje de participación de mercado (ver Tabla 56), el porcentaje de participación de mercado de Lunch Kids está entre 5\%-10\%, pero por ser una empresa nueva y de acuerdo con la capacidad instalada se comenzará con un $4.5 \%$.

Asimismo, para el crecimiento anual se tomó como base el promedio de crecimiento del sector otros servicios, de los últimos 10 años. (ver Tabla 57) 
Tabla 57.

Guía de aproximaciones de porcentaje de participación de mercado

\begin{tabular}{llll}
\hline $\begin{array}{l}\text { Qué tan grandes son tus } \\
\text { competidores }\end{array}$ & $\begin{array}{l}\text { Qué tantos competidores } \\
\text { tienes }\end{array}$ & $\begin{array}{l}\text { Qué tan similares son tus productos a } \\
\text { los suyos }\end{array}$ & \\
\hline & & Suál parece ser su porcentaje \\
\hline 1 Grandes & Muchos & Similares & $0-0.5 \%$ \\
2 Grandes & Algunos & Similares & $0-0.5 \%$ \\
3 Grandes & uno & Diferentes & $0.5 \%-5 \%$ \\
4 Grandes & Muchos & Diferentes & $0.5 \%-5 \%$ \\
5 Grandes & Algunos & Diferentes & $0.5 \%-5 \%$ \\
6 Grandes & uno & Similares & $10 \%-15 \%$ \\
7 Pequeños & Muchos & Similares & $5 \%-10 \%$ \\
8 Pequeños & Algunos & Diferentes & $10 \%-15 \%$ \\
9 Pequeños & Muchos & Diferentes & $10 \%-15 \%$ \\
10 Pequeños & Algunos & Similares & $20 \%-30 \%$ \\
11 Pequeños & Uno & Diferentes & $30 \%-50 \%$ \\
12 Pequeños & Uno & Sin competencia & $40 \%-80 \%$ \\
13 Sin competencia & Sin competencia & $80 \%-100 \%$ \\
\hline
\end{tabular}

Nota. Adaptado de "Calcula tu participación de mercado y punto de equilibrio" por Entrepreneur, 2011. Recuperado de https://www.entrepreneur.com/article/264164 
Tabla 58.

Producto bruto interno por sectores productivos (variaciones porcentuales reales) -

\section{Otros Servicios}

\begin{tabular}{cc}
\hline Año & Variación Porcentual \\
\hline 2007 & $8.7 \%$ \\
2008 & $8.7 \%$ \\
2009 & $3.6 \%$ \\
2010 & $8.8 \%$ \\
2011 & $7.0 \%$ \\
2012 & $7.3 \%$ \\
2013 & $6.1 \%$ \\
2014 & $5.1 \%$ \\
2015 & $4.1 \%$ \\
2016 & $4.0 \%$ \\
Variación Promedio & $6.3 \%$ \\
\hline
\end{tabular}

Nota. Adaptado de "BCRP Data. otros servicios", por Banco Central de Reserva del Perú, 2017. Recuperado de https://estadisticas.bcrp.gob.pe/estadisticas/series/anuales/resultados/PM04981AA/html/2007/2017/

Luego se calculó la tasa de mercado objetivo para cada año:

Tasa Mercado Objetivo $($ año 1) = Participación de mercado inicial

Tasa Mercado Objetivo (prox. años $)=$ Tasa año anterior $*(1+$ Crecimiento anual sector $)$

Tabla 59

Tasas de mercado objetivo (2017-2022)

\begin{tabular}{ccccccc}
\hline Año & 2017 & 2018 & 2019 & 2020 & 2021 & 2022 \\
\hline $\begin{array}{l}\text { Tasas de } \\
\text { mercado } \\
\text { objetivo }\end{array}$ & $4.5 \%$ & $4.79 \%$ & $5.09 \%$ & $5.41 \%$ & $5.75 \%$ & $6.12 \%$ \\
\hline Nota: Elaboración propia. & & & & & \\
\hline
\end{tabular}

Nota: Elaboración propia. 
Tabla 60.

Mercado objetivo proyectado 2017-2022 (cantidad de alumnos)

\begin{tabular}{clcccccc}
\hline \multirow{2}{*}{ Distrito } & $\begin{array}{c}\text { Nivel } \\
\text { Educativo }\end{array}$ & 2017 & 2018 & 2019 & 2020 & 2021 & 2022 \\
& Inicial & 138 & 155 & 173 & 193 & 215 & 239 \\
\multirow{2}{*}{ Ate } & Primaria & 265 & 293 & 323 & 356 & 392 & 432 \\
& Inicial & 41 & 63 & 68 & 74 & 79 & 86 \\
\multirow{5}{*}{ Santa Molina Anita } & Primaria & 82 & 125 & 134 & 144 & 154 & 165 \\
& Inicial & 58 & 64 & 70 & 77 & 85 & 94 \\
& Primaria & 124 & 135 & 146 & 157 & 170 & 184 \\
& Total & 708 & 834 & 914 & 1,002 & 1,096 & 1,199 \\
\hline
\end{tabular}

Nota: Elaboración propia.

\subsection{Pronóstico de ventas}

Para calcular la demanda se requiere conocer la frecuencia de compra de las loncheras saludables del público objetivo. Para lo cual se utilizó los resultados de la pregunta 11: Del Periodo escolar ¿Con qué frecuencia estaría dispuesto a consumir el programa de loncheras saludables? Se consideró 9 meses al año, ya que hay 2 meses de vacaciones, enero y febrero, 2 semanas de vacaciones en julio y 2 semanas en diciembre (ver Tabla 61).

Tabla 61.

Del período escolar ¿Con qué frecuencia estaría dispuesto a consumir el programa de loncheras saludables?

\begin{tabular}{lcccc}
\hline \multicolumn{1}{c}{ Frecuencia } & & $\%$ & $\begin{array}{c}\text { Frecuencia } \\
\text { Anualizada }\end{array}$ & Ponderado \\
\hline a. Una vez al mes. & 3 & $1 \%$ & 1.8 & 0.01 \\
b. Una vez cada 15 días. & 9 & $2 \%$ & 3.6 & 0.08 \\
c. Una vez a la semana. & 11 & $3 \%$ & 7.2 & 0.21 \\
d. 2 veces a la semana. & 27 & $7 \%$ & 14.4 & 1.01 \\
e. 3 veces a la semana. & 28 & $7 \%$ & 21.6 & 1.58 \\
f. 4 veces a la semana & 76 & $20 \%$ & 28.8 & 5.70 \\
g. 5 veces a la semana. & 230 & $60 \%$ & 36 & 21.56 \\
Total & 384 & $100 \%$ & & 30.15 \\
\hline
\end{tabular}

Nota: Elaboración propia. 
Tabla 62.

Cuadro resumen ventas por año (cantidad de loncheras)

\begin{tabular}{lccccc}
\hline $\begin{array}{l}\text { Cuadro resumen } \\
\text { Ventas por año }\end{array}$ & 2018 & 2019 & 2020 & 2021 & 2022 \\
\hline Mercado Objetivo & 834 & 914 & 1,002 & 1,096 & 1,199 \\
Inicial & 282 & 312 & 344 & 380 & 418 \\
Primaria & 552 & 603 & 657 & 716 & 780 \\
Frecuencia promedio de compra por año & 30 & 30 & 30 & 30 & 30 \\
Demanda Anual & 25,147 & 27,572 & 30,203 & 33,056 & 36,150 \\
Inicial & 8,493 & 9,397 & 10,382 & 11,453 & 12,619 \\
Primaria & 16,655 & 18,175 & 19,821 & 21,603 & 23,531 \\
Demanda Mensual & 2794 & 3064 & 3356 & 3673 & 4017 \\
Inicial & 944 & 1044 & 1154 & 1273 & 1402 \\
Primaria & 1851 & 2019 & 2202 & 2400 & 2615 \\
Demanda Semanal & 699 & 766 & 839 & 918 & 1004 \\
Inicial & 236 & 261 & 288 & 318 & 351 \\
Primaria & 463 & 505 & 551 & 600 & 654 \\
\hline
\end{tabular}

Nota: Elaboración propia.

Tabla 63.

Precio de paquetes semanales por año

$\begin{array}{llll}2018 & 2019 & 2020 & 2021\end{array}$

Inicial S/. $25.00 \quad$ S/. $25.00 \quad$ S/. $25.00 \quad$ S/. $25.00 \quad$ S/. 25.00

$\begin{array}{lllllll}\text { Primaria } & \text { S/. } 30.00 & \text { S/. } 30.00 & \text { S/ } 30.00 & \text { S/. } 30.00 & \text { S/. } 30.00\end{array}$

Nota: Elaboración propia. 
Tabla 64.

Programa de ventas por año

\begin{tabular}{|c|c|c|c|c|c|c|c|c|c|c|}
\hline \multirow{2}{*}{$\begin{array}{l}\text { Precio } \\
\text { Inicial }\end{array}$} & \multicolumn{2}{|c|}{2018} & \multicolumn{2}{|c|}{2019} & \multicolumn{2}{|c|}{2020} & \multicolumn{2}{|c|}{2021} & \multicolumn{2}{|c|}{2022} \\
\hline & $\mathrm{S} /$. & $179,932.12$ & $\mathrm{~S} /$. & $199,088.72$ & S/. & $219,950.34$ & $\mathrm{~S} /$. & $242,656.15$ & $\mathrm{~S} /$. & $267,356.06$ \\
\hline Primaria & $\mathrm{S} /$. & $423,423.79$ & $\mathrm{~S} /$. & $462,075.31$ & S/. & $503,924.68$ & $\mathrm{~S} /$. & $549,221.95$ & $\mathrm{~S} /$. & $598,236.01$ \\
\hline Total & $\mathrm{S} /$. & $603,355.92$ & $\mathrm{~S} /$. & $661,164.03$ & $\mathrm{~S} /$. & $723,875.02$ & $\mathrm{~S} /$. & $791,878.09$ & S/. & $865,592.07$ \\
\hline
\end{tabular}

Nota: Elaboración propia. 


\subsection{Aspectos críticos que impactan el pronóstico de ventas}

Los siguientes factores, pueden afectar las proyecciones del presente plan de negocio por lo que deben ser considerados a fin de establecer medidas de contingencia.

Entre los principales aspectos se pueden mencionar:

- La estabilidad económica del país, que puede limitar la inversión privada y en consecuencia la generación de empleo. Ello afectaría directamente en la proyección de ventas del proyecto de negocio ya que el público objetivo priorizaría gastos y prepararía sus alimentos en casa.

- Si bien es cierto que el mercado de loncheras saludables aún no tiene mucha oferta, la demanda tiene tendencia creciente por lo que puede surgir competencia que obligue a abaratar precios y disminuir el margen de ganancia.

- Inversión y actualización constante de tecnología, ya que es el medio más rápido y moderno de llegar al cliente y tener visibilidad entre sus contactos.

- La creciente tendencia a una alimentación saludable, principalmente para proteger a sus hijos de posibles enfermedades y/o trastornos alimenticios que pudieran afectar su desarrollo físico e intelectual.

- El actual estilo de vida acelerado donde ya no solo trabaja el padre sino también la madre y buscan optimizar tiempos y experiencias de servicios que simplifiquen sus vidas. 


\section{Capítulo V. Ingeniería del proyecto}

Según Sapag y Sapag (2008), la ingeniería del proyecto involucra los aspectos de mayor relevancia para la implementación del proyecto de negocio.

Es por ello que, con la ayuda de la información recopilada en los capítulos anteriores, el presente capítulo permitió determinar el equipamiento y recursos necesarios para el óptimo desarrollo de procesos a fin de lograr ofrecer un servicio eficiente y eficaz.

\subsection{Estudio de ingeniería}

La elección de un proceso productivo adecuado influyó en la necesidad de equipos y maquinaria necesaria para el desempeño de actividades, así como la necesidad de espacios para la disposición de la planta.

\subsubsection{Modelamiento y selección de procesos productivos}

Según Sapag y Sapag (2008) "El proceso de producción se define como la forma en que una serie de insumos se transforman en productos mediante la participación de una determinada tecnología (combinación de mano de obra, maquinaria, métodos y procedimientos de operación, etcétera)" (p. 145).

Los siguientes flujos de procesos productivos, muestran la elaboración de las tres líneas de servicio ofrecidas en el proyecto de negocio:

- Sánguches.

- Jugos y refrescos.

- Postres y ensaladas. 


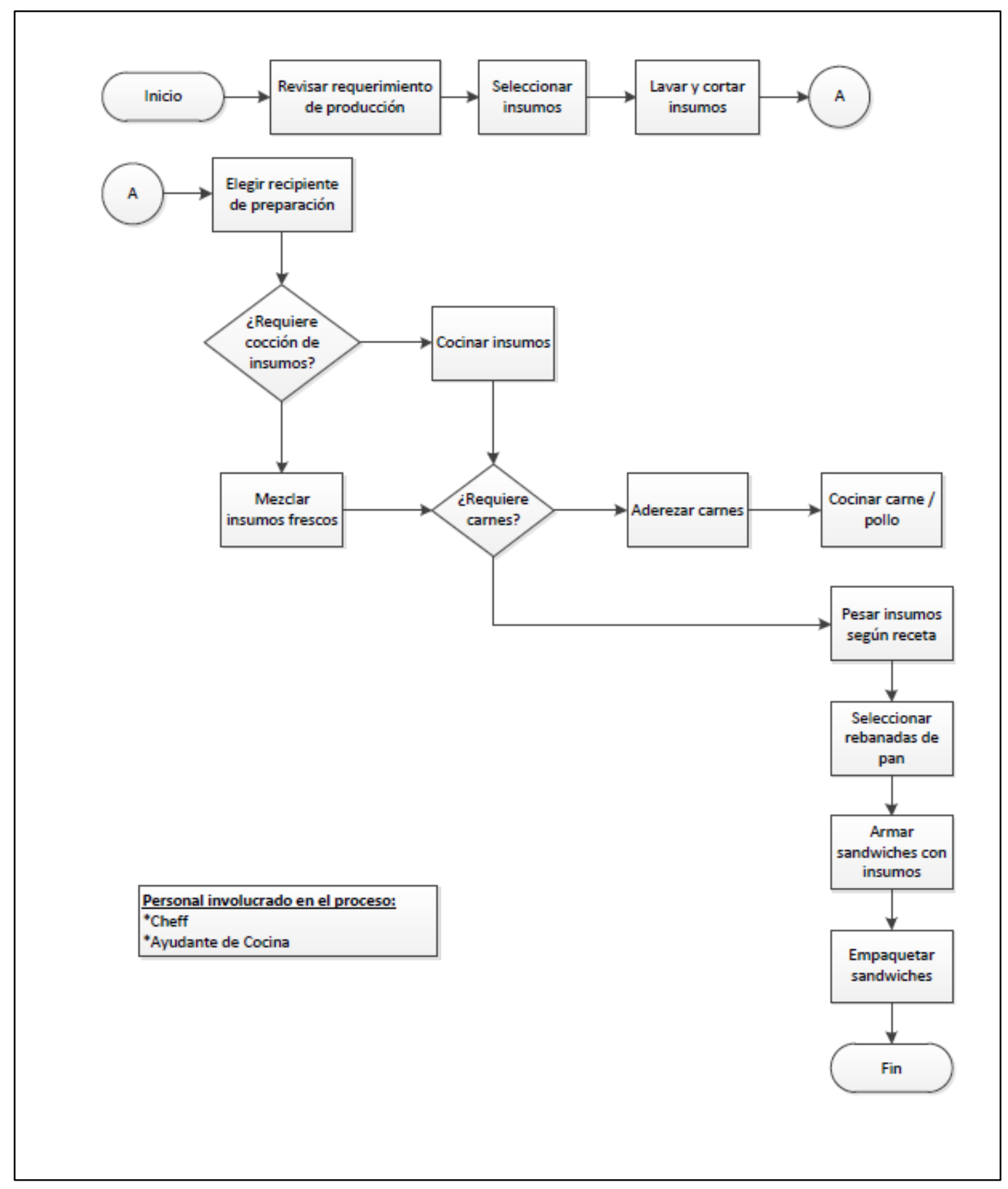

Figura 30. Flujo de preparación de sanguches. Elaboración propia. 


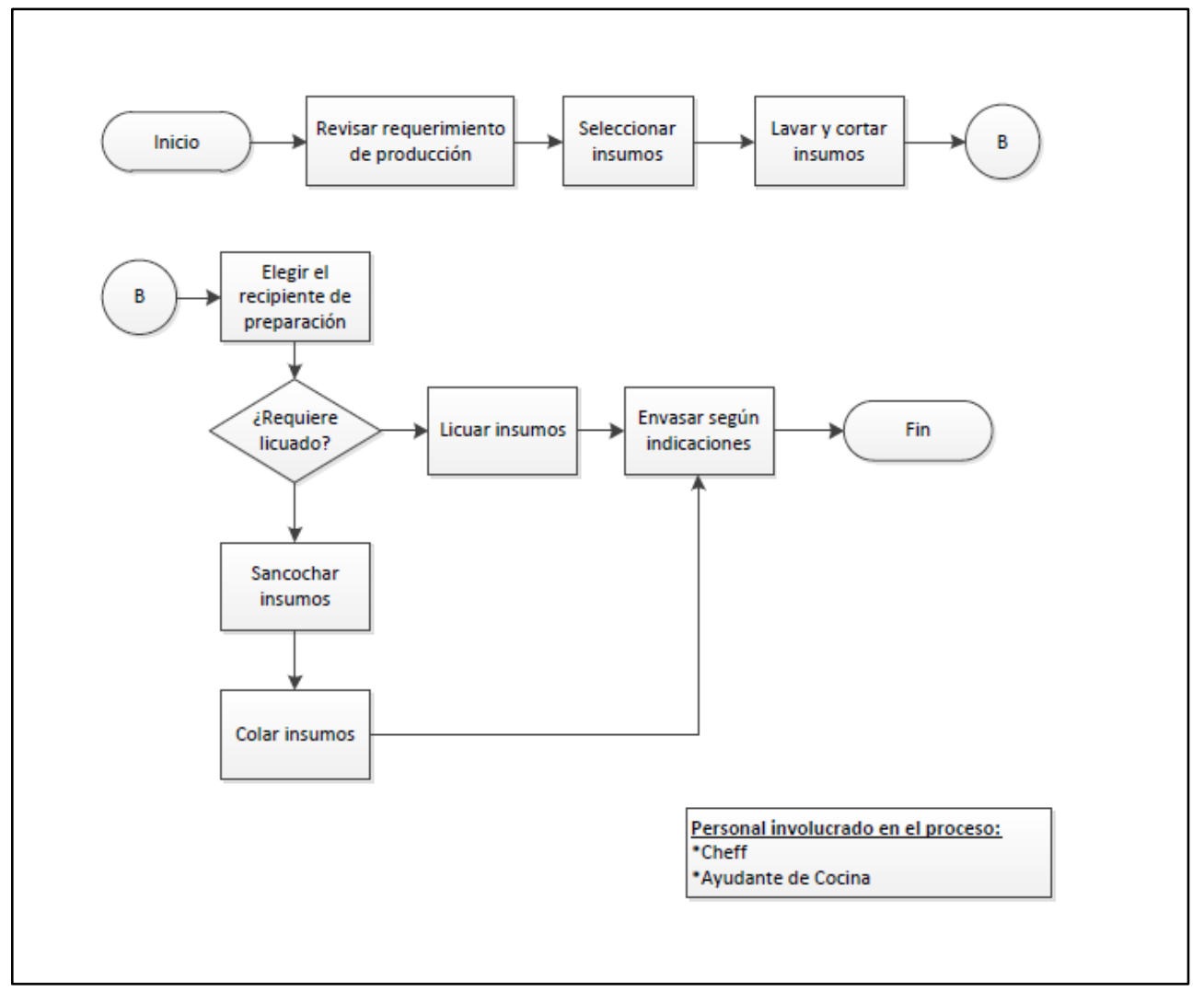

Figura 31. Flujo de preparación de jugos y/o refrescos. Elaboración propia.

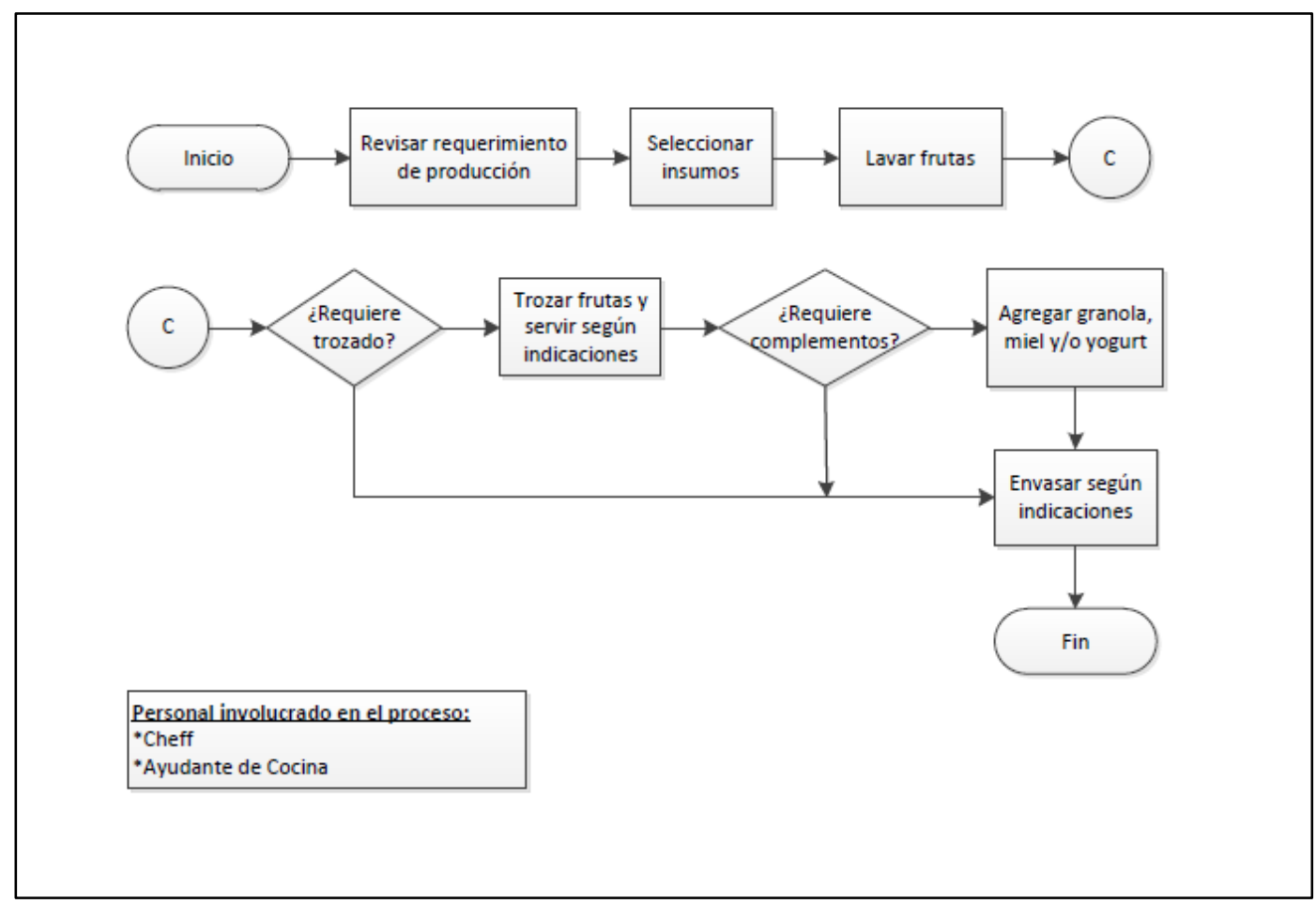

Figura 32. Flujo de preparación de postre y/o ensalada de fruta. Elaboración propia. 
A fin de optimizar costos, se ha considerado tener en cuenta la estacionalidad de frutas a nivel nacional, publicado por APEGA y proporcionado por el Ministerio de Agricultura y la Universidad Nacional Agraria La Molina.

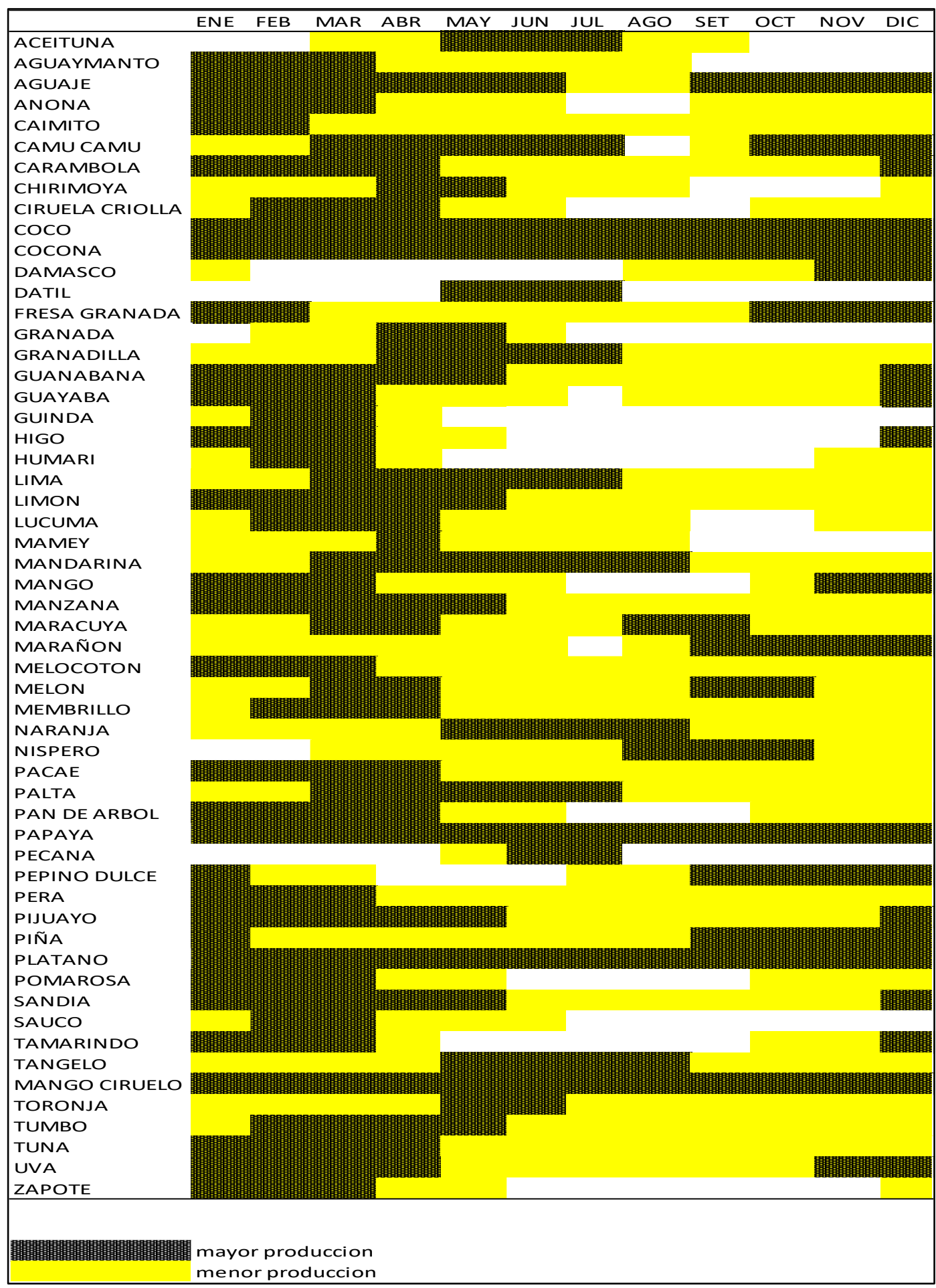

Figura 33. Calendario de estacionalidad de frutas a nivel nacional. Adaptado de "Calendario de frutas" por Vitality Perú, 2019. Recuperado de https://vitalityperu.com/calendario-de-frutas 


\subsubsection{Selección del equipamiento}

Según Sapag y Sapag (2008) "La alternativa tecnológica que se seleccione afectará directamente la rentabilidad del proyecto. Por ello, en vez de seleccionar la tecnología más avanzada, deberá elegirse aquella que optimice los resultados.” (p. 146).

Para iniciar el presente proyecto de negocio, y cumplir en forma óptima con los procesos de producción establecidos, se ha considerado invertir en los siguientes equipos:

Equipos de cocina

- Campana extractora industrial, para atrapar la grasa, humo y calor generados al momento de la cocción de alimentos.

- Cocina industrial con horno, indispensable para la cocción de alimentos

- Lavaderos industriales, para el lavado de utensilios utilizados en cada proceso y para el lavado de alimentos como carnes, verduras y frutas.

- Mesas de trabajo, para la preparación de los alimentos y envasado de los productos terminados.

- Congeladores, para la conservación de alimentos como carnes y frutas y verduras.

- Refrigeradora, para la conservación de alimentos menores como aderezos, yogurt, líquidos, etc.

- Licuadoras semi industriales, para el licuado de jugos.

- Horno Microondas

- Balanza para el pesado de porciones de recetas.

- Mesa auxiliar rodante - GP- INOX

- Guardaropas - locker metálico de 04 puertas

- Empaquetadora VAC Oster Food Sav-er V2860 


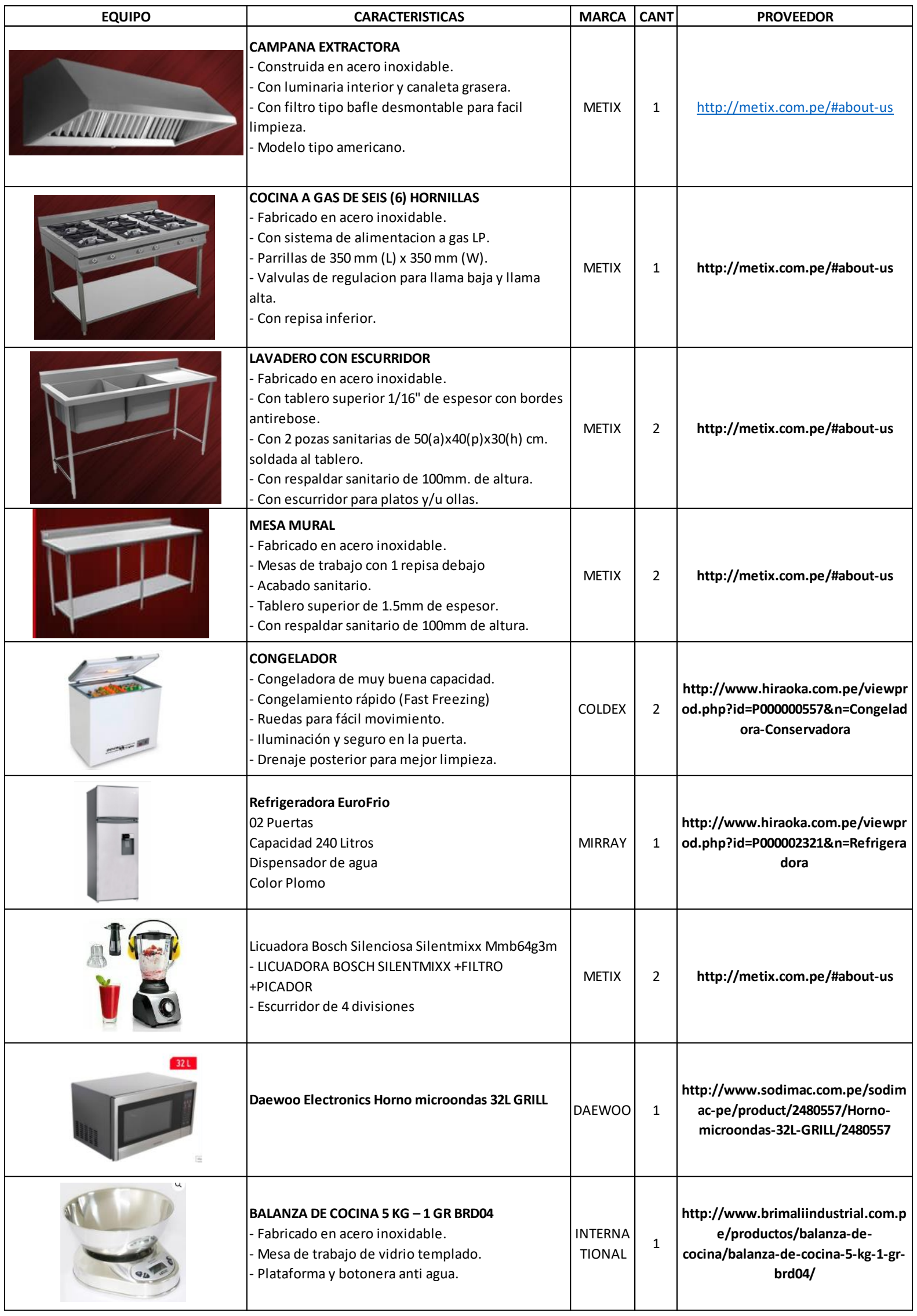

Figura 34. Equipos de Cocina. Elaboración propia. 
Utensilios ligeros y batería de cocina

- Estante para utensilios de cocina.

- Alacena para el almacenaje de empaques utilizados.

- 1 rallador

- Jarras de $1 \mathrm{lt}$

- 1 balanza matfer de hasta $10 \mathrm{~kg}$

- 1 navaja para corte de pan

- Caja conservadora Fasa Freeze \# 15lt

- Bowl de mezcla KMW $33 \mathrm{~cm}$

- 2 Bowl de mezcla KMW 27 cm

- 2 Bowl KMW Deluxe 1.3 lt

- 2 par de guantes de horno

- Olla Aro Sopera 36x28 4mm 28 Lt

- Olla Aro Salsera 26x18 3mm 8 Lt

- Botellas de Plástico 350 ml

- Bolsa sanguchera biodegradable

- Bolsa papel kraft nro 4

- Taper de fruta

- 2 Sartén Aro aluminio 4mm $40 \mathrm{~cm}$

- 2 Sartén Aro aluminio 3mm 28 cm

- 2 Espumaderas prof Facusa M/B

- 2 Tabla luna blas capi RECT 35x24 cm

- 2 Cuchillo Facusa Carnicero M/BL10

- 2 Cuchillo Facusa Carnes Pro M/BL8

- Botellas de Plástico 350 ml 
- Papel antigrasa para envolver alimentos

- Bolsas Papel Kraft Graso Jackets

- 2 Tachos Torito Basa con ruedas 801t

- 2 dispensadores de jabón

- Carritos para trapear, con trapeador

- Pack de escoba y recogedor DKASA

- 1 dispensadores de detergente líquido

- 1 mesa auxiliar rodante

- Guantes limpieza

Equipos Administrativos

- Computadora Oficina MIRAY: CPU + Monitor - HIRAOKA

- 5 cámaras de vigilancia - HIRAOKA

- Impresora Multifuncional HP Laser Jet - HIRAOKA

- Teléfono Fijo Vtech - HIRAOKA

Artículos de administrativos

- Escritorio cómputo

- Calculadora

- Perforador

- Sacagrapas

- Porta Clips

- Sello

- Porta Lapiceros

- Cuchilla 
- Tacho oficinas

- Tijeras

- Bandejas porta documentos

- Engrapador

- Sillas giratorias

\subsubsection{Layout}

Dado que el público objetivo del presente proyecto de negocio se encuentra ubicado en los distritos de Santa Anita, Ate y La Molina, el local se encuentra estratégicamente ubicado en el distrito de Ate, por su cercanía al Mercado Mayorista de Santa Anita.

A continuación, se muestra el layout del local completo que comprende un total de $90 \mathrm{~m}^{2}$, en los cuales se ha tratado de distribuir los ambientes de forma que se optimice tiempo en la manipulación de insumos y/o desplazamiento de personal.

Entre los ambientes se encuentran:

- Cocina (principal área de trabajo)

- Vestidores con ducha/baño para el personal masculino y femenino

- Oficina administrativa

- Baño de visita

- Estacionamiento 


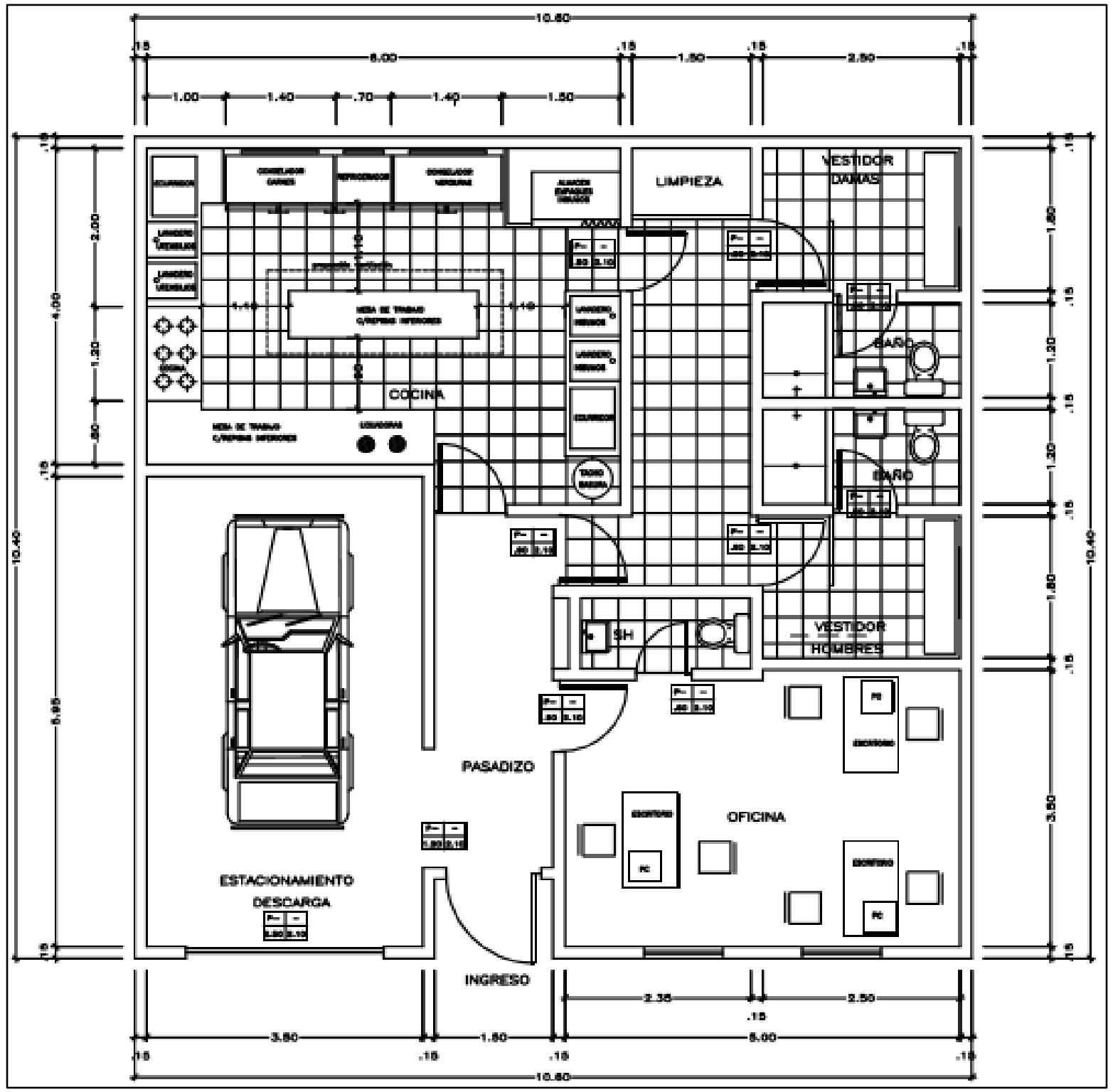

Figura 35. Layout del local. Elaboración propia.

Asimismo, considerando que la cocina es la principal área de trabajo del proyecto de negocio, se ha tenido especial cuidado en cuanto al layout de dicho ambiente, de tal forma que cada proceso se pueda realizar sin obstaculizar el desarrollo del otro. 


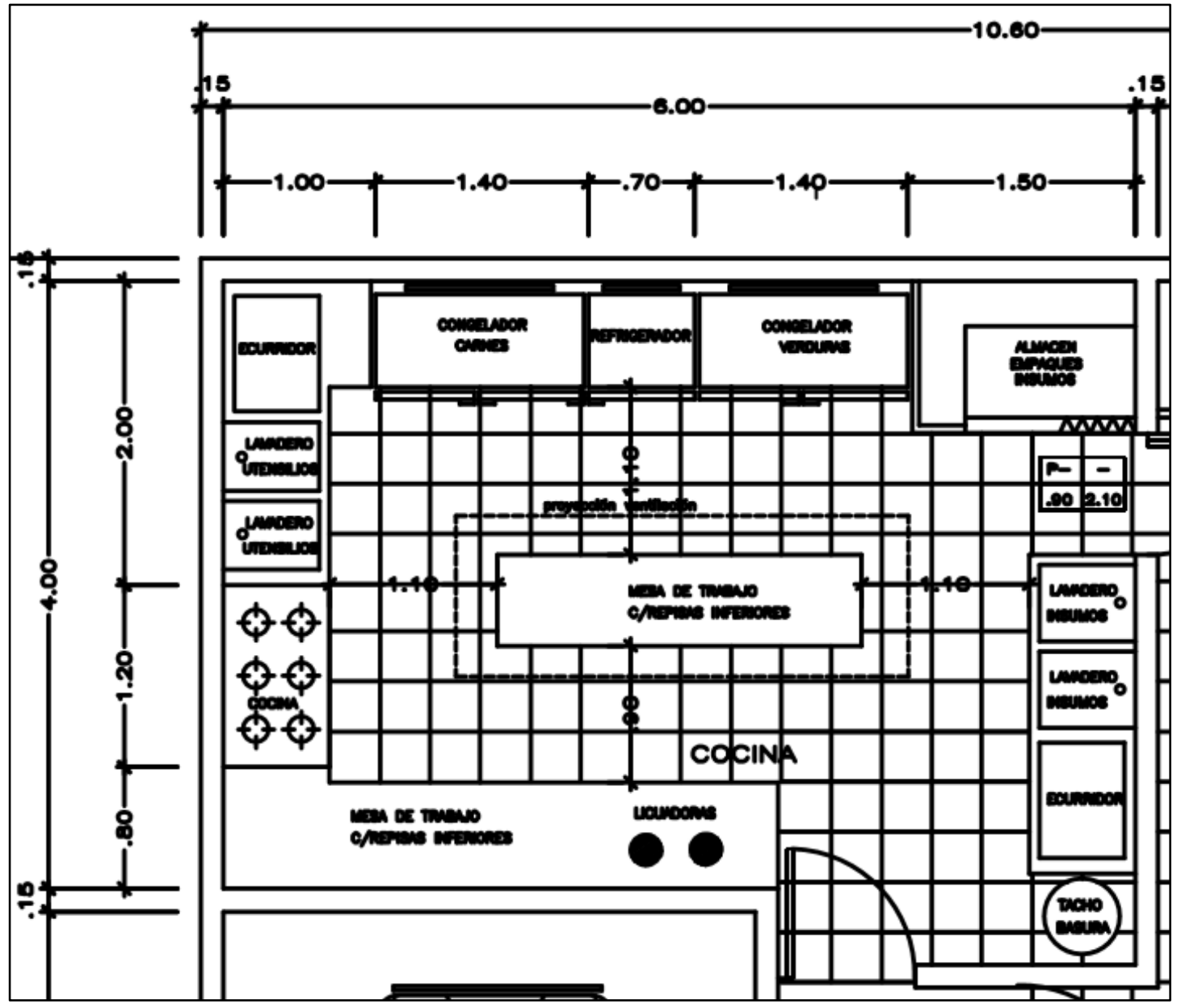

Figura 36. Layout de la cocina. Elaboración propia.

\subsubsection{Distribución de equipos y maquinarias}

La eficiente ubicación de los equipos en el área de cocina, optimizarán procesos y reducirán tiempos, por lo tanto, incrementará la producción, por ello se ha tratado de dividir los ambientes en: a) caliente, b) aseo, c) frío, y d) congelado, según siguiente detalle: 


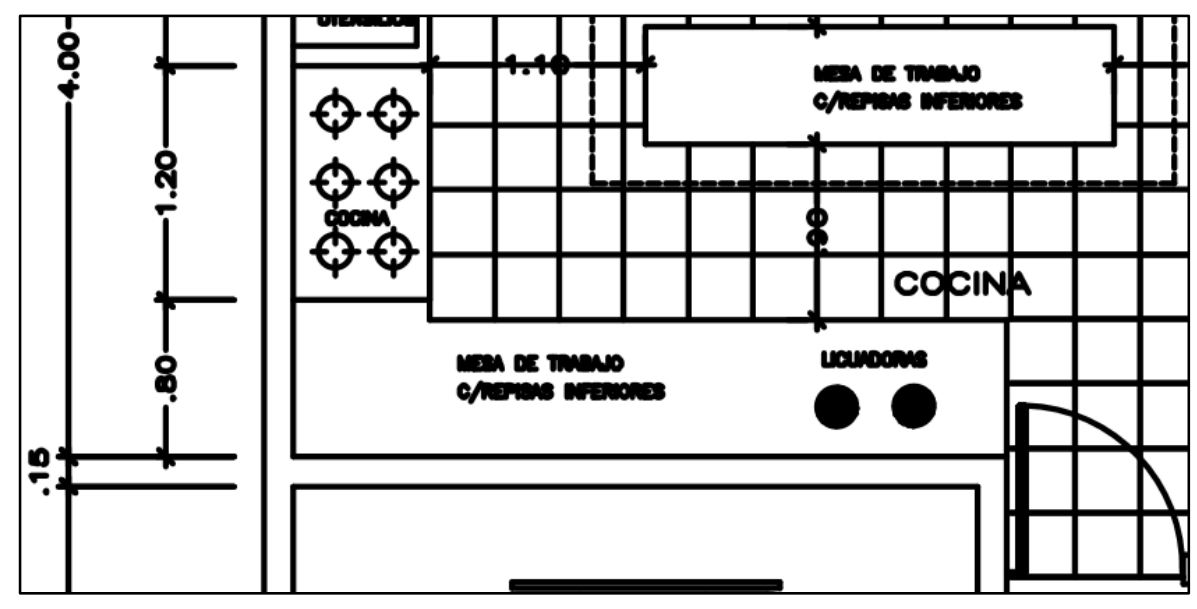

Figura 37. Ambiente caliente. Elaboración propia.

- Una mesa de trabajo estará ubicada al costado de la puerta de salida de la cocina, en esta mesa se realizarán los trabajos de cocina como desmenuzado, licuado, picado, etc.

- La cocina industrial, estará ubicada a continuación de la mesa de trabajo a fin de facilitar la manipulación de alimentos.

- La campana extractora estará ubicada sobre la cocina para evitar la circulación de grasas y vapores en el ambiente.

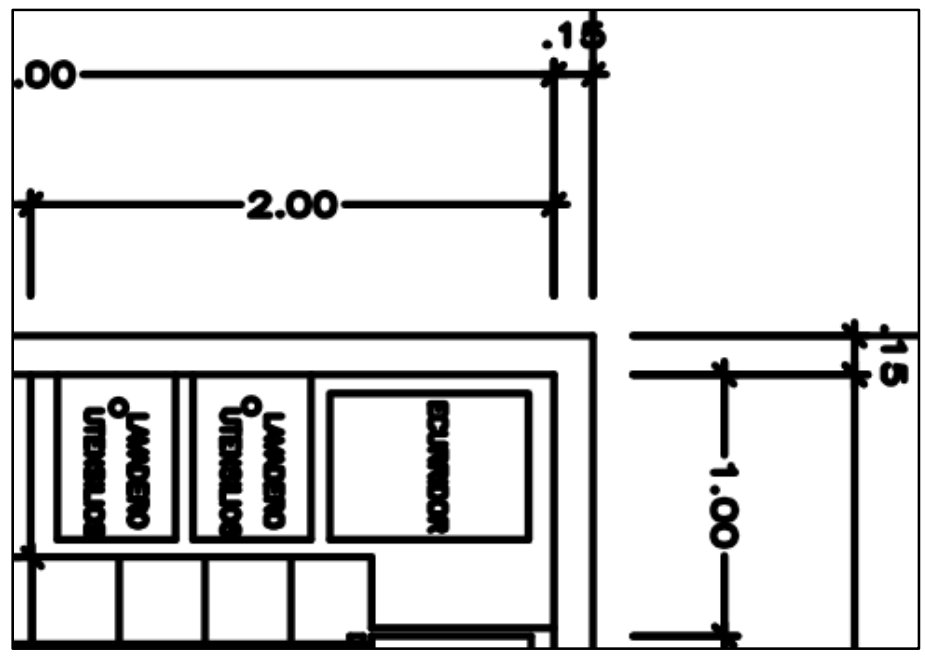

Figura 38. Ambiente de aseo de utensilios. Elaboración propia. 
- El lavadero de utensilios (de dos pozas), estará ubicado a continuación de la cocina a fin de facilitar el aseo de los utensilios utilizados en la elaboración de las recetas, contará también con un espacio para el escurrido de los utensilios antes de proceder a guardarlos después del uso.

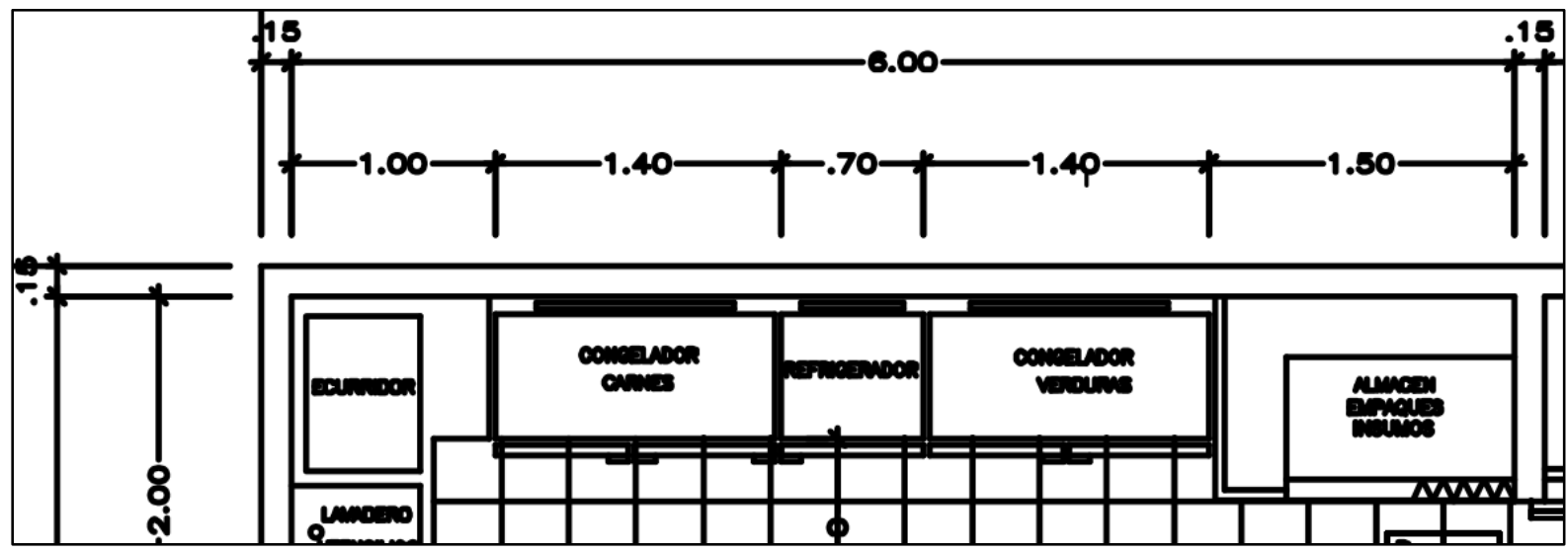

Figura 39. Ambiente frío. Elaboración propia.

- Los congeladores estarán ubicados al extremo opuesto del lavadero y divididos por la refrigeradora, a fin de evitar la mezcla de olores entre carnes y frutas y/o verduras.

- Al costado se encontrará el almacén de empaques e insumos que no requieren refrigeración, debidamente equipados con estanterías y una puerta corrediza para evitar el ingreso de olores y/o vapores que puedan dañar los empaques. 


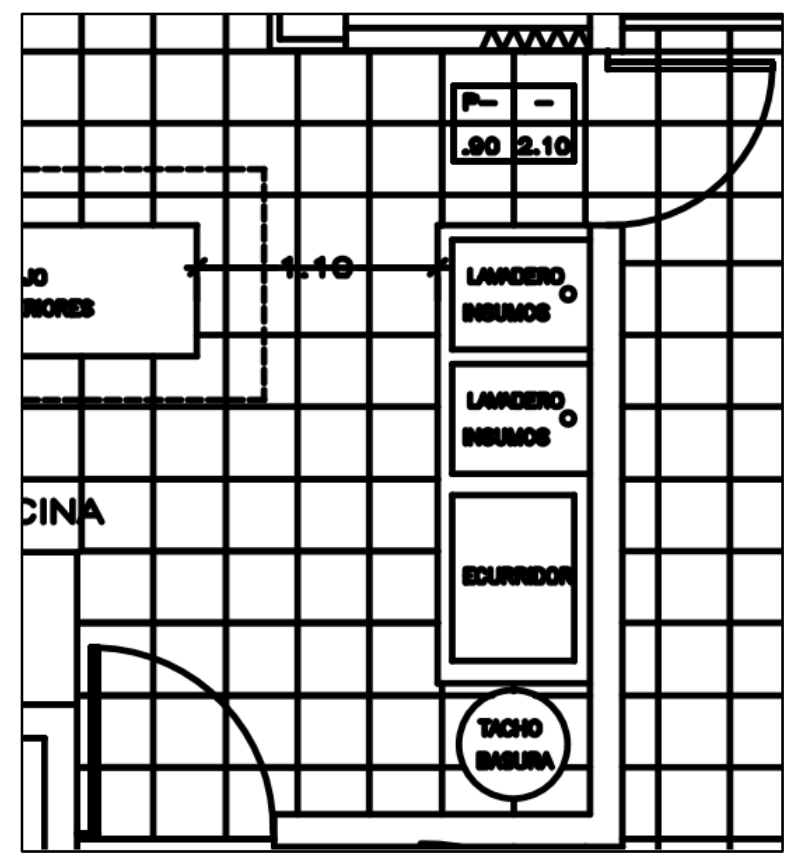

Figura 40. Ambiente de aseo de insumos. Elaboración propia.

- El lavadero de insumos (de dos pozas), estará ubicado entre la puerta de ingreso de personal e insumos y la puerta de salida, ello facilitará la limpieza de insumos ni bien lleguen a la cocina. Cuenta con un espacio para escurrir alimentos y otro para eliminar desechos de las frutas y verduras, cuyo recipiente será retirado inmediatamente después de terminar las tareas.

\subsection{Determinación del tamaño}

Según Sapag y Sapag (2008), la determinación del tamaño incide en el nivel de inversión y costos, y sobre todo en la rentabilidad que pueda generar el proyecto de negocio.

Cabe mencionar que el tamaño puede adecuarse según requerimientos posteriores. 
Tabla 65.

Ventas por año (cantidad de loncheras)

\begin{tabular}{lrrrrr}
\hline & 2018 & \multicolumn{1}{c}{2019} & \multicolumn{1}{c}{2020} & \multicolumn{1}{c}{2021} & \multicolumn{1}{c}{2022} \\
\hline Inicial & 8,493 & 9,397 & 10,382 & 11,453 & 12,619 \\
Primaria & 16,655 & 18,175 & 19,821 & 21,603 & 23,531 \\
Total anual & 25,147 & 27,572 & 30,203 & 33,056 & 36,150 \\
\hline
\end{tabular}

Nota: Elaboración propia.

\subsubsection{Proyección de crecimiento}

Para determinar el tamaño máximo diario de la preparación de loncheras se tomó como dato el número de loncheras prep

arados por 4 personas en 6 horas, estos datos se obtuvieron de las entrevistas a expertos (ver Tabla 66)

Tabla 66

Tamaño óptimo de Lunch Kids

\begin{tabular}{cccccc}
\hline TAMAÑO NORMAL & 2018 & 2019 & 2020 & 2021 & 2022 \\
\hline PORCENTAJE 100\% & $100 \%$ & $100 \%$ & $100 \%$ & $100 \%$ & $100 \%$ \\
Loncheras Anuales & 25147 & 27572 & 30203 & 33056 & 36150 \\
Loncheras semanales & 699 & 766 & 839 & 918 & 1004 \\
Loncheras diarias & 140 & 153 & 168 & 184 & 201 \\
\hline
\end{tabular}

\begin{tabular}{lccccc}
\hline \multicolumn{1}{c}{ Tamaño Máximo Diario } & 2018 & 2019 & 2020 & 2021 & 2022 \\
\hline $\begin{array}{l}\text { Nro. de loncheras preparadas en 6 } \\
\text { horas por 4 personas }\end{array}$ & 500 & 500 & 500 & 500 & 500 \\
$\begin{array}{l}\text { Total, pedidos de Loncheras diarias } \\
\text { realizados por los clientes de }\end{array}$ & 140 & 153 & 168 & 184 & 201 \\
$\begin{array}{l}\text { LUNCH KIDS } \\
\% \text { del total loncheras preparados } \\
\text { por LUNCH KIDS }\end{array}$ & $28 \%$ & $31 \%$ & $34 \%$ & $37 \%$ & $40 \%$ \\
\hline
\end{tabular}

Nota: Elaboración propia. 


\subsubsection{Recursos}

Según Hitt (2015), los recursos son todos los insumos que están incluidos en el proceso de producción de una empresa, como los bienes de capital, las habilidades de los empleados, las patentes, las finanzas y los administradores, y estos a su vez pueden ser divididos en tangibles e intangibles.

El proyecto Lunch kids, basará sus procesos en recursos tangibles e intangibles:

\section{Tangibles:}

- Insumos.

- Recursos organizacionales (detallados en el ítem 6.4).

- Diseño de la estructura organizacional deseada.

- $\quad$ Equipamiento (definido en el ítem 5.1.2.).

\section{Intangibles:}

Dentro de los intangibles se consideran:

- $\quad$ El nombre de la marca (determinado en el ítem 7.1.1.)

- $\quad$ Estrategia de producto.

- Conocimientos en gestión administrativa de los socios de la empresa.

Siendo los recursos intangibles activos que se van adquiriendo a lo largo del crecimiento del negocio y que son difíciles de analizar o imitar para los competidores, al inicio de las operaciones la marca Lunch Kids tendrá menor valor, pero gracias a las estrategias de marketing y publicidad se tiene como perspectiva posicionarla con un nombre de marca ampliamente conocido y apreciado por los clientes. 


\subsubsection{Tecnología}

En base al diseño del negocio el uso de la tecnología en conceptos de cocina no es necesariamente es necesaria, ya que los equipos no lo requieren, pero la tecnología si será requerida para la comunicación con el cliente, las órdenes de pedido y la distribución de productos. A continuación, mencionaremos la funcionalidad de cada una de estas tecnologías que se adquirirán:

- PC Advance VS1052 Core i3 19.5" 1TB 4GB

- Impresora Multifuncional Epson Ecotank L575 Wi-Fi

- Teléfono Ip Cisco 7911g

- Trío 30 Mbps Movistar

- Equipos móviles y planes post pago

- Microsoft Office 2013

\subsubsection{Flexibilidad}

Dentro de las características del tamaño del local, este debe contar entre $80 \mathrm{mts} 2 \mathrm{a}$ 100 mts2, esto debido a la implementación equipos de cocina, áreas administrativas, vestidores y entre otros.

Dentro de sus instalaciones cuenta con líneas de producción, congelados, lavado, cocina y almacenamiento. Con la posibilidad, a futuro, de adquirir maquinaria para sellado al vacío permitiendo mantener los productos con la mayor inocuidad.

\subsubsection{Selección del tamaño ideal}

El tamaño ideal para la Lunch Kids será de un área de 129 m2, debido a que se está considerando el espacio suficiente para cada área, además de los equipos que también se necesitan para cubrir la demanda proyectada. 


\subsection{Estudio de localización}

En este sentido Sapag y Sapag (2008) señalan que la importancia de una ubicación adecuada del proyecto consta de varias variables, cuya recuperación económica podría influir en la variación del resultado. Por ello se debe tener en cuenta estas variables de manera integrada como son la demanda, el transporte, la competencia entre otras.

Al realizarse el análisis de las encuestas se obtuvo que aproximadamente al $90 \%$ de los encuestados les gustaría que sus hijos reciban su lonchera en el aula o en la puerta del centro educativo, esto originó que se tenga en cuenta las variables de costo del local, las rutas de salidas para poder llegar a tiempo a los centros educativos considerando, además, la ubicación del mayor número de clientes potenciales, entre otras.

Por ello, se vio pertinente que, el local comercial para la preparación de los desayunos se encuentre ubicado en el límite de los distritos de Ate, La Molina y Santa Anita dado que es un punto medio entre los tres distritos, beneficioso considerando los tiempos necesarios para reparto, asegurando el cumplimiento del $100 \%$ de entregas a tiempo.

\subsubsection{Definición de factores locacionales}

Para definir la ubicación del local comercial se tuvo en cuenta los factores más relevantes como el número de centros educativos de inicial y primaria, al ser Ate el distrito que tiene el mayor número de centros educativos, también es el distrito que concentra la mayor cantidad de estudiantes en el segmento del público objetivo.

La cercanía al mercado objetivo en los distritos de Ate, Santa Anita y de La Molina, al ser distritos limítrofes y en donde se va a operar en esta primera etapa del proyecto, facilitaría la repartición de las loncheras saludables. 
Las rutas de salida también son importantes y en esta zona se cuenta con avenidas cercanas que facilitan la rápida distribución como son la Carretera Central, la Av. Urubamba, la Av. La Molina, la Av. Separadora Industrial, entre otras.

El precio de locales en Ate también juega un papel importante, esta zona es más económica que La Molina, e incluso Santa Anita, y los locales suelen tener un mayor metraje, lo que ayuda a organizar mejor la preparación, como es la distribución de las loncheras saludables.

Cercanía con proveedores, uno de los principales puntos para poder abastecer el negocio es el mercado mayorista que se encuentra ubicado en Ate y el mercado de frutas que se encuentra en San Luis, ambos bastante cerca de los puntos donde se busca ubicarse.

La seguridad en esta zona, se ha incrementado ya que existen empresas grandes que han ayudado con la implementación de más cámaras de seguridad, con servicios de vigilancia privados, logrando que en la zona se disminuya la inseguridad, por ejemplo, encontramos a Plaza Vea, Faber Castell, Atento, Editorial Navarrete, entre otras empresas.

Las opciones que se tienen son los siguientes tres locales: 


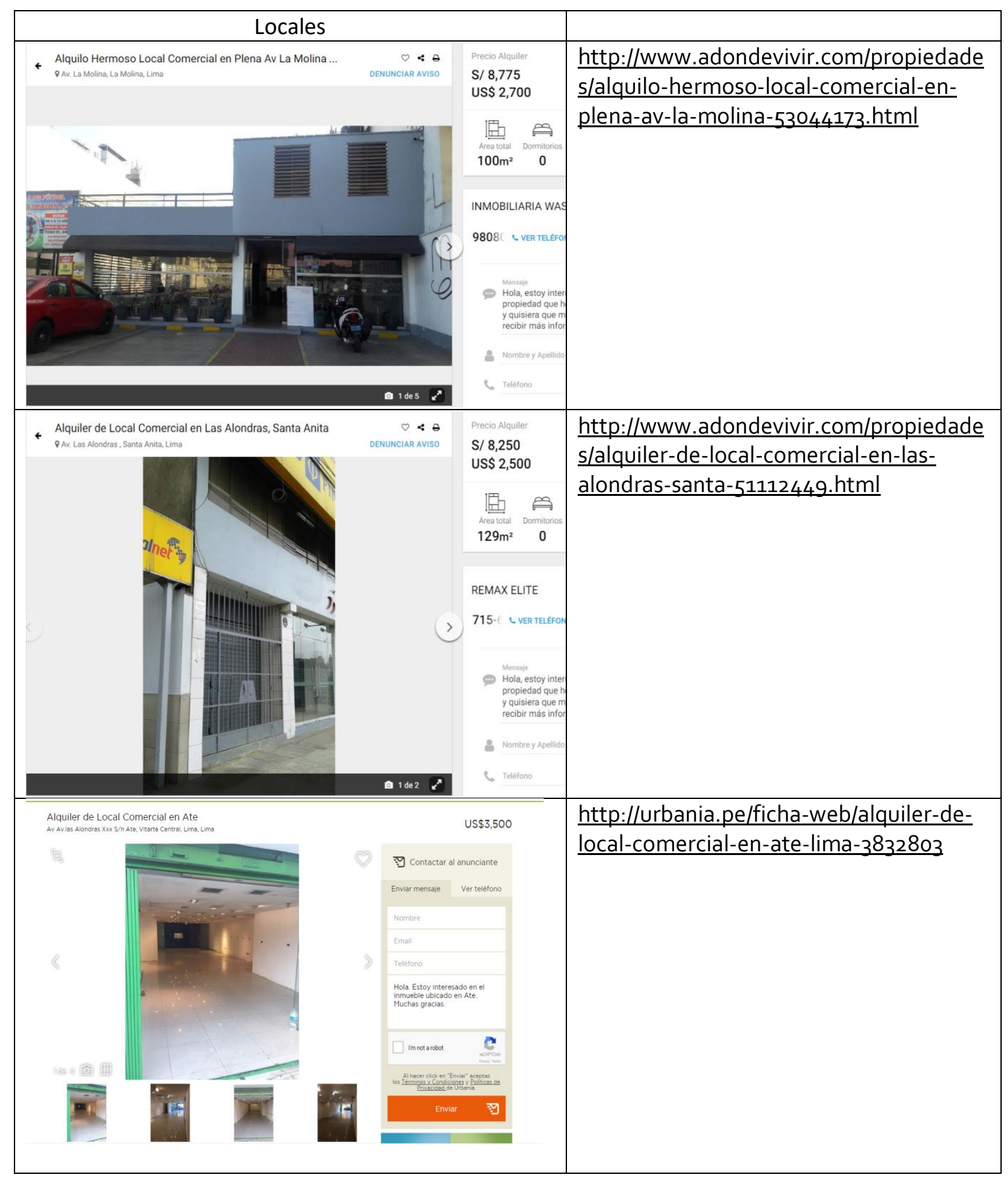

Figura 41. Locales evaluados. Elaboración propia. 
Se adjunta imagen del plano con los puntos donde se encuentran los locales propuestos.

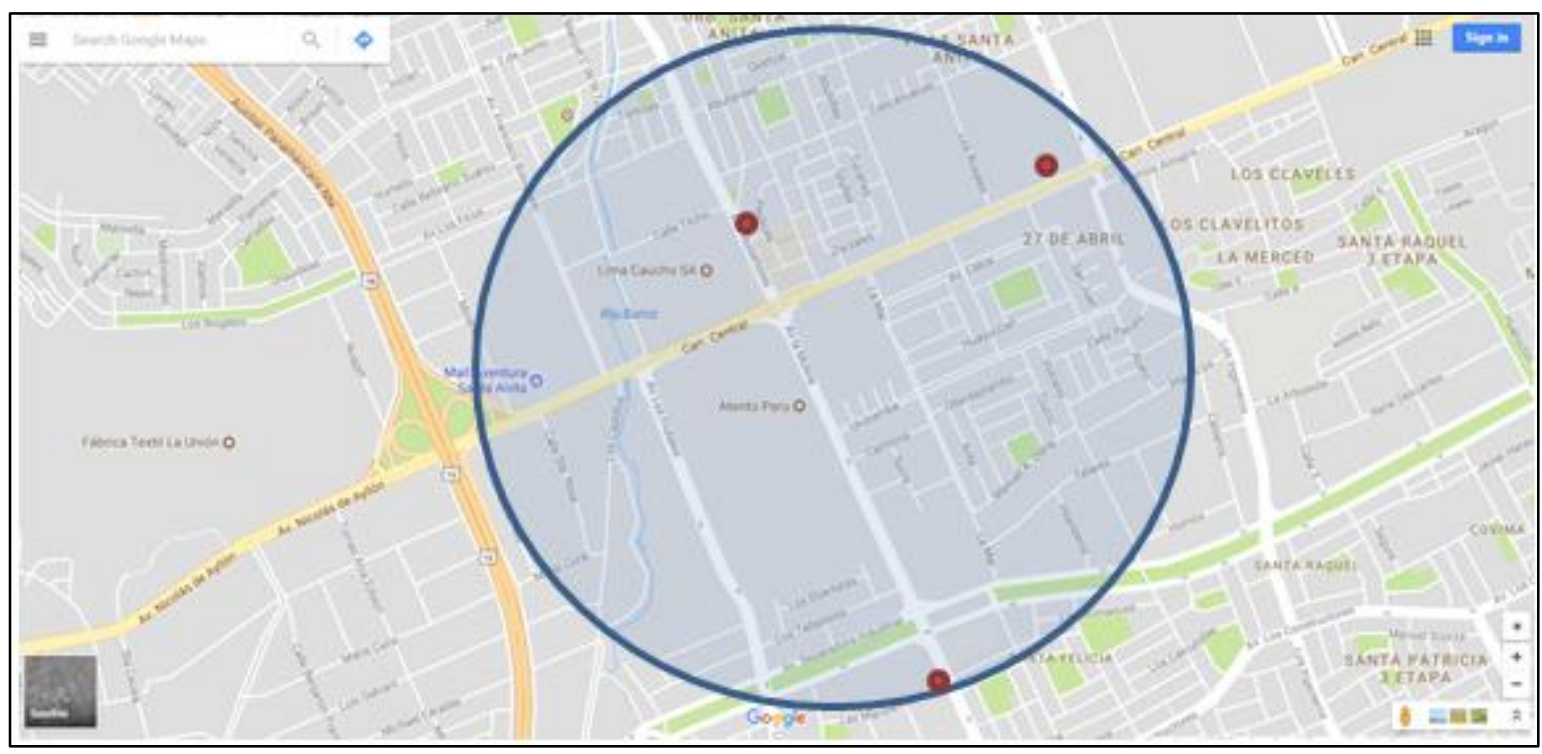

Figura 42. Mapa de los locales evaluados. Fuente: Google maps.

\subsubsection{Consideraciones legales.}

\subsubsection{Identificación del marco legal}

Para el local de preparación de loncheras saludables se debe cumplir con los siguientes trámites administrativos de acuerdo a la normativa del Perú y del distrito.

Licencia de Funcionamiento otorgada por la Municipalidad distrital de Ate, esta es la constancia que entrega la municipalidad donde otorga la autorización para poder desarrollar la actividad comercial en el distrito.

Los requisitos generales en la Municipalidad de Ate para la obtención de la licencia de funcionamiento son:

- Formato de solicitud de licencia de funcionamiento, la cual tiene carácter de declaración jurada y su distribución es gratuita, a este formato se le debe 
adjuntar el número de RUC y la copia del DNI del o de los representantes legales.

- Copia de la vigencia de poder del o de los representantes legales.

- Adjuntar número de comprobante de pago por derecho de trámite.

- Declaración jurada de observancia de condiciones de seguridad.

- Indicar el número del certificado de inspección técnica de seguridad en edificaciones (ITSE).

El plazo máximo para obtener la licencia de funcionamiento es de quince días hábiles.

Los costos para la obtención de la licencia de funcionamiento en la Municipalidad de Ate.

\begin{tabular}{|c|c|c|c|c|c|c|c|c|c|c|c|c|}
\hline \multirow[b]{2}{*}{$\begin{array}{c}\text { CENTRO DE } \\
\text { ACTIVIDAD } \\
\text { RESPONSABLE }\end{array}$} & \multirow[b]{2}{*}{ OBJETO DE COSTO } & \multirow[b]{2}{*}{$\begin{array}{l}\text { CANTIDAD } \\
\text { DE PRESTA- } \\
\text { CIONES } \\
\text { ANUALES }\end{array}$} & \multicolumn{7}{|c|}{ COSTOS UNITARIOS POR PRESTACIÓN (SI) } & \multirow[b]{2}{*}{$\begin{array}{l}\text { COSTO } \\
\text { UNITARIO } \\
\text { (SI) }\end{array}$} & \multirow[b]{2}{*}{$\begin{array}{c}\text { DERECHO } \\
\text { DE PAGO } \\
\text { (S) }\end{array}$} & \multirow[b]{2}{*}{ \% UIT } \\
\hline & & & PERSONAL & $\begin{array}{l}\text { MATERIAL } \\
\text { FUNGIBLE }\end{array}$ & $\begin{array}{l}\text { SERVICIOS } \\
\text { IDENTIFI- } \\
\text { CABLES }\end{array}$ & \begin{tabular}{|c|} 
MATERIAL \\
NO \\
FUNGIBLE
\end{tabular} & $\begin{array}{c}\text { SERVICIO } \\
\text { DE } \\
\text { TERCEROS }\end{array}$ & $\begin{array}{l}\text { DEPRECIA- } \\
\text { CIÓN Y } \\
\text { AMORTIZA- } \\
\text { CIÓN }\end{array}$ & FIJOS & & & \\
\hline $\begin{array}{l}\text { SUBGERENCIA DE } \\
\text { FORMALIZACIÓN, } \\
\text { PROMOCIÓN } \\
\text { EMPRESARIAL Y } \\
\text { TURISMO }\end{array}$ & $\begin{array}{l}\text { LICENCIA DE FUNCIONAMIENTO: } \\
\text { ESTABLECIMIENTOS CON UN ÁREA DE } \\
\text { HASTA 10OM2 CON ITSE BÁSICA EX } \\
\text { POST EN FORMA CONJUNTA CON LA } \\
\text { AUTORIZACIÓN DE ANUNCIO } \\
\text { PUBLICITARIO SIMPLE (ADOSADO A } \\
\text { FACHADA) YIO TOLDO }\end{array}$ & 50 & 113.01 & 1.81 & 6.00 & 0.00 & 0.00 & 0.00 & 0.00 & 120.82 & 120.80 & $3.058 \%$ \\
\hline
\end{tabular}

Figura 43. Resumen de costos de procedimientos administrativos y servicios prestados en exclusividad. Fuente: [Procedimiento para Licencia de funcionamiento] por Municipalidad de Ate, 2016. Recuperado de http://www.muniate.gob.pe/ate/files/licenciaFuncionamiento/PROCEDIMIENTO/1.\%20L.F.\% 20EX\%20POST-16.pdf 


\begin{tabular}{|c|c|c|c|c|c|c|c|c|c|c|c|c|}
\hline \multirow[b]{2}{*}{$\begin{array}{c}\text { CENTRO DE } \\
\text { ACTIVIDAD } \\
\text { RESPONSABLE }\end{array}$} & \multirow[b]{2}{*}{ OBJETO DE COSTO } & \multirow[b]{2}{*}{$\begin{array}{c}\text { CANTIDAD } \\
\text { DE PRESTA- } \\
\text { CIONES } \\
\text { ANUALES }\end{array}$} & \multicolumn{7}{|c|}{ COSTOS UNITARIOS POR PRESTACIÓN (SI) } & \multirow[b]{2}{*}{$\begin{array}{l}\text { COSTO } \\
\text { UNITARIO } \\
\text { (SI) }\end{array}$} & \multirow[b]{2}{*}{$\begin{array}{c}\text { DERECHO } \\
\text { DE PAGO } \\
\text { (SI) }\end{array}$} & \multirow[b]{2}{*}{ \% UIT } \\
\hline & & & PERSONAL & $\begin{array}{l}\text { MATERIAL } \\
\text { FUNGIBLE }\end{array}$ & $\begin{array}{l}\text { SERVICIOS } \\
\text { IDENTIFI- } \\
\text { CABLES }\end{array}$ & $\begin{array}{l}\text { MATERIAL } \\
\text { NO } \\
\text { FUNGIBLE }\end{array}$ & $\begin{array}{l}\text { SERVICIO } \\
\text { DE } \\
\text { TERCEROS }\end{array}$ & $\begin{array}{c}\text { DEPRECIA- } \\
\text { CIONN Y } \\
\text { AMORTIZA- } \\
\text { CIÓN }\end{array}$ & FIJOS & & & \\
\hline $\begin{array}{l}\text { SUBGERENCIA DE } \\
\text { FORMALIZACIÓN, } \\
\text { PROMOCIÓN } \\
\text { EMPRESARIAL Y } \\
\text { TURISMO }\end{array}$ & $\begin{array}{l}\text { LICENCIA DE FUNCIONAMIENTO: } \\
\text { ESTABLECIMIENTOS CON UN ÁREA DE } \\
\text { HASTA 100M2 CON ITSE BÁSICA EX } \\
\text { POST (La capacidad de almacenamiento } \\
\text { no debe ser mayor al } 30 \% \text { del área total } \\
\text { del establecimiento) }\end{array}$ & 829 & 49.74 & 1.59 & 0.00 & 0.00 & 0.00 & 0.00 & 0.00 & 51.34 & 51.30 & $1.299 \%$ \\
\hline
\end{tabular}

Figura 44. Resumen de costos de procedimientos administrativos y servicios prestados en exclusividad. Fuente: [Procedimiento para Licencia de funcionamiento] por Municipalidad de Ate, 2017. Recuperado de http://www.muniate.gob.pe/ate/files/licenciaFuncionamiento/PROCEDIMIENTO/1.\%20L.F.\% 20EX\%20POST-16.pdf

También se debe tener en cuenta que la aprobación de la licencia de funcionamiento está condicionada al cumplimiento de las normas de seguridad impuestas por el Instituto Nacional de Defensa Civil (INDECI) quienes previamente al otorgamiento de la licencia realizan una inspección ocular para verificar el cumplimiento, pudiendo hacer observaciones lo que automáticamente generaría la demora en el trámite hasta poder levantarlas.

También es importante obtener el permiso sanitario, pues este es obligatorio para los comercios que manipulen alimentos.

La verificación del cumplimiento de la norma sanitaria está a cargo de la municipalidad a través de la autoridad sanitaria municipal, quien es la encargada de velar por el cumplimiento de las normas, para garantizar que los alimentos y bebidas cuenten con la calidad sanitaria para el consumo humano. También es la encargada de verificar que las personas que manipulen los alimentos hayan recibido la capacitación que exige la Municipalidad de Lima Metropolitana para la obtención del carnet correspondiente. Esto consta en la ordenanza número 082. 


\subsubsection{Ordenamiento jurídico de la empresa}

De acuerdo a los tipos de sociedades, la empresa será constituida como una sociedad anónima cerrada y su denominación comercial será Lunch Kids S.A.C. la cual estará conformada por 4 socios, los cuales se detallan a continuación, así como sus aportes, los cuales figurarán en el testimonio de la misma.

- Cueva Romero, Carlos Enrique quien aportará el 25\% del capital social.

- Salas Ychocan, Rocio quien aportará el 25\% del capital social.

- Valverde Garay, Susana quien aportará el 25\% del capital social.

- Zavalaga Raborg, René Fernando quien aportará el 25\% del capital social.

La principal razón para que Lunch Kids sea constituida como una empresa de sociedad anónima cerrada es que la responsabilidad de obligaciones con terceros solo afectaría el patrimonio de la empresa y no afecta el patrimonio personal de los socios.

Los pasos para la formación de la empresa son los siguientes: 

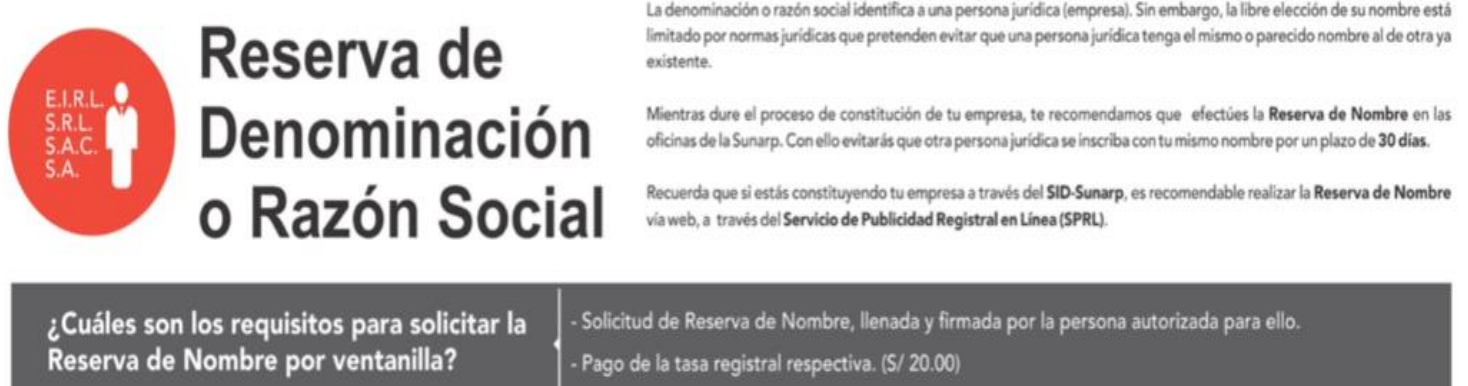

\section{¿CÓMO REALIZAR LA RESERVA DE NOMBRE VÍA WEB EN 24 HORAS?}
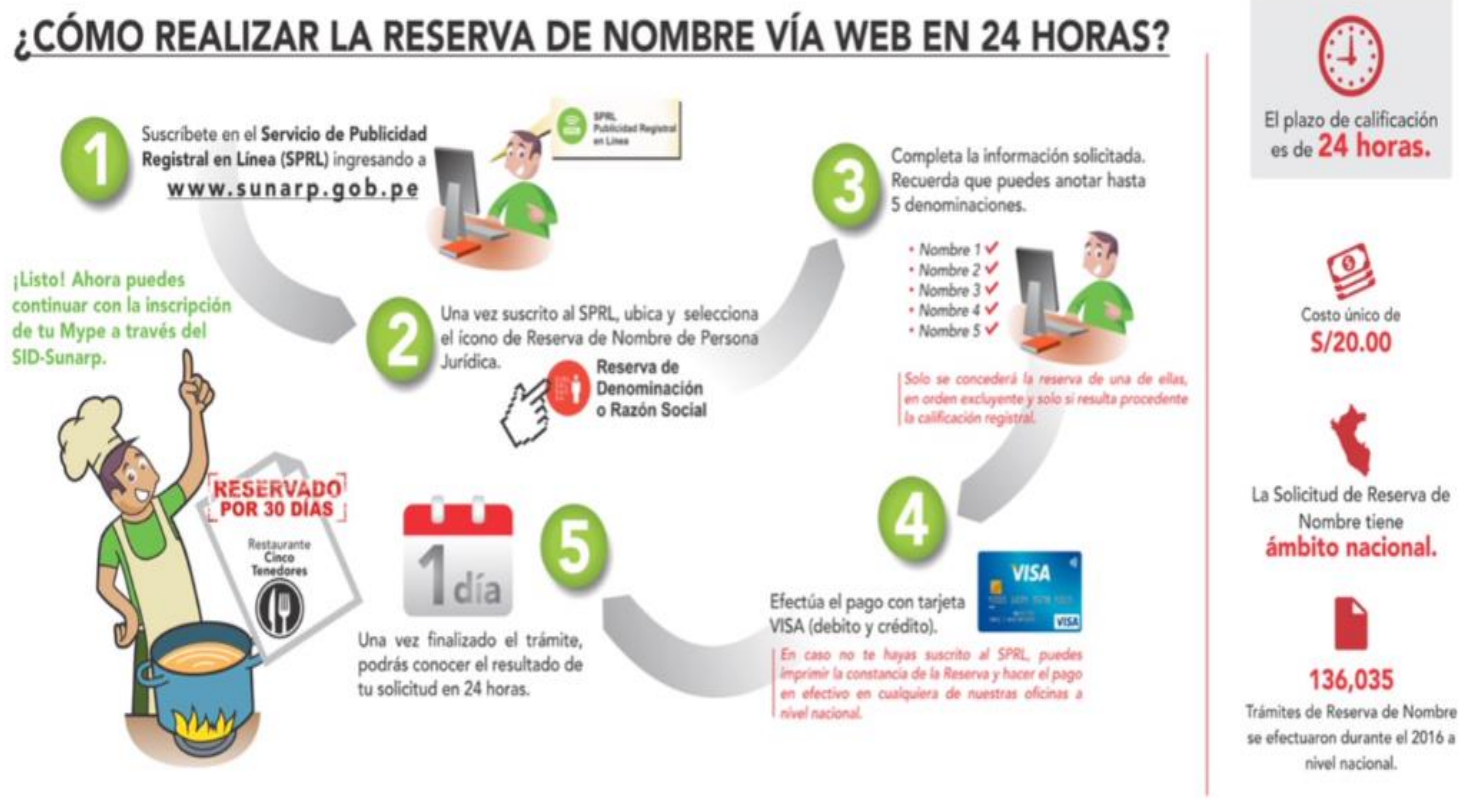

Fuente Sunarp.

Figura 45. Reserva de denominación o razón social. Fuente: Superintendencia Nacional de los Registros Públicos, 2017. Recuperado de https://www.sunarp.gob.pe/PRENSA/inicio/post/2017/01/05/conocecomo-reservar-la-denominacion-o-razon-social-de-tu-empresa-en-24-horas 
REGISTRA TU MYPE DE MANERA MÁS FÁCIL, RÁPIDA Y SEGURA CON EL
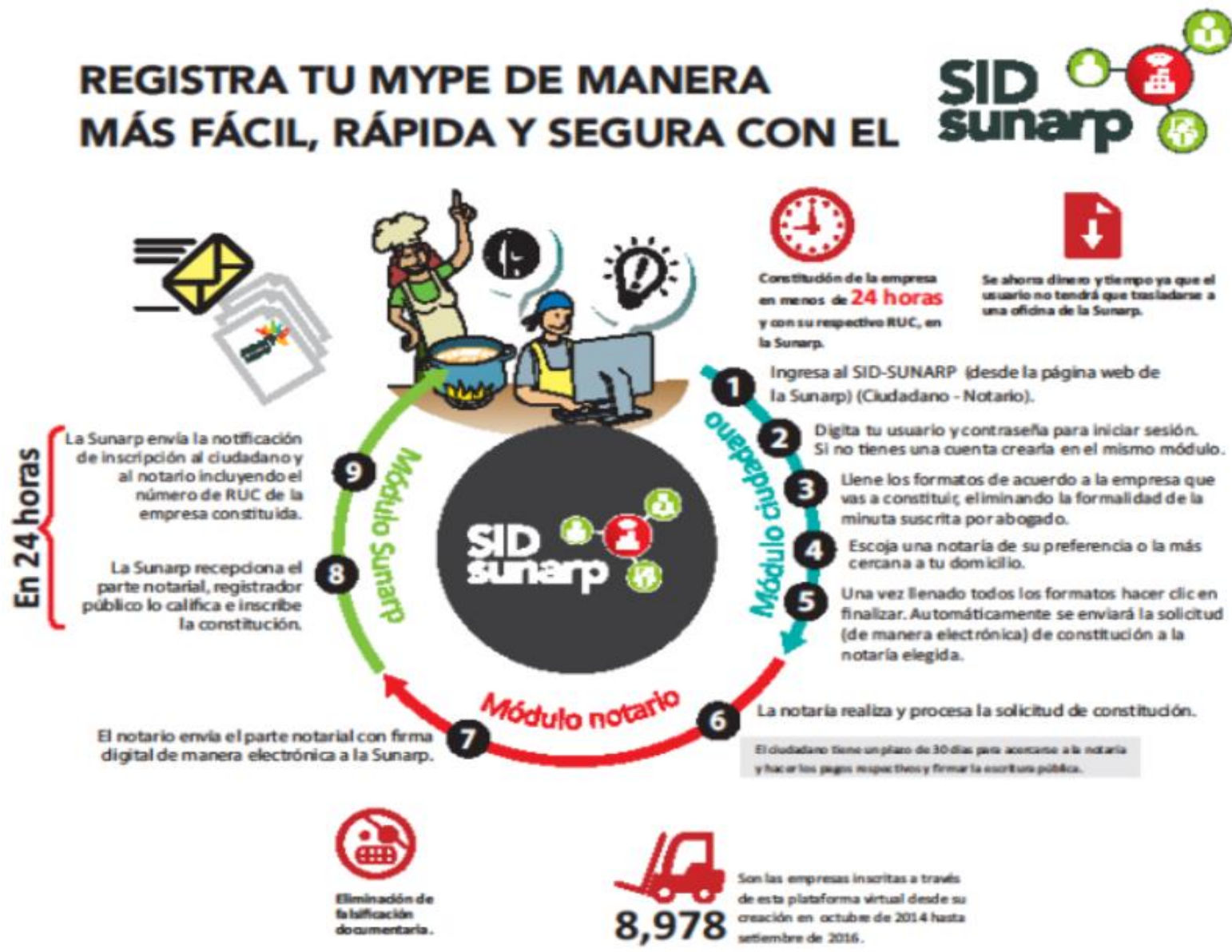

Figura 46. Registra tu Mype de manera más fácil, rápida y segura. Fuente: Superintendencia Nacional de los Registros Públicos, 2016. Recuperado de https://www.sunarp.gob.pe/PRENSA/inicio /post/2016/10/31/en-24-horas-se-puede-inscribir-una-empresa-en-la-sunarp 
Marca y Patente:

\section{GACETA ELECTRÓNICA DE PROPIEDAD INDUSTRIAL facilidades para el registro de una marca}

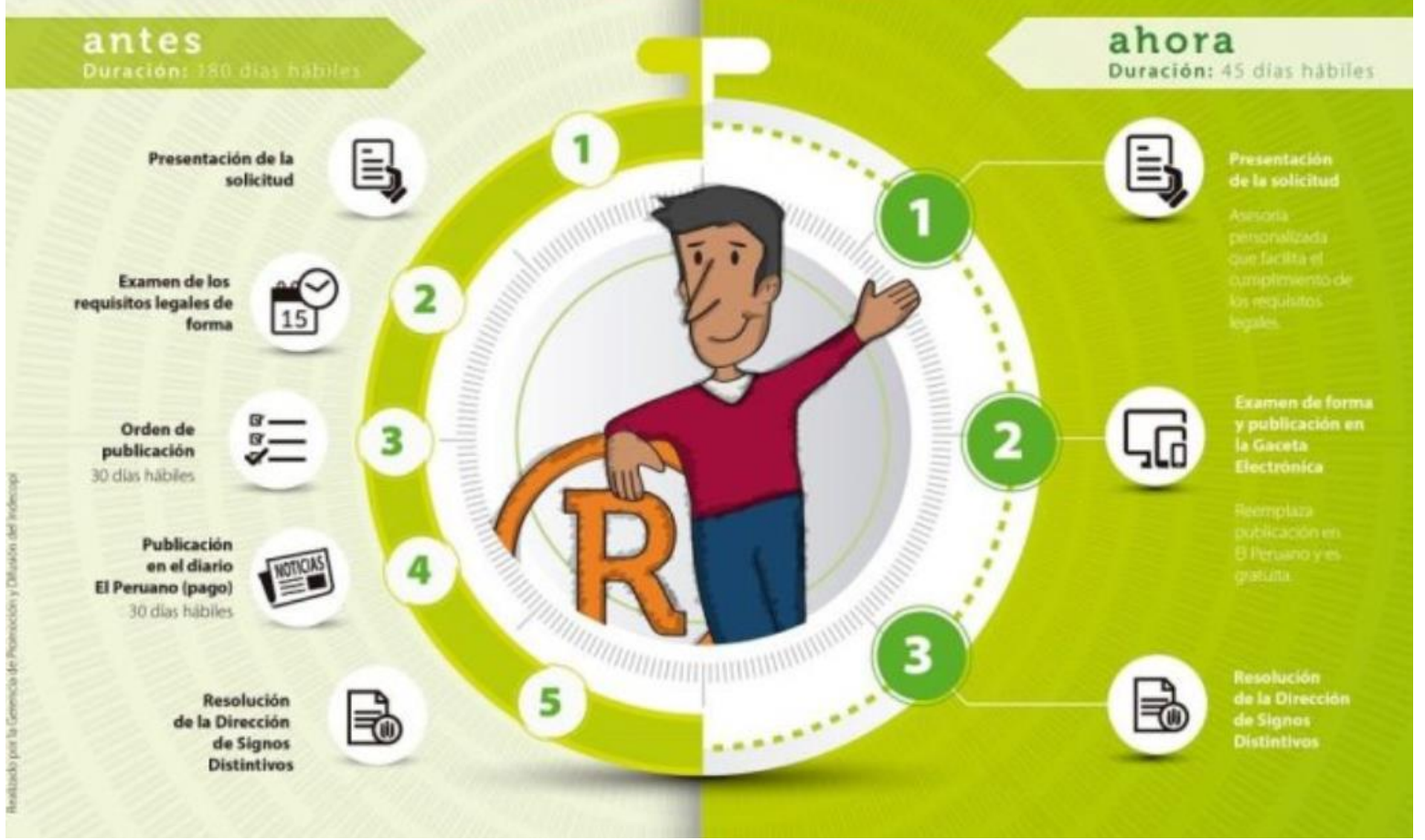

Figura 47. Facilidades para el registro de marca. Fuente: Indecopi: registro de marcas y patentes reduce costo hasta por S/ 500, 2017. Recuperado de https://gestion.pe/economia/empresas/indecopi-registro-marcaspatentes-reduce-costo-s-500-138691-noticia/ 


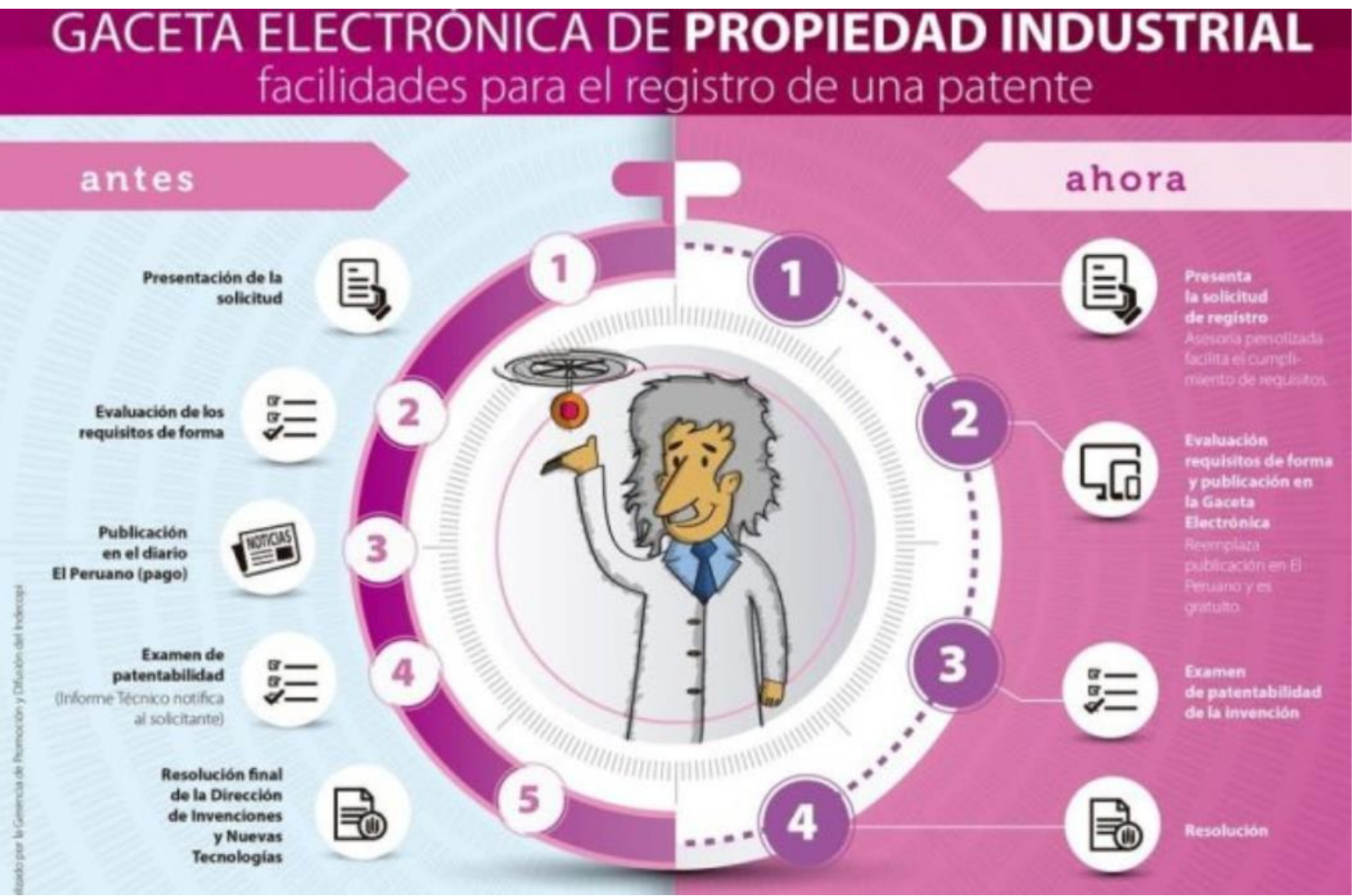

Figura 48. Facilidades para el registro de patente. Fuente: Indecopi: registro de marcas y patentes reduce costo hasta por S/ 500, 2017. Recuperado de https://gestion.pe/economia/empresas/indecopi-registro-marcaspatentes-reduce-costo-s-500-138691-noticia/

La empresa Lunch Kids S.A.C se acogerá al régimen general de impuesto a la renta para lo cual requiere contar con libros contables, los cuales deben ser legalizados por un notario en la primera hoja según la Ley 26501.

Según el régimen general se debe llevar la contabilidad a través de libros obligatorios como:

Libros societarios

- Libro de actas

- Registro de acciones 
Libros contables

- Libro de inventarios y balances

- Libro diario

- Libro mayor

Libros y registros auxiliares

- Libro de caja y banco

- Libro de remuneraciones

- Registro de compra

- Registro de venta

En este régimen la empresa está obligada a declarar mensualmente sus ventas, a declarar anualmente el impuesto a la renta y a efectuar retenciones correspondientes a rentas de cuarta y quinta categoría

\subsection{Determinación de la localización óptima}

Sapag y Sapag (2008), mencionan que uno de los métodos para poder determinar la ubicación adecuada del proyecto es el denominado método cualitativo por puntos, este consiste en definir los factores más relevantes y asignarles valores ponderados de acuerdo con la importancia que se le asigna a cada uno. Este método nos ayuda para poder comparar entre varias alternativas eligiendo la opción que obtenga un mayor puntaje.

Este método es el que se utilizó para determinar la mejor ubicación del local comercial para lo cual se evaluó tres locales cercanos al límite de los distritos de Ate, La Molina y Santa Anita el cual se presenta a continuación: 
Tabla 67

Cuadro del método cualitativo por puntos.

\begin{tabular}{|c|c|c|c|c|c|c|c|}
\hline \multirow[t]{2}{*}{ Factor } & \multirow[t]{2}{*}{ Peso } & \multicolumn{2}{|c|}{ Local A } & \multicolumn{2}{|c|}{ Local B } & \multicolumn{2}{|c|}{ Local C } \\
\hline & & Calificación & Ponderación & Calificación & Ponderación & Calificación & Ponderación \\
\hline $\begin{array}{l}\text { Cercanía mercado } \\
\text { objetivo }\end{array}$ & 0.3 & 5 & 1.5 & 7 & 2.1 & 6 & 1.8 \\
\hline Rutas de salida & 0.25 & 7 & 1.75 & 6 & 1.5 & 5 & 1.25 \\
\hline Precio de locales & 0.10 & 2 & 0.2 & 3 & 0.3 & 3 & 0.3 \\
\hline $\begin{array}{l}\text { Cercanía } \\
\text { proveedores }\end{array}$ & 0.15 & 2 & 0.3 & 5 & 0.75 & 5 & 0.75 \\
\hline Seguridad & 0.2 & 6 & 1.2 & 4 & 0.8 & 3 & 0.6 \\
\hline Total & 1.0 & & 4.95 & & 5.45 & & 4.7 \\
\hline
\end{tabular}


En conclusión, según lo obtenido por el método cualitativo de puntos y teniendo en cuenta los principales factores locacionales, el local de Lunch Kids que se tomará logró un puntaje de 5.45 y estará ubicado en el distrito de Ate. Teniendo un costo de alquiler mensual de S/ 8,250 y cuenta con un área de $129 \mathrm{~m} 2$.

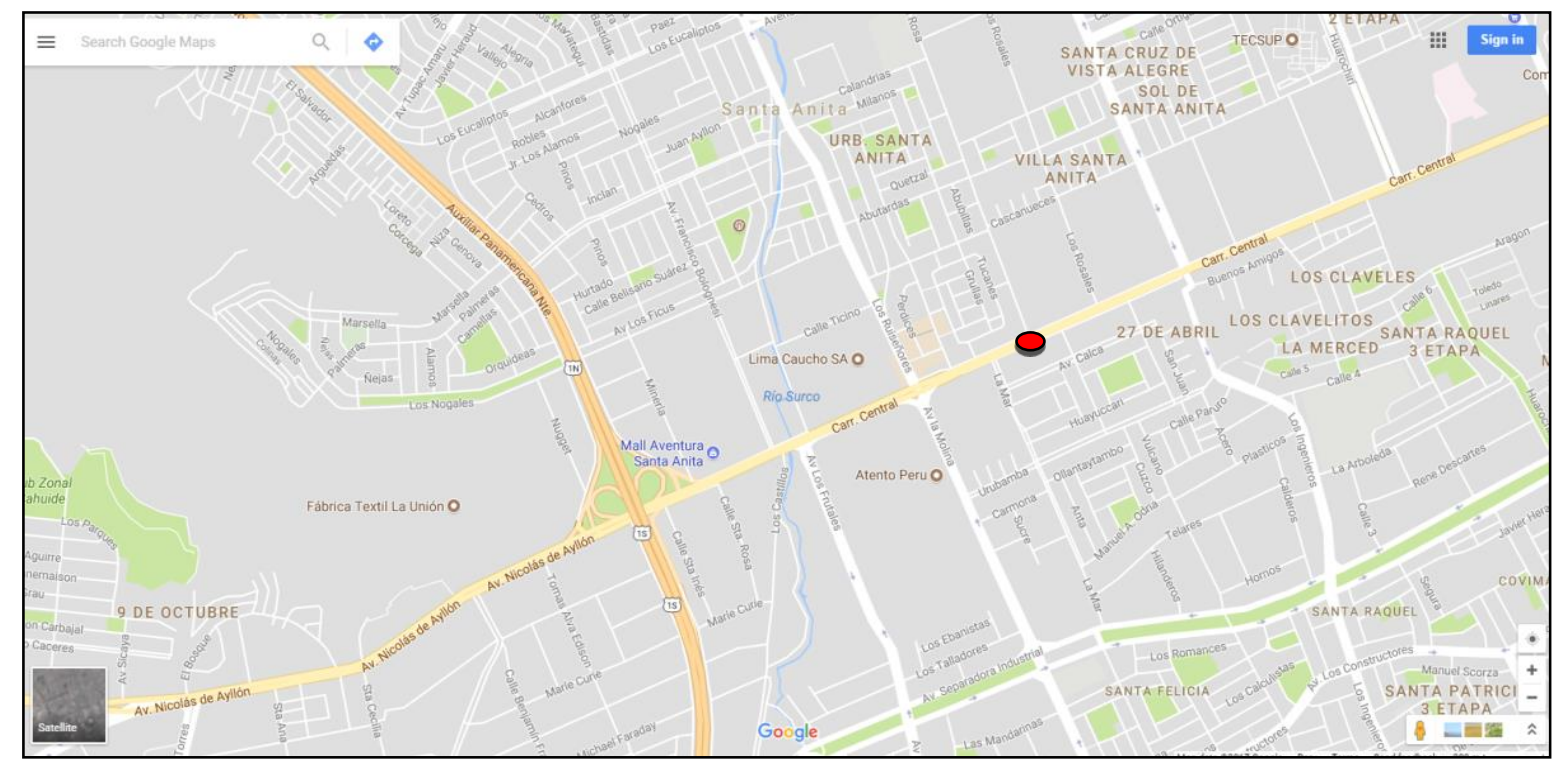

Figura 49. Mapa de local elegido. Fuente: Google maps. 


\section{Capítulo VI. Aspectos organizacionales}

En el presente capítulo se detallará la cultura organizacional deseada, presentando la visión, misión y principios que regirán en Lunch Kids S.A.C.

El motivo de la elección del nombre se explica a detalle en el Capítulo V, punto 5.3.2.2.

La empresa será constituida como una sociedad anónima cerrada, y su denominación comercial será Lunch Kids S.A.C. la cual estará conformada por 4 socios, los cuales se detallan a continuación, así como sus aportes, los cuales figurarán en el testimonio de la misma.

- Cueva Romero, Carlos Enrique quien aportara el 25\% del capital social.

- Salas Ychocan, Roció quien aportara el 25\% del capital social.

- Valverde Garay, Susana quien aportara el 25\% del capital social.

- Zavalaga Raborg, René Fernando quien aportara el 25\% del capital social.

También se va a presentar la estructura organizacional, se hará el diseño de los perfiles de los puestos claves, se presentará el esquema de las remuneraciones, compensaciones y/o incentivos. Así mismo las políticas de recursos humanos.

\subsection{Caracterización de la cultura organizacional deseada}

Según David (2013) el conjunto de creencias que dan origen a un negocio, cuando se ponen por escrito, deben tener una clara relación con la visión y la misión. Cuando el negocio va en crecimiento es necesario ir revisando este conjunto de creencias que fueron el cimiento o la base, normalmente la idea principal se mantiene en las actualizaciones de la visión y la misión.

\subsubsection{Visión}

La visión debe responder a la pregunta ¿Qué queremos llegar a ser? La visión bien hecha proporciona los cimientos para una buena misión. Es por ello que es importante establecer antes que nada la visión de la empresa, esta debe ser breve, se recomienda 
que sea una sola oración y debería haber sido construida con el aporte de la mayoría de los gerentes. (David, 2008)

Para determinar la visión de la empresa se debió responder a las preguntas:

- ¿Cómo nos vemos a futuro frente a la competencia?

- ¿Qué queremos ofrecer?

- ¿Cómo vemos a nuestros clientes?

Visión:

Ser la empresa líder en Lima, ofreciendo alternativas de loncheras saludables para niños en edad escolar, contribuyendo con nuestro país en la disminución de los índices de sobrepeso y obesidad.

\subsubsection{Misión}

Según David (2013) la misión de un negocio establece las prioridades en cuanto a estrategias, planes y funciones, este es el punto de inicio para el diseño de los puestos administrativos, pero también para el diseño de la estructura administrativa de la empresa. El señala que la declaración de la misión para que sea eficaz debe contener nueve características o componentes como son:

- Clientes. - ¿Quiénes son los clientes de la empresa?

- Productos y/o servicios. - ¿Cuáles son los más importantes que va a brindar la empresa?

- Mercados. - ¿Dónde está compitiendo la empresa?

- Tecnología. - ¿La empresa está actualizada en cuanto a tecnología?

- Preocupación por la supervivencia, el crecimiento y la rentabilidad.

- ¿Cómo está comprometida la empresa con el crecimiento del negocio, las finanzas?

- Filosofía. - ¿Cuáles son los valores, creencias, aspiraciones, ética de la empresa? 
- Auto concepto. - ¿Cuál es la mayor ventaja competitiva que tiene la empresa?

- Preocupación por su imagen. - ¿Compromiso de la empresa con su entorno, sabe responder a las preocupaciones ambientales, comunitarias y de la sociedad?

- Preocupación por los empleados. - ¿Son valiosos los empleados para la empresa?

Misión:

Ayudar a los padres de familia en la preparación de loncheras saludables para sus niños en edad escolar y ayudarlos en el cuidado de su salud, brindándoles tips sobre alimentación. Logrando ser una empresa referente en el cuidado de la niñez en nuestro país, despertando así el orgullo de nuestros colaboradores y accionistas.

\subsubsection{Principios}

Los principios de la empresa serán los siguientes

- Orientación al Cliente. - Este es uno de los más importantes, trabajamos con personas y estas son complejas, por lo tanto, el nivel de orientación que se tiene que lograr hacia ellos es alto, mucha empatía, comunicación clara, y altos niveles de servicio.

- Trabajo en equipo. - Es importante lograr un trabajo en equipo, sobre todo teniendo en cuenta que para este negocio se necesita de mucha coordinación.

- Responsabilidad. - En este negocio se trabaja con alimentos que después serán consumidos por niños por lo que es importante ser extremadamente responsables con las políticas de cuidado de la empresa.

- Puntualidad. - Se tiene el compromiso de cumplir con cada uno de los clientes, así que se debe de ser cuidadoso con la puntualidad, pues se tiene que asegurar que cada uno de los niños reciba a tiempo su lonchera saludable. 


\subsection{Formulación de estrategias del negocio}

Según Hitt (2015), la estrategia de negocio representa un conjunto integrado y coordinado de acciones que se utilizan para lograr una ventaja competitiva en mercados específicos.

Para David (2017), los tres libros más leídos de Michael Porter indican que las estrategias de negocios se dividen en tres ejes fundamentales a los cuales denominó estrategias genéricas

Eje 1: Liderazgo en costos, enfocado en consumidores sensibles al precio, de aquí se derivan dos estrategias genéricas, orientadas a grandes mercados

Tipo 1: estrategia de bajo costo

Tipo 2: estrategia de mejor valor

Eje 2: Diferenciación, debe ser diseñada de acuerdo a la necesidad de los consumidores para brindar un servicio único en la industria, enfocada a clientes insensibles al precio.

Tipo 3: Diferenciación

Eje 3: Enfoque, diseñado para cubrir necesidades de productos o servicios a muy bajos costos, de aquí se derivan dos estrategias genéricas, orientadas a pequeños mercados

Tipo 4: estrategia de bajo costo

Tipo 5: estrategia de mejor valor

Las 5 estrategias de negocios de Porter requieren de características de negocios específicas para su implementación, a fin de no afectar la ventaja competitiva la empresa (ver figura 50). 


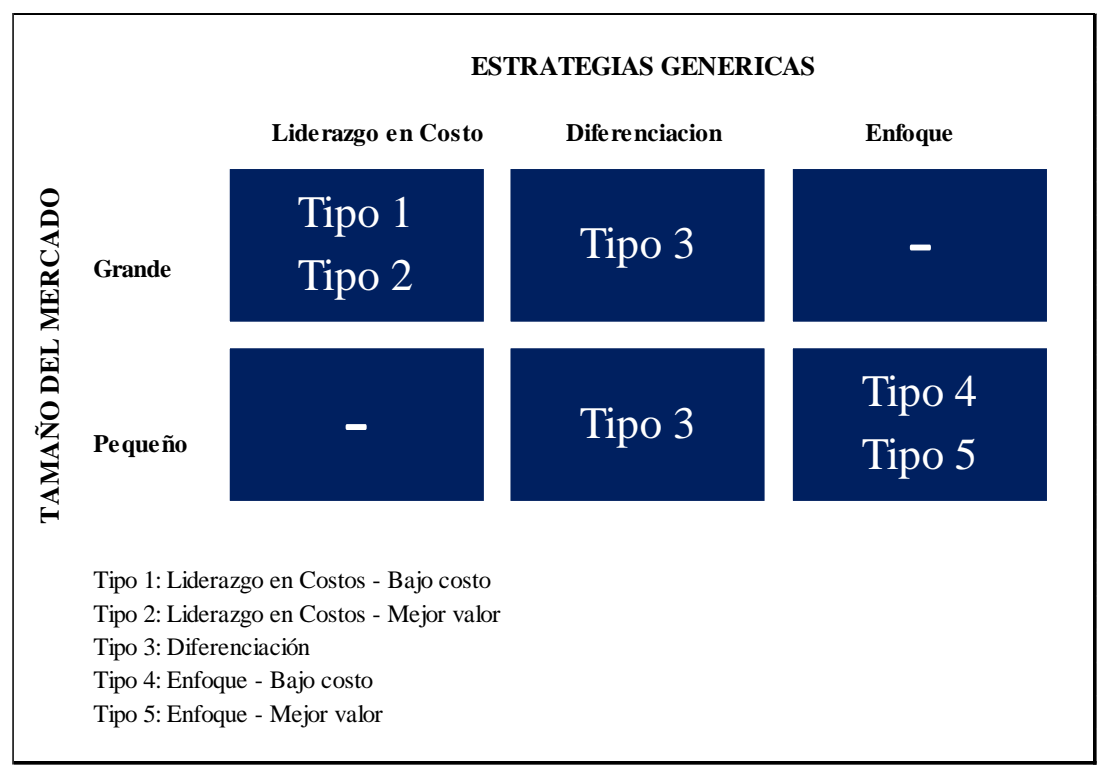

Figura 50. Estrategias de negocios. Fuente: Elaboración propia.

En el caso del presente proyecto, se aplicará la estrategia de mejor valor (tipo 5) Enfoque mejor valor, ya que se ofrece un determinado servicio a padres/madres de familia del NSE B y C, cuyos niños estudian en los distritos de La Molina, Ate y Santa Anita, y demuestran un especial interés por la alimentación saludable de sus hijos en las loncheras escolares.

Se eligió la estrategia Enfoque - mejor valor, ya que esta ofrece productos y/o servicios a precios más altos, que la estrategia Enfoque- bajo costo, pero con más beneficios, en consecuencia, la percepción es que las ofertas de la estrategia tipo 5 tienen mayor valor.

Además, para David (2017), la estrategia de enfoque de mejor valor (tipo 5) puede ser muy atractiva, sobre todo cuando pocos rivales, si los tuviera, intentan especializarse en el mismo segmento meta. Es así que podemos mencionar que el servicio que ofrece Lunch Kids no tiene competencia directa.

En la investigación cuantitativa se pudo identificar que en muchos hogares ambos padres trabajan y no siempre cuentan con el tiempo necesario para la preparación diaria de la lonchera escolar, por lo que consideran que la idea de negocio es de gran ayuda para no descuidar la sana alimentación de sus hijos. 
La oferta de valor de Lunch Kids, consiste en la elaboración de loncheras saludables, nutritivas, balanceadas y variadas para niños en edad escolar. Cada lonchera contiene una porción de fruta, sándwich saludable y refresco o agua (hasta 500ml) presentados en un empaque reciclable con abre fácil apropiado para la manipulación de los niños. 


\subsection{Determinación de las ventajas competitivas criticas}

Hitt (2015) establece que los recursos, las capacidades y las competencias centrales son la base para definir la ventaja competitiva, los recursos crean capacidades organizacionales y además, las capacidades son fuente de las competencias centrales de la empresa.

Para crear las capacidades de la empresa, es necesario analizar los factores internos de la organización, donde se combinan todos los recursos tangibles e intangibles los cuales fueron descritos en el ítem 5.2.2. Recursos.

Según Hitt (2015) para la construcción de las competencias centrales existen dos instrumentos el primero, consta de cuatro criterios específicos de la ventaja competitiva sostenible y el otro instrumento es el análisis de la cadena de valor.

Para determinar la ventaja competitiva del proyecto se utilizó el primer instrumento, la matriz basada en las capacidades valiosas, singulares, costosas de imitar e insustituibles, la cual ayuda a determinar que recursos y capacidades pueden alcanzar a ser ventajas competitivas sostenibles. 
Tabla 68.

Matriz para determinar la ventaja competitiva

\begin{tabular}{|c|c|c|c|c|c|}
\hline RECURSOS Y CAPACIDADES & VALIOSA & SINGULAR & COSTOSA & $\begin{array}{l}\text { DIFICIL DE } \\
\text { SUSTITUIR }\end{array}$ & $\begin{array}{c}\text { COMPETENCIA CENTRAL } \\
\text { FUENTE DE VENTAJA } \\
\text { COMPETITVA } \\
\end{array}$ \\
\hline $\begin{array}{l}\text { Gerencia con conocimientos en gestión y } \\
\text { planeamiento estratégico. }\end{array}$ & SI & SI & NO & SI & Ventaja competitiva temporal \\
\hline Servicio de Delivery & SI & NO & NO & NO & Paridad competitiva \\
\hline Presencia en redes sociales & SI & NO & NO & NO & Paridad competitiva \\
\hline Liquidez financiera & SI & SI & NO & SI & Ventaja competitiva temporal \\
\hline Ubicación del local en zona estratégica. & SI & SI & NO & SI & Ventaja competitiva temporal \\
\hline $\begin{array}{l}\text { Calidad de insumos y variedad en la } \\
\text { elaboración de loncheras nutritivas y } \\
\text { saludables }\end{array}$ & SI & SI & SI & SI & Ventaja competitiva sostenible \\
\hline Alianzas estratégicas con colegios. & SI & SI & NO & SI & Ventaja competitiva temporal \\
\hline La marca & SI & NO & NO & SI & Paridad competitiva \\
\hline $\begin{array}{l}\text { Servicios agregados (consultas } \\
\text { nutricionales) }\end{array}$ & SI & SI & NO & NO & Ventaja competitiva temporal \\
\hline
\end{tabular}


De acuerdo con los resultados de combinaciones de criterios para hallar la ventaja competitiva sostenible se determinó la ventaja competitiva del negocio que es la calidad de insumos y variedad en la elaboración de loncheras nutritivas y saludables.

\subsection{Diseño de la estructura organizacional deseada}

Sapag y Sapag (2008) indicaron sobre la posibilidad de establecer la estructura organizativa, la cual permite definir las necesidades de personal y estimar el costo de personal. Todo ello permitirá su aplicación posteriormente en las operaciones.

El diseño del negocio establece dos áreas principales: el área administrativa y de operaciones (cocina); así como también el personal asignado a cada una de las actividades a ser realizadas.

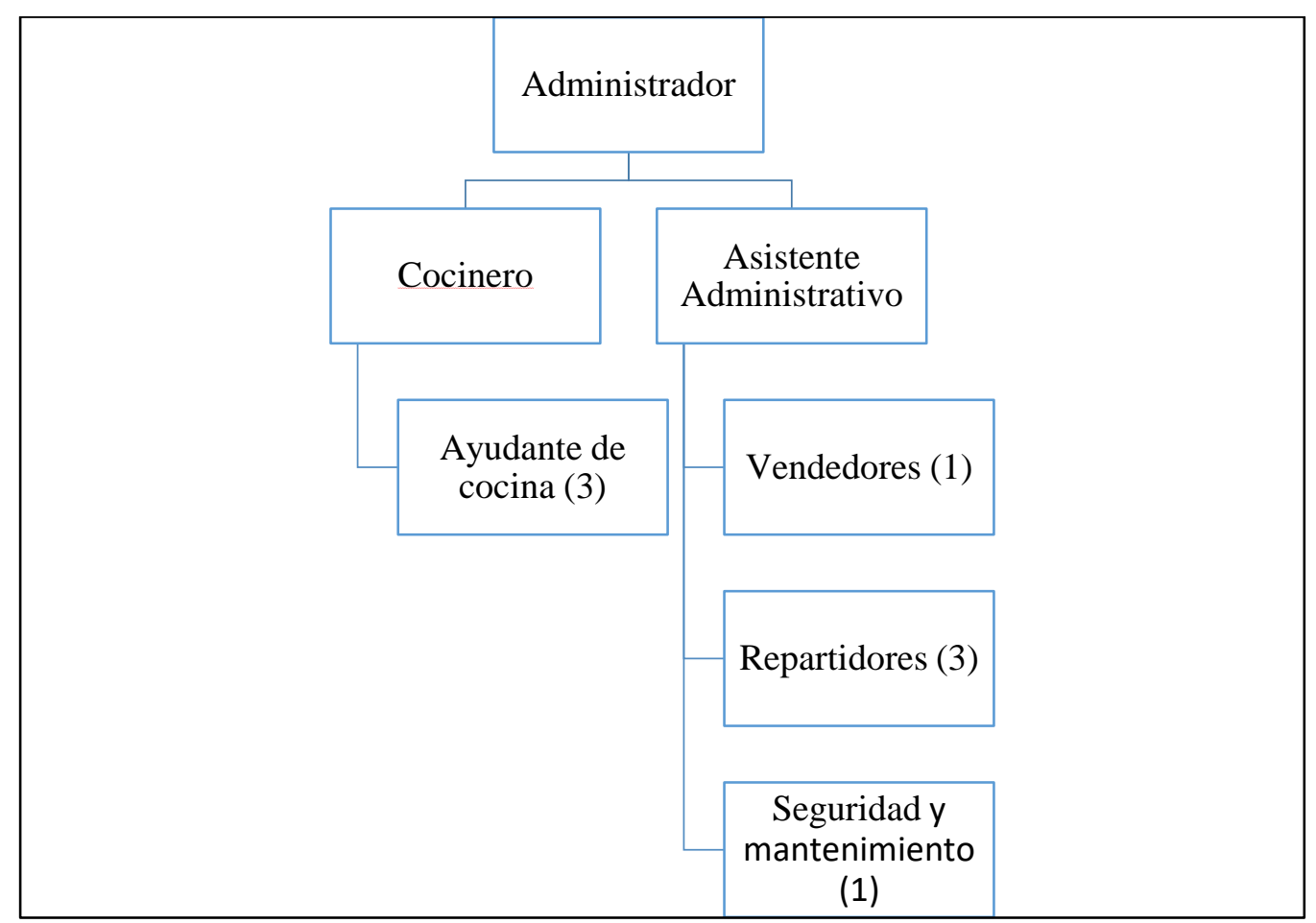

Figura 51. Organigrama del proyecto. Elaboración propia.

El presente organigrama permite establecer las relaciones y jerarquías dentro de la empresa; establece la presencia de un Administrador quien dirige los trabajos administrativos y operaciones, en busca de las metas establecidas. 
El administrador será responsable principalmente de la parte comercial, distribución, administrativa y logística de la empresa, así como realizar la coordinación constante con el área de operaciones.

El cocinero es el jefe de cocina y responsable de la parte operativa y elaboración de los productos a ser distribuidos a los clientes y que debe cumplir las especificaciones comerciales y de inocuidad establecidos.

\subsection{Diseño de los perfiles de puestos clave}

Sapag y Sapag (2008) señalan que la caracterización del personal hará posible determinar los requisitos de cada cargo y asignar una renta equivalente a las responsabilidades y funciones que le corresponden.

La descripción de los puestos se detalla en las siguientes tablas 
Tabla 69.

Descripción de puesto - Administrador

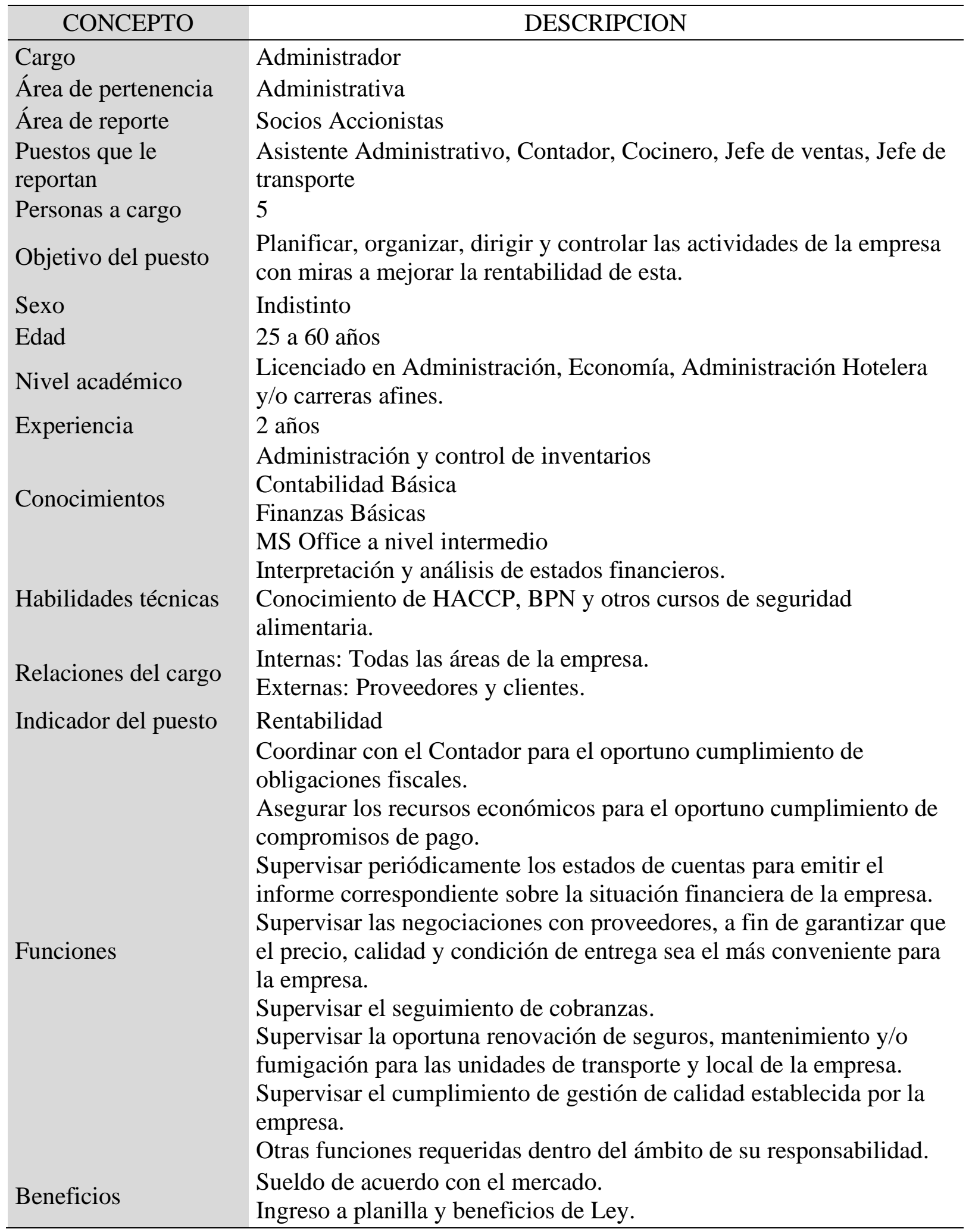

Nota: Elaboración propia. 
Tabla 70.

Descripción de puesto - Asistente administrativo

\begin{tabular}{|c|c|}
\hline CONCEPTO & DESCRIPCION \\
\hline Cargo & Asistente Administrativo \\
\hline Área de pertenencia & Administración \\
\hline Área de reporte & Administración - Administrador \\
\hline $\begin{array}{l}\text { Puestos que le } \\
\text { reportan }\end{array}$ & No aplica \\
\hline Personas a cargo & No aplica \\
\hline Objetivo del puesto & $\begin{array}{l}\text { Brindar soporte a las actividades cotidianas del Administrador, así } \\
\text { como facilitar la comunicación con las áreas dependientes y de } \\
\text { reporte. }\end{array}$ \\
\hline Sexo & Indistinto \\
\hline Edad & 23 a 55 años \\
\hline Nivel académico & $\begin{array}{l}\text { Técnico en Administración, Economía, Administración hotelera y/o } \\
\text { carreras afines }\end{array}$ \\
\hline Experiencia & 1 año \\
\hline Conocimientos & Manejo de herramientas MS office a nivel intermedio \\
\hline Habilidades técnicas & $\begin{array}{l}\text { Administración Básica. } \\
\text { Contabilidad Básica. }\end{array}$ \\
\hline Relaciones del cargo & $\begin{array}{l}\text { Internas: Todas las áreas de la empresa } \\
\text { Externas: Proveedores y clientes }\end{array}$ \\
\hline Indicador del puesto & \\
\hline Funciones & $\begin{array}{l}\text { Elaboración de informe de ventas y reparto diario. } \\
\text { Seguimiento de cobranzas y pago a proveedores. } \\
\text { Elaboración, seguimiento, archivo y custodia de documentos del } \\
\text { área. } \\
\text { Organización y seguimiento de la agenda del Administrador. } \\
\text { Seguimiento de vencimientos y elaboración de informes. } \\
\text { Atención telefónica a clientes y proveedores. } \\
\text { Seguimiento, control e informe de la asistencia del personal, así } \\
\text { como el informe diario al Contador. } \\
\text { Otras funciones requeridas dentro del ámbito de su responsabilidad. }\end{array}$ \\
\hline Beneficios & $\begin{array}{l}\text { Sueldo de acuerdo con el mercado. } \\
\text { Ingreso a planilla y beneficios de Ley. }\end{array}$ \\
\hline
\end{tabular}

Nota: Elaboración propia. 
Tabla 71

Descripción de puesto - Cocinero Jefe de cocina

\begin{tabular}{|c|c|}
\hline CONCEPTO & DESCRIPCION \\
\hline Cargo & Cocinero - Jefe de cocina \\
\hline Área de pertenencia & Producción \\
\hline Área de reporte & Administración - Administrador \\
\hline Puestos que le reportan & Ayudantes de cocina \\
\hline \multicolumn{2}{|l|}{ Personas a cargo } \\
\hline Objetivo del puesto & $\begin{array}{l}\text { Organizar, dirigir y controlar las actividades de su área con la } \\
\text { finalidad de cumplir en forma oportuna con la entrega de } \\
\text { productos dentro de los horarios establecidos. }\end{array}$ \\
\hline Sexo & Indistinto \\
\hline Edad & 24 a 55 años \\
\hline Nivel académico & Egresado de escuela de gastronomía \\
\hline Experiencia & 1 año \\
\hline Conocimientos & $\begin{array}{l}\text { Manipulación de alimentos. } \\
\text { Control de aprovisionamiento y conservación de alimentos. } \\
\text { Control de inventario y requerimiento oportuno de insumos. } \\
\text { HACCP, BPN u otros cursos de seguridad alimentaria. }\end{array}$ \\
\hline Habilidades técnicas & $\begin{array}{l}\text { Planificación de actividades diarias. } \\
\text { Aprovechamiento oportuno de insumos del almacén. }\end{array}$ \\
\hline Relaciones del cargo & $\begin{array}{l}\text { Internas: Administrador, Asistente Administrativa, Transporte. } \\
\text { Externas: Proveedores. }\end{array}$ \\
\hline \multicolumn{2}{|l|}{ Indicador del puesto } \\
\hline & $\begin{array}{l}\text { Selección, instrucción y/o capacitación de personal a cargo. } \\
\text { Elaboración y empaquetado de loncheras según cronograma de } \\
\text { pedidos establecido. }\end{array}$ \\
\hline Funciones: & $\begin{array}{l}\text { Revisión, control y requerimiento de reposición de equipos de } \\
\text { cocina. } \\
\text { Otras funciones requeridas dentro del ámbito de su } \\
\text { responsabilidad. }\end{array}$ \\
\hline Beneficios: & $\begin{array}{l}\text { Sueldo de acuerdo con el mercado } \\
\text { Ingreso a planilla y beneficios de Ley. }\end{array}$ \\
\hline
\end{tabular}

Nota: Elaboración propia. 
Tabla 72.

Descripción de puesto - Ayudante de cocina

\begin{tabular}{ll}
\hline \multicolumn{1}{c}{ CONCEPTO } & \\
\hline Cargo & Ayudante de cocina \\
Área de pertenencia & Producción \\
Área de reporte & Producción - Cocinero, Jefe de Cocina \\
Puestos que le reportan & No aplica \\
Personas a cargo & No aplica \\
Objetivo del puesto & Asistir al Jefe de Cocina y realizar las actividades asignadas \\
Sexo: & Indistinto \\
Edad: & 20 a 50 años \\
Estudios: & Estudios técnicos en cocina, no indispensable \\
Experiencia: & 1 año \\
Conocimientos & Manipulación de alimentos \\
Habilidades técnicas & Internas: Jefe directo \\
Relaciones del cargo & Externas: No aplica \\
Indicador del puesto & $\begin{array}{l}\text { Elaboración y empaquetado de loncheras según la indicación } \\
\text { del jefe directo. } \\
\text { Mantener en todo momento la higiene y orden de la cocina, }\end{array}$ \\
áreas de preparación y almacenamiento de alimentos. \\
Controlar y verificar la calidad de los insumos, así como \\
reportar al jefe directo sobre el cumplimiento de \\
requerimientos a los proveedores. \\
Realizar inventarios periódicos sobre el estado de utensilios y \\
equipos de cocina \\
Otras funciones requeridas dentro del ámbito de su \\
responsabilidad. \\
Sueldo de acuerdo con el mercado. \\
Ingreso a planilla y beneficios de Ley. \\
\hline
\end{tabular}

Nota: Elaboración propia. 
Tabla 73

Descripción de puesto - Vendedor

\begin{tabular}{ll}
\multicolumn{1}{c}{ CONCEPTO } & \\
\hline $\begin{array}{l}\text { Cargo } \\
\text { Área de pertenencia }\end{array}$ & Vendedor \\
Área de reporte & Comercial \\
Puestos que le reportan & Administrador \\
Personas a cargo & No aplica \\
Objetivo del puesto & Ventas \\
Sexo: & Indistinto \\
Edad: & 20 a 50 años \\
Estudios: & Estudios técnicos en Comunicaciones, Marketing, \\
Experiencia: & Administración y/o afines, no indispensable \\
Conocimientos & 1 año \\
Habilidades técnicas & Manipulación de alimentos \\
Relaciones del cargo & Comunicación en todo nivel \\
Indicador del puesto & Internas: Jefe directo \\
& Externas: Clientes potenciales \\
& \\
Funciones: & Búsqueda de convenios con escuelas del área de reparto. \\
& Promoción y venta de loncheras saludables. \\
Beneficios: & Otras funciones requeridas dentro del ámbito de su \\
responsabilidad. & Sueldo de acuerdo con el mercado. \\
\hline & Ingreso a planilla y beneficios de Ley. \\
\hline
\end{tabular}

Nota: Elaboración propia. 
Tabla 74

Descripción de puesto - Repartidor

\begin{tabular}{ll}
\hline \multicolumn{1}{c}{ CONCEPTO } & \\
\hline Cargo & Repartidor \\
Área de pertenencia & Transporte \\
Área de reporte & Administrador \\
Puestos que le reportan & No aplica \\
Personas a cargo & Ayudante de repartidor \\
Objetivo del puesto & Transporte y manipulación de jabas de loncheras \\
Sexo: & Hombre \\
Edad: & 20 a 50 años \\
Estudios: & Estudios técnicos, no indispensable \\
Experiencia: & 1 año \\
Conocimientos & Brevete A1 \\
Habilidades técnicas & Comunicación en todo nivel \\
Relaciones del cargo & Internas: Administrador \\
Indicador del puesto & Externas: Clientes potenciales \\
& \\
Funciones: & Transporte de loncheras a las escuelas asignadas. \\
& Recojo de jabas y ayudante de retorno a oficina. \\
& Otras funciones requeridas dentro del ámbito de su \\
Beneficios: & responsabilidad. \\
\hline
\end{tabular}

Nota: Elaboración propia. 


\subsection{Remuneraciones compensaciones e incentivos}

Las remuneraciones establecidas por la empresa toman en cuenta las siguientes consideraciones:

- Remuneración mínima vital

- Seguro social de salud

- Seguro de vida ley

- Régimen pensionario

- Compensación por tiempo de servicio

- Gratificaciones en julio y diciembre

- Vacaciones

- Asignación familiar

Las remuneraciones mensuales por puesto serán las siguientes:

Tabla 75

Remuneraciones mensuales

\begin{tabular}{lll}
\hline $\mathrm{N}^{\circ}$ & Puesto & Remuneración: \\
\hline 01 & Administrador & $\mathrm{S} / 2500.00$ \\
01 & Asistente administrativo & $\mathrm{S} / 1200.00$ \\
01 & Cocinero & $\mathrm{S} / 1200.00$ \\
03 & Ayudante de cocina & $\mathrm{S} / 930.00$ \\
01 & Vendedores & $\mathrm{S} / 930.00$ \\
03 & Repartidores & $\mathrm{S} / 930.00$ \\
01 & Mantenimiento & $\mathrm{S} / 930.00$ \\
\hline
\end{tabular}

Nota: Elaboración propia. 
Tabla 76

Planilla de personal Año 1 al año 3.

\begin{tabular}{|c|c|c|c|c|c|c|c|c|c|}
\hline Puesto & $\begin{array}{l}\text { Sueldo } \\
\text { Mensual }\end{array}$ & $\begin{array}{c}\text { Asignación } \\
\text { Familiar }\end{array}$ & $\begin{array}{c}\text { AFP* } \\
(11,54 \%)\end{array}$ & $\begin{array}{c}\text { CTS } \\
\text { Mensual }\end{array}$ & $\begin{array}{c}\text { Gratificación } \\
\text { Mensual }\end{array}$ & $\begin{array}{c}\text { Essalud } \\
(9 \%)\end{array}$ & Total Anual & \# Personal & Total \\
\hline Administrador & $\mathrm{S} / .2,500.00$ & S/.93.00 & $\mathrm{S} / .298 .31$ & S/.107.71 & S/.215.42 & $\mathrm{S} / .232 .65$ & S/.41,269.01 & 1 & $\mathrm{~S} / .41,269.01$ \\
\hline $\begin{array}{c}\text { Asistente } \\
\text { administrativo }\end{array}$ & S/.1,200.00 & $\mathrm{S} / .93 .00$ & S/.148.29 & S/.53.54 & S/.107.08 & S/.115.65 & S/.20,514.77 & 1 & S/.20,514.77 \\
\hline Cocinero & $\mathrm{S} / .1,200.00$ & S/.93.00 & S/.148.29 & S/.53.54 & S/.107.08 & S/.115.65 & S/.20,514.77 & 1 & S/.20,514.77 \\
\hline $\begin{array}{l}\text { Ayudante } \\
\text { Cocina }\end{array}$ & S/.930.00 & S/.93.00 & S/.107.90 & S/.38.96 & S/.77.92 & S/.84.15 & S/.14,927.09 & 3 & S/.44,781.26 \\
\hline Vendedor & $\mathrm{S} / .930 .00$ & S/.93.00 & S/.107.90 & S/.38.96 & S/.77.92 & S/.84.15 & S/.14,927.09 & 1 & S/.14,927.09 \\
\hline Mantenimiento & $\mathrm{S} / .930 .00$ & S/.93.00 & S/.107.90 & S/.38.96 & S/.77.92 & S/.84.15 & S/.14,927.09 & 1 & S/.14,927.09 \\
\hline \multirow[t]{2}{*}{ Repartidores } & S/.930.00 & S/.93.00 & S/.107.90 & S/.38.96 & S/.77.92 & S/.84.15 & S/.14,927.09 & 3 & S/.44,781.26 \\
\hline & & & & & & Total & $\mathrm{S} / .121,492.13$ & & S/.181,200.48 \\
\hline
\end{tabular}

Nota: Elaboración propia. 
Tabla 77

Planilla de personal Año 4 al año 5

\begin{tabular}{ccccccccccc}
\hline Puesto & $\begin{array}{c}\text { Sueldo } \\
\text { Mensual }\end{array}$ & $\begin{array}{c}\text { Asignación } \\
\text { Familiar }\end{array}$ & $\begin{array}{c}\text { AFP* } \\
(11,54 \%)\end{array}$ & $\begin{array}{c}\text { CTS } \\
\text { Mensual }\end{array}$ & $\begin{array}{c}\text { Gratificación } \\
\text { Mensual }\end{array}$ & $\begin{array}{c}\text { Essalud } \\
(9 \%)\end{array}$ & Total Anual & \# Personal & Total \\
\hline Administrador & $\mathrm{S} / .2,500.00$ & $\mathrm{~S} / .93 .00$ & $\mathrm{~S} / .298 .31$ & $\mathrm{~S} / .107 .71$ & $\mathrm{~S} / .215 .42$ & $\mathrm{~S} / .232 .65$ & $\mathrm{~S} / .41,269.01$ & 1 & $\mathrm{~S} / .41,269.01$ \\
$\begin{array}{c}\text { Asistente } \\
\text { administrativo }\end{array}$ & $\mathrm{S} / .1,200.00$ & $\mathrm{~S} / .93 .00$ & $\mathrm{~S} / .148 .29$ & $\mathrm{~S} / .53 .54$ & $\mathrm{~S} / .107 .08$ & $\mathrm{~S} / .115 .65$ & $\mathrm{~S} / .20,514.77$ & 1 & $\mathrm{~S} / .20,514.77$ \\
$\begin{array}{c}\text { Cocinero } \\
\text { Ayudante }\end{array}$ & $\mathrm{S} / .1,200.00$ & $\mathrm{~S} / .93 .00$ & $\mathrm{~S} / .148 .29$ & $\mathrm{~S} / .53 .54$ & $\mathrm{~S} / .107 .08$ & $\mathrm{~S} / .115 .65$ & $\mathrm{~S} / .20,514.77$ & 1 & $\mathrm{~S} / .20,514.77$ \\
$\begin{array}{c}\text { Cocina } \\
\text { Vendedor }\end{array}$ & $\mathrm{S} / .930 .00$ & $\mathrm{~S} / .93 .00$ & $\mathrm{~S} / .107 .90$ & $\mathrm{~S} / .38 .96$ & $\mathrm{~S} / .77 .92$ & $\mathrm{~S} / .84 .15$ & $\mathrm{~S} / .14,927.09$ & 4 & $\mathrm{~S} / .59,708.35$ \\
$\begin{array}{c}\text { Mantenimiento } \\
\text { Repartidores }\end{array}$ & $\mathrm{S} / .930 .00$ & $\mathrm{~S} / .93 .00$ & $\mathrm{~S} / .107 .90$ & $\mathrm{~S} / .38 .96$ & $\mathrm{~S} / .77 .92$ & $\mathrm{~S} / .84 .15$ & $\mathrm{~S} / .14,927.09$ & 1 & $\mathrm{~S} / .14,927.09$ \\
& & $\mathrm{~S} / .93 .00$ & $\mathrm{~S} / .107 .90$ & $\mathrm{~S} / .38 .96$ & $\mathrm{~S} / .77 .92$ & $\mathrm{~S} / .84 .15$ & $\mathrm{~S} / .14,927.09$ & 1 & $\mathrm{~S} / .14,927.09$ \\
& & $\mathrm{~S} / .93 .00$ & $\mathrm{~S} / .107 .90$ & $\mathrm{~S} / .38 .96$ & $\mathrm{~S} / .77 .92$ & $\mathrm{~S} / .84 .15$ & $\mathrm{~S} / .14,927.09$ & 3 & $\mathrm{~S} / .44,781.26$ \\
\hline
\end{tabular}

Nota: Elaboración propia. 


\subsection{Política de recursos humanos}

La política de recursos humanos tiene por objeto establecer el conjunto de normas de la relación laboral en la empresa. Brinda los principales servicios, obligaciones y deberes dentro de la empresa:

\section{Derechos de la empresa:}

Es derecho exclusivo de la empresa planear, organizar, coordinar, administrar, dirigir y controlar las actividades del personal en el centro de trabajo. Además, tiene comprendido lo siguiente:

- Establecer y modificar horarios de trabajo

- Introducir nuevos métodos de trabajo

- Contratar nuevo personal de acuerdo a las necesidades

- Celebrar contratos de trabajo a plazo indeterminado, plazo fijo, tiempo completo y a tiempo parcial

- Transferir, descartar o rotar a un colaborador a diferentes puestos, cuando lo considere necesario para sus funciones

- Dirigir y controlar la realización de las labores asignadas a sus colaboradores.

\section{Obligaciones de la empresa:}

Dentro de las obligaciones encontramos:

- Dar cumplimiento a la legislación laboral vigente.

- Cumplir con el pago oportuno de las remuneraciones.

- Cumplir con las condiciones de salud, higiene y seguridad.

- Proporcionar un ambiente adecuado de trabajo

- Brindar disposiciones de uniformes según requerimiento del puesto. 


\section{Capítulo VII. Plan de marketing}

\subsection{Estrategias de marketing}

De acuerdo con Kotler y Lane (2016), para desarrollar una estrategia de marketing se necesita trabajar de forma conjunta la disciplina y flexibilidad, con la finalidad de saber cuál es el camino planificado, pero con la posibilidad a mejorarlo de forma constante. (p. 35).

\subsubsection{Estrategia de producto}

Según Ferrell y Hartline (2012) una buena estrategia de producto se enfoca en todos los elementos de la oferta de producto más que en un solo elemento. (p.191).

\section{a. Marca}

Conforme a lo señalado por Ferrell y Hartline (2012) las marcas son importantes para atraer la afluencia de los clientes, ya que esta brinda la confianza de la compra. (p. 204).

El nombre de la empresa es "Lunch Kids", que es la traducción de lonchera para niños y es el nombre con el que se identificó el mayor porcentaje de personas tanto en los focus como en las encuestas.

\section{b. Logotipo.}

De acuerdo a Ferrell y Hartline (2012) la imagen de un producto es la impresión general, positiva o negativa que los clientes se forman. (p. 213).

Para crear el logo, primero se debía concebir el nombre de la empresa y relacionarlo con el mercado objetivo, los niños, a quienes llama la atención los colores vivos. 


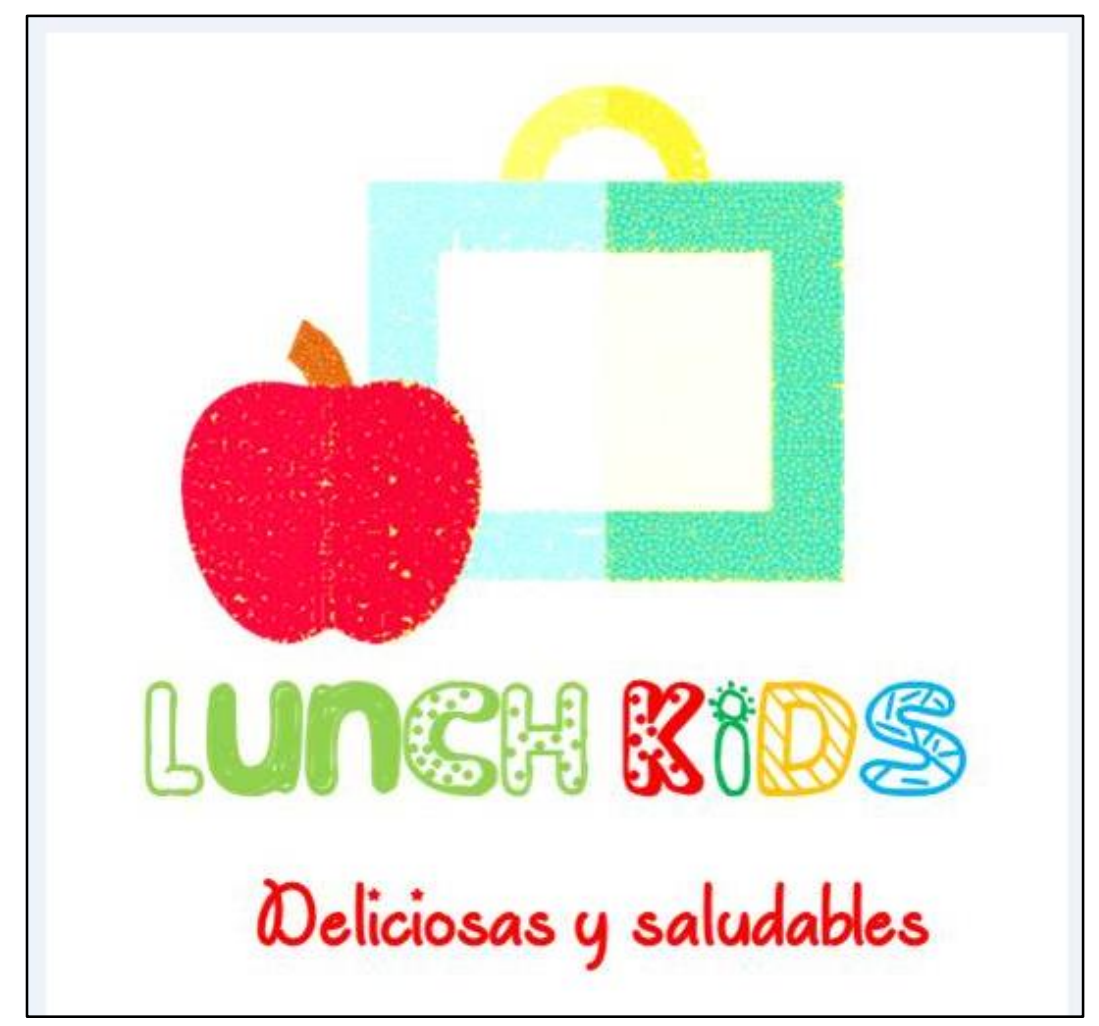

Figura 52. Logo "Lunch kids". Fuente: Elaboración propia.

\section{c. Slogan}

El slogan es la frase que describe el producto y servicio, el cual ayuda a diferenciarlo de los demás competidores. Se consideró una frase fácil de recordación para el público objetivo. El slogan elegido por los encuestados fue "Deliciosas y saludables", es decir los niños podrán disfrutar de alimentos agradables al paladar y a la vez nutritivas y saludables para su organismo.

\section{d. Carta}

Las alternativas de loncheras son variadas y programadas semanalmente, según la recomendación del nutricionista para la debida asimilación de nutrientes y proteínas que contiene cada lonchera. 
Tabla 78

Contenido de loncheras (semanal)

\begin{tabular}{|c|c|c|c|c|}
\hline Semana & Día & Sánguche (Constructores/energéticos/protectores) & Refresco & Fruta \\
\hline \multirow{5}{*}{1} & Lunes & atún & piña & mandarina \\
\hline & Martes & Galletas de quinua & naranjada & piña en trozos \\
\hline & Miércoles & 4 huevito de codorniz con galletas de soda & piña & granadilla \\
\hline & Jueves & sangrecita criolla & limonada & mandarina \\
\hline & Viernes & tortilla de zanahoria y cebolla & manzana & manzana \\
\hline \multirow{5}{*}{2} & Lunes & pollo con lechuga y tomate & Chicha morada & mandarina \\
\hline & Martes & choclo desgranado con trocitos de queso & limonada & mandarina \\
\hline & Miércoles & palta, huevo, lechuga & manzana & granadilla \\
\hline & Jueves & Galletas de avena con castaña & carambola & uva \\
\hline & Viernes & papa con queso & Chicha morada & durazno \\
\hline \multirow{5}{*}{3} & Lunes & huevito de codorniz con trocitos de papa & carambola & mandarina \\
\hline & Martes & Galletas de higo & cebada & manzana \\
\hline & Miércoles & atún & piña & mandarina \\
\hline & Jueves & pollo con lechuga & naranjada & durazno \\
\hline & Viernes & aceituna y huevo sancochado & carambola & \\
\hline \multirow{5}{*}{4} & Lunes & choclo rebozado con huevo & cebada & tuna \\
\hline & Martes & queso fresco & membrillo & mandarina \\
\hline & Miércoles & Galletas de salvado de trigo & piña & naranja \\
\hline & Jueves & tortilla de zanahoria y cebolla & manzana & manzana \\
\hline & Viernes & yogurt natural & cebada & plátano seda \\
\hline \multirow{5}{*}{5} & Lunes & huevitos de codorniz con trocitos de queso & limonada & granadilla \\
\hline & Martes & hamburguesa cacera & piña & manzana \\
\hline & Miércoles & Galletas de germen de trigo & naranjada & piña en trozos \\
\hline & Jueves & pollo con zanahoria, tomate y lechuga & carambola & durazno \\
\hline & Viernes & jamón de pavita & Chicha morada & plátano seda \\
\hline
\end{tabular}




\section{e. Envase.}

De acuerdo con Ferrell y Hartline, (2012) "Cuando los paquetes en una línea de productos tienen el mismo aspecto y sensación, los clientes pueden identificarlos con mayor rapidez.”. (p. 195).

La presentación de los productos se realizará a través de bolsas de papel reciclable las cuales contará con un sanguches, una fruta y una botella de refresco natural.

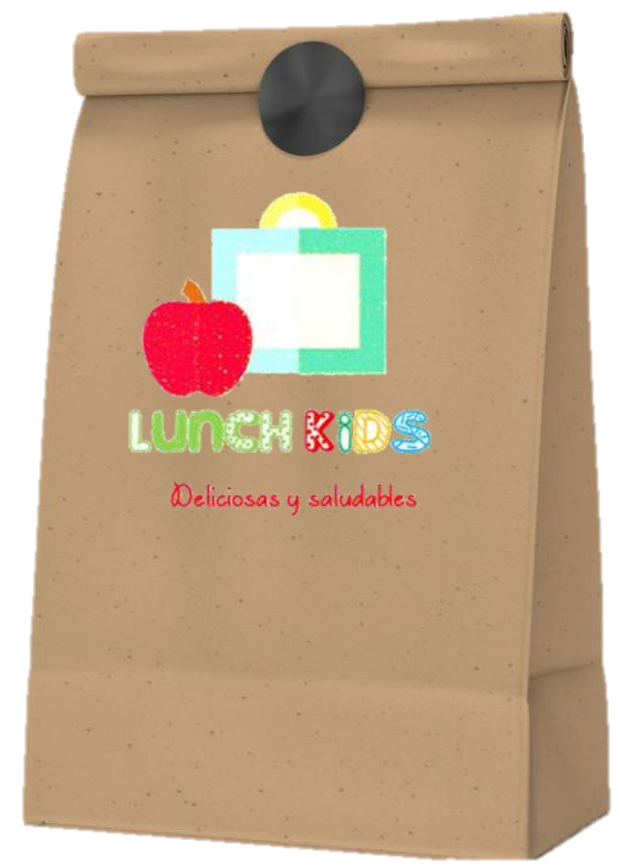

Figura 53. Empaque. Elaboración propia.

\subsubsection{Estrategia de precio}

Según Ferrell y Hartline (2012) las estrategias de fijación de precios pueden variar de acuerdo al ciclo de vida del producto. (p. 239)

La fijación de precios estará en función al valor percibido, considerando la imagen que se proyectará al cliente con respecto al producto ofrecido, la garantía del servicio y la distribución. En función a ello se tomarán en cuenta los siguientes factores: 
- Percepciones de valor de los clientes

Mediante la información obtenida en los estudios cuantitativos y cualitativos en cuanto al precio que están dispuestos a pagar por el servicio, se pudo determinar que el precio está entre 5 y 6 soles. Según la encuesta realizada, un $64 \%$ indicó que compraría el producto a un precio entre 5 y 6 soles. (ver Tabla 78).

Tabla 79

Resultado de encuesta - Rango de precio

Pregunta 8 ¿Cuánto estaría dispuesto a pagar por una lonchera saludable que incluye refresco, sanguche y fruta?

\begin{tabular}{clcc}
\hline \multicolumn{1}{c}{ Respuesta } & Cantidad & Porcentaje \\
\hline a. & Menos de S/3 & 8 & $2 \%$ \\
b. & De S/3 a menos de S/5 & 17 & $4 \%$ \\
c. & De S/5 a menos de S/6 & 247 & $64 \%$ \\
d. De S/6 a menos de S/7 & 83 & $22 \%$ \\
e. De S/7 a menos de S/8 & 17 & $4 \%$ \\
f. De S/8 a menos de S/9 & 9 & $2 \%$ \\
g. & Más de S/. 9 soles & 3 & $1 \%$ \\
& Total & 384 & $100 \%$ \\
\hline
\end{tabular}

Nota: Elaboración propia.

- Costos del producto

Segun Ferrell y Hartline (2012) los costos de comercialización y producción son de mucha importancia ya que estos determinan los ingresos y utilidades de la empresa. (p. 237).

Para fijar el precio se determinó los costos de producción como se muestra en la siguiente tabla, asimismo se sumará los costos de distribución y un margen de utilidades. (ver Tabla 79). 
Tabla 80.

Costos de producción de una lonchera

\begin{tabular}{|c|c|c|c|c|c|c|c|c|c|}
\hline Sem. & Día & Sanguche (Constructores/energéticos/protectores) & Refresco & Fruta & $\begin{array}{l}\text { Costo de } \\
\text { producción } \\
\text { Primaria }\end{array}$ & $\begin{array}{l}\text { Costo de } \\
\text { producción } \\
\text { Inicial } \\
\end{array}$ & $\begin{array}{c}\text { Gatos de } \\
\text { distribución }\end{array}$ & Sub total & $\begin{array}{l}\text { Precio Final } \\
\text { Margen } 80 \%\end{array}$ \\
\hline \multirow{5}{*}{1} & Lunes & Atún & piña & $\begin{array}{l}\text { mandarina } \\
\text { piña en }\end{array}$ & S/. 2.52 & S/. 1.90 & S/. 0.01 & $\mathrm{~S} / .2 .53$ & S/. 4.55 \\
\hline & Martes & Galletas de quinua & naranjada & trozos & S/. 2.87 & S/. 1.75 & S/. 0.01 & S/. 2.88 & S/. 5.19 \\
\hline & Miércoles & 4 huevito de codorniz con galletas de soda & piña & granadilla & S/. 3.23 & S/. 2.59 & S/. 0.01 & S/. 3.24 & S/. 5.83 \\
\hline & Jueves & sangrecita criolla & limonada & mandarina & $\mathrm{S} / .2 .25$ & S/. 1.87 & $\mathrm{~S} / .0 .01$ & S/. 2.26 & S/. 4.07 \\
\hline & Viernes & tortilla de zanahoria y cebolla & manzana & manzana & S/. 1.44 & $\mathrm{~S} / .1 .30$ & $\mathrm{~S} / .0 .01$ & S/. 1.45 & S/. 2.61 \\
\hline \multirow{5}{*}{2} & Lunes & pollo con lechuga y tomate & Chicha morada & mandarina & S/. 2.25 & S/. 1.80 & S/. 0.01 & S/. 2.26 & S/. 4.07 \\
\hline & Martes & choclo desgranado con trocitos de queso & limonada & mandarina & S/. 3.15 & S/. 2.61 & S/. 0.01 & S/. 3.16 & S/. 5.68 \\
\hline & Miércoles & palta, huevo, lechuga & manzana & granadilla & S/. 2.23 & S/. 1.92 & S/. 0.01 & S/. 2.24 & S/. 4.03 \\
\hline & Jueves & Galletas de avena con castaña & carambola & uva & $\mathrm{S} / .2 .45$ & S/. 1.57 & S/. 0.01 & S/. 2.46 & S/. 4.42 \\
\hline & Viernes & papa con queso & Chicha morada & durazno & S/. 2.27 & S/. 1.75 & S/. 0.01 & S/. 2.28 & S/. 4.11 \\
\hline \multirow{5}{*}{3} & Lunes & huevito de codorniz con trocitos de papa & carambola & mandarina & S/. 3.25 & S/. 2.36 & S/. 0.01 & S/. 3.26 & S/. 5.86 \\
\hline & Martes & Galletas de higo & cebada & manzana & $\mathrm{S} / .2 .03$ & $\mathrm{~S} / .1 .33$ & $\mathrm{~S} / .0 .01$ & S/. 2.04 & S/. 3.68 \\
\hline & Miércoles & atún & piña & mandarina & S/. 2.52 & S/. 1.64 & S/. 0.01 & S/. 2.53 & S/. 4.55 \\
\hline & Jueves & pollo con lechuga & naranjada & durazno & $\mathrm{S} / .2 .19$ & S/. 1.61 & $\mathrm{~S} / .0 .01$ & S/. 2.20 & S/. 3.95 \\
\hline & Viernes & aceituna y huevo sancochado & carambola & & S/. 1.90 & S/. 1.17 & S/. 0.01 & S/. 1.91 & S/. 3.43 \\
\hline \multirow{5}{*}{4} & Lunes & choclo rebozado con huevo & cebada & tuna & S/. 3.14 & S/. 2.14 & S/. 0.01 & S/. 3.15 & S/. 5.67 \\
\hline & Martes & queso fresco & membrillo & mandarina & S/. 2.19 & S/. 1.73 & S/. 0.01 & $\mathrm{~S} / .2 .20$ & S/. 3.97 \\
\hline & Miércoles & Galletas de salvado de trigo & piña & naranja & S/. 2.54 & S/. 1.65 & $\mathrm{~S} / .0 .01$ & S/. 2.55 & S/. 4.59 \\
\hline & Jueves & tortilla de zanahoria y cebolla & manzana & $\begin{array}{l}\text { manzana } \\
\text { plátano }\end{array}$ & S/. 1.59 & S/. 1.26 & S/. 0.01 & S/. 1.60 & S/. 2.88 \\
\hline & Viernes & yogurt natural & cebada & seda & S/. 1.95 & S/. 1.41 & S/. 0.01 & S/. 1.96 & S/. 3.53 \\
\hline \multirow{6}{*}{5} & Lunes & huevitos de codorniz con trocitos de queso & limonada & granadilla & $\mathrm{S} / .3 .68$ & $\mathrm{~S} / .2 .76$ & $\mathrm{~S} / .0 .01$ & S/. 3.69 & S/. 6.63 \\
\hline & Martes & hamburguesa cacera & piña & $\begin{array}{l}\text { manzana } \\
\text { piña en }\end{array}$ & S/. 1.79 & S/. 1.26 & S/. 0.01 & $\mathrm{~S} / .1 .80$ & S/. 3.25 \\
\hline & Miércoles & Galletas de germen de trigo & naranjada & trozos & S/. 2.87 & S/. 1.75 & S/. 0.01 & S/. 2.88 & S/. 5.19 \\
\hline & Jueves & pollo con zanahoria, tomate y lechuga & carambola & $\begin{array}{l}\text { durazno } \\
\text { plátano }\end{array}$ & S/. 2.24 & S/. 1.64 & S/. 0.01 & S/. 2.25 & S/. 4.05 \\
\hline & Viernes & Jamón de pavita & Chicha morada & seda & S/. 1.36 & S/. 1.02 & S/. 0.01 & S/. 1.37 & S/. 2.47 \\
\hline & & & & Promedio & 2.07 & 1.75 & 0.01 & 2.41 & 4.33 \\
\hline
\end{tabular}


Para hallar el costo promedio por lonchera se utilizó como referencia los costos de producción de loncheras para nivel primaria, siendo los costos de distribución los mismos tanto para inicial como primaria, con un margen de $80 \%$ de utilidades obteniendo así el precio promedio de una lonchera, por 4.33 soles.

Cruzando información tanto de los costos y estudio cualitativo y cuantitativo se obtuvo un precio de 5 soles como precio base por lonchera para nivel inicial y 6 soles para nivel primario.

Asimismo, se utilizará estrategia de ajuste de precios, como descuentos por compras por paquetes semanales, quincenales y mensuales.

\section{Tabla 81}

Descuento por compras-precio por paquetes

\begin{tabular}{lrcc}
\hline Paquete & \multicolumn{1}{c}{ Precio } & Descuento & $\begin{array}{c}\text { Precio Final por } \\
\text { paquete }\end{array}$ \\
\hline Semanal & S/. 30.00 & $5 \%$ & S/. 29 \\
Quincenal & S/. 60.00 & $7 \%$ & S/. 56 \\
Mensual & S/. 120.00 & $9 \%$ & S/. 109 \\
\hline
\end{tabular}

Nota: Elaboración propia.

\subsubsection{Estrategia de distribución}

Como menciona Kotler y Lane (2012), un canal de distribución consiste en un conjunto de organizaciones interdependientes que participan en el proceso de poner un producto o servicio a disposición del consumidor.

El canal de distribución que se utilizará será el directo, ya que se llegará a los clientes finales sin intermediarios. 


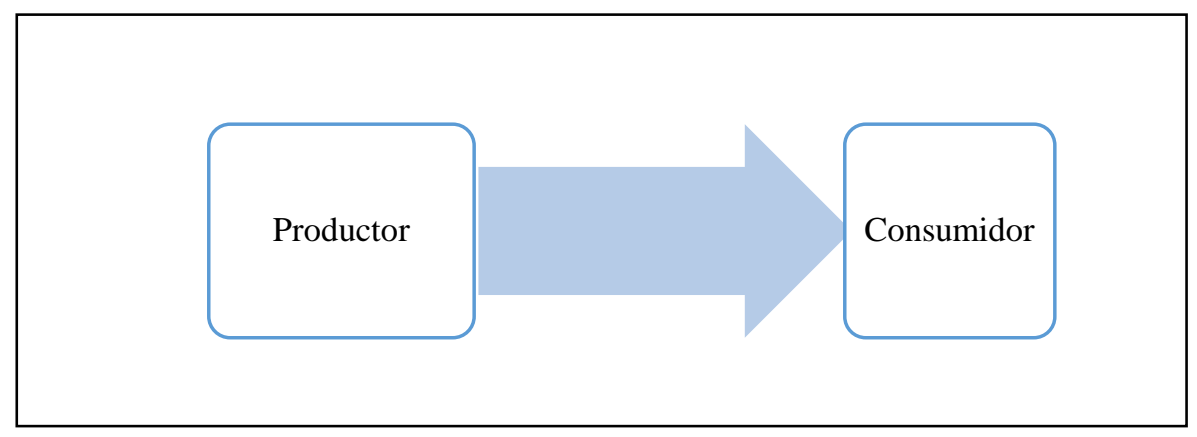

Figura 54. Canal de Distribución. Elaboración propia.

Los canales que se utilizarán para acceder al servicio serán a través de un portal web, Facebook y por teléfono.

El centro de operaciones estará ubicado en el distrito de Ate, ya que permitirá llegar fácilmente a los distritos donde se ubica nuestro público objetivo.

Para realizar la distribución de las loncheras se utilizará vehículos de la empresa.

Los proveedores están ubicados cerca al centro de operaciones, como son el mercado de frutas y MAKRO, ubicados en el distrito de Santa Anita, facilitando así la provisión de insumos para el producto.

A continuación, el proceso de distribución: 


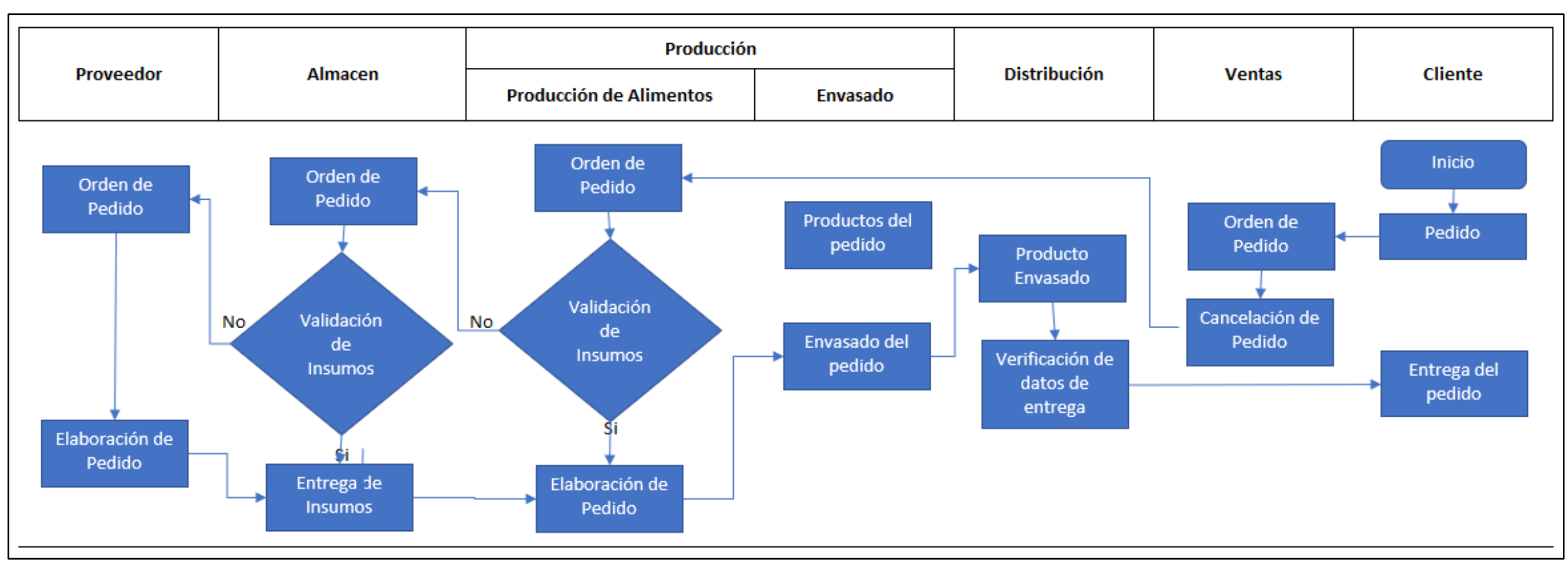

Figura 55. Proceso de Distribución. Adaptado de Gestión de procesos, Pérez. J. (2007). 


\subsubsection{Estrategia de promoción y publicidad}

Según Russel y Lane (1994), la publicidad debe buscar predisponer al consumidor a comprar un producto o servicio.

Asimismo, Dirksen y Kroeger (1984), indican que la publicidad beneficia tanto a consumidores, porque se encuentran mejor informados sobre los productos de su interés, y a los productores porque atrae a sus clientes que terminan incrementando sus utilidades.

Es con esta finalidad que los productores utilizaron estrategias promocionales para que su mensaje llegue en forma efectiva al potencial consumidor.

\section{a. Reparto de volantes.}

Semanas previas a la inauguración de la empresa dos personas repartirán volantes en:

- Los alrededores de la puerta de colegios más cercanos en la zona de Ate, La Molina y Santa Anita, esta repartición se realizará a la hora de ingreso y salida de los alumnos.

- Al ingreso de los supermercados de la zona a media mañana que es cuando las madres realizan compras del día.

- Al ingreso de los centros de esparcimiento para niños en edad escolar, principalmente los fines de semana.

\section{b. Alianzas estratégicas.}

- Con principales colegios de la zona, para acceder a una reunión de padres de familia e informar sobre las bondades del servicio de Lunch Kids y los descuentos a los que 
se puede acceder al tomar una semana de prueba en dicha reunión. De esta forma los colegios acceden a descuentos especiales.

- Con médicos pediatras de la zona, para que recomienden los servicios de Lunch Kids como una alternativa de lonchera saludable para sus hijos en edad escolar.

- Con centros de esparcimiento de menores, con la finalidad de publicitar los servicios de cada empresa entre los potenciales clientes en común.

- Se realizarán convenios con los colegios en los cuales se ofrecerán participación en actividades específicas y publicidad a través de los canales de comunicación al público en general con la finalidad que las entidades brinden las facilidades de ingreso y entrega de las loncheras en las puertas de los salones de los alumnos de primaria e inicial. Los acuerdos de la alianza se detallan en el modelo de convenio detallado en el anexo $\mathrm{N}^{\circ} 16$.

\section{c. Página web}

- Donde se publicará la misión, visión, valores, responsabilidad social y todo lo relacionado a la cultura organizacional de la empresa, así como los servicios que brinda.

- Para que los padres puedan informarse mejor sobre los servicios ofrecidos, ver imágenes de loncheras ofrecidas, realizar consultas en línea e incluso realizar la contratación del servicio en línea.

- Mediante la habilitación del código de asociado donde los padres podrán acceder a información nutricional adecuada para los niños en edad escolar. 


\section{d. Redes sociales}

- Se realizará una campaña de intriga en Facebook y Twitter que permitirá llegar a un mayor número de personas y dar a conocer el servicio brindado por Lunch Kids. El responsable del posteo de actividades será el administrador.

\subsection{Estrategia de ventas}

Según Lambin (2009), la planificación y creación de una estrategia de ventas efectiva, requiere mirar a largo plazo las metas de ventas y análisis del ciclo de negocios.

Es así que, la estrategia de venta a utilizar será diferente en cada etapa del producto, según el siguiente detalle:

\section{a. Fase introductoria}

Según Ferrell y Hartline, (2012) esta etapa inicia cuando el desarrollo ya se encuentra culminado y concluye cuando las ventas muestran que los clientes aceptan de manera favorable el producto. (p. 217)

Dado que no se tiene competencia que se dedique exclusivamente a brindar este servicio, se considera que el cliente potencial puede sentirse atraído por lo novedoso del servicio.

Para ello se realizarán las siguientes estrategias:

- Iniciar con precios promedios, dado que al tratarse de alimentos no se podría tener una buena imagen al ofrecer costos muy reducidos.

- Brindar un código de afiliado a los clientes para que puedan recibir información personalizada sobre los paquetes de consumo y también poder recolectar sus datos para contactarlos en fechas especiales.

- Realizar activaciones en colegios de la zona a fin de dar a conocer los servicios que se ofrecen. 
- Realizar alianzas con centros de recreación escolar, consultorios de pediatría, movilidad escolar, los mismos colegios, entre otros para dar a conocer los servicios ofrecidos.

\section{b. Fase de crecimiento}

Según Ferrell y Hartline (2012) en esta etapa la curva de venta puede ir en aumento y disminuir hacia el final del periodo de crecimiento. (p. 219).

Para esta etapa Lunch Kids contará con el reconocimiento de sus clientes quienes podrán recomendar sus servicios con la seguridad de que no quedarán mal.

Para ello se realizarán las siguientes estrategias:

- Mantener las alianzas para promover el consumo de los productos ofrecidos.

- Crear un Fan Page para que los mismos clientes puedan compartirlo con sus contactos y así captar más clientes.

- Buscar nuevas combinaciones de loncheras según la estacionalidad de los insumos.

- Realizar activaciones particulares anuales para los niños que son los principales clientes.

- Buscar abrir nuevos locales para abastecer colegios de otras zonas.

\section{c. Fase de estacionaria}

En esta etapa el clima competitivo se torna más agresivo y el indicador clave de desempeño es la participación de mercado, por ello el objetivo de Lunch Kids será posicionarse en la mente de los consumidores, así como crear y mantener lealtad a la marca.

Para ello se realizarán las siguientes estrategias:

- Loncheras especiales en la fecha del cumpleaños de los niños.

- Saludos virtuales a los padres en fechas especiales

- Activaciones realizadas exclusivamente para clientes de Lunch Kids 


\section{d. Fase de madurez}

De acuerdo con Ferrell y Hartline (2012) en esta etapa no habrá crecimiento de competencia a menos que hayan encontrado una diferenciación de producto que sea significativa para el cliente. (p. 220).

En esta etapa el objetivo prioritario de Lunch Kids será defender y de ser posible expandir la participación de mercado, así como ganar una ventaja competitiva sustentable sobre los competidores directos que surgirán en el tiempo.

Para ello se realizarán las siguientes estrategias:

- Buscar abastecer nuevos requerimientos de los clientes, como por ejemplo bocaditos saludables para cumpleaños.

- Buscar la posibilidad de brindar los servicios a un nuevo mercado.

\section{e. Fase de declive.}

Ferrell y Hartline (2012) señalan que en esta etapa las ventas disminuyen de manera significativa lo cual afecta los ingresos de la empresa (p. 223).

En esta etapa no existirá crecimiento y las ventas podrían demostrar una disminución debido a cambios en los hábitos alimenticios, cambios en el estilo de vida del entorno social e incluso en el entorno económico.

Lo recomendable sería traspasar el negocio o liquidarlo y vender activos para recuperar la inversión inicial.

\subsubsection{Plan de ventas}

Según Kotler y Armstrong (2012), los planes de ventas establecidos por la empresa tienen como finalidad de establecer las estrategias los objetivos de ventas planeados. Por tal motivo se ha estructurado el siguiente plan: 
Tabla 82

Cronograma de actividades al año

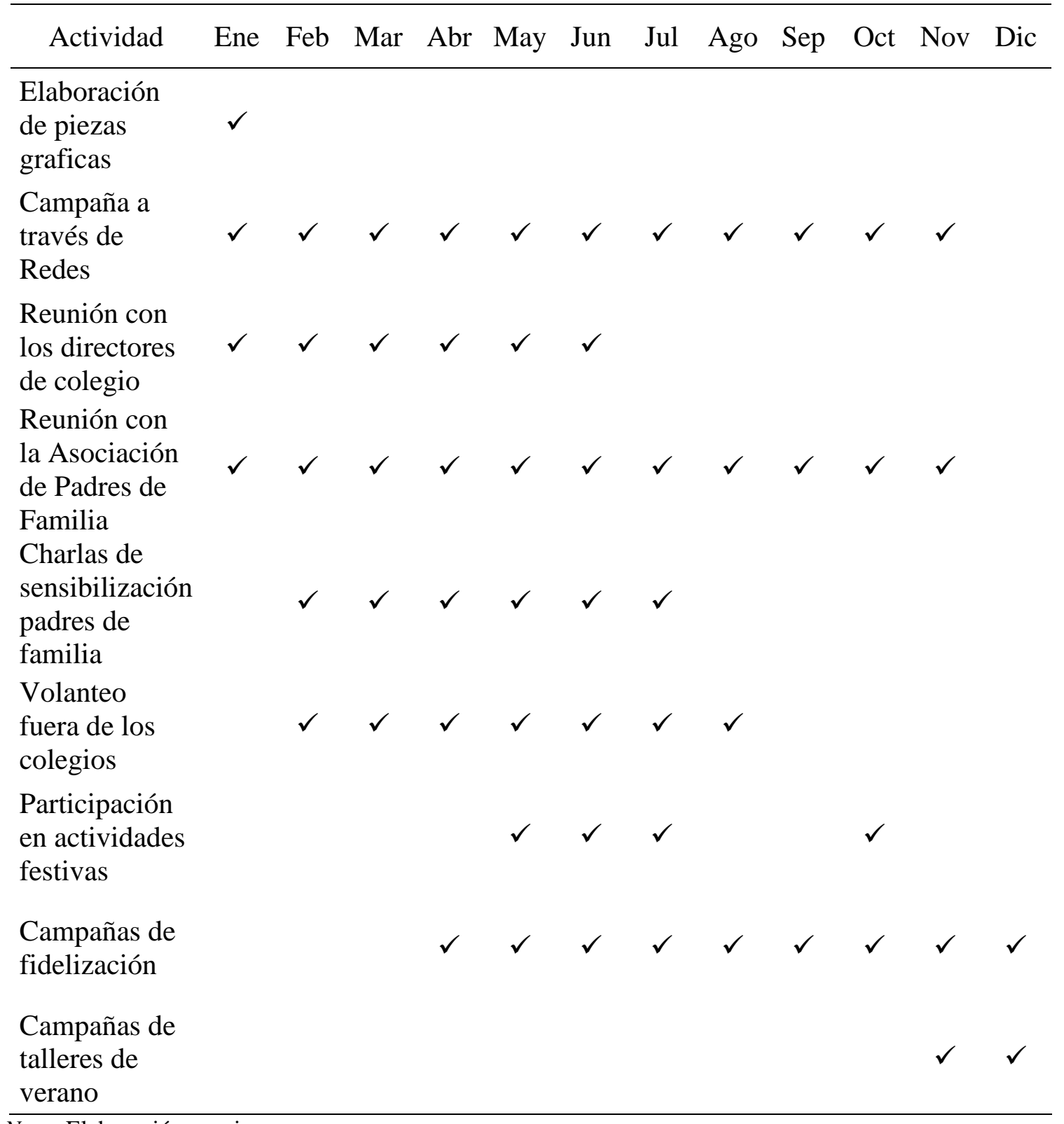

Nota: Elaboración propia.

Dentro de las estrategias para la difusión y comercialización de nuestros productos se establece potenciar la presencia a través de las redes sociales, la presencia ante la dirección de los diversos centros educativos y las asociaciones de padres de familia. Las acciones para la captación de clientes están definidas a través de charlas de sensibilización, volanteo fuera de los centros educativos y presencia en las actividades desarrolladas por los colegios. 
Dentro de los objetivos y metas de cada una de estas acciones tenemos:

Tabla 83

Resultados esperados por actividad

\begin{tabular}{|c|c|c|}
\hline Actividad & Objetivos & Metas \\
\hline $\begin{array}{l}\text { Campaña a través } \\
\text { de redes }\end{array}$ & $\begin{array}{l}\text { Registro de base de datos de } \\
\text { interesados }\end{array}$ & $\begin{array}{l}\text { Captación del } 10 \% \text { en } \\
\text { ventas efectivas }\end{array}$ \\
\hline $\begin{array}{l}\text { Reunión con los } \\
\text { directores de } \\
\text { colegio }\end{array}$ & $\begin{array}{l}\text { Establecer } 15 \text { reuniones } \\
\text { mensuales }\end{array}$ & $\begin{array}{l}10 \text { visitas efectivas a } \\
\text { directores de colegios }\end{array}$ \\
\hline $\begin{array}{l}\text { Reunión con la } \\
\text { Asociación de } \\
\text { Padres de Familia }\end{array}$ & $\begin{array}{l}\text { Establecer } 15 \text { reuniones } \\
\text { mensuales }\end{array}$ & $\begin{array}{l}10 \text { visitas efectivas a la } \\
\text { asociación de padres de } \\
\text { familias }\end{array}$ \\
\hline $\begin{array}{l}\text { Charlas de } \\
\text { Sensibilización } \\
\text { padres de familia }\end{array}$ & $\begin{array}{l}\text { Desarrollar } 10 \text { charlas de } \\
\text { sensibilización }\end{array}$ & $\begin{array}{l}\text { Captación del } 30 \% \text { en } \\
\text { ventas efectivas }\end{array}$ \\
\hline $\begin{array}{l}\text { Volanteo fuera de } \\
\text { los colegios }\end{array}$ & $\begin{array}{l}\text { Entrega de volantes a padres } \\
\text { de familia }\end{array}$ & $\begin{array}{l}\text { Captación del } 10 \% \text { en } \\
\text { ventas efectivas }\end{array}$ \\
\hline $\begin{array}{l}\text { Participación en } \\
\text { actividades } \\
\text { Festivas }\end{array}$ & Participación en 10 colegios & $\begin{array}{l}\text { Captación del } 10 \% \text { en } \\
\text { ventas efectivas }\end{array}$ \\
\hline $\begin{array}{l}\text { Campañas de } \\
\text { fidelización }\end{array}$ & $\begin{array}{l}\text { Establecer contacto con el } \\
100 \% \text { de los clientes }\end{array}$ & $\begin{array}{l}\text { Fidelización del } 100 \% \text { de } \\
\text { los clientes }\end{array}$ \\
\hline $\begin{array}{l}\text { Campañas de } \\
\text { Talleres de verano }\end{array}$ & $\begin{array}{l}\text { Promoción de productos en } \\
10 \text { colegios }\end{array}$ & $\begin{array}{l}\text { Captación del } 25 \% \text { en } \\
\text { ventas efectivas }\end{array}$ \\
\hline
\end{tabular}

Nota: Elaboración propia.

\subsubsection{Políticas de servicios y garantías}

Según Lovelock y Wirtz (2009) al establecer los procesos de los servicios también se deben establecer los métodos y el funcionamiento del mismo, los cuales se vinculan para crear la proposición de valor que se ha prometido a los clientes. (p. 225) 
Las políticas establecidas por la empresa para determinar los servicios a ser brindados se detallan a continuación:

a. Políticas generales

- Propuesta de valor (salud y alimentación) a los niños de educación inicial y primaria.

- Cumplimiento en los pedidos realizados.

- Establecer políticas de calidad y mejora continua.

- $\quad$ Acciones correctivas y preventivas de equipos y servicios brindados.

- Cumplimiento de las normas HACCP y las buenas prácticas de manufactura.

b. Política de compras.

- Establecer medidas de control sobre los proveedores en base a la calidad de los productos y precios.

- Evaluación para nueva contratación de proveedores.

- Elaboración de calendario de productos en base a la estación de producción.

c. Políticas de ventas.

- Al momento de realizar un pedido el cliente deberá completar un formulario donde se detalla la información general del cliente, información del servicio y declaración jurada de salud del menor de edad.

- La información podrá realizarse a través de Facebook, WhatsApp y correo electrónico.

- Los formatos deberán ser completados, firmados y enviados por vía electrónica. 
- La entrega de los productos se realizará en el transcurso de la mañana, antes del inicio de recreo programado en cada colegio, la recepción se realizará en cada aula por parte de los tutores de cada grupo, quienes podrán validar la hora de entrega del producto.

- Los pagos de los servicios se realizarán a través de transferencia bancaria y la cancelación del 100\% del servicio.

\section{d. Políticas Post Venta}

- Validación del servicio y calidad de este.

- En caso de problemas de salud por parte de los consumidores, se realizarán análisis médicos posteriores durante las próximas 48 horas. Los resultados serán brindados a los padres o apoderados de los niños. 


\section{Capítulo VIII. Planificación financiera}

En el presente capítulo se realizó el análisis financiero del proyecto loncheras saludables, con el fin de determinar la inversión total necesaria para iniciar el negocio, los costos, las inversiones futuras, los gastos administrativos y el presupuesto de compras, marketing y ventas. Asimismo, presentar los resultados del estado de ganancias y pérdidas, balance general y flujos proyectados.

\subsection{La inversión}

Según Sapag y Sapag (2008), las inversiones en las empresas son determinadas por la estructura organizativa establecida para realizar sus operaciones, así como también su tamaño y las funciones de cada unidad. Todo ello establecerá las inversiones de materiales, equipos y capital de trabajo.

\subsubsection{Inversión pre-operativa}

Como Sapag y Sapag (2008) señalan, los bienes tangibles pueden ser insumos o equipos para la operación de la empresa, es la inversión de activos fijos previa a la puesta en marcha.

En el siguiente cuadro se puede apreciar de manera desagregada las inversiones necesarias en activos tangibles. La inversión total es de S/. 66,298 (ver Tabla 83) 
Tabla 84 .

Activos tangibles

\begin{tabular}{lcr}
\hline Inversión Activos Tangibles & \multicolumn{2}{c}{ Importe } \\
\hline Total activos depreciables & S/. & 61,284 \\
Total activos no depreciables & S/. & 5,013 \\
Total activos fijos tangibles & S/. & 66,298 \\
\hline
\end{tabular}

Nota: Elaboración propia.

Asimismo, Sapag y Sapag (2008) indica que los bienes intangibles están compuestos por los gastos asociados a proyectos de ampliación, construcción, gestiones diversas (licencias, adquisición, marketing, gestión de cobranzas, etc.)

En el siguiente cuadro se puede apreciar de manera desagregada las inversiones necesarias en activos intangibles para el inicio de las operaciones. La inversión total en activos fijos intangibles es de S/. 53,200.37.

Tabla 85 .

Activos intangibles

\begin{tabular}{llr}
\hline \multicolumn{1}{c}{ Inversión activos Intangibles } & & \multicolumn{1}{c}{ Importe } \\
\hline Constitución de empresa & S/ & $1,841.00$ \\
Lanzamiento Marketing & S/ & $17,688.00$ \\
Instalación de empresa & S/ & $33,671.37$ \\
Activo Intangible & S/ & $53,200.37$ \\
\hline
\end{tabular}

Nota: Elaboración propia.

\subsubsection{Inversión en capital de trabajo}

Sapag y Sapag (2008) señalaron que el conjunto de recursos necesarios, para la realización de las operaciones del proyecto en un tiempo determinado, lo cual cubre la capacidad y tamaño de sus actividades es la que constituye la inversión en capital de trabajo. 
Al finalizar el proyecto, se determinó considerar solo un 50\% de recuperación de capital de trabajo, por la vida útil de algunos equipos.

La inversión de capital de trabajo se calculó y cuyo monto asciende a S/52,716.81 
Tabla 86.

Capital de trabajo

\begin{tabular}{|c|c|c|c|c|c|c|}
\hline & & 2018 & 2019 & 2020 & 2021 & 2022 \\
\hline Ventas & & S/. 603,355.92 & S/. $661,164.03$ & S/. $723,875.02$ & S/. 791,878.09 & S/. 865,592.07 \\
\hline Variacion porcentual & & 1.10 & 1.09 & 1.09 & 1.09 & \\
\hline Capital de trabajo & S/. $-52,716.81$ & S/. $-57,767.66$ & S/. $-63,246.89$ & S/. $-69,188.50$ & S/. $-75,629.09$ & \\
\hline Variación de capital de trabajo & & S/. $\quad-5,050.85$ & S/. $\quad-5,479.23$ & S/. $\quad-5,941.61$ & S/. $\quad-6,440.59$ & \\
\hline Resultado de capital de trabajo & & & & & & S/. $75,629.09$ \\
\hline
\end{tabular}

Nota: Elaboración propia. 


\subsubsection{Costo del proyecto}

Como Sapag y Sapag (2008) señalaron, la importancia de los costos del proyecto que brindara la estimación de los costos futuros del trabajo del evaluador, así como también los diversos elementos a ser valorizados como desembolsos.

Los costos de proyectos totales necesarios para poner en marcha el proyecto se muestran en la tabla de costo del proyecto, los cuales se detallan a continuación.

Tabla 87.

Costo del proyecto

\begin{tabular}{lll}
\hline \multicolumn{1}{c}{ Concepto } & & Total \\
\hline Inversión Fija Tangible & S/ & $66,297.63$ \\
Inversión Fija Intangible & S/ & $53,200.37$ \\
Capital de Trabajo & S/ & $52,741.06$ \\
Costo del Proyecto & S/ & $172,239.06$ \\
\hline Nota: Elaboración propia. & &
\end{tabular}

\subsubsection{Inversiones futuras}

Según Sapag y Sapag (2008), adicionalmente a las inversiones las organizaciones deben planificar según el ciclo de vida de la empresa la reinversión y nuevas inversiones considerando: la depreciación, horas de trabajo de los equipos, la imagen corporativa y económica.

En el trascurso de los próximos cinco años se evalúa considerar inversiones en infraestructura y equipos, con la finalidad de mejorar los servicios y productos de la empresa, esta inversión futura se puede visualizar en la inversión del capital de trabajo (ver Tabla 86). 


\subsection{Financiamiento}

Como Sapag y Sapag (2008) señalaron, que el análisis de la tasa de descuento empleada en la evaluación de un proyecto, la cual permite establecer el precio a ser cancelado por conceptos de financiamiento.

\subsubsection{Endeudamiento y condiciones}

Según Sapag y Sapag (2008), las organizaciones deberán reembolsar a un futuro establecido un pago por concepto de préstamos el cual en su mayoría es un monto mayor al brindado inicialmente.

Se solicitará un préstamo al banco el cual representa el 23\% del total de inversiones, considerando el 50\% de la inversión en activo tangible y 50\% del capital de trabajo. El siguiente cuadro muestra el financiamiento total teniendo en cuenta el préstamo en base a la tasa establecida por Mibanco.

Los requisitos establecidos para la obtención del crédito son:

- Copia de DNI de los socios

- Recibo de luz, agua o teléfono

- Documentos de residencia del representante legal apoderado y/o avales

- Acta de constitución de la empresa

- Vigencia de poderes actualizada con antigüedad no mayor a 15 días

- Declaración de renta anual y 3 últimos PDT

- Documentos de propiedad del inmueble que será otorgado en garantía, la cual podría ser cualquiera de nuestras propiedades, de acuerdo con lo que indique la entidad financiera. 
Tabla 88

Condiciones de financiamiento - MiBanco

\begin{tabular}{cc}
\hline Concepto & Monto \\
\hline Préstamo & S/. 40,000.00 \\
Periodos & 60 \\
TEA & $19 \%$ \\
TEM & 0.014601687 \\
\hline
\end{tabular}

Nota: Elaboración propia. 
Tabla 89

Programa de pagos financieros

\begin{tabular}{|c|c|c|c|c|}
\hline Periodo & Interés & Amortización & Cuota & Saldo \\
\hline 0 & & & & S/. 40,000.00 \\
\hline 1 & S/. 584.07 & $\mathrm{~S} / . \quad 421.30$ & S/. 1,005.37 & S/. 39,578.70 \\
\hline 2 & S/. 577.92 & S/. 427.45 & S/. 1,005.37 & S/. 39,151.25 \\
\hline 3 & S/. 571.67 & S/. 433.69 & S/. 1,005.37 & S/. 38,717.56 \\
\hline 4 & S/. 565.34 & S/. $\quad 440.02$ & S/. 1,005.37 & S/. 38,277.54 \\
\hline 5 & S/. 558.92 & S/. 446.45 & S/. 1,005.37 & S/. 37,831.09 \\
\hline 6 & S/. 552.40 & S/. 452.97 & S/. 1,005.37 & S/. 37,378.12 \\
\hline 7 & S/. 545.78 & S/. 459.58 & S/. 1,005.37 & S/. 36,918.54 \\
\hline 8 & S/. 539.07 & S/. 466.29 & S/. 1,005.37 & S/. $36,452.25$ \\
\hline 9 & S/. 532.26 & S/. $\quad 473.10$ & S/. 1,005.37 & S/. 35,979.15 \\
\hline 10 & S/. 525.36 & S/. 480.01 & S/. 1,005.37 & S/. 35,499.14 \\
\hline 11 & S/. 518.35 & S/. $\quad 487.02$ & S/. 1,005.37 & S/. 35,012.12 \\
\hline 12 & S/. 511.24 & S/. 494.13 & S/. 1,005.37 & S/. $34,517.99$ \\
\hline 13 & S/. 504.02 & S/. 501.34 & S/. 1,005.37 & S/. 34,016.65 \\
\hline 14 & S/. 496.70 & S/. 508.66 & S/. 1,005.37 & S/. 33,507.98 \\
\hline 15 & S/. 489.27 & S/. $\quad 516.09$ & S/. 1,005.37 & S/. 32,991.89 \\
\hline 16 & S/. 481.74 & $\mathrm{~S} / . \quad 523.63$ & S/. 1,005.37 & S/. 32,468.26 \\
\hline 17 & S/. 474.09 & S/. 531.27 & S/. 1,005.37 & S/. 31,936.99 \\
\hline 18 & S/. 466.33 & S/. $\quad 539.03$ & S/. 1,005.37 & S/. 31,397.96 \\
\hline 19 & S/. 458.46 & S/. $\quad 546.90$ & S/. 1,005.37 & S/. 30,851.06 \\
\hline 20 & S/. 450.48 & S/. 554.89 & S/. $1,005.37$ & S/. 30,296.17 \\
\hline 21 & S/. 442.38 & S/. 562.99 & S/. 1,005.37 & S/. 29,733.18 \\
\hline 22 & S/. 434.15 & S/. $\quad 571.21$ & S/. 1,005.37 & S/. 29,161.97 \\
\hline 23 & S/. 425.81 & S/. 579.55 & S/. 1,005.37 & S/. 28,582.42 \\
\hline 24 & S/. 417.35 & S/. 588.01 & S/. 1,005.37 & S/. 27,994.41 \\
\hline 25 & S/. 408.77 & $\begin{array}{ll}\mathrm{S} / . & 596.60\end{array}$ & S/. 1,005.37 & $\mathrm{S} / .27,397.81$ \\
\hline 26 & S/. 400.05 & S/. 605.31 & S/. 1,005.37 & S/. 26,792.49 \\
\hline 27 & S/. 391.22 & S/. $\quad 614.15$ & S/. 1,005.37 & S/. 26,178.35 \\
\hline 28 & S/. 382.25 & S/. $\quad 623.12$ & S/. 1,005.37 & S/. 25,555.23 \\
\hline 29 & S/. 373.15 & S/. $\quad 632.22$ & S/. 1,005.37 & S/. 24,923.01 \\
\hline 30 & S/. 363.92 & S/. $\quad 641.45$ & S/. 1,005.37 & S/. 24,281.57 \\
\hline 31 & S/. 354.55 & S/. $\quad 650.81$ & S/. $1,005.37$ & S/. 23,630.75 \\
\hline 32 & S/. 345.05 & S/. $\quad 660.32$ & S/. 1,005.37 & S/. 22,970.44 \\
\hline 33 & S/. 335.41 & S/. $\quad 669.96$ & S/. 1,005.37 & S/. 22,300.48 \\
\hline 34 & S/. 325.62 & S/. $\quad 679.74$ & S/. $1,005.37$ & S/. $21,620.74$ \\
\hline 35 & S/. 315.70 & S/. $\quad 689.67$ & S/. 1,005.37 & S/. 20,931.07 \\
\hline 36 & S/. 305.63 & S/. 699.74 & S/. $1,005.37$ & S/. $20,231.34$ \\
\hline 37 & S/. 295.41 & S/. 709.95 & S/. 1,005.37 & S/. 19,521.38 \\
\hline 38 & S/. 285.05 & S/. 720.32 & S/. 1,005.37 & S/. 18,801.06 \\
\hline 39 & S/. 274.53 & S/. 730.84 & S/. 1,005.37 & S/. 18,070.22 \\
\hline 40 & S/. 263.86 & S/. 741.51 & S/. $1,005.37$ & S/. 17,328.72 \\
\hline 41 & S/. 253.03 & S/. $\quad 752.34$ & S/. 1,005.37 & S/. 16,576.38 \\
\hline 42 & S/. 242.04 & S/. 763.32 & S/. $1,005.37$ & S/. 15,813.06 \\
\hline 43 & S/. 230.90 & S/. $\quad 774.47$ & S/. 1,005.37 & S/. 15,038.59 \\
\hline 44 & S/. 219.59 & S/. $\quad 785.78$ & S/. 1,005.37 & S/. 14,252.81 \\
\hline 45 & S/. 208.12 & S/. $\quad 797.25$ & S/. 1,005.37 & S/. 13,455.56 \\
\hline 46 & S/. 196.47 & S/. 808.89 & S/. 1,005.37 & S/. 12,646.67 \\
\hline 47 & S/. 184.66 & S/. 820.70 & S/. 1,005.37 & S/. 11,825.97 \\
\hline 48 & S/. 172.68 & S/. 832.69 & S/. 1,005.37 & S/. $10,993.28$ \\
\hline 49 & S/. 160.52 & S/. 844.84 & S/. 1,005.37 & S/. 10,148.44 \\
\hline 50 & S/. 148.18 & S/. 857.18 & S/. 1,005.37 & S/. 9,291.26 \\
\hline 51 & S/. 135.67 & S/. 869.70 & S/. $1,005.37$ & S/. $8,421.56$ \\
\hline 52 & S/. 122.97 & S/. 882.40 & S/. $1,005.37$ & S/. $7,539.16$ \\
\hline 53 & S/. 110.08 & S/. 895.28 & S/. 1,005.37 & S/. $\quad 6,643.88$ \\
\hline 54 & S/. 97.01 & S/. 908.35 & S/. 1,005.37 & S/. $5,735.53$ \\
\hline 55 & S/. 83.75 & $\mathrm{~S} / . \quad 921.62$ & S/. 1,005.37 & S/. $4,813.91$ \\
\hline 56 & S/. 70.29 & S/. 935.07 & S/. 1,005.37 & S/. $3,878.84$ \\
\hline 57 & S/. 56.64 & S/. 948.73 & S/. 1,005.37 & S/. $\quad 2,930.11$ \\
\hline 58 & S/. 42.78 & S/. 962.58 & S/. 1,005.37 & S/. $1,967.53$ \\
\hline 59 & S/. 28.73 & S/. 976.64 & S/. $1,005.37$ & S/. $\quad 990.90$ \\
\hline 60 & S/. 14.47 & S/. $\quad 990.90$ & S/. 1,005.37 & 0.00 \\
\hline
\end{tabular}

Nota: Elaboración propia. 


\subsubsection{Capital y costo de oportunidad}

Según la inversión fija e inversión de capital de trabajo, se ha optado por trabajar con $77 \%$ de capital propio y $23 \%$ de préstamo. (ver Tabla 90)

Tabla 90.

Inversión total y capital de trabajo

\begin{tabular}{lccccc}
\hline \multicolumn{1}{c}{ Concepto } & \multicolumn{2}{c}{ Total } & \multicolumn{2}{c}{ Capital propio } & \multicolumn{2}{c}{ Deuda } \\
\hline Inversión Fija Tangible & S/. & $66,297.63$ & S/. & $46,297.63$ & \multicolumn{2}{c}{ S/. 20,000.00 } \\
Inversión Fija Intangible & S/. & $53,200.37$ & S/. & $53,200.37$ & S/. \\
Capital de Trabajo & S/. & $52,741.06$ & S/. & $32,741.06$ & S/. 20,000.00 \\
\hline Costo del Proyecto & S/. & $172,239.06$ & S/. & $132,239.06$ & S/. 40,000.00 \\
\hline$\%$ & \multicolumn{2}{c}{$100 \%$} & & $77 \%$ & $23 \%$ \\
\hline
\end{tabular}

Nota: Elaboración propia.

Para obtener el costo de oportunidad del proyecto o tasa de retorno requerido se calculó el CAPM basados en:

- Beta de la industria

- Tasa libre de riesgo

- Rendimiento de mercado

\section{Beta}

El coeficiente beta $(\beta)$ utilizado fue del sector Food Processing, información proporcionada por Betas Damodaran 2017.

Para determinar el costo de oportunidad se requiere el beta apalancado, para ello se utiliza la siguiente formula $[\mathrm{Ba}=\mathrm{Bd} *(1+((\mathrm{D} / \mathrm{E}) *(1-\mathrm{t}))]$, tomando en cuenta el nivel de endeudamiento. 
Tabla 91.

Cálculo de Beta apalancado

\begin{tabular}{lcc}
\hline Concepto & $\mathrm{Ba}=\mathrm{Bd} *(1+((\mathrm{D} / \mathrm{E}) *(1-\mathrm{t}))$ & Dato \\
\hline$\%$ Financiamiento & $\mathrm{D}$ & $23 \%$ \\
$\%$ Capital Propio & $\mathrm{E}$ & $77 \%$ \\
Tasa de impuesto a la & $\mathrm{t}$ & $29.5 \%$ \\
Renta & & 0.75 \\
Beta desapalancado & $\mathrm{Bd}$ & 0.91 \\
Beta Apalancado & $\mathrm{Ba}$ & \\
\hline
\end{tabular}

Nota. Elaboración propia.

\section{Determinación del Rendimiento de Mercado y Tasa de Libre riesgo.}

El rendimiento de mercado se ha calculado del promedio de todos los rendimientos desde el año 1986 al 2016 obteniendo un $11.73 \%$.

La tasa libre de riesgo se ha determinado del promedio de los rendimientos de los bonos americanos desde el año 1986 al 2016 obteniendo un $7.12 \%$.

La información se obtuvo de los retornos históricos estimados por el autor Damoradan de Customized Geometric risk premium estimator. 
Tabla 92.

Rendimientos de 1986 al 2016 - promedio aritmético

\begin{tabular}{|c|c|c|}
\hline Año & Bono Tesoro USA & Mercado \\
\hline 1986 & $24.28 \%$ & $18.49 \%$ \\
\hline 1987 & $-4.96 \%$ & $5.81 \%$ \\
\hline 1988 & $8.22 \%$ & $16.54 \%$ \\
\hline 1989 & $17.69 \%$ & $31.48 \%$ \\
\hline 1990 & $6.24 \%$ & $-3.06 \%$ \\
\hline 1991 & $15.00 \%$ & $30.23 \%$ \\
\hline 1992 & $9.36 \%$ & $7.49 \%$ \\
\hline 1993 & $14.21 \%$ & $9.97 \%$ \\
\hline 1994 & $-8.04 \%$ & $1.33 \%$ \\
\hline 1995 & $23.48 \%$ & $37.20 \%$ \\
\hline 1996 & $1.43 \%$ & $22.68 \%$ \\
\hline 1997 & $9.94 \%$ & $33.10 \%$ \\
\hline 1998 & $14.92 \%$ & $28.34 \%$ \\
\hline 1999 & $-8.25 \%$ & $20.89 \%$ \\
\hline 2000 & $16.66 \%$ & $-9.03 \%$ \\
\hline 2001 & $5.57 \%$ & $-11.85 \%$ \\
\hline 2002 & $15.12 \%$ & $-21.97 \%$ \\
\hline 2003 & $0.38 \%$ & $28.36 \%$ \\
\hline 2004 & $4.49 \%$ & $10.74 \%$ \\
\hline 2005 & $2.87 \%$ & $4.83 \%$ \\
\hline 2006 & $1.96 \%$ & $15.61 \%$ \\
\hline 2007 & $10.21 \%$ & $5.48 \%$ \\
\hline 2008 & $20.10 \%$ & $-36.55 \%$ \\
\hline 2009 & $-11.12 \%$ & $25.94 \%$ \\
\hline 2010 & $8.46 \%$ & $14.82 \%$ \\
\hline 2011 & $16.04 \%$ & $2.10 \%$ \\
\hline 2012 & $2.97 \%$ & $15.89 \%$ \\
\hline 2013 & $-9.10 \%$ & $32.15 \%$ \\
\hline 2014 & $10.75 \%$ & $13.52 \%$ \\
\hline 2015 & $1.28 \%$ & $1.36 \%$ \\
\hline 2016 & $0.69 \%$ & $11.74 \%$ \\
\hline Promedio & $7.12 \%$ & $11.73 \%$ \\
\hline
\end{tabular}

Nota: Elaboración propia. 


\section{Determinación del CAPM.}

El costo de oportunidad es la rentabilidad esperada a la que se renuncia para invertir en un proyecto de riesgo similar.

Para determinar el costo de oportunidad del capital (COK) se ha utilizado el modelo CAPM (Capital Asset Pricing Model), el cual señala que la tasa requerida de rentabilidad es igual a la tasa libre de riesgo más una prima por riesgo.

Este modelo tiene en cuenta la sensibilidad del riesgo de mercado, representado por la beta $(\beta)$, en este caso se utilizó del sector Food Processing, así como el rendimiento de mercado y Rendimiento activo libre riesgo.

Aplicando la fórmula de determinación del costo de oportunidad, se halla el COK nominal USA, pero para tener una mayor precisión, se considera la inflación promedio USA de los años 2000 -2016, para hallar el cok real USA. Asimismo, para hallar el COK Perú se toma como referencia el promedio de Riesgo País Perú siendo 2.67\% y la inflación Perú promedio de los años 2000-2016. 
Tabla 93.

Fórmula para la determinación de COK PERU

\begin{tabular}{|c|c|c|c|}
\hline Concepto & Base & Sigla & Dato \\
\hline Rendimiento activo & Tasa Libre de riesgo USA(T- & & \\
\hline libre riesgo & Bonds)Damodaran(1986-2016) & $\mathrm{Rf}$ & $7.12 \%$ \\
\hline Rendimiento de & Rendimiento USA(S\&P 500)- & & \\
\hline Mercado & $\begin{array}{c}\text { Damodaran(1986-2016) } \\
\text { Beta Industria Food Processing }\end{array}$ & $\mathrm{Rm}$ & $11.73 \%$ \\
\hline Beta desapalancado & (Damodaran) & $\mathrm{Bd}$ & 0.75 \\
\hline $\begin{array}{l}\text { Beta Apalancado } \\
\text { COK NOMINAL }\end{array}$ & $\mathrm{Ba}=\mathrm{Bd} *((1+(\mathrm{D} / \mathrm{E}) *(1-\mathrm{t}))$ & $\mathrm{Ba}$ & 0.91 \\
\hline $\begin{array}{l}\text { USA } \\
\text { Inflación Estados }\end{array}$ & $\mathrm{Rf}+(\mathrm{Ba} *(\mathrm{Rm}-\mathrm{Rf}))$ & & $11.34 \%$ \\
\hline Unidos & $\begin{array}{l}\text { Inflación USA Promedio (2000-2016) } \\
((1+\text { cok nominal USA }) /(1+\text { inflación }\end{array}$ & & $2.18 \%$ \\
\hline COK Real USA & usa))-1 & & $8.96 \%$ \\
\hline Riesgo País Perú & Riesgo País Perú(2000-2016) & & $2.67 \%$ \\
\hline COK Perú real & Cok Real USA+Riesgo País Perú & & $11.64 \%$ \\
\hline Inflación Perú & Inflación Peru Promedio (2000-2016) & & $2.82 \%$ \\
\hline COK Perú Nominal & $((1+$ cok real Perú)*(1+inflación Perú) $)-1$ & & $14.78 \%$ \\
\hline
\end{tabular}

El COK Perú para esta inversión es de $14.78 \%$. Esta tasa se utilizará para descontar el flujo de caja Financiero.

\subsubsection{Costo de capital promedio ponderado}

Según Sapag y Sapag (2008), el WACC (Weighted Average Cost of Capital), o también denominado coste promedio ponderado es la tasa de descuento utilizada para descontar los flujos de caja futuros cuando se valora un proyecto de inversión.

Para hallar el WACC se ha considerado la estructura de inversión del proyecto, es decir el porcentaje de capital propio y financiado, el cok, el impuesto a la renta y la tasa efectiva anual ofrecida por la entidad financiera. 
Tabla 94.

Fórmula para la determinación de WACC

\begin{tabular}{lccc} 
Concepto & Base & Sigla & Dato \\
\hline Deuda & Estructura de financiamiento & $\mathrm{D}$ & 40,000 \\
Capital Propio & Estructura de financiamiento & $\mathrm{E}$ & $132,239.06$ \\
\% Deuda & $(\mathrm{D} /(\mathrm{E}+\mathrm{D}))$ & & $23 \%$ \\
\% Capital propio & $(\mathrm{E} /(\mathrm{E}+\mathrm{D}))$ & $77 \%$ \\
Tasa de impuesto a la renta & Legislación Vigente & $\mathrm{t}$ & $29.50 \%$ \\
Cok & & $\mathrm{ke}$ & $14.78 \%$ \\
Costo de la deuda & $\mathrm{TCEA}$ del préstamo & $\mathrm{kd}$ & $19 \%$ \\
Costo promedio de Capital & $\mathrm{WACC}=\mathrm{Ke} * \mathrm{E} /(\mathrm{E}+\mathrm{D})+\mathrm{Kd} *(1-\mathrm{t}) * \mathrm{D} /(\mathrm{E}+\mathrm{D})$ & & $14.46 \%$ \\
\hline
\end{tabular}

Nota. Elaboración propia.

El costo promedio de Capital para esta inversión es de 14.46\%. Esta tasa se utilizará para descontar el flujo de caja económico.

\subsection{Presupuestos base}

\subsubsection{Presupuesto de ventas}

Para hallar el presupuesto de ventas anuales primero se identificó la intención de compra del público objetivo para cada tipo de lonchera, luego se multiplico por la frecuencia de compra y finalmente por el precio de venta descontando el IGV. (Ver Tablas 95, 96 y 97) 
Tabla 95. Ventas en unidades por año

Ventas en unidades por año

\begin{tabular}{lccccc}
\hline $\begin{array}{l}\text { Cuadro resumen } \\
\text { Ventas por año }\end{array}$ & 2018 & 2019 & 2020 & 2021 & 2022 \\
\hline Mercado Objetivo & 834 & 914 & 1,002 & 1,096 & 1,199 \\
Inicial & 282 & 312 & 344 & 380 & 418 \\
Primaria & 552 & 603 & 657 & 716 & 780 \\
& 30 & 30 & 30 & 30 & 30 \\
Frecuencia promedio de compra por año & & & & & \\
Demanda Anual & 25,147 & 27,572 & 30,203 & 33,056 & 36,150 \\
Inicial & 8,493 & 9,397 & 10,382 & 11,453 & 12,619 \\
Primaria & 16,655 & 18,175 & 19,821 & 21,603 & 23,531 \\
\hline
\end{tabular}

Nota: Elaboración propia.

Tabla 96.

Precio semanal sin IGV

\begin{tabular}{lcc}
\hline & \multicolumn{2}{c}{ Precio Semanal Sin IGV } \\
\hline Inicial & S/. & 21.19 \\
Primaria & S/. & 25.42 \\
\hline
\end{tabular}

Nota: Elaboración propia. 
Tabla 97.

Presupuesto de ventas

\begin{tabular}{|c|c|c|c|c|c|c|c|c|c|c|}
\hline \multirow{2}{*}{$\begin{array}{l}\text { Precio } \\
\text { Inicial }\end{array}$} & \multicolumn{2}{|c|}{2018} & \multicolumn{2}{|c|}{2019} & \multicolumn{2}{|c|}{2020} & \multicolumn{2}{|c|}{2021} & \multicolumn{2}{|c|}{2022} \\
\hline & $\mathrm{S} /$. & $179,932.12$ & $\mathrm{~S} /$. & $199,088.72$ & $\mathrm{~S} /$. & $219,950.34$ & $\mathrm{~S} /$. & $242,656.15$ & S/. & $267,356.06$ \\
\hline Primaria & S/. & $423,423.79$ & S/. & $462,075.31$ & $\mathrm{~S} /$. & $503,924.68$ & $\mathrm{~S} /$. & $549,221.95$ & S/. & $598,236.01$ \\
\hline Total & S/. & $603,355.92$ & S/. & $661,164.03$ & $\mathrm{~S} /$. & $723,875.02$ & S/. & $791,878.09$ & S/. & $865,592.07$ \\
\hline
\end{tabular}

Nota: Elaboración propia. 


\subsubsection{Presupuesto de costos y producción}

Para hallar el presupuesto de costos y producción se realizó una sumatoria de los gastos incurridos en:

- Materia prima (MP), como son los insumos para la elaboración de las loncheras.

- Mano de obra directa (MOD), compuesta por la planilla del cocinero y ayudantes, cuyo trabajo recae directamente en elaborar las loncheras.

- Costos indirectos de fabricación (CIF), que serían los gastos generados por servicios compartidos del proyecto.

(ver Tabla 98)

El consolidado de dicha información muestra los costos de producción incurridos en cada año del proyecto (ver Tabla 99) 
Tabla 98.

Presupuesto de costos de producción unitario

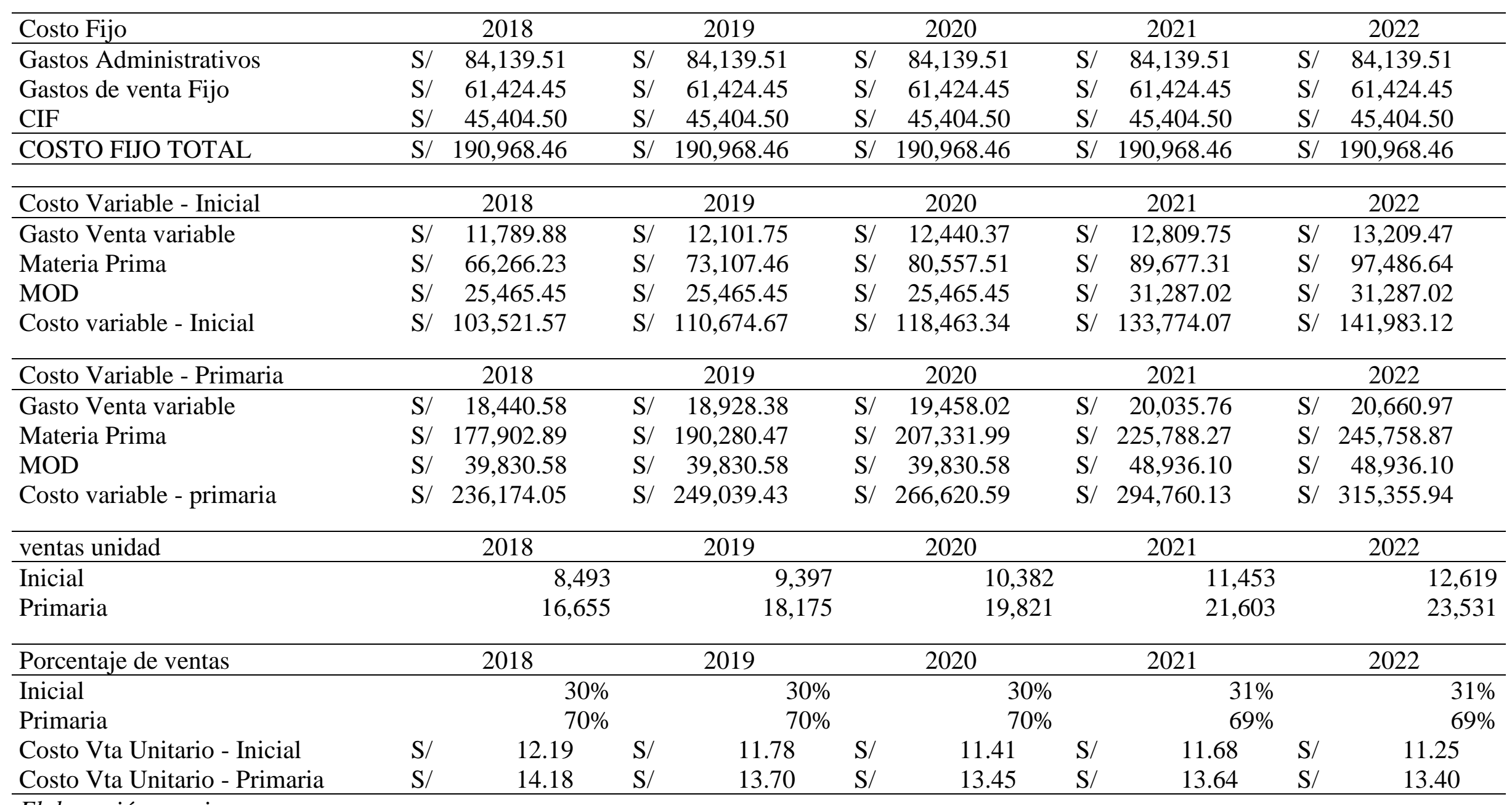

Elaboración propia 
Tabla 99.

Presupuesto de costos de producción

\begin{tabular}{|c|c|c|c|c|c|}
\hline & 2018 & 2019 & 2020 & 2021 & 2022 \\
\hline MP & S/ $244,169.12$ & S/ 263,387.93 & S/ $287,889.50$ & S/ $315,465.58$ & S/ 343,245.51 \\
\hline MOD & S/ $\quad 65,296.03$ & S/ $\quad 65,296.03$ & S/ $\quad 65,296.03$ & S/ $80,223.12$ & S/ $80,223.12$ \\
\hline CIF & S/ $\quad 45,404.50$ & $\mathrm{~S} / \quad 45,404.50$ & $\mathrm{~S} / \quad 45,404.50$ & $\mathrm{~S} / \quad 45,404.50$ & $\mathrm{~S} / \quad 45,404.50$ \\
\hline CTO DE PRODUCCION & S/ $354,869.65$ & S/ $374,088.46$ & S/ 398,590.03 & S/ 441,093.19 & $\mathrm{S} / 468,873.12$ \\
\hline
\end{tabular}

Nota: Elaboración propia. 


\subsubsection{Presupuesto de compras}

Para hallar el presupuesto de compras se ha realizado una sumatoria de costos de los insumos necesarios para la elaboración de loncheras durante cada semana, así como los empaques necesarios. (ver Tabla 100) 
Tabla 100.

Loncheras semanales

\begin{tabular}{|c|c|c|c|c|}
\hline Semana & Día & $\begin{array}{c}\text { Sánguche } \\
\text { (Constructores/energéticos/protectores) }\end{array}$ & Refresco & Fruta \\
\hline \multirow{5}{*}{1} & Lunes & atún & piña & $\begin{array}{l}\text { mandarina } \\
\text { piña en }\end{array}$ \\
\hline & Martes & Galletas de quinua & naranjada & trozos \\
\hline & Miércoles & 4 huevito de codorniz con galletas de & niña & granadilla \\
\hline & Jueves & sangrecita criolla & limonada & mandarina \\
\hline & Viernes & tortilla de zanahoria y cebolla & $\begin{array}{l}\text { manzana } \\
\text { Chicha }\end{array}$ & manzana \\
\hline \multirow{5}{*}{2} & Lunes & pollo con lechuga y tomate & morada & mandarina \\
\hline & Martes & choclo desgranado con trocitos de queso & limonada & mandarina \\
\hline & Miércoles & palta, huevo, lechuga & manzana & granadilla \\
\hline & Jueves & Galletas de avena con castaña & $\begin{array}{l}\text { carambola } \\
\text { Chicha }\end{array}$ & uva \\
\hline & Viernes & papa con queso & morada & durazno \\
\hline \multirow{5}{*}{3} & Lunes & huevito de codorniz con trocitos de papa & carambola & mandarina \\
\hline & Martes & Galletas de higo & cebada & manzana \\
\hline & Miércoles & atún & piña & mandarina \\
\hline & Jueves & pollo con lechuga & naranjada & durazno \\
\hline & Viernes & aceituna y huevo sancochado & carambola & \\
\hline \multirow{5}{*}{4} & Lunes & choclo rebozado con huevo & cebada & tuna \\
\hline & Martes & queso fresco & membrillo & mandarina \\
\hline & Miércoles & Galletas de salvado de trigo & piña & naranja \\
\hline & Jueves & tortilla de zanahoria y cebolla & manzana & $\begin{array}{l}\text { manzana } \\
\text { plátano }\end{array}$ \\
\hline & Viernes & $\begin{array}{l}\text { yogurt natural } \\
\text { huevitos de codorniz con trocitos de }\end{array}$ & cebada & seda \\
\hline \multirow{6}{*}{5} & Lunes & queso & limonada & granadilla \\
\hline & Martes & hamburguesa cacera & piña & manzana \\
\hline & Miércoles & Galletas de germen de trigo & naraniada & $\begin{array}{l}\text { piña en } \\
\text { trozos }\end{array}$ \\
\hline & Jueves & pollo con zanahoria, tomate y lechuga & carambola & durazno \\
\hline & & & Chicha & plátano \\
\hline & Viernes & jamón de pavita & morada & seda \\
\hline
\end{tabular}


Seguidamente, con el dato de intención y frecuencia de compra del público objetivo se ha procedido a calcular los insumos necesarios para cada semana y finalmente totalizar las compras anuales. (Ver Tabla 101) 
Tabla 101.

Presupuesto de compras

\begin{tabular}{|c|c|c|c|c|c|c|c|c|c|c|}
\hline & \multicolumn{2}{|c|}{2018} & \multicolumn{2}{|c|}{2019} & \multicolumn{2}{|c|}{2020} & \multicolumn{2}{|c|}{2021} & \multicolumn{2}{|c|}{2022} \\
\hline Inicial & S/ & $66,266.23$ & $\mathrm{~S} /$ & $73,107.46$ & $\mathrm{~S} /$ & $80,557.51$ & $\mathrm{~S} /$ & $89,677.31$ & $\mathrm{~S} /$ & $97,486.64$ \\
\hline Primaria & $\mathrm{S} /$ & $177,902.89$ & $\mathrm{~S} /$ & $190,280.47$ & S/ & $207,331.99$ & $\mathrm{~S} /$ & $225,788.27$ & $\mathrm{~S} /$ & $245,758.87$ \\
\hline Total Materia Prima & $\mathrm{S} /$ & $244,169.12$ & $\mathrm{~S} /$ & $263,387.93$ & $\mathrm{~S} /$ & $287,889.50$ & $\mathrm{~S} /$ & $315,465.58$ & S/ & $343,245.51$ \\
\hline
\end{tabular}




\subsubsection{Presupuesto de costo de ventas}

Se ha considerado para el presupuesto de Costo de Ventas, la Materia Prima, MOD

y CIF, debido a que no se cuenta con inventario inicial y final de productos terminados, ya que se producen a pedido. (ver Tabla 102) 
Tabla 102.

Presupuesto de costos de ventas

\begin{tabular}{lccccc}
\hline & 2018 & 2019 & 2020 & 2021 & 2022 \\
\hline MP & S/ $244,169.12$ & S/ $263,387.93$ & S/ $287,889.50$ & S/ 315,465.58 & S/ 343,245.51 \\
MOD & S/ $65,296.03$ & S/ $65,296.03$ & S/ $65,296.03$ & S/ $80,223.12$ & S/ 80,223.12 \\
CIF & S/ 45,404.50 & S/ 45,404.50 & S/ 45,404.50 & S/ 45,404.50 & S/ 45,404.50 \\
Costo de Venta & S/ $354,869.65$ & S/ 374,088.46 & S/ 398,590.03 & S/ 441,093.19 & S/ 468,873.12 \\
\hline
\end{tabular}

Nota: Elaboración propia. 


\subsubsection{Presupuesto de gastos administrativos}

El presupuesto de gastos administrativos incluye todos los gastos pertenecientes a la administración de Lunch Kids, tales como son la planilla del personal administrativo (Administrador y Asistente Administrativo), los servicios básicos (Agua, luz, teléfono e internet), además la depreciación de equipos de administración y útiles de oficina. Cabe mencionar que los gastos de administración de cada año se mantienen constantes durante todo el horizonte de evaluación. (ver Tabla 103). 
Tabla 103.

Presupuesto de gastos administrativos

\begin{tabular}{|c|c|c|c|c|c|c|c|c|c|c|}
\hline & \multicolumn{2}{|r|}{2018} & \multicolumn{2}{|c|}{2019} & \multicolumn{2}{|c|}{2020} & \multicolumn{2}{|r|}{2021} & \multicolumn{2}{|c|}{2022} \\
\hline Planilla & $\mathrm{S} /$ & $66,573.22$ & S/ & $66,573.22$ & $\mathrm{~S} /$ & $66,573.22$ & $\mathrm{~S} /$ & $66,573.22$ & S/ & $66,573.22$ \\
\hline Servicios Básicos & $\mathrm{S} /$ & $6,624.00$ & $\mathrm{~S} /$ & $6,624.00$ & $\mathrm{~S} /$ & $6,624.00$ & $\mathrm{~S} /$ & $6,624.00$ & $\mathrm{~S} /$ & $6,624.00$ \\
\hline Depreciación & $\mathrm{S} /$ & $9,184.29$ & $\mathrm{~S} /$ & $9,184.29$ & $\mathrm{~S} /$ & $9,184.29$ & $\mathrm{~S} /$ & $9,184.29$ & $\mathrm{~S} /$ & $9,184.29$ \\
\hline Amortización & $\mathrm{S} /$ & $1,934.56$ & $\mathrm{~S} /$ & $1,934.56$ & $\mathrm{~S} /$ & $1,934.56$ & $\mathrm{~S} /$ & $1,773.35$ & $\mathrm{~S} /$ & $1,773.35$ \\
\hline Útiles de oficina & $\mathrm{S} /$ & $1,758.00$ & $\mathrm{~S} /$ & $1,758.00$ & $\mathrm{~S} /$ & $1,758.00$ & $\mathrm{~S} /$ & $1,758.00$ & $\mathrm{~S} /$ & $1,758.00$ \\
\hline Total & $\mathrm{S} /$ & $86,074.07$ & $\mathrm{~S} /$ & $86,074.07$ & $\mathrm{~S} /$ & $86,074.07$ & $\mathrm{~S} /$ & $85,912.86$ & $\mathrm{~S} /$ & $85,912.86$ \\
\hline
\end{tabular}

Nota: Elaboración propia. 


\subsubsection{Presupuesto de marketing y ventas}

El presupuesto de marketing y ventas contiene la planilla de ventas, como son el vendedor y los repartidores, asimismo también se consideró el combustible, revisiones técnicas, renovaciones del SOAT de las trimotos de carga, además se estableció que los gastos de marketing sean $4 \%$ de las ventas, acciones de marketing detalladas en el capítulo VII. (ver Tabla 104). 
Tabla 104

Presupuesto de gastos marketing y ventas

\begin{tabular}{|c|c|c|c|c|c|}
\hline GASTOS VENTA & 2018 & 2019 & 2020 & 2021 & 2022 \\
\hline Planilla & S/ $59,708.35$ & S/ $59,708.35$ & S/ $59,708.35$ & S/ 59,708.35 & S/ 59,708.35 \\
\hline Combustible & S/ $\quad 1,674.73$ & S/ $\quad 1,835.85$ & S/ $2,010.66$ & S/ $2,200.24$ & S/ $2,405.78$ \\
\hline Revisiones técnicas & 63.56 & 63.56 & 63.56 & 63.56 & 63.56 \\
\hline Renovación SOAT & S/ $\quad 1,652.54$ & S/ $\quad 1,652.54$ & S/ $\quad 1,652.54$ & S/ $1,652.54$ & S/ $\quad 1,652.54$ \\
\hline Gastos de marketing & S/ $28,652.70$ & S/ $29,300.25$ & S/ $30,003.46$ & S/ 30,771.55 & S/ 31,602.38 \\
\hline TOTAL & S/ $91,751.89$ & S/ $92,560.55$ & S/ $93,438.57$ & S/ 94,396.24 & $\mathrm{S} / 95,432.61$ \\
\hline
\end{tabular}

Nota: Elaboración propia. 


\subsubsection{Presupuesto de gastos financieros}

El presupuesto de gastos financieros incluye los intereses del préstamo solicitado. (ver Tabla 105).

Además, se muestra el programa de pagos otorgado para un préstamo de S/ 40,000 soles y financiado a 5 años con pagos mensuales. (ver Tabla 89). 
Tabla 105.

Presupuesto de gastos financieros

\begin{tabular}{|c|c|c|c|c|c|}
\hline & 2018 & 2019 & 2020 & 2021 & 2022 \\
\hline Interés & S/. $\quad 6,582.37$ & S/. $\quad 5,540.79$ & $\mathrm{~S} / . \quad 4,301.31$ & S/. $\quad 2,826.33$ & S/. $\quad 1,071.10$ \\
\hline Amortización & S/. $\quad 5,482.01$ & S/. $\quad 6,523.59$ & S/. $\quad 7,763.07$ & S/. $\quad 9,238.05$ & S/. $10,993.28$ \\
\hline Total & S/. $12,064.38$ & S/. $12,064.38$ & S/. $12,064.38$ & S/. $12,064.38$ & $\mathrm{~S} / .12,064.38$ \\
\hline
\end{tabular}

Nota: Elaboración propia. 


\subsection{Presupuestos de resultados}

\subsubsection{Estado de resultados proyectado}

El estado de resultados proyectado se realizó en moneda nacional y el período de análisis se dio entre los años 2018 al 2022 (horizonte de evaluación de 5 años). Las ventas se calcularon en base a la proyección de ventas que fueron obtenidas de acuerdo con el estudio de mercado y precio establecido del producto en el plan de Marketing, además la depreciación de activos es lineal. (ver Tabla 106) 
Tabla 106.

Estado de resultados proyectado

\begin{tabular}{|c|c|c|c|c|c|c|c|c|c|c|c|}
\hline & 2017 & & 2018 & & 2019 & & 2020 & & 2021 & & 2022 \\
\hline Ventas & & $\mathrm{S} /$. & $603,355.92$ & $\mathrm{~S} /$. & $661,164.03$ & $\mathrm{~S} /$. & $723,875.02$ & $\mathrm{~S} /$. & $791,878.09$ & $\mathrm{~S} /$. & $865,592.07$ \\
\hline Costo de Ventas & & $\mathrm{S} /$. & $354,869.65$ & $\mathrm{~S} /$. & $374,088.46$ & $\mathrm{~S} /$. & $398,590.03$ & $\mathrm{~S} /$. & $441,093.19$ & $\mathrm{~S} /$. & $468,873.12$ \\
\hline Utilidad Bruta & & $\mathrm{S} /$. & $248,486.27$ & $\mathrm{~S} /$. & $287,075.57$ & $\mathrm{~S} / \mathrm{.}$ & $325,285.00$ & $\mathrm{~S} /$. & $350,784.90$ & $\mathrm{~S} /$. & $396,718.95$ \\
\hline Gasto Administrativo & & $\mathrm{S} /$. & $84,139.51$ & $\mathrm{~S} /$. & $84,139.51$ & $\mathrm{~S} / \mathrm{.}$ & $84,139.51$ & S/. & $84,139.51$ & $\mathrm{~S} /$. & $84,139.51$ \\
\hline Gasto de Venta & & $\mathrm{S} /$. & $91,654.92$ & $\mathrm{~S} /$. & $92,454.59$ & $\mathrm{~S} / \mathrm{.}$ & $93,322.85$ & $\mathrm{~S} /$. & $94,269.96$ & $\mathrm{~S} /$. & $95,294.89$ \\
\hline Utilidad Operativo & & $\mathrm{S} / \mathrm{.}$ & $72,691.84$ & $\mathrm{~S} /$ & $110,481.47$ & $\mathrm{~S} / \mathrm{.}$ & $147,822.64$ & $S /$. & $172,375.43$ & $\mathrm{~S} /$. & $217,284.55$ \\
\hline Impuestos $29.50 \%$ & & $\mathrm{~S} /$. & $21,444.09$ & $\mathrm{~S} /$. & $32,592.03$ & $\mathrm{~S} / \mathrm{.}$ & $43,607.68$ & $S /$. & $50,850.75$ & $\mathrm{~S} /$. & $64,098.94$ \\
\hline Utilidad Neta & & $\mathrm{S} /$. & $51,247.75$ & $\mathrm{~S} /$. & $77,889.44$ & $\mathrm{~S} / \mathrm{.}$ & $104,214.96$ & $S /$. & $121,524.68$ & $\mathrm{~S} /$. & $153,185.60$ \\
\hline
\end{tabular}




\subsubsection{Estado de situación financiera proyectado}

Es necesario recalcar que no se tiene cuentas por cobrar, debido a que todo se paga por anticipado. En cuanto a pasivos tenemos la deuda a largo plazo que es por el préstamo obtenido al inicio de operaciones. (ver Tabla 107). 
Tabla 107.

Estado de situación financiera proyectado

\begin{tabular}{|c|c|c|c|c|c|c|c|c|c|c|c|c|}
\hline \multirow[b]{2}{*}{ Activo } & \multicolumn{3}{|c|}{2017} & \multicolumn{2}{|l|}{2018} & \multicolumn{2}{|l|}{2019} & \multicolumn{2}{|l|}{2020} & \multicolumn{2}{|l|}{2021} & 2022 \\
\hline & & & & & & & & & & & & \\
\hline Efectivo & $\mathrm{S} /$. & $92,716.81$ & S/. & $143,964.56$ & $S /$. & $221,854.00$ & S/. & $326,068.96$ & S/. & $447,593.64$ & $\mathrm{~S} /$. & $600,779.24$ \\
\hline Mercaderias & $\mathrm{S} /$. & - & $\mathrm{S} / \mathrm{.}$ & - & $\mathrm{S} /$. & - & $\mathrm{S} /$. & - & $\mathrm{S} /$. & - & $\mathrm{S} / \mathrm{.}$ & - \\
\hline Cuentas $\mathrm{x}$ cobrar & $\mathrm{S} /$. & - & $\mathrm{S} /$. & - & $\mathrm{S} /$. & - & $\mathrm{S} /$. & - & $\mathrm{S} /$. & - & $\mathrm{S} /$. & - \\
\hline \multicolumn{13}{|l|}{ Afijo } \\
\hline Activo tangible & S/. & $66,297.63$ & S/. & $55,965.97$ & $\mathrm{~S} /$. & $45,634.30$ & S/. & $35,302.63$ & $\mathrm{~S} /$. & $24,970.96$ & S/. & $14,639.30$ \\
\hline Activo intangible & $\mathrm{S} /$. & $53,200.37$ & S/. & $53,200.37$ & $S /$. & $53,200.37$ & $\mathrm{~S} / \mathrm{.}$ & $53,200.37$ & S/. & $53,200.37$ & $\mathrm{~S} / \mathrm{.}$ & $53,200.37$ \\
\hline ACTIVO & S/. & $212,214.82$ & S/. & $253,130.90$ & $S /$. & $320,688.67$ & $\mathrm{~S} /$. & $414,571.96$ & S/. & $525,764.98$ & $\mathrm{~S} / \mathrm{.}$ & $668,618.91$ \\
\hline \multicolumn{13}{|l|}{ Pasivo } \\
\hline Prestamo & S/ & $40,000.00$ & S/. & $34,517.99$ & $S /$. & $27,994.41$ & S/. & $20,231.34$ & $\mathrm{~S} /$. & $10,993.28$ & S/. & 0.00 \\
\hline PASIVO & $\mathrm{S} /$ & $40,000.00$ & $\mathrm{~S} /$ & $34,517.99$ & $\mathrm{~S} /$. & $27,994.41$ & $\mathrm{~S} /$. & $20,231.34$ & $\mathrm{~S} /$ & $10,993.28$ & $\mathrm{~S} /$ & 0.00 \\
\hline \multicolumn{13}{|l|}{ Patrimonio } \\
\hline Capital & $\mathrm{S} /$. & $172,214.82$ & $\mathrm{~S} / \mathrm{.}$ & $167,365.16$ & S/. & $163,557.08$ & $\mathrm{~S} /$. & $160,988.48$ & $\mathrm{~S} /$. & $159,894.87$ & $\mathrm{~S} /$. & $160,556.48$ \\
\hline Resultados & & 0 & $\mathrm{~S} /$. & $51,247.75$ & $\mathrm{~S} /$. & $129,137.18$ & $\mathrm{~S} /$. & $233,352.15$ & $\mathrm{~S} /$. & $354,876.83$ & $\mathrm{~S} / \mathrm{.}$ & $508,062.43$ \\
\hline PATRIMONIO & $\mathrm{S} /$. & $172,214.82$ & $S /$. & $218,612.91$ & $S /$. & $292,694.26$ & $\mathrm{~S} /$. & $394,340.63$ & $\mathrm{~S} /$. & $514,771.69$ & $\mathrm{~S} /$. & $668,618.91$ \\
\hline PASIVO + PATRIMONIO & $\mathrm{S} / \mathrm{.}$ & $212,214.82$ & $\mathrm{~S} / \mathrm{.}$ & $253,130.90$ & $\mathrm{~S} /$. & $320,688.67$ & $\mathrm{~S} /$. & $414,571.96$ & $\mathrm{~S} / \mathrm{.}$ & $525,764.98$ & $\mathrm{~S} /$ & $668,618.91$ \\
\hline
\end{tabular}




\subsubsection{Flujo de caja proyectado}

Como Sapag y Sapag (2008) mencionan, el flujo de caja proyectado para el estudio de un proyecto es uno de los elementos más importantes, dado que, sobre los resultados obtenidos se analizará la viabilidad del mismo. Además, tienen como objetivo, medir la rentabilidad del proyecto, de los recursos propios, y la capacidad de pago frente a los préstamos que se utilizaron en su financiación. (Ver Tabla 108)

Según Baca (2016) define contablemente el capital de trabajo como la diferencia entre el activo circulante y el pasivo circulante, pero a su vez desde el enfoque práctico está representado por el capital adicional (distinto de la inversión en activo fijo y diferido) con el que se debe contar para que empiece a funcionar la empresa, es decir financiar la primera producción antes de recibir ingresos, a través de la compra de materia prima, pago de mano de obra directa, créditos en las primeras ventas, además de contar con efectivo para gastos diarios de la empresa, todo esto formará el activo circulante, pero, así como hay que invertir en estos rubros, también se puede obtener crédito a corto plazo en conceptos como impuestos, algunos servicios, proveedores, y esto es el pasivo circulante.

Además, señala que la Inversión en Capital de Trabajo se diferencia de la inversión en activo fijo y diferido, debido a que estas últimas pueden recuperarse por la vía Fiscal, mediante la depreciación y la amortización; por el contrario, el Capital de Trabajo no puede recuperarse por estos medios dada su naturaleza de circulante; pero puede resarcirse en su totalidad a la finalización del Proyecto.

Al finalizar el proyecto, se determinó considerar solo un 50\% de recuperación de capital de trabajo, por la vida útil de algunos equipos. 
Tabla 108.

Flujo de caja proyectado

\begin{tabular}{|c|c|c|c|c|c|c|c|c|c|c|c|c|}
\hline & \multicolumn{3}{|c|}{2017} & \multicolumn{2}{|l|}{2018} & \multicolumn{2}{|l|}{2019} & \multicolumn{2}{|l|}{2020} & \multicolumn{2}{|l|}{2021} & \multirow{2}{*}{$\begin{array}{r}2022 \\
153,185.60\end{array}$} \\
\hline Utilidad Neta & & & $\mathrm{S} /$. & $51,247.75$ & $\mathrm{~S} / \mathrm{s}$ & $77,889.44$ & $\mathrm{~S} / \mathrm{s}$ & $104,214.96$ & $\mathrm{~S} / \mathrm{s}$ & $121,524.68$ & $\mathrm{~S} / \mathrm{.}$ & \\
\hline Depreciación & & & $\mathrm{S} /$. & $10,331.67$ & $\mathrm{~S} /$. & $10,331.67$ & $\mathrm{~S} / \mathrm{.}$ & $10,331.67$ & $\mathrm{~S} / \mathrm{.}$ & $10,331.67$ & $\mathrm{~S} /$. & $10,331.67$ \\
\hline Amortización & & & $\mathrm{S} /$. & $10,640.07$ & $\mathrm{~s} / \mathrm{.}$ & $10,640.07$ & $\mathrm{~S} / \mathrm{.}$ & $10,640.07$ & $\mathrm{~S} / \mathrm{.}$ & $10,640.07$ & $\mathrm{~S} / \mathrm{.}$ & $10,640.07$ \\
\hline \multirow[t]{2}{*}{ FLUJO CAJA OPERATIVO } & & & $\mathrm{S} /$ & $72,219.49$ & $\mathrm{~S} /$ & $98,861.18$ & $\mathrm{~S} /$ & $125,186.70$ & S/ & $142,496.42$ & $\mathrm{~s} /$ & $174,157.35$ \\
\hline & & 2017 & & 2018 & & 2019 & & 2020 & & 2021 & & 2022 \\
\hline inversión Fija Tangible & $-S /$ & $66,297.63$ & & & & & & & & & & \\
\hline inversión Fija Intangible & $-S /$ & $53,200.37$ & & & & & & & & & & \\
\hline Capital Trabajo & $-S /$ & $52,716.81$ & & & & & & & & & & \\
\hline variación capital trabajo & & & $-S /$ & $5,050.85$ & $-S /$ & $5,479.23$ & $-S /$ & $5,941.61$ & $-S /$ & $6,440.59$ & & \\
\hline recuperación Capital trabajo & & & & & & & & & & & S/ & $37,814.54$ \\
\hline \multirow[t]{2}{*}{ FLUJO CAJA INVERSION } & $-S /$ & $172,214.82$ & $-S /$ & $5,050.85$ & $-S /$ & $5,479.23$ & $-S /$ & $5,941.61$ & $-S /$ & $6,440.59$ & S/ & $37,814.54$ \\
\hline & \multicolumn{3}{|c|}{2017} & \multicolumn{2}{|l|}{2018} & \multicolumn{2}{|l|}{2019} & \multicolumn{2}{|l|}{2020} & \multicolumn{2}{|l|}{2021} & 2022 \\
\hline \multicolumn{13}{|l|}{ FLUJO CAJA DEUDA } \\
\hline Préstamo & S/ & $40,000.00$ & & & & & & & & & & \\
\hline amortización & & & $-S /$ & $5,482.01$ & $-S /$ & $6,523.59$ & $-S /$ & $7,763.07$ & $-S /$ & $9,238.05$ & $-S /$ & $10,993.28$ \\
\hline interés & & & $-S /$ & $6,582.37$ & $-S /$ & $5,540.79$ & $-S /$ & $4,301.31$ & $-S /$ & $2,826.33$ & $-S /$ & $1,071.10$ \\
\hline Escudo Fiscal $29.50 \%$ & & & S/ & $1,941.80$ & S/ & $1,634.53$ & S/ & $1,268.89$ & $\mathrm{~S} /$ & 833.77 & S/ & 315.97 \\
\hline FLUJO CAJA DEUDA & $\mathrm{S} /$ & $40,000.00$ & $-S /$ & $10,122.58$ & $-S /$ & $10,429.85$ & $-S /$ & $10,795.49$ & $-S /$ & $11,230.61$ & $-S /$ & $11,748.41$ \\
\hline FLUJO CAJA ECONOMICO & $-S /$ & $172,214.82$ & $\mathrm{~S} /$ & $67,168.64$ & S/ & $93,381.95$ & S/ & $119,245.10$ & $\mathrm{~S} /$ & $136,055.84$ & $\mathrm{~S} /$ & $211,971.89$ \\
\hline FLUJO CAJA FINANCIERO & $-S /$ & $132,214.82$ & S/ & $57,046.06$ & S/ & $82,952.11$ & S/ & $108,449.60$ & S/ & $124,825.22$ & S/ & $200,223.48$ \\
\hline
\end{tabular}




\section{Capítulo IX. Evaluación económica financiera}

Como Sapag y Sapag (2008) lo señalan, para la evaluación de un proyecto la parte financiera es vital pues menciona que el dinero, cuando transcurre en el tiempo debe ser remunerado con una rentabilidad que el inversionista va a exigir al proyecto por no usar hoy su dinero y más bien aplazarlo su consumo a un futuro, lo que se conoce como el valor del dinero en el tiempo.

En este sentido se ha evaluado la viabilidad del proyecto Lunch Kids S.A.C desde este punto de vista financiero, analizando algunos indicadores de rentabilidad como son el valor actual neto (VAN), la tasa interna de retorno (TIR). También se analizó el riesgo del proyecto teniendo en cuenta la sensibilidad y el análisis de tres tipos de escenarios.

\subsection{Evaluación financiera}

Para el cálculo del proyecto se determinó un horizonte de cinco años que va del año 2018 al 2022, esto no significa que al quinto año el proyecto termine, pues aún tendría flujos positivos. Para este cálculo se tomó en cuenta una tasa de crecimiento de $6.3 \%$ que es el promedio de los últimos diez años, con esto se calculó el valor terminal del proyecto traído al quinto año.

\subsubsection{TIR}

Sapag y Sapag (2008) indicaron que la TIR representa la tasa de interés más alta que el inversionista puede pagar sin perder dinero, si todos los fondos que se necesitan para la inversión se tomaran prestados y el préstamo se pagara con los ingresos. 
La tasa interna de retorno (TIR) puede calcularse con la fórmula:

$$
\sum_{t=1}^{n} \frac{B N_{t}}{(1+r)^{t}}-I_{0}=0
$$

BN: Representa el beneficio neto del flujo en el periodo

t: Tiempo

r: Tasa interna de retorno

En el presente proyecto se realizó el cálculo de la TIR Económico y de la TIR Financiera de las cuales se obtuvo los siguientes resultados:

TIR Económico (TIRE): 51\%

TIR Financiera (TIRF): 60\%

La diferencia entre ello es que en el flujo económico se tiene en cuenta la inversión más el préstamo que se está tomando, en cambio en el financiero solo se tiene en cuenta el capital propio.

La TIR es mayor al COK (14.78\%), por lo que el proyecto es rentable. 
Tabla 109.

Cálculo TIR económico

\begin{tabular}{|c|c|c|c|c|c|c|c|c|c|c|c|}
\hline & 2017 & & 2018 & & 2019 & & 2020 & & 2021 & & 2022 \\
\hline & $-S / 172,214.82$ & S/ & $67,168.64$ & S/ & $93,381.95$ & S/ & $119,245.10$ & S/ & $136,055.84$ & S/ & $211,971.89$ \\
\hline WACC & $14.46 \%$ & & & & & & & & & & \\
\hline TIRE & $51 \%$ & & & & & & & & & & \\
\hline Periodo de recuperación & 2.12 años & & & & & & & & & & \\
\hline descontado & (2 año, 1 mes) & & & & & & & & & & \\
\hline Costo Beneficio & 2.30 & & & & & & & & & & \\
\hline
\end{tabular}

Nota: Elaboración propia.

Tabla 110.

Cálculo TIR financiero

\begin{tabular}{|c|c|c|c|c|c|c|c|c|c|c|c|}
\hline & 2017 & & 2018 & & 2019 & & 2020 & & 2021 & & 2022 \\
\hline & $-S / 132,214.82$ & S/ & $57,046.06$ & S/ & $82,952.11$ & S/ & $108,449.60$ & S/ & $124,825.22$ & S/ & $200,223.48$ \\
\hline $\mathrm{COK}$ & $14.78 \%$ & & & & & & & & & & \\
\hline TIRF & $60 \%$ & & & & & & & & & & \\
\hline Periodo de recuperación & 1.91 años & & & & & & & & & & \\
\hline descontado & (1 año, 11 meses) & & & & & & & & & & \\
\hline Costo Beneficio & 2.70 & & & & & & & & & & \\
\hline
\end{tabular}

Nota: Elaboración propia. 


\subsubsection{VAN}

Sapag y Sapag (2008) indicaron que el Valor Actual Neto (VAN) representa la diferencia entre todos sus ingresos y egresos del proyecto expresado en moneda actual. Y se busca que el resultado sea igual o mayor a 0

El valor actual neto (VAN) puede calcularse con la fórmula:

$$
V A N=\sum_{t=1}^{n} \frac{B N_{t}}{(1+i)^{t}}-I_{0}
$$

BN: Representa el beneficio neto del flujo en el periodo t: Tiempo

i: Tasa de descuento

En el presente proyecto se realizó el cálculo del VAN Económico y del VAN Financiero de las cuales se obtuvo los siguientes resultados:

VAN Económico (VANE): S/ 224,441.90

VAN Financiera (VANF): S/224,578.54

En este caso se cumple lo que se pide con respecto al VAN que este debe ser mayor a 0 , por lo que podemos validar que el proyecto es rentable para los inversionistas. 
Tabla 111.

Cálculo VAN económico

\begin{tabular}{|c|c|c|c|c|c|c|c|c|c|c|c|c|}
\hline & \multicolumn{2}{|r|}{2017} & \multicolumn{2}{|c|}{2018} & \multicolumn{2}{|r|}{2019} & \multicolumn{2}{|r|}{2020} & \multicolumn{2}{|r|}{2021} & \multicolumn{2}{|r|}{2022} \\
\hline & $-S$ & / $172,214.82$ & $\mathrm{~S} /$ & $67,168.64$ & $\mathrm{~S} /$ & $93,381.95$ & S/ & $119,245.10$ & $\mathrm{~S} /$ & $136,055.84$ & S/ & $211,971.89$ \\
\hline VANE & $\mathrm{S} /$ & $224,441.90$ & & & & & & & & & & \\
\hline
\end{tabular}

Nota: Elaboración propia.

Tabla 112.

Cálculo VAN financiero

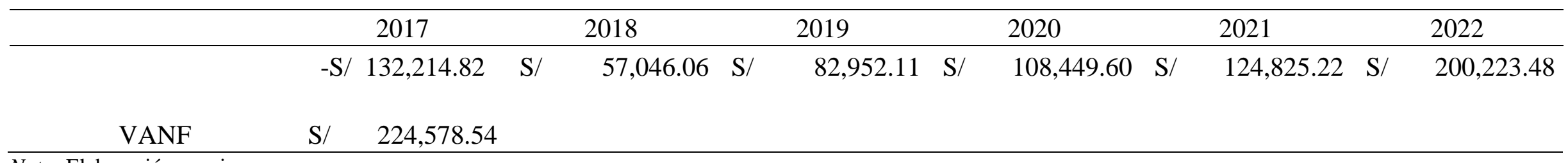

Nota: Elaboración propia. 


\subsubsection{ROE}

ROE (Return On Equity): También conocido como rentabilidad patrimonial. En este caso se puede observar que desde el inicio del proyecto en el año 2018 hasta el año 2022 el ROE muestra un comportamiento muy similar. Por lo que se puede observar que en el año 2018 por cada $\mathrm{S} / 1.00$ sol invertido rendirá 0.23 soles.

El R.O.E se calcula con la siguiente fórmula:

Rentabilidad Patrimonial $=$ (ROE)
Utilidad Neta

Patrimonio

Tabla 113.

Cálculo del ROE

\begin{tabular}{lccccc}
\hline & 2018 & 2019 & 2020 & 2021 & 2022 \\
\hline Utilidad & $\mathrm{S} / .51,247.75$ & $\mathrm{~S} / .77,889.44$ & $\mathrm{~S} / .104,214.96$ & $\mathrm{~S} / .121,524.68$ & $\mathrm{~S} / .153,185.60$ \\
Neta & $\mathrm{S} / .218,612.91$ & $\mathrm{~S} / .292,694.26$ & $\mathrm{~S} / .394,340.63$ & $\mathrm{~S} / .514,771.69$ & $\mathrm{~S} / .668,618.91$ \\
Patrimonio & $\mathrm{S} / 44 \%$ & $26.61 \%$ & $26.43 \%$ & $23.61 \%$ & $22.91 \%$ \\
ROE & $23.4 \%$ & & &
\end{tabular}

Nota: Elaboración propia.

\subsubsection{Ratios}

Sanz (2011) menciona, que los Ratios son la forma más tradicional para analizar los estados financieros, estos se dividen en ratios de liquidez, solvencia, rentabilidad, actividad. Para el caso del presente proyecto analizaremos los Ratios de rentabilidad los cuales se detallan a continuación:

Rentabilidad del activo: Con esta ratio se observa la rentabilidad de los activos, muestra la eficiencia en su uso. Se calcula con la siguiente fórmula:

Rentabilidad del Activo = Utilidad Neta

Total activo 
Margen de utilidad bruta: Este Ratio sirve para conocer cuánto genera la empresa para cubrir sus gastos operativos. Se calcula con la siguiente fórmula:

Margen Utilidad Bruta = Utilidad Bruta Ventas

En el caso del presente proyecto significa que por ejemplo en el año 2018 por cada S/. 1.00 Sol que vende la empresa, genera 0.41 soles para cubrir los gastos operativos.

Margen de utilidad neta: Indica el margen de utilidad neta que la empresa está esperando por una venta. Se calcula con la siguiente fórmula:

Margen Utilidad Neta $=\quad \frac{\text { Utilidad Neta }}{\text { Ventas }}$

En el caso del presente proyecto significa que por ejemplo en el año 2018 por cada S/ 1.00 Sol que generó la empresa, se utilizaron 0.08 Soles en gastos operativos.

Tabla 114.

Principales ratios

\begin{tabular}{lccccc}
\hline & 2018 & 2019 & 2020 & 2021 & 2022 \\
\hline $\begin{array}{l}\text { Rentabilidad del } \\
\text { Activo }\end{array}$ & $20.25 \%$ & $24.29 \%$ & $25.14 \%$ & $23.11 \%$ & $22.91 \%$ \\
$\begin{array}{l}\text { Margen Utilidad } \\
\text { Bruta }\end{array}$ & $41.18 \%$ & $43.42 \%$ & $44.94 \%$ & $44.30 \%$ & $45.83 \%$ \\
$\begin{array}{l}\text { Margen Utilidad } \\
\text { Neta }\end{array}$ & $8.49 \%$ & $11.78 \%$ & $14.40 \%$ & $15.35 \%$ & $17.70 \%$ \\
\hline $\begin{array}{l}\text { Nota: } \text { Elaboración propia. } \\
\text { N }\end{array}$ & & & & & \\
\hline
\end{tabular}




\subsection{Análisis de riesgo}

Como Sapag y Sapag (2008) indicaron, el riesgo existe cuando nos enfrentamos a una situación en la cual una decisión que tomamos tiene más de un posible resultado y la posibilidad de que cada uno de los resultados se pueda estimar. En caso estas posibilidades no se conozcan o no se puedan determinar se dice que existe incertidumbre.

Para el caso del presente proyecto se analizaron los riesgos tomando en cuenta el punto de equilibrio, la sensibilidad y los posibles escenarios que nos podrían presentar en el proyecto.

\subsubsection{Análisis de punto de equilibrio}

Para hallar el punto de equilibrio del proyecto se tomó en cuenta los costos variables con la proyección de ventas con lo que se obtuvo el costo variable unitario, a raíz de esto se armaron los márgenes de contribución tanto de inicial y primaria.

A partir de este se obtuvo el punto de equilibrio tanto en número de unidades como el punto de equilibrio en monto. De estos resultados se obtuvo por ejemplo que en el 2018 el número de loncheras de equilibrio fue de 18,061, y en monto S/ 436,365.32 
Tabla 115.

Punto de equilibrio (en cantidad)

\begin{tabular}{lrrrr}
\hline & 2018 & 2019 & 2020 & 2021 \\
\hline Punto de equilibrio & 18,061 & 17,321 & 16,893 & 2022 \\
Inicial & 5,386 & 5,216 & 5,133 & 17,231 \\
Primaria & 12,675 & 12,106 & 5,280 & 5,185 \\
\hline
\end{tabular}

Nota: Elaboración propia.

Tabla 116

Punto de equilibrio (en soles)

\begin{tabular}{|c|c|c|c|c|c|c|c|c|}
\hline & & & & & & & 2021 & 2022 \\
\hline Inicial & S/ $114,115.55$ & S/ & $110,503.94$ & $\mathrm{~S} /$ & $108,746.59$ & $\mathrm{~S} /$ & $111,867.73$ & S/ $109,839.47$ \\
\hline Primaria & S/ $\quad 322,249.77$ & $\mathrm{~S} /$ & $307,769.18$ & $\mathrm{~S} /$ & $298,977.06$ & $\mathrm{~S} /$ & $303,838.41$ & S/ $294,932.21$ \\
\hline Punto de equilibrio & S/ $436,365.32$ & S/ & $418,273.12$ & $\mathrm{~S} /$ & $407,723.65$ & $\mathrm{~S} /$ & $415,706.14$ & S/ $\quad 404,771.69$ \\
\hline
\end{tabular}

Nota: Elaboración propia. 


\subsubsection{Análisis de sensibilidad}

Según Sapag y Sapag (2008), indicaron que al formular un proyecto es necesario tener en cuenta la mayor cantidad de antecedentes para que las personas que deban tomar la decisión de ejecutar el proyecto cuenten con todos los elementos de juicio suficientes para una buena toma de decisión. Por ello el desarrollar un análisis de sensibilidad permite medir que tan sensible es la evaluación realizada en uno o varios parámetros.

Para el proyecto se calculó la sensibilidad tomando en cuenta la variación de la participación en rangos de $0.5 \%$, con él se calculó la TIR y el VAN.

Se hizo el mismo análisis con el precio, variándolo en el mismo rango y realizando el cálculo de la TIR y el VAN. 
Tabla 117.

Sensibilidad y escenarios con variación de la participación

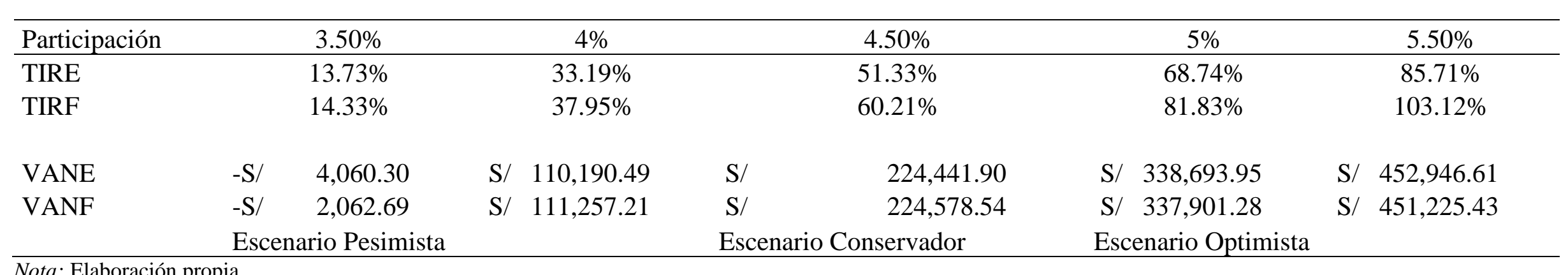
Nota: Elaboración propia.

Tabla 118.

Sensibilidad y escenarios con variación del precio

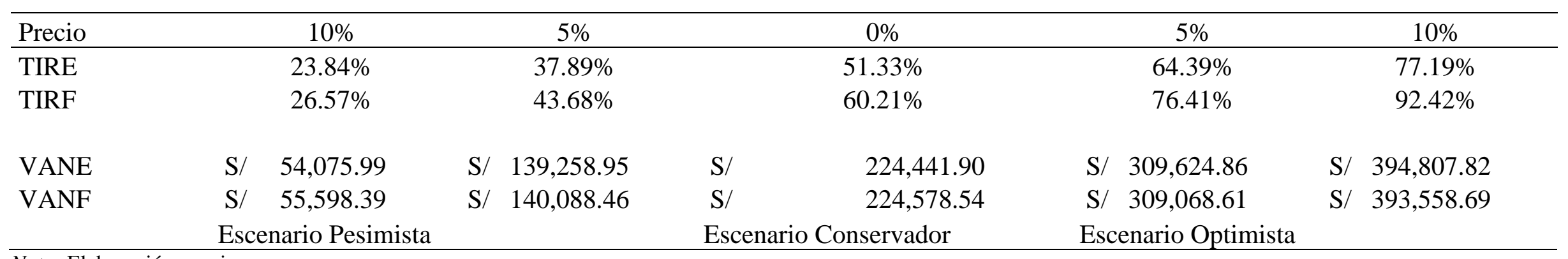
Nota: Elaboración propia. 


\subsubsection{Análisis de escenarios}

Para el análisis de escenarios se tomaron los cuadros del punto anterior y se analizaron tres tipos de escenarios:

a. Escenario Pesimista: Teniendo en cuenta la participación como variable, muestra que en caso de tener una participación de 3.5\% la TIR y el VAN serían negativos y por lo tanto el proyecto no debería ejecutarse, sin embargo, si se tiene como mínimo una participación de $4 \%$ del mercado la TIR y el VAN serían positivos y aún en este escenario el proyecto sería viable. Y teniendo como variable el precio, si este disminuye hasta un $10 \%$ de la propuesta inicial tanto la TIR y el VAN serían positivos y el proyecto podría ejecutarse.

b. Escenario Conservador: Es el escenario donde se trabajó el proyecto, teniendo en cuenta una participación de mercado de $4.5 \%$, en donde la TIR y el VAN son positivos y bastantes atractivos para cualquier persona que desee invertir. El mismo resultado se obtuvo con los precios trabajados en el proyecto.

c. Escenario Optimista: Con la variación de la participación del mercado entre 5\% y $5.5 \%$ se obtuvo una TIR y un VAN también bastante atractivos para los inversionistas. Por el lado de los precios si estos se incrementan entren 5\% y $10 \%$ los resultados de la TIR y el VAN permanecen siendo atractivos para los inversionistas.

\subsubsection{Matriz de riesgos y plan de mitigación}

Según el Project Management Institute, Inc (2013), efectuar el análisis cualitativo de riesgos, permite priorizar los riesgos para determinar las acciones posteriores, considerando la probabilidad de ocurrencia e impacto de dichos riesgos. Este proceso permite reducir el nivel de incertidumbre y enfocarse en los riesgos de alta prioridad. 
Tabla 119.

Análisis de riesgos

\begin{tabular}{|c|c|c|c|c|c|}
\hline Código & Nombre & $\begin{array}{l}\text { Objetivo } \\
\text { impactado }\end{array}$ & $\begin{array}{l}\text { Probabilidad } \\
\text { de ocurrencia }\end{array}$ & Impacto & Severidad \\
\hline $\mathrm{R} 1$ & $\begin{array}{l}\text { Problemas legales } \\
\text { por incumplimiento } \\
\text { de contrato con los } \\
\text { proveedores }\end{array}$ & Financiero & $50.0 \%$ & $60.0 \%$ & $30.0 \%$ \\
\hline $\mathrm{R} 2$ & $\begin{array}{l}\text { Subida en la tasa de } \\
\text { cambio }\end{array}$ & Financiero & $30.0 \%$ & $40.0 \%$ & $12.0 \%$ \\
\hline $\mathrm{R} 3$ & $\begin{array}{l}\text { Cambios en las } \\
\text { leyes peruanas }\end{array}$ & Legislativo & $30.0 \%$ & $20.0 \%$ & $6.0 \%$ \\
\hline $\mathrm{R} 4$ & $\begin{array}{l}\text { Alta rotación de } \\
\text { personal }\end{array}$ & Organizativo & $50.0 \%$ & $40.0 \%$ & $20.0 \%$ \\
\hline $\mathrm{R} 5$ & $\begin{array}{l}\text { Entrada de } \\
\text { productos sustitutos }\end{array}$ & Competencia & $50.0 \%$ & $20.0 \%$ & $10.0 \%$ \\
\hline R6 & $\begin{array}{l}\text { Entrada de posibles } \\
\text { competidores }\end{array}$ & Competencia & $50.0 \%$ & $60.0 \%$ & $30.0 \%$ \\
\hline $\mathrm{R} 7$ & $\begin{array}{l}\text { Imitación del } \\
\text { concepto de } \\
\text { negocio. }\end{array}$ & Competencia & $30.0 \%$ & $60.0 \%$ & $18.0 \%$ \\
\hline $\mathrm{R} 8$ & $\begin{array}{l}\text { Subida de precios } \\
\text { de los insumos }\end{array}$ & Calidad & $30.0 \%$ & $40.0 \%$ & $12.0 \%$ \\
\hline $\mathrm{R} 9$ & $\begin{array}{l}\text { Accidentes } \\
\text { laborales }\end{array}$ & Operacional & $10.0 \%$ & $60.0 \%$ & $6.0 \%$ \\
\hline
\end{tabular}


Tabla 120.

Matriz de riesgos probabilidades e impacto

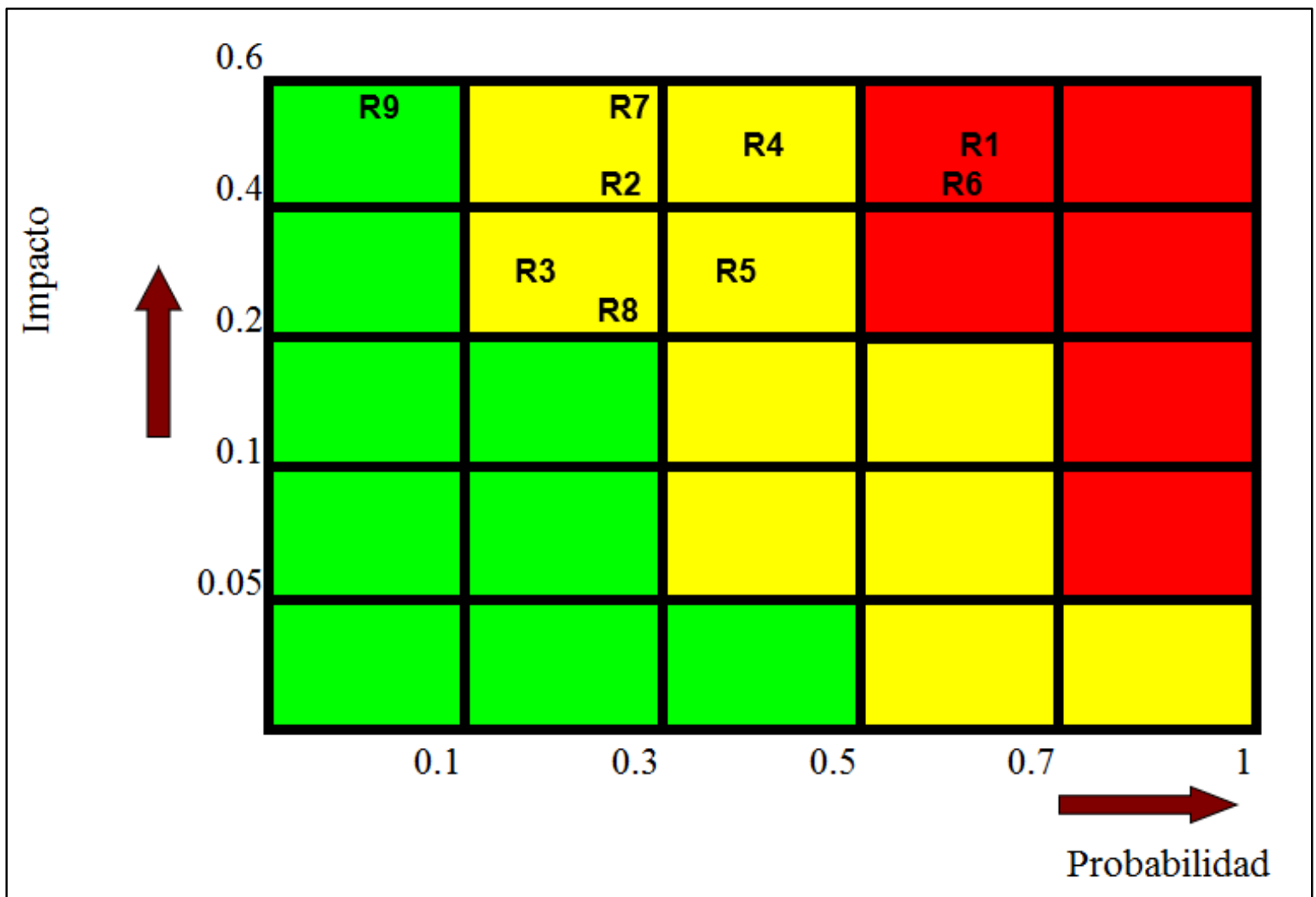

Nota: Elaboración propia. 
Tabla 121.

Plan de respuesta de riesgos

\begin{tabular}{|c|c|c|c|c|c|c|c|}
\hline Código & Nombre & $\begin{array}{l}\text { Objetivo } \\
\text { impactado }\end{array}$ & $\begin{array}{l}\text { Probabilidad de } \\
\text { ocurrencia }\end{array}$ & Impacto & Severidad & $\begin{array}{l}\text { Tipo de } \\
\text { respuesta }\end{array}$ & Descripción de Respuesta \\
\hline $\mathrm{R} 1$ & $\begin{array}{l}\text { Problemas legales } \\
\text { por incumplimiento } \\
\text { de contrato con los } \\
\text { proveedores }\end{array}$ & Financiero & $50.0 \%$ & $60.0 \%$ & $30.0 \%$ & Mitigar & $\begin{array}{l}\text { Establecer un mínimo de tres ( } 3 \text { ) empresas proveedoras } \\
\text { por producto, considerando: estándares de calidad, } \\
\text { cumplimientos y facilidades en la gestión. }\end{array}$ \\
\hline $\mathrm{R} 2$ & $\begin{array}{l}\text { Subida en la tasa de } \\
\text { cambio }\end{array}$ & Financiero & $30.0 \%$ & $40.0 \%$ & $12.0 \%$ & Evitar & $\begin{array}{l}\text { Todo compromiso financiero será adquirido en moneda } \\
\text { nacional, con finalidad de evitar impacto directo por el } \\
\text { tipo de cambio. }\end{array}$ \\
\hline R3 & $\begin{array}{l}\text { Cambios en las leyes } \\
\text { peruanas }\end{array}$ & Legislativo & $30.0 \%$ & $20.0 \%$ & $6.0 \%$ & Aceptar & $\begin{array}{l}\text { Conocimiento y adaptación inmediata a las nuevas } \\
\text { normativas establecidas por ley. }\end{array}$ \\
\hline $\mathrm{R} 4$ & $\begin{array}{l}\text { Alta rotación de } \\
\text { personal }\end{array}$ & Organizativo & $50.0 \%$ & $40.0 \%$ & $20.0 \%$ & Evitar & $\begin{array}{l}\text { Establecer perfiles de puestos adecuados a cada actividad, } \\
\text { realizar un adecuado proceso de selección, cumplir las } \\
\text { obligaciones de beneficios establecidos por ley y crear un } \\
\text { adecuado clima organizacional. }\end{array}$ \\
\hline R5 & $\begin{array}{l}\text { Entrada de productos } \\
\text { sustitutos }\end{array}$ & Competencia & $50.0 \%$ & $20.0 \%$ & $10.0 \%$ & Mitigar & Diferenciación del producto y servicio. \\
\hline R6 & $\begin{array}{l}\text { Entrada de posibles } \\
\text { competidores }\end{array}$ & Competencia & $50.0 \%$ & $60.0 \%$ & $30.0 \%$ & Mitigar & Diferenciación del producto y servicio. \\
\hline R7 & $\begin{array}{l}\text { Imitación del } \\
\text { concepto de negocio. }\end{array}$ & Competencia & $30.0 \%$ & $60.0 \%$ & $18.0 \%$ & Evitar & $\begin{array}{l}\text { Innovación constante tanto del producto y mejora del } \\
\text { servicio. }\end{array}$ \\
\hline $\mathrm{R} 8$ & $\begin{array}{l}\text { Subida de precios de } \\
\text { los insumos }\end{array}$ & Calidad & $30.0 \%$ & $40.0 \%$ & $12.0 \%$ & Mitigar & $\begin{array}{l}\text { Contar con alternativas de insumos evaluando: precios y } \\
\text { estacionalidad, sin afectar el valor nutricional requerido. }\end{array}$ \\
\hline R9 & Accidentes laborales & Operacional & $10.0 \%$ & $60.0 \%$ & $6.0 \%$ & Evitar & $\begin{array}{l}\text { Establecer políticas Seguridad y Salud en el trabajo, con } \\
\text { acciones correctivas y preventivas. }\end{array}$ \\
\hline
\end{tabular}




\section{Conclusiones y recomendaciones}

En el presente capitulo se detallan los aspectos más importantes identificados en el desarrollo de la presente investigación, clasificados en conclusiones y recomendaciones.

\section{Conclusiones}

1. Se determinó la viabilidad del plan de negocio loncheras saludables en colegios particulares de educación inicial y primaria, que en principio se proyectó a colegios de los distritos Ate, Santa Anita y La Molina.

2. Se realizó un análisis del entorno de la empresa y determino que el mercado nacional muestra un entorno favorable tanto político como social para la ejecución de un negocio de loncheras saludables, ya que tanto el Estado como entidades particulares promueven el consumo de alimentos no procesados acompañado también de actividad física diaria.

3. El estudio de mercado identifico una creciente tendencia hacia el consumo de alimentos saludables principalmente para niños de educación inicial y primaria que se encuentran en etapa de crecimiento.

4. Se identifico el mercado objetivo en padres de familia con hijos en colegios de educación inicial y primaria que pertenecen al NSE B y C.

5. Se determino que la propuesta de negocio consta de dos áreas definidas, el área de operaciones y el área administrativa, y dado que se inician actividades con 11 colabores la empresa es una Pyme.

6. Se diseño el plan de marketing y de ventas potenciando la presencia de la empresa a través de las redes sociales, así también como estableciendo alianzas con colegios, centros recreacionales, centros pediátricos, etc.

7. Se analizo la viabilidad económica y/o financiera para la implementación del negocio y concluyo que la rentabilidad supera el $60 \%$ y el periodo de recuperación es un año y siete meses.

\section{Recomendaciones}

1. Se recomienda implementar la idea de negocio lo antes posible en el nicho de mercado identificado, dado que por la poca competencia que existe en el sector es una opción de 
servicio interesante, que atiende la necesidad de alimentación saludable que es tendencia en el Perú y el mundo.

2. Aprovechar los proyectos de Ley que regulan la venta de alimentos saludables e incluyen también a los quioscos de colegios ya que genera una competencia sana supervisada por el Estado.

3. Aprovechar la creciente tendencia por la alimentación saludable y las campañas de concientización de diferentes entidades gubernamentales.

4. Aprovechar la falta de tiempo que tienen hoy los padres de familia para la elaboración diaria de la lonchera escolar de sus hijos y brindar alternativas variadas según estacionalidad de frutas.

5. Seleccionar personal experto en el rubro para garantizar la adecuada preparación de loncheras saludables y gestión administrativa eficiente.

6. Aprovechar la conectividad de internet en el país y el acceso a información globalizada para llegar al público objetivo y promocionar el servicio de loncheras saludables.

7. Aprovechar la estabilidad económica que ha venido presentando el Perú en los últimos años. 


\section{Referencias}

Andina (2014, 22 de agosto). Convocan a concurso escolar de loncheras y quioscos saludables. Recuperado de http://www.andina.com.pe/agencia/noticia-convocan-aconcurso-escolar-loncheras-y-quioscos-saludables-519999.aspx

Apega. (2011, 27 de setiembre) ¿Cómo sacarles el jugo a las frutas peruanas? Recuperado de http://www.apega.pe/noticias/prensa-y-difusion/como-sacarle-el-jugo-a-las-frutasperuanas.html

Asociación peruana de empresas de investigación de mercados (2016). Niveles

Socioeconómicos 2016. Recuperado de http://apeim.com.pe/wpcontent/uploads/2019/11/APEIM-NSE-2016.pdf

Baca, G. (2016). Evaluación de proyectos. (8a. ed.). Recuperado de https://www.ebooks724.com:443/?il=4613\&pg=198

Banco central de reserva del perú (2017). Reporte de inflación setiembre 2017. Panorama actual y proyecciones macroeconómicas 2017-2019. Recuperado de http://www.bcrp.gob.pe/docs/Publicaciones/ReporteInflacion/2017/setiembre/reporte-de-inflacion-setiembre-2017.pdf

Banco central de reserva del perú (2017). Reporte de inflación marzo 2017. Panorama actual y proyecciones macroeconómicas 2017-2018. Recuperado de http://www.bcrp.gob.pe/docs/Publicaciones/Reporte-Inflacion/2017/marzo/reportede-inflacion-marzo-2017.pdf

Banco central de reserva del perú. (2017). BCRPData. Otros Servicios. Lima: BCRP. Recuperado de https://estadisticas.bcrp.gob.pe/estadisticas/series/anuales/resultados/PM04981AA/ht $\mathrm{ml} / 2007 / 2017 /$ 
Bernal, C. (2016). Metodología de la investigación: administración, economía, humanidades y ciencias sociales. (4a ed.). Bogotá.: Pearson.

Cabrera, J. R. (2015). Programa de educación nutricional orientado al logro de un estilo de vida saludable en estudiantes de educación primaria (Tesis de maestría inédita). Universidad San Ignacio de Loyola, Lima.

Calcula tu participación de mercado y punto de equilibrio. (2011). Entrepreneur. Recursos humanos. Recuperado de https://www.entrepreneur.com/article/264164

Datum internacional (2013). Los peruanos no cuentan con la información nutricional necesaria para seguir una dieta saludable. Estudio de Opinión Pública sobre nutrición y hábitos de alimentación saludable. Recuperado de http://www.datum.com.pe/new_web_files/files/pdf/HAS.pdf

David, F. \& David, F. (2017). Conceptos de administración estratégica (17a ed.). México, D.F.: Pearson Educación. Recuperado de https://www.ebooks724.com:443/?il=5029\&pg=172

David, F. (2013). Conceptos de administración estratégica (14a ed.). México, D.F.: Pearson Educación.

Decreto supremo N $017-2017-S A$ Reglamento de la Ley N 30021, Ley de promoción de la alimentación saludable para niños, niñas y adolescentes. (17 de junio 2017). En Diario Oficial El Peruano, Normas Legales, 25-29. Perú. Recuperado de http://busquedas.elperuano.com.pe/download/url/decreto-supremo-que-aprueba-elreglamento-de-la-ley-n-30021-decreto-supremo-n-017-2017-sa-1534348-4

Decreto supremo No $007-98-S A$. Aprueban el reglamento sobre vigilancia y control sanitario de alimentos y bebidas (1998). Recuperado de https://apps.contraloria.gob.pe/pvl/files/D.S.\%20007-98-SA.pdf

Dirksen, C. J. \& Kroeger, A. (1984). Publicidad. México, D.F.: Continental 
Ecoempaques. [Página oficial de Facebook]. Recuperado de https://www.facebook.com/ecoempaques

El Comercio. Tendencia Saludable (04 de agosto de 2017). Entérate sobre el avance de la alimentación saludable en el Perú. El Comercio. Recuperado de http://elcomercio.pe/suplementos/comercial/educacion-nutricion/enterate-sobreavance-alimentacion-saludable-peru-1002916

El Comercio (15 de junio de 2017) ¿Cómo se etiquetan los alimentos en América Latina para identificar los menos saludables? El Comercio. Recuperado de http://elcomercio.pe/economia/mundo/etiqueta-alimentos-funciona-otros-paisesamerica-latina-434621

Ferrell, O. C. \& Hartline, M. D. (2012). Estrategia de marketing (2a ed.). México, D.F.: Cengage learning.

Gestión (04 de julio de 2017) Indecopi: registro de marcas y patentes reduce costo hasta por S/ 500, 2017. Recuperado de https://gestion.pe/economia/empresas/indecopi-registromarcas-patentes-reduce-costo-s-500-138691-noticia/

Gestión (05 de abril de 2017). Lima orgánica: “el mercado de comida saludable ha evolucionado favorablemente por la demanda del público”. Gestión. Recuperado de https://gestion.pe/tendencias/lima-organica-mercado-comida-saludable-evolucionadofavorablemente-demanda-publico-132445-noticia/

Gestión (31 de marzo de 2016). ¿Cómo una empresa incorpora la responsabilidad social corporativa? Gestión. Recuperado de https://gestion.pe/opinion/empresa-incorporaresponsabilidad-social-corporativa-145636-noticia/

Guía de los fundamentos para la dirección de proyectos (Guía del PMBOK). (2013). Pennsylvania: Project Management Institute, 2013. Recuperado de 
https://infosil.usil.edu.pe/?url=http://search.ebscohost.com/login.aspx?direct=true\&db $=$ cat $00852 \mathrm{a} \& \mathrm{AN}=$ usi.30767\&lang=es\&site=eds-live

Hitt, M., Irelnd, R. \& Hoskisson, R. (2015). Administración estratégica: competitividad y globalización: conceptos y casos. (11a ed.). México, D.F.: Cengage learning.

Instituto nacional de estadística e informática (2017a). Producción nacional diciembre 2016 (Informe técnico $\mathrm{N}^{\circ}$ 2). Lima: INEI. Recuperado de https://www.inei.gob.pe/media/principales_indicadores/02-informe-tecnicon02_produccion-nacional-dic2016.pdf

Instituto nacional de estadística e informática (2017b). Boletín Censos Nacionales 2017: XII de población y VII de vivienda y III de Comunidades indígenas, 2017. Lima: INEI. Recuperado de https://www.inei.gob.pe/media/MenuRecursivo/publicaciones_digitales/Est/Lib1437/1 ibro.pdf

Instituto nacional de estadística e informática (2016a). Producción nacional octubre 2016 (Informe técnico $\mathrm{N}^{\circ} 12$ ). Lima: INEI. Recuperado de https://www.inei.gob.pe/media/MenuRecursivo/boletines/informe-tecnicon12_produccion_oct2016.pdf

Instituto nacional de estadística e informática (2016b). Planos estratificados de Lima Metropolitana a nivel de manzana 2016. Lima: INEI. Recuperado de https://www.inei.gob.pe/media/MenuRecursivo/publicaciones_digitales/Est/Lib1403/1 ibro.pdf

Instituto nacional de estadística e informática (2015a). Estado de la población peruana 2015. Lima: INEI. Recuperado de https://www.inei.gob.pe/media/MenuRecursivo/publicaciones_digitales/Est/Lib1251/ Libro.pdf 
Instituto nacional de estadística e informática (2015b). Perú: estructura empresarial 2014.

Lima: INEI. Recuperado de

https://www.inei.gob.pe/media/MenuRecursivo/publicaciones_digitales/Est/Lib1262/i ndex.html

Instituto nacional de estadística e informática (2010). Clasificación industrial internacional uniforme: de todas las actividades económicas. Revisión 4. Lima: INEI. Recuperado de

https://www.inei.gob.pe/media/MenuRecursivo/publicaciones_digitales/Est/Lib0883/ Libro.pdf

Instituto nacional de salud. (2018). Número y proporción de casos con diagnostico nutricional según indicador P/T por distritos (01 de enero de 2015 - 31 de marzo de 2017). Recuperado de https://tablerodemando.ins.gob.pe/desnutricion/aguda/departamentos Instituto nacional de la salud (2017). Observatorio de nutrición y estudio del sobrepeso y obesidad - Indicadores a nivel nacional - Dashboard. Recuperado de observateperu.ins.gob.pe/

Instituto nacional de salud (20 abril 2016). Incremento de sobrepeso y obesidad en niños de 5 a 9 años [Archivo de video]. Recuperado de http://www.portal.ins.gob.pe/en/galeriade-videos/1017-incremento-de-sobrepeso-y-obesidad-en-ninos-de-5-a-9-anos

Instituto nacional de salud. (2015). Informe Técnico: Lonchera Escolar en Estudiantes de Nivel Primario, Perú 2013. Lima: Ministerio de Salud. Recuperado de https://web.ins.gob.pe/sites/default/files/Archivos/cenan/van/vigilacia_poblacion/Info rme_de_Lonchera_Escolar_2013.pdf

Instituto nacional de salud. (2013). Sala situacional alimentaria nutricional 5. Sobrepeso y obesidad. Lima: INS. Recuperado de 
https://web.ins.gob.pe/sites/default/files/Archivos/cenan/van/sala_nutricional/sala_3/0 1_Sala_Situacional_Alimentaria_Nutricional_5_Sobrepeso_y_obesidad.pdf Instituto nacional de salud (2012). Refrigerio escolar. Recuperado de https://web.ins.gob.pe/es/alimentacion-y-nutricion/recetas-y-refrigerios/refrigerioescolar

Kotler, P. (2013). Fundamentos de marketing (11a ed.). México D.F.: Pearson.

Kotler, P. \& Armstrong, G. (2017). Marketing (16a ed.). México, D.F.: Pearson.

Kotler, P. \& Armstrong, G. (2012). Marketing (14a ed.). México, D.F.: Pearson.

Kotler, P. \& Keller, K. (2016). Dirección de marketing (15a ed.). México, D.F.: Pearson.

Kotler, P. \& Keller, K. (2012). Dirección de marketing (14a ed.). México, D.F.: Pearson.

Lambin. J. J. (2009). Dirección de marketing (2a ed.). México, D.F.: McGraw-Hill.

Ley 30021, Ley de promoción de la alimentación saludable para niños, niñas y adolescentes.

(2013). En diario oficial El Peruano 494937. Perú

Ley N 29571 Código de Protección y Defensa del Consumidor (2010). Instituto Nacional de defensa de la competencia y de la protección de la propiedad intelectual. Perú.

Recuperado de https://www.indecopi.gob.pe/documents/20195/177451

CodigoDProteccionyDefensaDelConsumidor\%5B1\%5D.pdf/934ea9ef fcc9-48b8$9679-3 \mathrm{e} 8 \mathrm{e} 2493354 \mathrm{e}$

Liria, R. (2012). Consecuencias de la obesidad en el niño y el adolescente: un problema que requiere atención [version electrónica]. Revista Peruana de Medicina Experimental y Salud Publica, 29(3), 357-360. Recuperado de http://www.scielo.org.pe/scielo.php?script=sci_arttext\&pid=S172646342012000300010 
Lopez, S (1 de julio de 2016). Políticas fiscales contra la obesidad: ineficaces y lesivas. La República. Recuperado de https://www.larepublica.co/empresas/politicas-fiscalescontra-la-obesidad-ineficaces-y-lesivas-2395346

Lovelock, C. \& Wirtz, J. (2009). Marketing de servicios (6a ed.). México, D.F.: Pearson.

Malhotra, N. (2008). Investigación de mercados. México, D.F.: Pearson Educación, 2008.

Malo, M., Castillo, N. \& Pajita, D. (2017). La obesidad en el mundo. An Fac med., 78 (2), 67-72. Recuperado de https://www.researchgate.net/publication/318480868_La_ obesidad_en_el_mundo.

McDaniel C. \& Gates R. (2016). Investigación de mercados. (11a ed.). México, D.F.: Cengage learning.

Ministerio de economía y finanzas (2017). Marco Macroeconómico Anual 2018-2021. Lima: MEF. Recuperado de https://www.mef.gob.pe/contenidos/pol_econ/marco_macro/MMM_2018_2021.pdf

Ministerio de economía y finanzas (2012). Perú: Política de inversión pública en ciencia, tecnología e investigación. Ministerio de Economía y Finanzas. Prioridades, 20132020. Lima: MEF. Recuperado de https://www.mef.gob.pe/contenidos/inv_publica/docs/novedades/2013/agosto/Lineam ientos_CTI.pdf

Ministerio de educación, Unidad de estadística educativa (ESCALE). (2016). Padrón de Instituciones Educativas y Programas que gestiona la Unidad de Estadística del Ministerio de Educación 2016. Recuperado de http://escale.minedu.gob.pe/padron-deiiee

Ministerio de salud (23 de setiembre de 2017). Hackers permanecerán 30 horas desarrollando aplicativo móviles para mejorar servicios de salud. Lima: MINSA. Recuperado de 
https://www.gob.pe/institucion/minsa/noticias/13271-hackers-permaneceran-30horas-desarrollando-aplicativos-moviles-para-mejorar-servicios-de-salud

Ministerio de salud (2016). MINSA dará a conocer los alimentos que no son saludables para la población. Recuperado de http://www.minsa.gob.pe/?op=51\&nota=18607

Ministerio de salud (03 de febrero de 2015). Digesa exhorta a municipios cumplir función de vigilancia. Recuperado de http://www.digesa.minsa.gob.pe/noticias/Febrero2015/nota8.asp

Ministerio de la producción (2015). Anuario estadístico industrial, MYPE y comercio interno. Lima: PRODUCE. Recuperado de http://www.produce.gob.pe/documentos/estadisticas/anuarios/anuario-estadisticomype-2015.pdf

Montaño, F (2017). Leyes que son letra muerta por falta de reglamentación. Recuperado de http://larepublica.pe/impresa/sociedad/863288-leyes-que-son-letra-muerta-por-faltade-reglamentacion

Municipalidad de Ate. (2017) [Procedimiento para Licencia de funcionamiento]. Recuperado de http://www.muniate.gob.pe/ate/files/licenciaFuncionamiento/PROCEDIMIENTO/1.\% 20L.F.\%20EX\%20POST-16.pdf

Organización Mundial de la Salud. (2018, 31 de agosto). Centro de prensa. Alimentación sana. (Nota descriptiva No 394). Recuperado de http://www.who.int/mediacentre/factsheets/fs394/es/

Organización Mundial de la Salud. (2015). Alimentos y bebidas ultraprocesados en América latina: tendencias, efecto sobre la obesidad e implicaciones para las políticas públicas. Washington: OMS. Recuperado de http://iris.paho.org/xmlui/bitstream/handle/123456789/7698/9789275318645_esp.pdf 
Pérez. J. (2007). Gestión de procesos. Madrid: ESIC Editorial.

Pichihua S. (30 de setiembre de 2016). En el Perú se evalúa el uso del asistente virtual. El Peruano. Recuperado de http://www.elperuano.pe/noticia-tecnologiay-salud46080.aspx

Porter, M. (2010). Ventaja competitiva: creación y sostenibilidad de un rendimiento superior. Madrid: Piramide.

Rengifo, T. (2017). Tendencias del mercado de lo natural. La República. Recuperado de https://larepublica.pe/marketing/860310-tendencias-del-mercado-de-lo-natural/

Reyes, F. (03 de agosto de 2016). Perú: datos de telecomunicaciones [mensaje en un blog]. Recuperado de http://telecomunicaciones-peru.blogspot.com/2016/03/peru-datos-detelecomunicaciones.html

Rodriguez, D., \& Valldeoriola, R. (2012). Metodología de la investigación. Catalunya: UOC. Recuperado de http://zanadoria.com/syllabi/m1019/mat_cast-nodef/PID_001485561.pdf

Romainville, M. (16 de mayo de 2017). Ley contra la comida chatarra cumple 4 años sin reglamento. El Comercio. Recuperado de http://elcomercio.pe/economia/ley-comidachatarra-cumple-4-anos-reglamento-422280

RPP vital (2015, 26 de febrero). Las loncheras no reemplazan al desayuno. Recuperado de http://vital.rpp.pe/salud/las-loncheras-no-reemplazan-al-desayuno-noticia-773035 RPP noticias (2017, 17 de enero). El impacto ecológico del uso de la tierra y edificios en ciudades de América Latina. Recuperado de http://rpp.pe/peru/actualidad/el-impactoecologico-del-uso-de-la-tierra-y-edificios-en-ciudades-de-america-latina-noticia1024434

Russell, T., Lane, W. (1994). Kleppner Publicidad (12a ed.). México, D.F.: Prentice-Hall Hispanoamericana. 
Sanz, C. (2011). Guía de los principales ratios. Acciones e Investigaciones Sociales, (14), 137-152. doi: https://doi.org/10.26754/ojs_ais/ais.200214216

Sapag, N. \& Sapag, R. (2008). Preparación y evaluación de proyectos (5a ed.). [Bogotá]: McGraw-Hill.

Soto, B. (19 de marzo de 2015). El consumo de productos orgánicos crece entre los peruanos. El Comercio, A12. Recuperado de http://www.actualidadambiental.pe/wpcontent/uploads/2015/03/elcomercio_2015-03-19_p12.pdf

Superintendencia nacional de los registros públicos. (2017a) Registra tu Mype de manera más fácil, rápida y segura. Recuperado de https://www.sunarp.gob.pe/PRENSA/inicio/file.axd?file=/2016/31102016-2.pdf

Superintendencia nacional de los registros públicos. (2017b) Reserva de denominación o razón social. Recuperado de Recuperado de https://www.sunarp.gob.pe/PRENSA/inicio/post/2017/01/05/conoce-como-reservarla-denominacion-o-razon-social-de-tu-empresa-en-24-horas

Vera-Romero, O. \& Vero-Romero, F. (2013). Evaluación del nivel socioeconómico: presentación de una escala adaptada en una población de Lambayeque. Revista Cuerpo Médico, 6(1), 41-45. Recuperado de https://dialnet.unirioja.es/descarga/articulo/4262712.pdf 


\section{Anexos}

Anexo 1. Ficha técnica de la investigación cualitativa Focus Group (dirigido a padres)

\section{Objetivo de la investigación}

Determinar la aceptación o rechazo del producto "Loncheras Saludables" para niños en edad escolar de educación inicial y primaria.

Determinar el comportamiento de consumo de alimentos saludables en los niveles socioeconómicos $\mathrm{B}$ y $\mathrm{C}$.

\section{Contenido}

- Antecedentes

- Estilo de vida y preferencias alimenticias.

○ Rol de los padres en la alimentación de sus hijos.

- Hábitos de preparación de lonchera

- Consideraciones a tener en cuenta para la lonchera escolar.

○ Lugares preferidos para compra de insumos.

- Conceptos de nutrición

- Conocimiento de las consecuencias de los desórdenes alimenticios.

○ Alimentos preferidos por los niños.

- Evaluación de la propuesta de negocio

- Presentación de propuesta de servicio.

- Precio propuesto, intención de compra y forma de pago.

- Presentación del producto

- Degustación del producto.

○ Sugerencia de presentación y comercialización.

- Contraste entre concepto y producto

○ Percepción.

○ Mejoras.

- Cierre

○ Resumen y agradecimiento. 


\section{Perfil del participante}

Padres de familia del NSE B y C, con niños en colegios particulares de educación inicial y primaria.

4. Determinación de número de focus group que se realizarán

\begin{tabular}{ccc}
\hline Nro. de Focus & Participantes & $\begin{array}{c}\text { Nro de } \\
\text { participantes }\end{array}$ \\
\hline 02 & Padres de educación inicial \\
y/o primaria & 11 y 09 \\
\hline
\end{tabular}

\section{Guía de pautas, la cual tiene la siguiente secuencia}

\section{- Fase de presentación}

Buenos días (buenas tardes) mi nombre es............... maestrista de MCE de USIL y me encuentro realizando este focus group para la investigación cualitativa de nuestro proyecto de negocio.

Ahora, me gustaría conocer un poco más de ustedes, por lo que quisiera que me digan su nombre, edad y de cuantos miembros está conformada su familia y cuáles son las edades de sus hijos.

Bueno, quisiera que me digan, si saben para que estamos reunidos

Realmente estamos acá reunidos para conversar de un tema que actualmente preocupa no solo a las familias sino también a las empresas y Estado peruano, por lo cual les pediría que sean completamente sinceros y que no se dejen influenciar por nadie.

También deben saber que no existen respuestas incorrectas, todas son respuestas igualmente válidas.

Asimismo, les comunicamos que la información a tratar en esta sesión es estrictamente académica y será utilizada para fines de investigación, por lo que será grabada. 
Les agradeceré puedan apagar sus celulares o ponerlos en modo de vibrador para aprovechar al máximo la reunión.

\section{○ Diseño de fase de calentamiento}

Presentación de los participantes, conformación de su familia y donde vive.

\section{○ Listado de preguntas}

\section{Antecedentes}

1. ¿Qué entiende por alimentación saludable?

2. ¿Ha escuchado usted sobre loncheras saludables?, ¿qué escucho?

3. ¿Cuál es la principal razón para brindar a sus hijos loncheras saludables?

\section{Hábitos de preparación de lonchera}

1. Usualmente, ¿Qué alimentos incluye en la lonchera de sus hijos?

2. Generalmente, ¿Compra o prepara la lonchera de sus hijos?, ¿Quién la elabora?

\section{Conceptos de nutrición}

1. ¿Le gustaría recibir información sobre lonchera saludables?, ¿Por qué medio?

2. ¿Conoce usted cómo se prepara una lonchera saludable?, ¿Qué le pondría de proteínas?, ¿vitaminas?, ¿minerales? (juego de mesa).

\section{Evaluación de la propuesta de negocio}

1. Por la propuesta de servicio que ofrece la lonchera saludable ¿usted adquiriría estos servicios?

2. ¿Lo recomendaría?, ¿Por qué?

\section{Presentación del producto}

1. Degustación del producto

2. ¿Conoce otros negocios que ofrecen el servicio de lonchera saludable?

3. ¿Cuál recuerda? 


\section{Contraste entre concepto y producto}

1. ¿Qué productos le gustaría que incluyan las loncheras?

2. ¿Qué le parece la ración de la lonchera según las siguientes presentaciones?

3. ¿Considera que los precios son apropiados?

4. ¿Qué otro servicio recomendaría para las loncheras saludables?

5. ¿Dónde le gustaría encontrar un lugar que venta lonchera saludable?

6. ¿Cuánto pagaría por una lonchera saludable?

7. ¿Qué información le gustaría recibir con este servicio?

8. ¿Si tuviera una tarjeta de lonchera saludable, que tipo de promociones desearía recibir?

9. ¿Qué factores considera para adquirir loncheras saludables?

\section{Cierre}

1. Resumen, comentarios adicionales de participantes y agradecimiento 
Anexo 2. Ficha técnica de investigación cualitativa Focus Group (dirigida a docentes)

\section{Objetivo de la investigación}

Conocer la tendencia alimenticia en cuanto a la lonchera escolar, así como conocer la presencia de las autoridades educativas en la nutrición de los niños de educación inicial y primaria.

\section{Contenido}

○ La nutrición en la etapa escolar.

- Educación alimentaria en los centros educativos nivel inicial y primaria.

○ Hábitos alimenticios del alumno.

○ Información de los refrigerios escolares.

- Evaluación de la propuesta de negocio.

○ Cierre.

\section{Perfil del participante}

Docentes de educación inicial y primaria de colegios particulares de Lima Metropolitana del NSE B y C.

4. Determinación de numero de focus group que se realizarán

\begin{tabular}{ccc}
\hline Nro. de focus & Participantes & $\begin{array}{c}\text { Nro. de } \\
\text { participantes }\end{array}$ \\
\hline 1 & $\begin{array}{c}\text { Docentes de educación inicial } \\
\text { Docentes de educación } \\
\text { primaria }\end{array}$ & 10 \\
1 & . & \\
\hline
\end{tabular}




\section{Guía de pautas, la cual tiene la siguiente secuencia}

\section{○ Fase de presentación}

Buenos días (buenas tardes) mi nombre es................ candidato a magister de la MCE de USIL y me encuentro realizando este focus group para la investigación cualitativa de nuestro proyecto de negocio.

Ahora, me gustaría conocer un poco más de ustedes, por lo que quisiera que me digan su nombre, edad y de cuántos miembros está conformada su familia y cuáles son las edades de sus hijos.

Bueno, quisiera que me digan, si saben para que estamos reunidos

Realmente estamos acá reunidos para conversar de un tema que actualmente preocupa no solo a las familias sino también a las empresas y Estado peruano, por lo cual les pediría que sean completamente sinceros y que no se dejen influenciar por nadie.

También deben saber que no existen respuestas incorrectas, todas son respuestas igualmente válidas.

Asimismo, les comunicamos que la información a tratar en esta sesión es estrictamente académica y será utilizada para fines de investigación, por lo que será grabada.

Les agradeceré puedan apagar sus celulares o ponerlos en modo de vibrador para aprovechar al máximo la reunión.

\section{○ Diseño de fase de calentamiento}

Presentación de los participantes, ¿Por qué estudio educación inicial/primaria?, ¿Dónde enseña?, ¿Cuántas aulas tiene a su cargo?.

\section{$\bigcirc$ Listado de preguntas}

\section{La nutrición en la etapa escolar}

1. ¿Qué tan importante es la nutrición en la etapa escolar en relación con el rendimiento escolar?

2. ¿Consideran ustedes que una nutrición adecuada de los niños influye en su desarrollo físico e intelectual? 
3. ¿Por qué creen que es esencialmente importante que sus alumnos tomen desayuno?

4. ¿Consideran ustedes que los niños deberían comer algo a media mañana?

5. ¿Consideran que es importante que los alumnos lleven una lonchera balanceada y nutritiva a la vez?

\section{Educación alimentaria en los centros educativos de nivel inicial y primaria}

1. ¿Considera usted que los centros educativos contribuyen en la formación de hábitos alimentarios de sus alumnos? ¿De qué manera contribuyen?

2. ¿Se incluye en la malla curricular temas relacionados con una adecuada alimentación?

3. ¿Qué rol cumplen ustedes como docentes para mejorar los hábitos alimenticios de sus alumnos?

4. ¿Han escuchado sobre el reglamento de la Ley de promoción de la alimentación saludable para niños, niñas y adolescentes (Ley $\left.\mathrm{N}^{\circ} 30021\right)$ ?

5. ¿Los quioscos del colegio, cumplen con el reglamento de la Ley de promoción de la alimentación saludable para niños, niñas y adolescentes (Ley $\mathrm{N}^{\circ} 30021$ ), la cual regula los productos que se comercializan en los quioscos escolares?

6. ¿Consideran ustedes que el quiosco y/o cafeterías escolares donde enseñan son saludables y adecuadas para sus alumnos?

\section{Hábitos alimenticios del alumno}

7. ¿Qué opinión tienen sobre los hábitos alimenticios de sus alumnos?

8. ¿Usualmente que contiene la lonchera de sus alumnos?

9. ¿Sus alumnos traen loncheras preparadas en casa o traen dinero para compran en el quiosco del colegio?

10. ¿Algún alumno suyo tiene problemas de obesidad?, ¿Cómo afecta ello a su rendimiento escolar?

\section{Información de los refrigerios escolares}

11. ¿Cuántos refrigerios tienen al día y en que horario?

12. ¿Cuántos minutos duran los refrigerios? 
13. Coméntennos ¿cómo es el momento del refrigerio escolar?

\section{Evaluación de propuesta de negocio}

14. Presentación del producto

15. ¿Qué ventajas encuentra en este nuevo servicio "Loncheras saludables”?

16. ¿Qué sugerencias tendría para el empaque de este producto?

17. ¿Recomendarían a los padres de familia un servicio que brinde loncheras saludables y nutritivas para sus hijos?

\section{Cierre}

18. Resumen, comentarios adicionales de participantes y agradecimiento 
Anexo 3. Ficha técnica de la entrevista a profundidad Expertos del Sector: Nutrición

\section{Objetivo de la investigación}

Conocer el tipo de alimentos recomendados para niños en etapa escolar, así como las porciones necesarias y su valor nutricional.

\section{Contenido}

- Datos generales

- Hábitos alimenticios

- Consecuencias de una mala alimentación

- Nociones básicas de una lonchera escolar saludable

- Recomendaciones generales

\section{Perfil del participante}

Nutricionistas. Se realizaron las entrevistas a las siguientes especialistas:

\section{Ana María Muñoz Jauregui}

Maestría en Bioquímica y Nutrición por la Universidad San Martín de Porres, Bachiller en Farmacia y Bioquímica en la Universidad Mayor de San Marcos. Directora de la Escuela Profesional Ciencia de los Alimentos de la Facultad de Farmacia y Bioquímica de la Universidad Mayor de San Marcos.

\section{Teresa Blanco Blasco}

Doctora en Farmacia y Bioquímica por la Universidad Mayor de San Marcos, Postítulo de Bromatología Nutricionista y de Química Farmacéutica. Directora de la carrera de nutrición de la UPC

\section{Cuestionario}

\section{Frase de presentación}

Buenos días (buenas tardes) Dra.... mi nombre es soy candidato a magister de la MCE de la Escuela de Post Grado de la USIL y me encuentro realizando una investigación sobre Loncheras Saludables para niños en etapa escolar a 
nivel inicial y primaria, un tema que actualmente preocupa no solo a las familias sino también a las empresas y Estado peruano.

Le comunico que la información a tratar en esta entrevista es estrictamente académica y será utilizada para fines de investigación, por lo que será publicada en nuestra tesis.

Desde ya muchas gracias por su tiempo

\section{Datos generales}

1. ¿Cuál es su especialidad y cuéntenos brevemente su experiencia laboral?

\section{Hábitos alimenticios}

2. ¿Cómo deberían ayudar los padres, a formar buenos hábitos alimenticios en sus hijos?

3. ¿Cómo podemos introducir hábitos saludables dentro de los gustos de los niños?

\section{Consecuencias de una mala alimentación}

4. ¿Cuáles son las consecuencias en la salud de los niños si se tiene una mala alimentación?

5. ¿Cuáles son los factores que predisponen a la obesidad en los niños?

6. ¿Por qué cree usted que la obesidad crece y afecta principalmente a los niños entre los 6 y 10 años de edad?

7. En caso de obesidad infantil ¿qué alimentos recomendaría?

\section{Nociones básicas de una lonchera escolar saludable}

8. ¿Por qué es importante la lonchera escolar?, ¿La lonchera reemplaza el desayuno?

9. Desde el punto de vista nutricional ¿qué debe contener una lonchera adecuada para niños en edad escolar?

10. ¿Qué tipos de refresco o bebida recomienda?

11. En cuanto a la cantidad y/o porción de las loncheras, ¿Se debe tener en cuenta la edad del niño, el peso, la talla y la actividad física? 
12. ¿Las loncheras pueden variar de acuerdo a la temporada del año?, ¿Qué tipo de alimentos recomendaría para cada temporada?

13. ¿Cuántas calorías al día debe consumir un niño dependiendo su edad (1-3, 4-6, 7-10)?

14. Para niños con enfermedades como alergias, anemia, sobrepeso etc., ¿La lonchera puede ser igual que la de un niño sano?, ¿Qué tipo de lonchera se recomienda?

15. En cuanto a la variedad, ¿Qué alimentos debemos incluir en la semana y/o a diario?

16. ¿Qué tipo de alimentos no son recomendados para incluir en una lonchera saludable?

17. ¿Cómo se consigue que los alimentos que contienen una lonchera se conserven adecuadamente?

18. ¿En qué tipo de recipientes debe guardarse los alimentos de la lonchera escolar?

19. ¿Qué se debe considerar para el correcto transporte de los alimentos?

20. ¿Cuáles son los beneficios de una lonchera saludable?

\section{Recomendaciones}

21. Durante el crecimiento del niño en la etapa escolar, ¿Qué recomendaciones nutricionales brindaría?

\section{Cierre}

22. ¿Tiene alguna recomendación o comentario adicional?

23. Muchas gracias por su tiempo Hasta luego. 
Anexo 4: Ficha técnica de la entrevista a profundidad Expertos del sector: Restaurantes

\section{Objetivo de la investigación}

Conocer la percepción de los clientes de la comida saludable.

\section{Contenido}

- Datos generales

- Mercado de la comida saludables

- Datos generales del negocio

- Funcionamiento del negocio

- Recomendaciones generales

\section{Perfil del participante}

Dueños de restaurantes de comida saludable en Lima.

\section{Cuestionario}

\section{Frase de presentación}

Buenos días (buenas tardes) mi nombre es... soy candidato a magister de la MCE de la Escuela de Post Grado de la USIL y me encuentro realizando una investigación sobre Loncheras Saludables para niños en etapa escolar a nivel inicial y primaria, un tema que actualmente preocupa no solo a las familias sino también a las empresas y Estado peruano.

Le informo que la información a tratar en esta entrevista es estrictamente académica y será utilizada para fines de investigación, por lo que será publicada en nuestra tesis.

Desde ya muchas gracias por su tiempo

\section{Datos generales}

1. ¿Cuál es su nombre?

2. ¿Qué cargo tiene en la empresa? 


\section{Mercado de la comida saludable}

3. ¿Cómo percibe el crecimiento de la comida saludable en Lima?

4. ¿Cómo ha evolucionado la demanda de la comida saludable estos últimos años?

5. ¿Cuáles son las tendencias para los próximos años?

\section{Datos generales del negocio}

1. ¿Cómo se llama su negocio y donde está ubicado?

2. ¿Cuánto tiempo viene funcionando su negocio?, ¿Cuál es la tendencia de su mercado?

3. ¿Cómo se animó a apostar por este mercado?, ¿Cuáles fueron las principales barreras de entrada?, (infraestructura, permisos, inversión, etc.)

\section{Funcionamiento del negocio}

9. Considera usted que ¿la tendencia de su mercado está en crecimiento?, ¿Con cuánto personal cuenta actualmente?

10. ¿A quiénes considera sus principales proveedores? (hipermercados, mayoristas, etc.)

11. En su experiencia, ¿Qué insumos considera son más perecibles?, ¿Maneja un control de inventarios?

12. ¿Cuál es la estacionalidad del negocio?

13. ¿Qué equipos considera usted muy necesarios para la elaboración de comida/jugos saludables?

14. ¿Cuáles son los medios más efectivos para llegar a su público objetivo?

\section{Recomendaciones Generales}

15. ¿Tienen alguna recomendación o comentario adicional?

16. Muchas gracias por su tiempo. Hasta luego. 
Anexo 5. Filtro de Focus group

Datos de Control

Nombre:

Dirección:

Ocupación:

Teléfono Fijo:

Distrito:

Edad:

Celular:

Indicaciones: Marque con una X sobre la letra de la respuesta que corresponda.

Filtro \#1: Vivienda

1. ¿En qué distrito vive?

a. Santa Anita.

b. Ate

c. La Molina.

d. Otros

Filtro \#2: Edad

2. ¿Qué edad tiene?

a. Entre 18 y 22 años.

b. Entre 23 y 37 años.

c. Entre 38 y 45 años.

d. Más de 45 años.

Filtro \#3: Nivel Socio Económico

3. El tipo de vivienda en la que vive es:

a. Propia.

b. Alquilada.

c. Familiar.

d. Otros.

4. ¿Cuál es su nivel de ingreso promedio familiar mensual (en soles)?

a. De 0 a S/. 2,320.

b. De S/. 2,321 a S/. 3,445.

c. De S/. 3,456 a S/. 5,605.

d. De S/. 5,606 a S/. 10,859.

e. Más de S/. 10,860.

5. ¿Cuenta en su hogar con servicio de internet?

a. Sí, permanentemente.

b. Sí, eventualmente.

c. No.

6. ¿Cuenta en su hogar con vehículo propio?

a. Sí.

b. No. 
Anexo 6. Acta de la primera sesión del focus group (padres de familia)

$\begin{array}{ll}\text { Lugar } & \text { USIL - Sede La Molina } \\ \text { Fecha } & 10 \text { octubre 2017 } \\ \text { Hora de inicio } & 13: 00 \\ \text { Hora de termino } & 14: 20 \\ \text { Segmento } & \text { NSE B y C } \\ \text { Criterio } & \text { Padres con hijos en educación inicial y/o primaria }\end{array}$

Asistentes (10)

\begin{tabular}{|c|c|c|c|c|c|}
\hline $\begin{array}{l}\text { Nombre } \\
\text { Padre de } \\
\text { Familia }\end{array}$ & $\begin{array}{l}\text { Edad } \\
\text { Niño }\end{array}$ & $\begin{array}{l}\text { ¿Colegio } \\
\text { Particular? }\end{array}$ & Distrito Colegio & $\begin{array}{c}\text { Nombre del } \\
\text { Colegio }\end{array}$ & NSE \\
\hline Roy & $\begin{array}{l}5 \text { y } 7 \\
\text { años }\end{array}$ & Particular & Ate & $\begin{array}{c}\text { CLORINDA } \\
\text { MATTO DE } \\
\text { TURNER }\end{array}$ & B \\
\hline Magaly & 7 años & Particular & Sta Anita & $\begin{array}{c}\text { ERNEST } \\
\text { HEMINGWAY }\end{array}$ & $\mathrm{C}$ \\
\hline Percy & 7 años & Particular & Sta Anita & $\begin{array}{l}\text { SAN JUDAS } \\
\text { TADEO }\end{array}$ & B \\
\hline Welinton & 5 años & Particular & Sta Anita & $\begin{array}{l}\text { SAN ANTONIO } \\
\text { DE PADUA }\end{array}$ & B \\
\hline Rocio & 8 años & Particular & La Molina & $\begin{array}{l}\text { NEW JEAN } \\
\text { PIAGET } \\
\text { COLLEGE }\end{array}$ & $\mathrm{C}$ \\
\hline Mayra & 8 años & Particular & Sta Anita & $\begin{array}{c}\text { MARIA } \\
\text { MONTESSORI }\end{array}$ & $\mathrm{C}$ \\
\hline Veronica & 5 años & Particular & Ate & $\begin{array}{c}\text { CLORINDA } \\
\text { MATTO DE } \\
\text { TURNER }\end{array}$ & B \\
\hline Christian & 4 años & Particular & Ate & CRISTO REINA & B \\
\hline José & 4 años & Particular & La Molina & & $\mathrm{C}$ \\
\hline Ruth & $\begin{array}{l}3 \text { y } 4 \\
\text { años }\end{array}$ & Particular & Ate & $\begin{array}{c}\text { CIENTIFICO } \\
\text { ISAAC NEWTON }\end{array}$ & B \\
\hline Fernando & $\begin{array}{l}7 \text { y } 8 \\
\text { años }\end{array}$ & Particular & Ate & CRUZ SACO & $\mathrm{C}$ \\
\hline
\end{tabular}

Buenas tardes con todos, mi nombre es Rocío Salas, soy alumna de la Maestría de Ciencias Empresariales de acá de la Universidad San Ignacio de Loyola, y con nuestro grupo nos encontramos realizando un focus para la investigación cualitativa de nuestro proyecto de 
negocio. Me gustaría conocer un poquito de ustedes por lo que quisiera que me digan su nombre, su edad y de cuántos miembros está compuesta su familia y la edad de sus hijos.

Mi nombre es Roy Gutierrez, en mi familia somos 4 personas, mamá y los dos menores, el mayor tiene 7 y el menor 5 años.

Mi nombre es Magaly, tengo 26 años, vivo con mi mamá, mi hermana y mi hijita que tiene 7 años.

Mi nombre es Percy Ríos, somos tres en la familia, mi hijita tiene 7 años.

Mi nombre es Welintong Escalante, somos 4 integrantes en la familia, la mayor tiene 5 años, la menor tiene un año y seis meses.

Mi nombre es Rocío Izaguirre, somos 5, el mayor tiene 21, la segunda tiene 16 y la última 8.

Mi nombre es Mayra, mi familia está compuesta por 2, mi hija y yo, la cual tiene 8 años.

Mi nombre es Fernando Gonzales, mi familia está compuesta por 4 personas, mi esposa, mis hijos y yo. El mayor de mis hijos tiene 8 años y se llama José Fernando y la segunda María Celeste que tiene 7 años.

Mi nombre es Verónica, mi familia está compuesta por 4 miembros, mi esposo, mis dos hijos, el mayor de 14 años y el menor de 5 años.

Mi nombre es Vicent, tengo 31 años, mi familia está integrada por tres personas, mi esposa, mi hijo de 4 años y yo.

Mi nombre es José María, mi familia está conformada por 4 personas, mi esposa, mis dos hijos, el mayor de 4 años y el menor de 11 meses.

Mi nombre es Ruth de Dueñas, mi familia está compuesta por 4 personas, mi esposo y mis dos pequeñas, Andrea de 4 años y Romina de 3 años.

Moderador: Bueno, no sé si las personas que los han invitado les han comentado para que estamos acá reunidos, el tema del focus o algo, ¿tienen alguna idea? 
Participantes: Bueno en mi caso sí, Kike me comento que era sobre loncheras saludables por lo que me pareció interesante.

Moderador: Sí efectivamente el tema es loncheras saludables, me he dado cuenta en la presentación que todos tienen niños pequeños aún en edad escolar.

Estamos reunidos aquí para ver este tema de loncheras saludables, es un tema que se está tratando bastante y no solamente por el impulso que le está dando ahora el Estado sino que las personas también se están preocupando por el tema, por nuestra salud, por la salud de nuestros hijos.

Les quiero comunicar que, para tratar esta sesión, toda la información será utilizada solo para fines académicos, por lo que estamos grabando para después poder analizar la información. También les voy a agradecer que si cuentan con celulares los puedan apagar o poner en silencio para poder avanzar más rápido.

Moderador: ¿Qué entienden por alimentación saludable?

Participantes: Entiendo que es una alimentación adecuada para los niños dependiendo de la edad, la actividad física que realizan y en caso tengan alguna enfermedad o dolencia que no les permita comer con normalidad.

Tiene que ser una lonchera que sea completa que contenga frutas, verduras, proteína y líquido.

Por ejemplo, en mi caso a mi hija no le gusta comer mucho, prefiere todo sancochado, le mando choclo, queso. Lo importante que me indicaron es que tenga una proteína, una fruta y bastante líquido. Lo que si no le gusta que le envíe es huevo.

La lonchera saludable es aquella que tiene todos los nutrientes, es balanceada y entiendo que estamos evitando todos los productos con preservantes, como los jugos procesados que son más dañinos que por ejemplo un emoliente. 
Moderador: ¿Cuentan con el apoyo de un familiar, o una persona contratada, o ustedes se levantan más temprano para preparar la lonchera, o de repente el colegio les brinda alguna opción?

Participantes: En nuestro caso nos organizamos para poder preparar la lonchera, tratamos de ir poniendo cosas nuevas y felizmente nos va muy bien, algunas veces por el tiempo solo le mandamos una fruta, un yogurt y agua.

Yo tengo el apoyo de una tía, pero normalmente yo en la noche anterior ya le voy dejando algo listo porque en la mañana no me da el tiempo.

En nuestro caso también nos organizamos, pero en casos de emergencias si debemos recurrir al cafetín para que pueda comprar su lonchera.

En el caso del colegio de mis hijos ellos tienen tres veces a la semana educación física y ya está pauteado que estos días solo deben llevar agua, no les permiten llevar otro tipo de líquido.

En mi caso me doy el tiempo de prepararles cosas en la casa, un keke, unas galletas, trato de evitar los productos industriales, incluso hay días que tienen talleres y se quedan hasta las 4 pm y hay un grupo de padres que hacen su negocio y brindan alternativas, pero la verdad esos días si trato de organizarme para enviarle algo más consistente y hecho en casa.

Moderador: Tienen una noción general de lo que significa una lonchera saludable, sin embargo, me gustaría saber ¿Si alguno de ustedes conoce al detalle por ejemplo el tema de las porciones, hoy tengo que mandar 50 gr de queso, 80 gr de proteína, etc.?

Participantes: En su totalidad indicaron no saber de las porciones o medidas, incluso uno manifestó que se hace actualmente al "ojo".

Moderador: ¿Qué les parecería el servicio de loncheras saludables, este es un servicio que estamos evaluando en nuestro plan de negocio de la maestría, las alternativas que les brindaremos estarán revisadas por un nutricionista, y va de acuerdo a la edad y actividad física 
de los niños, de manera que nos aseguramos en bridarles las raciones adecuadas? ¿Incluso ustedes podrían escoger las combinaciones que les gustaría enviar a sus hijos?

Participantes: Sería una idea muy buena, sobre todo, para las personas que no tienen quien los ayude, o tienen poco tiempo, o no saben que poner en las loncheras.

A mí también me parece interesante, pero si me gustaría tener más información, por ejemplo ¿cuáles son las opciones, como las entregarían, en dónde, ¿cuánto es el costo?

Si me vas ahorrar tiempo, si me vas ahorrar dinero, y va a estar balanceado con lo que necesita mi hijo es grandioso, sería un excelente negocio.

Me gusta porque no solo nos saca la presión de la preparación de la lonchera en el día a día, sino que también me ahorro el tiempo y la preocupación de las compras de la semana, por ejemplo, yo también los fines de semana tengo que comprar las cosas de la semana y para eso ya debo tener una idea de la lonchera de toda la semana.

A mí también me parece interesante sin embargo me gustaría que haya una plantilla de las opciones con los aportes de cada alimento, porque como ya conversamos los padres no sabemos si le debo dar 100 gr de esto o 300 gr de otro y muchas veces solo lo hacemos adivinando, si ustedes me ponen opciones cómo sé que no estoy dándole más calorías de las que debe consumir mi hijo. Es importante que haya esta información, e incluso de repente agregar un cuadro de la actividad de mi hijo, no debería ser la misma lonchera un día normal de solo clases a un día que tenga que realizar mucho deporte.

Moderador: ¿Cuál sería un precio razonable que ustedes estarían dispuestos a pagar para contratar el servicio?

Participantes: Creo que debería estar entre los S/ 4.00 y S/ 5.00

Yo también estaría de acuerdo en un precio aproximado de S/ 5.00 que es lo gastamos en promedio. 
La mayoría de las participantes indico estar de acuerdo en un precio promedio de S/ 5.00 soles

Participante: A mí me preocupa un poco los envases, ¿cómo se va a distribuir?

Moderador: Tenemos algunos ejemplos de envases que se los vamos a mostrar para que nos den su idea, pero estábamos evaluando hacerlo como una cajita feliz, que a los niños les encanta.

Participantes: El problema que veo ahí es la cantidad de desecho que estamos generando, estamos hablando que si en la semana compro 5 loncheras voy a botar desecho los 5 días. Y ahora que estamos en una época de cuidado del medio ambiente deberíamos tener una opción de empaque reciclable, por semana.

Yo creo que debería ser una bolsa de papel, lo cual sería más práctico para los niños

Yo no creo que debería ser una lonchera reciclable, los niños son distraídos, y es complicado para entregar las loncheras para el día siguiente, me parece que la mejor opción es la bolsa de papel.

Yo propondría en la bolsa un dibujo, para que los niños puedan pintar, o un juego, me parece que es importante tener en cuenta a los niños, son ellos los que muchas veces incentivan a los padres a la compra.

Yo tendría cuidado con lo de los dibujos o juegos, porque la hora de la lonchera es para comer, a mí no me gustaría que mi hijo en vez de comer este jugando.

Moderador: ¿Alguna sugerencia adicional que nos recomendarían?

Participantes: Me gustaría saber cuál es el plan de marketing, como se van a dar a conocer, en redes sociales, o alguna otra forma, incluso me parece que este tipo de servicio es más potente cuando la recomendación es boca a boca. 
Yo recomendaría que adicionalmente a este servicio, evalúen la opción de fiestas, hoy los niños en las fiestas no comen nada saludable, sería ideal que con la misma logística los fines de semana puedan atender fiestas con opciones saludables.

Moderador: ¿Les pediría que nos ayuden votando por el nombre y slogan que mejor se adecue a nuestro proyecto?

Participantes: Cada uno eligió un número y voto por la opción que le pareció mejor.

Muchas gracias por su participación y sus recomendaciones, nos va servir mucho en el desarrollo de nuestro proyecto. 
Anexo 7. Acta de la segunda sesión del focus group (padres de familia)

Lugar USIL - Sede La Molina

Fecha $\quad 13$ octubre 2017

Hora de inicio 13:00

Hora de termino 14:05

Segmento

NSE B y C

Criterio Padres con hijos en educación inicial y/o primaria

Asistentes (10)

\begin{tabular}{|c|c|c|c|c|c|}
\hline $\begin{array}{l}\text { Nombre } \\
\text { Padre de } \\
\text { Familia }\end{array}$ & Edad Niño & $\begin{array}{c}\text { ¿Colegio } \\
\text { Particular? }\end{array}$ & Distrito Colegio & Nombre del Colegio & NSE \\
\hline Janeth & 6 años & Particular & Ate & Innova & $\mathrm{C}$ \\
\hline Gianina & 7 años & Particular & La Molina & Trilce & B \\
\hline Juana & 5 años & Particular & La Molina & $\begin{array}{c}\text { INMACULADO } \\
\text { CORAZON DE MARIA }\end{array}$ & B \\
\hline Joshua & 5 años & Particular & Sta. Anita & DIVINO MAESTRO & $\mathrm{C}$ \\
\hline Karen & 7 años & Particular & Ate & $\begin{array}{l}\text { CORAZON DE } \\
\text { GUADALUPE }\end{array}$ & $\mathrm{C}$ \\
\hline Angie & 6 años & Particular & Sta. Anita & DON BOSCO & $\mathrm{C}$ \\
\hline Miriam & 4 años & Particular & Sta. Anita & $\begin{array}{c}\text { NUESTRA SEÑORA } \\
\text { DEL ROSARIO }\end{array}$ & B \\
\hline Noemi & 7 y 10 años & Particular & Ate & CRUZ SACO & $\mathrm{C}$ \\
\hline Mariela & 8 años & Particular & La Molina & JEAN PIAGET & B \\
\hline
\end{tabular}

Moderador: Gracias por venir, buenas tardes, mi nombre es René Zavalaga yo soy maestrista de la MCE de USIL. Primero nos encontramos realizando un focus para una investigación cualitativa de nuestro proyecto de negocio que estamos haciendo en la maestría. 
Me gustaría conocer un poco más de ustedes, quisiera que digan su nombre, su edad, de cuantos miembros está compuesta su familia. No se si empezamos contigo Janet.

Participante: Mi nombre es Janet soy madre de una niñita de 6 años.

Moderador: Ok

Participante: Mi nombre es Noemí, soy mamá de dos niños, uno de 10 y otro de 7, vivo en la casa de mi mamá, y está compuesta por 4 personas.

Moderador: Ok, Gracias.

Participante: Mi nombre es Gianinna, tengo un hijo de 7 años, y tengo muchos años, ¿qué más?

Moderador: ¿familia, cuantos miembros son?

Participante: Ah somos 3

Moderador: Son 3 Ok, gracias. ¿Joshua?

Participante: Ah bueno mi nombre lo dice ahí, tengo 40 años, tengo un hijo de 5 años y bueno en la familia están los abuelos, con la mami.

Moderador: Gracias

Participante: Hola me llamo Angie, tengo 28 años, tengo un hijo de 7 años, perdón 6 años recién cumplidos y vivo en casa de mis abuelos, pero aparte, tengo un departamento en donde vivo con mi esposo, somos tres.

Moderador: Ok.

Participante: Hola, buenas tardes, mi nombre es Miriam, tengo 28 años y vivo con mi pareja y con mi hijita que tiene 4 añitos.

Moderador: Ok

Participante: Hola buenas tardes mi nombre es Karen, tengo 30 años, vivo con mi hija de 7 añitos, en realidad bueno vivo con mis padres también, somos 6 .

Moderador: Ok 
Participante: Buenas tardes mi nombre es Mariela, tengo 27 años, mi familia está compuesta por 3 personas, mi esposo, mi hijo y yo. Mi hijo Gonzalo tiene 8 años y también vivo con mis padres.

Moderador: Ok

Participante: Buenas tardes, mi nombre es Juana, tengo una hija de 5 años, vivo con mi esposo en la casa de mis padres.

Moderador: Ok. Gracias. ¿Ustedes saben para que estamos acá reunidos, les han comentado algo?

\section{Participantes: No}

Moderador: Ok, realmente estamos acá reunidos por un tema que preocupa hoy bastante al tema de la sociedad, que es básicamente en tema de niños por ejemplo la obesidad. El tema creo que se está desbordando un poco. Nosotros hemos investigado y las cifras básicamente en los últimos dos o tres años ha subido casi a $200 \%$, entonces es un tema que si preocupa. Y es un tema que está a nivel mundial incluso. Les pediría si es que me pudieran decir más o menos o si es que ustedes han escuchado por ejemplo de alimentación saludable, es libre el que quiera participar.

Participante: Si claro yo por ejemplo si a partir de... Yo tengo anemia, entonces la contraje en el embarazo, y de ahí si se me ha hecho bien difícil subir mi hemoglobina, entonces eso me ha hecho más consiente por el tema de mi hijo. Mi hijo no tiene anemia, pero si en un momento lo tuvo al principio, entonces yo sé que al tener poca, baja hemoglobina, es más, se hace más vulnerable para adquirir cualquier otra enfermedad ¿no?. Entonces a partir de eso me he estado informando y si he hecho un plan de comida saludable, más que para mí, para él en realidad. Y si por ejemplo Matías es muy poco, bueno ya está acostumbrado también desde muy chiquito, Matías no te toma nada de gaseosas, no le gusta los dulces, entonces si es algo que se ha acostumbrado desde muy pequeño no, lo único dulce que come es la torta y suficiente, no 
es de muchas golosinas. Y si trato de.... lo que ahora me cuesta un poco, pero lo hace es las verduras, por ejemplo, el brócoli, la espinaca, no es que me lo pida no, quiero una porción de brócoli, pero si yo se lo pongo no me haces líos, entonces creo que estoy yendo por buen camino, por lo menos no me dice que no.

Moderador: Que bueno. En realidad, me estaba olvidando de decirles que básicamente la información que vamos a tratar en esta sesión es estrictamente académica, la cual será utilizada para fines de investigación, por eso que lo estamos grabando. ¿Alguien más que quiera participar?

Participante: Yo también hice un proyecto de loncheras nutritivas, justo mi hija había nacido, y es ahí donde más me informe, más me enfoque en el tema de loncheras ya que se quedan hasta tarde en el colegio, y ya en el nido procuran darle los alimentos donde ya me dan un cronograma. Me preocupe bastante en la lonchera ya que era mamá primeriza, no sabía. Entonces me di cuenta de que a veces uno por desconocimiento le puede mandar una cajita de frugos diario, pero no pues, estuve leyendo y sé que consta de tres partes una lonchera eso me ha ayudado, igual que Angie también mi hijita no es que le encante las verduras, a mí tampoco me gustan pero por el tema que a veces tengo que sentarme con ella tengo que comer las verduras, no me las rechaza, tampoco es que le encantan, ella en si es flaquita, y yo también tenía el temor de que por ser flaca tenga anemia o no sé alguna enfermedad, pero el doctor mismo me dijo que no necesariamente al ver que un niño sea robustito es que esté bien, y me dijo que ella el peso se le iba a ver en los huesos y que estaba muy bien y que esa era su contextura porque papá y mamá son delgados.

Moderador: Ok, bueno Juana gracias, porque justo has aterrizado un poco la idea de porque estamos acá, básicamente nosotros lo que estamos tratando o haciendo dentro de esta investigación va hacia ese lado, loncheras saludables, básicamente por el tema de los niños. Hoy la mayoría de los hogares el papá y la mamá trabajan y es bien complicado el tema de 
elaborar las loncheras y a veces de verdad por no darnos o tener ese tiempo básicamente lo que hacemos es ir a Plaza Vea, Wong, compramos galletas, kekitos, jugos y lo metemos a la lonchera y listo, sin saber realmente a veces el daño que le estamos haciendo a nuestros hijos. Entonces me queda claro que en tu caso Juana has investigado el tema de las loncheras saludables, pero ¿alguien más que de repente haya visto este tema, como lo maneja?

Participante: Bueno en mi caso en el colegio de mi hijo prácticamente nos han dado unas cosas de qué es lo que no debe contener la lonchera, justamente para incentivar la comida saludable, ya que los profesores en una reunión comentaron que la alimentación repercute en los conocimientos, que muchas veces por una mala alimentación ellos se duermen. De una u otra forma nos dicen qué cosas son adecuadas de acuerdo a su edad también, porque hay que ver la edad y los alimentos que pueden comer porque de eso también depende el desgaste que ellos hacen en los juegos.

Moderador: Ok, ¿alguien más?

Participante: Bueno como dicen también en el colegio de mi hijo por ejemplo si tú le mandas esto lo retienen y te mandan una nota en la agenda, indicando que lo más saludable que puedes mandar es agua o un refresco, pero bajo de azúcar, fruta, dependiendo del niño si es en la mañana un pan o sanguchito de pollo o un huevo sancochado, con una avena, pero nada de gaseosas o esto.

Moderador: ¿Y cuál es normalmente la principal razón para que les den a sus hijos loncheras saludables? Por ejemplo, en el caso de Angie ella nos comentaba que por el tema de la anemia que ella tuvo, eso la empuja a hacer que sus hijos coman sano. En los demás que es normalmente lo que nos motiva a darle a nuestros hijos una lonchera saludable.

Participante: en mi caso no sé, por ejemplo, mi hijo, el mayor, come demasiado, mi hija la segunda hay que meterle la comida a la boca, mi hijo no te come carne, no te comía pollo, no te comía pescado, se lo hacía en croquetas ahora me come pollo y pescado, pero si le encanta 
bastante lo que es menestras y el arroz, él es fortachón, tiene 10 años y está de mi vuelo, cuando lo traigo al trabajo nadie cree que tiene 10 años.

Participante: En el colegio de mi hija, a parte de la lonchera que uno tiene que llevar hay unos estándares que sean saludables, adicionalmente hay un calendario en el cual cada padre de familia se compromete un día a llevar una comida que el colegio te indica por ejemplo te dice ahora toca mazamorra, o toca algo que es usualmente un líquido y un sólido que se comparte entre todo el salón, y que está bajo los estándares que sea comida saludable, etc. Entonces combina lo que tu llevas de casa con algo que comen los chicos de manera uniforme.

Moderador: Y actualmente hoy, por ejemplo, ¿quién les prepara la lonchera a sus hijos?

Participantes: Normalmente los padres

Moderador: ¿Pero a veces tenemos una chica que nos ayuda en la casa, un familiar?

Participante: $\mathrm{Si}$, por ejemplo, en mi caso mi hijo es un poco eticoso, y hay algunas cosas que no le gustan, por ello se algunas cosas que le gusta y son nutritivas le pregunto, por ejemplo, ¿esta semana que vas a llevar de lonchera? Le gusta el queso Edam, entonces le mando proteínas, lácteos, y tengo un cuadrito de las cosas que mando.

Moderador: Normalmente ¿de que consta la lonchera que le hacen a sus hijos? Ustedes que la preparan por ejemplo ¿qué le ponen normalmente a la lonchera?

Participante: Yo normalmente le pongo yogurt, con un pan y una fruta.

Participante: Yo casi igual fruta, de todas maneras, una fruta, un sanguche de algo, huevo, y liquido una botella de agua.

Participante: En el colegio de mi hija no les prohíben nada, pero yo le mando su agua, su fruta, algún pan con camote, huevo.

Moderador: Y a ustedes les gustaría recibir información sobre loncheras saludables, por ejemplo, correos.

Participantes: Ah sí claro. 
Moderador: Bueno nosotros básicamente lo que estamos haciendo aquí es armando un tema de un proyecto para loncheras saludables, en el que estamos viendo varias opciones. Nos gustaría saber, por ejemplo, para ustedes ¿qué debería contener una lonchera saludable aparte de lo que me han dicho de fruta, qué tan bueno es por ejemplo que nosotros incluyamos dentro de una propuesta que lleven avena, un día maca o quinua u otro tipo de fruta, pan, porque a veces los niños son bien eticosos no, a veces por ejemplo bien complicado hacer el pan con pollo, ¿no? No a todos les gusta, ¿cómo les gustaría que se maneje ese tema?

Participante: Bueno respetando lo que siempre debe tener una lonchera, un lácteo, se que también debe tener algo de cereal, la fruta y la bebida, si se respeta esos 4 que he leído sería genial, se podría incluir de una u otra manera a veces como motivar a los niños con un tema de figuritas, no figuritas si no formar con la comida para que les sea atractivo comer.

Moderador: Ya, si por ejemplo nosotros como proyecto estamos haciendo esto de las loncheras saludables y les proponemos a ustedes que nosotros nos encargaríamos de las loncheras saludables de sus hijos respetando más o menos estos estándares que ustedes nos han comentado, que tenga una proteína, lácteo, el tema de jugo naturales u opciones como avena, que tanto les gustaría a ustedes este producto o este servicio.

Participante: ¿Ósea la lonchera preparada?

Moderador: Correcto la idea es que nosotros, digamos les mandemos un calendario de toda la semana, por ejemplo, lo que va a incluir por día y nosotros nos encargamos de llevar estas loncheras a sus hijos, para un poco sacar esa carga que tenemos ahora, por el tema del tiempo como les decía, básicamente el tema del tiempo que es bastante complicado.

Participante: O a veces uno se olvida de comprar, y esta ¡uy! me olvide de comprar o ¡uy! se acabó y no me di cuenta, porque justo todas trabajamos llegamos cansadas en la noche y ¡uy! no compre esto, falto comprar otro. 
Moderador: ¿Y a veces las ideas también se nos acaban no? Y no sabemos que mandarles ya. ¿Qué tanto les gustaría este servicio?

Participante: Y este tema logístico como lo han planteado, porque llegar a la casa, eventualmente mi hija sale 6:15 am que viene su movilidad a recogerla, entonces antes de esa hora tendría que tener con $100 \%$ de certeza que no me van a fallar.

Moderador: Claro, ahora nosotros lo que estamos pensando es ir directamente al centro educativo, porque hoy como tu mencionas los niños salen súper temprano, pero si un standard es que la mayoría de los niños tiene su primer recreo entre 10 y 11 de la mañana, lo que a nosotros nos da una capacidad para poder atenderlos, llegar y no fallarles. Esa sería digamos una propuesta que estamos evaluando de cómo repartirlo.

Participante: Pero ahí hay una observación, si ustedes lo van a entregar en el colegio tienen que esperar al niño a que lo reciba, porque una vez que el niño entre ya no permiten pasar nada.

Participante: Lo otro es de repente cambiar el enfoque de tu cliente no que sean los papás necesariamente sino que sean los colegios, por ejemplo en el colegio de mi hija para nosotros si se nos hace bien pesado preparar chicha morada para 20 niños, o nos piden que les hagamos causa para 20 niños, quizás sea más fácil que alguien nos proponga como papas, nosotros nos encargamos de esa comida que es uniforme para todos y ya nosotros nos olvidamos de eso de estar cargando el balde con el refresco, podría ser una alternativa.

Moderador: No claro de hecho que también lo habíamos pensado, básicamente igual como estamos haciendo un focus group ahora con ustedes que son los padres, vamos a hacer uno junto con los profesores por ejemplo y ver. De hecho, que tiene que haber un tema de ser aliado con los colegios, ahora también otra propuesta es estar antes de cuando estén entrando básicamente los niños al colegio, estar ahí y entregarle la lonchera a cada uno, es un tema que estamos trabajando aún en cuanto a la distribución. Pero si de todas maneras tenemos mapeado 
de repente una cuestión con los colegios porque si es importante. ¿Ahora ustedes conocen alguna empresa que hoy les brinde este servicio de loncheras saludables?

Participantes: No conocemos, loncheras saludables no, yo sí.

Moderador: Sí, Nos podrías comentar

Participante: Yo si conozco, por esa vez que investigue hace dos años, acá en la Molina ya hay, no están en los colegios, están en nidos, no me acuerdo el nombre muy bien, pero como que trabajaban con un grupo de nidos, donde estos le permitían que puedan ingresar. Eso es lo que acuerdo, pero sí sé que acá en la Molina si he escuchado.

Moderador: Ok, ¿después nadie más?

Participante: En el colegio de mi hijo si dan ese servicio

Moderador: ¿El mismo colegio?

Participante: El mismo colegio, porque tiene su mismo concesionario y el colegio solo le permite comida saludable.

Moderador: Ok, ahora básicamente hay una ley que promulgó el gobierno sobre comida saludable, pero no se aplica en todos los lugares porque faltaba una reglamentación en esa ley, por eso no todos los colegios lo aplican, están tratando de ingresar a este tema de comida saludable, pero no es en todos los colegios, ya que prohíben que los concesionarios te vendan un pan con hotdog, gaseosas, recién están tratando de adecuarse a eso. ¿Cómo consideran que debe ser la ración en la lonchera?

Participante: Adecuada al niño, porque a veces se desesperan y lo dejan, todo por salir al recreo, a veces le mando un montón de cosas y me regresa la fruta, no hay tiempo me dice. También es de acuerdo a la edad y a los nutrientes que el niño necesita. Aparte el niño muchas veces solo quiere jugar, él no quiere comer, solo salir a jugar. 
Moderador: Ese es un tema que también nosotros cuestionábamos y nos preguntábamos por ejemplo si hoy en día los profesores les ponen alguna clase de nota en las agendas de sus hijos indicándoles, por ejemplo, hoy su hijo no quiso comer la lonchera.

Participantes: Sí, si nos mandan.

Participante: A mí en el actual colegio de mi hijo no me están mandando, pero si en el nido más que nada de los chiquitos de dos años ahí si me mandaban si no había comido la lonchera.

Moderador: Porque es importante tener ese feedback del colegio porque efectivamente a veces se dedican a jugar y no sabemos si se están alimentando o no.

Participante: Por ejemplo, en el caso de mi hijo el sale de recreo y se van a jugar fútbol cuando yo le mando cosas como para que se siente, una frutita picada la regresa, a comparación si le mando un plátano caminando para ir a jugar futbol lo va pelando, pero que se siente no.

Moderador: ¿Cual consideran que sería un precio adecuado para este tema de loncheras?

Participantes: Eso dependiendo de los ingredientes que contenga, de la calidad y presentación, por ejemplo, a mi hija yo le pongo Pediasure, la botellita porque le gusta, a veces incluso se toma el Pediasure pero no me ha comido el sanguchito, por eso tendrías que ver no.

Moderador: ¿En promedio?

Participantes: 6 soles, 7 soles

Moderador: ¿Qué otros servicios recomendarían para este tema de loncheras saludables? Algo que no haya mencionado y se les venga a ustedes a la mente, por ejemplo, me gustaría que a mi hijo también le dieran esto.

Participante: El tema de un nutricionista es importante, yo creo que si se respaldan con un nutricionista a nosotros también nos interesaría y sé que para cada niño es diferente, por ejemplo, si este niño está sufriendo de anemia no le vas a dar la misma porción que la de un niño que esta normal o entre comillas a un niño que este obeso, así ella podría analizar a cada uno de los niños y adecuar la lonchera a cada uno o a su necesidad. 
Participante: También tienes que averiguar el gusto de los niños, porque si a él no le gusta tu lonchera simplemente no la van a comer, por más nutricionista o algo son los gustos de ellos.

Participante: Tener más de una opción para que le puedas preguntar qué quiere comer y le das opciones sanas, ah eso quieres, entonces te mando eso. Y que sean variadas también porque mandarle granadilla todos los días por ejemplo y me dice ya me harté de la granadilla, por eso que sean variadas para que puedan elegir. Como todos trabajamos creo que una forma de comunicación sería por correo, de repente al momento que inicie el servicio, hola que tal mi hijo es Gonzalo, tiene tantos años, estas son las cosas que le gusta, y también que diga mira estas son las cosas que yo suelo enviar, que tenga una evaluación, claro tampoco vamos a pedir que el nutricionista entre y evalué a cada niño, pero sí que nos brinde sugerencias.

Moderador: Claro justo empezando les preguntaba si les gustaría recibir información de nutrición básicamente era por eso, ya que buscamos como un valor agregado mandarles información nutricional, si bien es cierto nosotros nos queremos dedicar al tema de loncheras saludables, creemos que es importante en el tema de ayudarlos en el proceso digamos diario de sus hijos porque a veces puede ser una lonchera saludable, llegan a casa y le das una hamburguesa no hacemos nada, por eso la idea es también un poco ayudarlos en qué cosa debe contener un almuerzo una comida, las porciones y de hecho que para eso si vamos a tener feedback de un nutricionista, una persona que nos va a ayudar a determinar eso. ¿Qué promociones les gustaría recibir por parte de nosotros? ¿Digamos ya estamos brindándoles el servicio los estamos atendiendo, que clases de promociones les gustaría recibir, que valorarían?

Participante: ¡De repente una vez a la semana, tu eres mi cliente te envío una lonchera, a mí no!! Al papá. Como un plus. Una ensaladita, un almuerzo cosa que tú no te lo esperas porque tú el servicio lo contratas para tu hijo, ósea que bonito que al medio día te llega un detalle.

Moderador: Ok, ¿alguna otra idea? 
Participante: En los cumpleaños de los niños, no sé una lonchera gratis para ellos o que tenga una sorpresa, unas galletas grandes de avena por ejemplo adornado con una carita feliz, no sé una cosa así.

Moderador: Les quiero pedir que por favor nos ayuden con el tema del logo, tenemos logos y nombres se los queremos mostrar, tenemos varias ideas y que ustedes nos vayan diciendo cuál de estas les gusta más, igual se las voy pasando la idea es que nos vayan diciendo el número para nosotros llevar el control de la más votada.

Participantes: Esa pregunta debería ser para los niños, ellos son los que van a escoger por un tema de colores, pero para captar la atención de un niño pones la imagen de su dibujo favorito y ya está.

Moderador: Eso lo tenemos que evaluar porque con esto de la nueva ley está prohibido que los alimentos tengan imágenes de súper héroes, por ejemplo en el tema de cereales lo usamos mucho en Perú, muchas veces hay hasta un superhéroe que no conocemos pero hay un súper héroe en el cereal, cosa que por ejemplo no se da hoy ni en Ecuador, ni en Chile, ya que ellos hoy tienen otro tipo de legislación y está totalmente prohibido que instes a los niños al consumo del producto a raíz de la imagen de un superhéroe.

Participante: Pero en el tema del logo no creo que haya problema, porque el que va a ver eso es el papá, que va a ver el logo.

Moderador: Lo que si nos recomendaron por ejemplo en el tema de los empaques que ahora también se los vamos a pasar para que los vean, pero era poner como hay en Mc Donald, Bembos las figuras para pintar, poner en la bolsa un dibujo, un juego algo que los llame sin la necesidad que los distraiga tanto ya que básicamente lo que queremos es que ellos coman, por ello estamos evaluando esas alternativas.

Participante: Pero eso de los juegos tiene que ir de acuerdo a la edad, las formas en la comida, los panes con formas, así como los panqueques en forma de ositos, etc. 
Moderador: Acá hay unas ideas de empaques de loncheras, se las vamos a pasar para que vean y nos puedan decir cual le gusta más, como debería ser la presentación.

Participantes: Podría ser de cartón con forma de un perrito, un gatito. Estas son muy como para adultos. Podría ser la bolsa, pero con otro diseño. Es más ahora en los cumpleaños se estila a dar esas bolsas de papel tipo pan solo que en la parte de adelante le ponen la figura.

Gracias por su tiempo 
Anexo 8. Acta de la primera sesión del focus group (docentes nivel inicial - primaria)

$\begin{array}{ll}\text { Lugar } & \text { USIL - Sede La Molina } \\ \text { Fecha } & 16 \text { octubre 2017 } \\ \text { Hora de inicio } & 18: 00 \\ \text { Hora de termino } & 7: 00 \\ \text { Criterio } & \text { Docentes de educación inicial }\end{array}$

Asistentes (10)

1. Raquel

2. Anahí

3. María

4. Luciana

5. María Alejandra

6. Evelyn

7. Juana

8. Mónica

9. Marlene

10. Ada

Buenas tardes, mi nombre es Susana Valverde, soy estudiante de la maestría de Ciencias Empresariales de la USIL, actualmente nos encontramos realizando la investigación cualitativa de un plan de negocio para obtener nuestra tesis de grado.

Me gustaría saber un poco de ustedes, quisiera que me digan su nombre y en qué colegio están enseñando.

Bueno yo soy Luciana, tengo 25 años y actualmente estoy dando clases en un colegio de educación inicial en Santa Anita

Soy Anahí tengo 24 años, actualmente soy docente de un colegio de educación inicial en Lima

Soy Alejandra tengo 26 años, y trabajo en un colegio de educación inicial en Ate.

Soy María Alejandra, tengo 25 años y soy docente de educación inicial en un colegio de La Molina 
Soy Evelyn, tengo 28 años y soy docente de educación inicial en un colegio de La Santa Anita.

Soy Juana, tengo 30 años y soy docente de educación inicial en un colegio de La Molina Soy Mónica, tengo 27 años y soy docente de educación inicial en un colegio de La Molina

Soy Marlene, tengo 32 años y soy docente de educación inicial en un colegio de La Molina Soy Ada, tengo 29 años y soy docente de educación inicial en un colegio de Ate

Bueno, quería informarles que en esta entrevista no existen respuestas buenas o malas, todas ayudaran al desarrollo de nuestro trabajo, así es que pueden responder con total libertad.

Además, esta entrevista será grabada y publicada para fines estrictamente académicos.

Me gustaría me indiquen porque eligieron estudiar Educación Inicial:

Todas las entrevistadas indicaron que tuvieron vocación por la docencia inicial desde temprana edad, consideran que tienen paciencia para los niños y son conscientes que no solo es querer hacer algo sino asumir la responsabilidad de todo lo que involucra la carrera.

\section{¿Tienen conocimiento del tema que trataremos en esta entrevista?}

Nos dijeron algo de loncheras saludables para niños de educación inicial.

\section{¿Qué tan importante creen que es la nutrición en la etapa escolar?}

Pienso que una alimentación adecuada influye de sobremanera en el rendimiento escolar de los pequeños.

A veces vemos niños cansados, somnolientos e incluso pueden hasta dormirse en clase, ello muchas veces se debe a que no reciben el primer alimento del día en forma adecuada, ya sea por tiempo o desconocimiento de los padres que piensan que el desayuno puede ser reemplazado por la lonchera de media mañana. 
Una de nuestras funciones es también orientar a los padres sobre la adecuada alimentación de sus hijos y así no perjudiquen el desarrollo intelectual y físico de sus hijos.

\section{¿Consideran que la lonchera escolar es importante para el rendimiento de los niños?}

Yo tengo a cargo niños de 2 años y para nosotras es importante la lonchera de media mañana porque renueva la energía de los niños, así sea algo mínimo, pero los revitaliza y están más dispuestos a seguir aprendiendo o participando de actividades.

Yo trabajo con niños de 5 años y son niños que realizan mayor actividad física, siempre están corriendo, quieren jugar, preguntan de todo, todo el tiempo y es notorio cuando uno de ellos está tranquilo, o parece cansado. Para nosotras ello es señal de que algo puede estar mal en sus hábitos alimenticios.

Es importante que los niños se alimenten a media mañana para que recuperen energías, en algunos casos los padres les brindan un buen desayuno y pueden mantenerse activos toda la mañana, pero generalmente es necesario recuperar energías para que continúen con sus actividades de la mañana en forma óptima.

Depende mucho también de la actividad física que desarrollen los niños durante el día.

¿Consideran que los centros educativos influyen en la formaciónn de hábitos alimenticios de los alumnos?, ¿De qué manera?

En mi experiencia, he tenido la oportunidad de trabajar en colegios públicos y privados. Los centros educativos organizan charlas para padres orientando sobre la importancia de la alimentación saludable de sus hijos, algunos nidos dan loncheras a los alumnos y organizan todo un plan de nutrición para los niños.

En el nido donde trabajo, se brinda una lista de alimentos nutritivos para los niños y no se permite que la lonchera incluya alimentos que no son saludables, ello es como parte del servicio que brinda e colegio. 
También está prohibido que, en fechas especiales como cumpleaños, los padres lleven dulces, gaseosas o alimentos con alto contenido de azúcar.

Cuando realice prácticas en Cantagallo, les daban desayuno a los niños y estos variaban entre leche de soya, atún, huevo, queso, palta, etc.

En colegios del estado es el PRONAA quien se encarga de brindar los desayunos saludables para los niños de educación inicial.

\section{¿La carrera de educación Inicial, incluye materias relacionadas a la nutrición o} alimentación saludable?

Yo creo que en general en todos los cursos siempre nos dan pautas sobre alimentación saludable y la combinación de alimentos.

Tenemos un curso de desarrollo físico y salud de niño, que trata de convivencia saludable y aspecto físico, no necesariamente tiene el tema en específico, pero si nos brinda conocimiento sobre material educativo no tóxico para niños, conservación del medio ambiente que nos ayuda a orientar a los padres de forma acertada.

¿Han escuchado sobre el Reglamento de la Ley de alimentación saludable para niños, niñas y adolescentes?

La totalidad de docentes indicó no conocer la ley, ni haber observado la adecuación en algunos de sus centros educativos.

¿Cómo son los kioscos en los colegios donde ustedes están enseñando, son saludables, qué tipo de alimentos ofrecen?

En el colegio ahora si son saludables, ya no venden gaseosas, ni galletas. Los niños llevan sus botellas de agua para que puedan llenarlas.

Pero no en todos los colegios, hay algunos donde aún hay para todos los gustos 


\section{¿Entonces donde ustedes enseñan, consideran que son kioscos saludables?}

Donde estamos trabajando actualmente no hay kioscos, los niños tienen que llevar sus loncheras, pero cuando nos tocó ir a Cantagallo si pude observar que había y ofrecían sanguches de hotdog, panchitos.

Creo que la comunidad también tiene que ver, contribuye ya que desde niños te dicen mira están vendiendo panchos y te compran.

\section{A ver, ustedes que están ahí en el salón con los niños ¿usualmente que contiene la}

\section{lonchera de sus alumnos?}

Bueno lo que normalmente observo en la lonchera de mis niños son fruta, en mi caso son 7 niños y todos llevan una fruta, después por ahí un dulce o un keke hecho en casa, galletas hechas en casa, la mayoría de las cosas hechas en casa, y solo tengo un niño que si tiene una nutricionista exclusivamente para él.

También vemos que le envían quinua, mazamorra morada, huevo, pan con queso y hasta supremas de pollo.

Y de bebidas agua o algún jugo, pero hecho en casa, como emoliente, jugo de naranja, o jugo de otra fruta, pero natural.

\section{¿Algún alumno de sus salones tienen problemas de obesidad, desnutrición o algo?}

En mi salón en estimulación si tengo un niño que sufre de obesidad, pero básicamente se dió porque lo cuidaba la abuela, la mamá trabajaba y la abuelita para que a veces no llore mucho le daba mucha comida, dulces. Incluso la mamá lo tuvo que llevar al nutricionista porque estaba demasiado subido de peso.

En los demás casos los docentes indicaron no tener casos similares o niños con algún problema. 
¿Cuántos refrigerios tienen en el día y en que horario?

En todos los casos indicaron solo uno a las 10:30 am porque los niños ingresan a las 8:30 am.

¿Y cuántos minutos dura el refrigerio?

30 minutos

Coméntenme por favor ¿cómo es el momento del refrigerio?, ¿apoyan a los niños?, o ¿ellos comen solos?

Yo tengo al menos dos niños que comen solos. Pero siempre nos repartimos con la auxiliar, cada uno va viendo grupos de dos. Entre nosotros nos vamos ayudando, porque hay siempre que apoyarlos en algo.

Bueno en realidad el producto que nosotros estamos ofreciendo es el de loncheras saludables, que sea nutritiva, balanceada de acuerdo con la edad del niño, el sexo y el peso del niño, que sea variada también.

¿Ustedes que recomendaciones y/o sugerencias nos darían con respecto a nuestro producto?

Que sea variada porque se aburren del sabor, que tenga máximo tres cosas, un jugo para que ellos puedan escoger.

¿Por favor podrían ayudarnos recomendándonos un logo de los propuestos?

Cada docente eligió su opción, y recomendaron que sea lo más colorido posible, para que llame la atención de los niños.

Gracias por su tiempo y sus propuestas. 
Anexo 9. Acta de la segunda sesión del focus group (docentes nivel primaria)

Lugar $\quad$ USIL - Sede La Molina

Fecha $\quad 26$ octubre 2017

Hora de inicio $\quad$ 19:00

Hora de termino $\quad 19: 50$

Criterio Docentes de educación primaria

Asistentes

1. Liliana

2. Sara

3. María Luisa

4. Silvia

5. Lizeth

6. Karin

7. Sonia

8. Ana

9. Mónica

10. Patricia

Fase de presentación

Buenas tardes, mi nombre es Rocío Salas, soy alumna de la Maestría de Ciencias Empresariales y actualmente mi grupo y yo nos encontramos realizando la investigación cualitativa de un proyecto de negocio para nuestro trabajo de Tesis.

Quisiera que por favor se presenten y nos indiquen desde cuando ejercen su profesión. 
Mi nombre es Liliana, soy profesora de educación primaria desde el año 1991, egresada de UNMSM

Mi nombre es Sara, soy docente de educación primaria hace 9 años y soy egresada de la USMP.

Mi nombre es Silvia, soy docente de educación física desde hace 20 años y soy egresada de la UNFV.

Mi nombre es Mónica, soy profesora de educación primaria desde el año 2001 y soy egresada de la USMP

Soy Ana Carpio, soy profesora desde hace casi 15 años y soy egresada de la Universidad Inca Garcilaso de la Vega.

Mi nombre es Sonia, yo soy profesora desde hace poco más de 20 años y soy egresada de la UNMSM.

Yo estudie en la PUCP, ejerzo la docencia desde hace poco más de 15 años y mi nombre es Patricia Casado.

Mi nombre es Karin, estudie educación en la UNFV y ejerzo desde hace 10 años aproximadamente.

Mi nombre es Lizeth, soy profesora de educación primaria desde hace 5 años.

Mi nombre es María Luisa, soy profesora desde hace 12 años.

Bueno, estamos reunidos aquí para conversar sobre un tema que actualmente preocupa no solo al Estado sino también a empresas y público en general.

Quisiera comentarles que en este focus no hay respuesta mala o buena, todas nos serán de mucha ayuda en nuestra investigación por lo que les pedimos que sean sinceros al momento de participar.

Asimismo, les comunicamos que la información tratada en este focus es estrictamente académica y será utilizada para fines de investigación por lo que será grabada. 


\section{$\underline{\text { La nutrición en la etapa escolar }}$}

Para iniciar la sesión me gustaría me indiquen: ¿Qué tan importante considera usted la nutrición en la etapa escolar?, y si afecta el rendimiento del alumno.

Considero que si es importante porque de ello depende que tan atento pueda estar el alumno en clase, si no ha tomado un buen desayuno el niño viene a clase cansado y con sueño, y están más preocupados por el recreo para poder comer algo.

La mala alimentación afecta también el comportamiento del niño en clase, es notorio cuando un niño va al colegio habiendo tomado desayuno, porque está atento a la clase y siempre está participando o al menos haciendo bulla, pero se hace notar (risas).

El niño que va al colegio sin tomar desayuno normalmente está bostezando en clase y a veces hasta durmiendo y por más que intentemos buscar su participación es imposible.

Definitivamente una adecuada alimentación es importante porque es la base del desarrollo físico e intelectual del niño.

Casi has respondido nuestra siguiente pregunta, ¿Coinciden entonces que una adecuada nutrición influye en el desarrollo físico e intelectual del niño?

El grupo en general coincide que la adecuada alimentación de los alumnos influye en su desarrollo físico e intelectual, porque tienen diferente comportamiento en clase y también es evidente en su desempeño diario.

\section{¿Por qué creen que es esencialmente importante que sus alumnos tomen desayuno?}

Es la principal alimentación del día.

Considerando las horas que el niño está en el colegio, es necesario que vaya con un buen desayuno que lo ayude a estar con energías al empezar la mañana. 
Les ayuda a estar más atentos en clase, por lo tanto, favorece su comprensión de los temas tratados en clase.

\section{¿Consideran que los niños deberían comer una lonchera balanceada y nutritiva a}

\section{media mañana?}

Definitivamente sí porque es esencial para recuperar energías por el desgaste intelectual.

Pienso que es importante, pero, lamentablemente los niños no toman decisiones pensando en nutrición o alimentos saludables y lo primero que compran es un sanguche de hamburguesa o pollo que acompañan con cremas y papas al hilo que termina siendo una fuente importante de grasas saturadas.

En mi caso tengo alumnos que llevan lonchera y generalmente es un sanguche y un refresco en toma todo, a veces una fruta; como también hay niños que llevan alimentos procesados como Frugos y galletas que a la larga perjudican su salud porque contienen mucha azúcar.

\section{$\underline{\text { Educación alimentaria en los centros educativos de nivel primaria }}$}

¿Considera usted que los centros educativos contribuyen en la formación de hábitos alimenticos de los alumnos?, de qué manera?

Ahora, por ejemplo, en la cafetería del colegio solo venden alimentos saludables, no venden gaseosas, dulces o tortas. Están optando más por las frutas y agua de tiempo.

En realidad, el colegio es un complemento a la educación recibida en casa, si el niño está acostumbrado a consumir ciertos alimentos que no son saludables para su organismo, quizás no los pueda comprar dentro del colegio, pero igual los comprará camino a su casa.

En el colegio donde trabajo, se pide a los padres enviar loncheras saludables a sus hijos, en lo posible no enviar dinero ni bebidas procesadas, en lo posible solo agua. 
Es cierto, de un tiempo a esta parte los padres también se preocupan por la alimentación saludable de sus hijos y poco a poco están cambiando los alimentos que incluían en las loncheras por otros más naturales y saludables al organismo.

\section{¿Qué rol cumplen los profesores para mejorar los hábitos alimenticios de los alumnos?}

Yo tengo un alumno que tiene problemas de sobrepeso y normalmente lleva frutas y agua en su lonchera, los padres no le envían dinero y regularmente la madre me consulta cómo va su comportamiento en clase, si come su lonchera y participa de la clase.

Yo tenía una alumna que siempre llevaba gaseosa o néctar de frutas procesado y galletas de chocolate, al ver que era muy frecuente, tuve que hablar con su abuela para explicarle que esa comida le hacía daño a la niña, he notado que poco a poco ha ido cambiando sus hábitos alimenticios y ahora la mayoría de los días lleva fruta y agua. Aún combina con comida chatarra, pero ¿el cambio debe ser gradual ¿no?

\section{¿Consideran que los quioscos o cafetería del colegio ofrecen alimentos saludables y} adecuados para los alumnos?

En la cafetería de mi colegio si se ha restringido la venta de golosinas y gaseosas, se está optando por comidas saludables.

Bueno donde yo trabajo no venden comida chatarra a los niños, pero los profesores si podemos comprar, entonces por ahí existe incomodidad por parte de los alumnos porque sienten que los están marginando.

\section{$\underline{\text { Hábitos alimenticios del alumno }}$}

¿Qué opinión tienen sobre los hábitos alimenticios de sus alumnos? 
Los hábitos alimenticios se forman en casa, de ahí que los profesores debemos estar en constante contacto con los padres de familia para poder orientarlos.

En el colegio donde trabajo, eventualmente se dan charlas sobre alimentación saludable a los padres y formas de preparar loncheras nutritivas para sus hijos.

\section{¿Generalmente, los alumnos llevan loncheras preparadas en casa?, ¿o llevan dinero para comprar algo?, ¿qué alimentos forman parte de esta lonchera?}

De 25 alumnos que tengo, entre 15 y 18 llevan lonchera preparada en casa, puede ser un sanguche o fruta y refrescos; los demás llevan la lonchera de casa, pero con productos comprados como golosinas y jugos en caja.

Yo tengo 20 alumnos y prácticamente todos llevan loncheras hechas en casa, puede ser fruta picada en táper o quizás una manzana o mandarina que son más fáciles de comer, de refresco generalmente agua de tiempo, salvo que sea el día de educación fisca y ahí si llevan su botella de agua.

¿Ha notado que alguno de sus alumnos tenga problemas de obesidad?, ¿como afecta ello a su rendimiento escolar?

En mi caso no, quizás algún alumno un poquito subido de peso, pero nada que comprometa su desempeño en clase.

Yo tengo un alumno que está con nutricionista, pero no estoy segura si su caso llegaría a ser obesidad, igual su madre está al pendiente de su desempeño en el colegio y se comunica frecuentemente conmigo.

\section{Información de los refrigerios escolares}

¿Cuántos refrigerios tienen al día, en qué horarios y cuánto duran? 
En educación primaria tenemos la hora de recreo que dura 20 minutos, inicia a las 10:30 a.m., en ese tiempo el alumno debe aprovechar consumir su lonchera, ir a los servicios y despejarse un poco de los estudios.

Si a las 10:30 a.m. el recreo dura un promedio de 25 minutos como máximo,

10:30 a.m. suena el timbre de primaria y los alumnos pueden salir al patio principal o cafetería a despejarse un poco, ahí aprovechan para consumir sus loncheras.

Todos asienten la cabeza indicando que el horario es el mismo en sus colegios.

\section{Coméntenos un poco cómo es el momento del refrigerio escolar}

Normalmente suena el timbre y los alumnos salen al patio principal o la cafetería, no todos llevan lonchera así es que un grupo se va a la cafetería a consumir su lonchera y puede que algunos estén conversando en el patio comiendo una fruta.

En mi caso, los alumnos son libres de salir o quedarse en el aula conversando. Siempre se les recomienda salir a tomar aire para que así reiniciemos la clase más despejados.

\section{Evaluación de propuesta de negocio}

Se presentó el producto y se consultó: ¿Qué ventajas encuentra en este nuevo servicio

\section{"Loncheras Saludables"?}

El servicio me parece novedoso y sobre todo práctico para los padres de familia.

Sobre todo, ahora que los padres no tienen tiempo de preparar loncheras en las mañanas.

¿Pero cómo lo entregarían?, ¿en su casa?

Si tiene opciones variadas de loncheras sería fabuloso para que los niños no se aburran de lo mismo.

$\mathrm{Si}$, así como es saludable, ven la forma de que también sea agradable al gusto de los niños, sería un éxito. 
Me parece interesante, sobre todo porque los padres estarían seguros que sus hijos están consumiendo alimentos saludables al organismo en vez de comprar comida chatarra en la cafetería del colegio.

\section{¿Tiene alguna sugerencia para el empaque?}

Debería ser un empaque que sea fácil de desechar y no contamine el medio ambiente.

La bolsa de papel es práctica, pero deberían tener cuidado de que soporte la botella de agua.

\section{¿Recomendaría a los padres de familia este servicio?}

Si lo recomendaría, sobre todo a los padres que envían dinero a sus hijos.

Es una buena alternativa que aliviaría el estrés de las mañanas para preparar loncheras de los niños

Personalmente, tengo una niña en educación primaria y es todo un caos preparar la lonchera en las mañanas antes de que llegue su movilidad, eso sin contar las compras del fin de semana.

Es un servicio interesan que facilitaría la vida de los padres que tienen niños en edad escolar

\section{Agradecemos su valioso tiempo,}


Anexo 10: Primera entrevista a profundidad expertos del sector restaurante

\section{Objetivo de la investigación}

Conocer la percepción de los clientes de la comida saludable.

\section{Contenido}

- Datos generales

- Mercado de la comida saludable

- Datos generales del negocio

- Funcionamiento del negocio

- Recomendaciones generales

\section{Perfil del participante}

Administradores de restaurantes de comida saludable en Lima.

\section{Cuestionario}

\section{Frase de presentación}

Buenos días (buenas tardes) mi nombre es. soy candidato a Magister de la MCE de la Escuela de Post Grado de la USIL y me encuentro realizando una investigación sobre Loncheras Saludables para niños en etapa escolar en el nivel inicial y primaria, un tema que actualmente preocupa no solo a las familias sino también a las empresas y Estado peruano.

Le informo que la información a tratar en esta entrevista es estrictamente académica y será utilizada para fines de investigación, por lo que será publicada en nuestra tesis.

Desde ya muchas gracias por su tiempo

\section{Datos generales}

1. ¿Cuál es su nombre?

Maribel Flores Macklemburg

2. ¿Qué cargo tiene en la empresa?

Gerente de Kymcha Restaurante 


\section{Mercado de la comida saludable}

3. ¿Cómo percibe el crecimiento de la comida saludable en Lima?

Percibe un gran crecimiento en todo el sector. Desde restaurantes hasta cafeterías y ferias, que ofrecen productos orgánicos en su carta.

4. ¿Cómo ha evolucionado la demanda de la comida saludable estos últimos años?

Ha evolucionado a gran nivel. Las cafeterías, incluso, ofrecen panes gluten- free, productos a base de granos andinos, opciones orgánicas, brownies saludables, que ayudan a cuidar la salud.

5. ¿Cuáles son las tendencias para los próximos años?

La gente está empezando a cuidar su salud. Comer saludable está de moda. Asimismo, la necesidad del cuidado físico está influyendo sobre la oferta y el estilo de vida del consumidor. Por ejemplo, los negocios ofrecen refrescos endulzados con panela; y en las fiestas infantiles se han reemplazado las golosinas por opciones más saludables.

\section{Datos generales del Negocio}

6. ¿Cómo se llama su negocio y donde está ubicado?

El negocio se llama Kymcha Restaurante y está ubicado en Miraflores.

7. ¿Cuánto tiempo viene funcionando su negocio?, ¿Cuál es la tendencia de su mercado? Alrededor de un año. La carta lleva desde ensaladas hasta comida casera.

8. ¿Cómo se animó a apostar por este mercado?, ¿Cuáles fueron las principales barreras de entrada?, (infraestructura, permisos, inversión, etc.)

Se animó por su experiencia en el rubro de hoteles y restaurantes. Después de años trabajando en el rubro, quiso emprender su propio restaurante.

No encontró muchas barreras, ya que sus familiares fueron su principal contacto y mecanismo para atraer gente al negocio. De la misma forma, un familiar la ayudó con el proceso de obtención de la licencia y el diseño del local.

\section{Funcionamiento del negocio}

9. Considera usted que, ¿La tendencia de su mercado está en crecimiento?, ¿Con cuánto personal cuenta actualmente?

El personal está conformado por 15 personas.

10. ¿A quiénes considera sus principales proveedores? (hipermercados, mayoristas, etc.) 
Sus principales proveedores son Laive, comerciantes del mercado de Surquillo y La Parada.

11. En su experiencia, ¿Qué insumos considera son más perecibles?

Los insumos más perecibles son las frutas por los postres frescos que se venden y se tienen mucho cuidado ya que la cocina es un espacio de trabajo caliente. Cuando las frutas no están en inventario se debe congelar la pulpa.

12. ¿Maneja un control de inventarios?

Se cuenta con personal encargado del control de inventario.

13. ¿Cuál es la estacionalidad del negocio?

La temporada fuerte es abril y mayo ya que las personas vuelven de la playa, pero en invierno se mueve más personas. Enero, febrero y marzo es baja la demanda, pero en horarios de almuerzo se tiene clientela, pero en la noche muy poco.

14. ¿Qué equipos considera usted muy necesarios para la elaboración de comida/jugos saludables?

El tipo de producto sería las mesas de trabajo que son refrigeradas en la parte de abajo, porque en la elaboración es cortar y guardar, sobre todo para que no se contamine y te dure mejor el producto. Otro equipo es una cámara congeladora con dos puertas para una mejor distribución y que viene con repisas.

15. ¿Cuáles son los medios más efectivos para llegar a su público objetivo?

Las relaciones con el cliente, el servicio y que la persona responsable este ahí para el cliente. Lo más sensible es el servicio por lo que más rota es la persona que atiende a tu cliente.

\section{Recomendaciones Generales}

16. ¿Tiene alguna recomendación o comentario adicional?

Me parece que las loncheras saludables son lo más interesante que se puede hacer y el público de a pocos está concientizandose de su importancia en la alimentación de los niños.

\section{Muchas gracias por su tiempo. Hasta luego.}


Anexo 11 Segunda entrevista a profundidad con expertos del sector restaurante

\section{Objetivo de la investigación}

Conocer la percepción de los clientes de la comida saludable.

\section{Contenido}

- Datos generales

- Mercado de la comida saludable

- Datos generales del negocio

- Funcionamiento del negocio

- Recomendaciones generales

\section{Perfil del participante}

Administradores de restaurantes de comida saludable en Lima.

\section{Cuestionario}

\section{Frase de presentación}

Buenos días (buenas tardes) mi nombre es. soy candidato a Magister de la MCE de la Escuela de Post Grado de la USIL y me encuentro realizando una investigación sobre Loncheras Saludables para niños en etapa escolar en el nivel inicial y primaria, un tema que actualmente preocupa no solo a las familias sino también a las empresas y Estado peruano.

Le informo que la información a tratar en esta entrevista es estrictamente académica y será utilizada para fines de investigación, por lo que será grabada.

Desde ya muchas gracias por su tiempo

\section{Datos generales}

1. ¿Cuál es su nombre?

Giancarlo Guerrero Canales

2. ¿Qué cargo tiene en la empresa? 
Jefe de operaciones de las unidades de negocio

\section{Mercado de la comida saludable}

3. ¿Cómo percibe el crecimiento de la comida saludable en Lima?

Hace aproximadamente tres años hubo un crecimiento del $50 \%$ del interés por parte de los clientes en intentar buscar opciones saludables, productos con insumos saludables y todo ello trajo como consecuencia que el concepto de comida en algunos establecimientos se vaya cambiando. Esto va de la mano con toda la comunicación y las redes sociales que hablan mucho de la alimentación saludable.

4. ¿Cómo ha evolucionado la demanda de la comida saludable estos últimos años?

La percepción de las personas era que lo rico va de la mano con lo grasoso o que no es saludable, pero ahora se le dice que lo saludable es rico y muy parecido a lo que el cliente prefiere, las personas comenzaron a tener un mayor interés y lo incluyen dentro de su comida cotidiana.

5. ¿Cuáles son las tendencias para los próximos años?

Esto va ir en crecimiento de todas maneras, ya que en comparación al año 2016 las líneas saludables que ofrecemos han crecido en un $38 \%$. El verano va a ser crucial, ya que la gente va a comenzar a consumir más para cuidarse por el verano.

\section{Datos generales del Negocio}

6. ¿Cómo se llama su negocio y donde está ubicado?

Di Café y Café del Santo. Di Café solo está ubicado en La Molina y Café del Santo está en los locales de la Universidad San Ignacio de Loyola (La Molina, Lima Norte y Magdalena).

7. ¿Cuánto tiempo viene funcionando su negocio?

Di Café once años y Café del Santo tres años. 
8. ¿Cuál es la tendencia de su mercado?

El Di Café está bien posicionado a comparación de años anteriores, las ventas han subido, nos hemos colocado entre las mejores cafeterías de comida saludable, estamos en el ranking de las 5 marcas más frecuentes de consumo. Café del Santo solo tiene presencia para los alumnos de las diferentes sedes.

9. ¿Cómo se animó a apostar por este mercado?

La universidad tomo la decisión de apostar por el concepto de comida saludable e implementar un nuevo modo de vida, por ello se retiraron las gaseosas de las tiendas, se ofrecen edulcorantes y otros. A partir del 2016 se ofreció una carta formal de comida saludable.

10. ¿Cuáles fueron las principales barreras de entrada?, (infraestructura, permisos, inversión, etc.)

La poca fe de la gente por el producto, ya que le cuesta mucho consumir o experimentar algo nuevo fuera de lo que consume habitualmente, por ello le ofrecíamos degustaciones pequeñas para que vayan encontrando con cuales productos se identifican.

\section{Funcionamiento del negocio}

11. Considera usted que, ¿La tendencia de su mercado está en crecimiento?, Definitivamente hay un gran mercado que se puede cautivar.

12. ¿Con cuánto personal cuenta actualmente?

El personal está conformado por atención al cliente 17 personas y en la cocina 13 personas.

13. ¿A quiénes considera sus principales proveedores? (hipermercados, mayoristas, etc.) 
Contamos con proveedores que nos abastecen dentro de la misma universidad, en base a un requerimiento que hacemos tenemos, dependiendo del precio y calidad, proveedores definidos. Ejemplo: Príncipe que se encarga solo de verduras, el Bife que solo es proteínas, son proveedores del rubro, que tienen buena aceptación, precios competitivos, y te abastecen en base a tus requerimientos.

14. En su experiencia, ¿Qué insumos considera son más perecibles?

Los insumos más perecibles son las frutas y verduras, las ensaladas no tienen más de dos días de vida, las ensaladas de frutas no duran más de un día y los que tienen más duración son las galletas y los kekes.

15. ¿Maneja un control de inventarios?

Todos los establecimientos cuentan con un kardex diario, de inventario inicial, ingreso del día e inventario final. Todos los días se descarga al sistema que brinda el reporte mensual del full cost, que es el porcentaje entre lo que compras y lo que vendes que es un $35 \%$ entre lo que uno invierte en insumo y lo que uno recibe de ingresos.

16. ¿Cuál es la estacionalidad del negocio?

La mayor demanda es entre marzo a diciembre, las épocas de verano las ventas bajan en un $60 \%$ por que el público se va a la playa.

17. ¿Qué equipos considera usted muy necesarios para la elaboración de comida/jugos saludables?

En el negocio la salad bar (barra de ensaladas) y el horno compresor que hace que el producto regenere a la calidad del producto inicial como se refrigeró, sin dañar las características de sabor, olor, tamaño o peso.

18. ¿Cuáles son los medios más efectivos para llegar a su público objetivo?

Actualmente el marketing digital para el público en general, para alumnos y administrativos los correos masivos. 


\section{Recomendaciones Generales}

19. ¿Tiene alguna recomendación o comentario adicional?

Es una tendencia a crecer, ya que las mamás hoy en día están más concientizadas en esto y se ha vuelto hasta una moda. Esta oportunidad de mercado es una gran apuesta.

Muchas gracias por su tiempo. Hasta luego. 
Anexo 12. Segunda entrevista a profundidad con expertos del sector: Nutrición

\section{Objetivo de la investigación}

Conocer el tipo de alimentos recomendados para niños en etapa escolar, así como las porciones necesarias y su valor nutricional.

\section{Contenido}

- Datos generales

- Hábitos alimenticios

- Consecuencias de una mala alimentación

- Nociones básicas de una lonchera escolar saludable

- Recomendaciones generales

\section{Perfil del participante}

Nutricionista.

\section{Cuestionario}

\section{Frase de presentación}

Buenos días (buenas tardes) Dra. Teresa Blanco de Alvarado mi nombre es Enrique Cueva, soy candidato a Magisteer de MCE de la Escuela de Post Grado de la USIL y me encuentro realizando una investigación sobre Loncheras Saludables para niños en etapa escolar a nivel inicial y primaria, un tema que actualmente preocupa no solo a las familias sino también a las empresas y Estado peruano.

Le comunico que la información a tratar en esta entrevista es estrictamente académica y será utilizada para fines de investigación, por lo que será publicada en nuestra tesis.

Desde ya muchas gracias por su tiempo

\section{Datos generales}

1. ¿Cuál es su especialidad y cuéntenos brevemente su experiencia laboral? 
Soy Doctora en Farmacia y Bioquímica por la Universidad Mayor de San Marcos, tengo un Postítulo de Bromatología Nutricionista y de Analista Química Farmacéutica. Directora de la Carrera de nutrición de la UPC.

Todo eso me abrió un mundo para la gente que quiere ser sana, para ayudar a identificar que se consume, como se consume y como alimentar a nuestros niños.

\section{Hábitos alimenticios}

2. ¿Cómo deberían ayudar los padres, a formar buenos hábitos alimenticios en sus hijos?

La madre peruana es la más nutricionista de todo el mundo, y los padres deben considerar cuatro cosas que muy importantes en la lonchera del niño:

Fuente de agua, el niño corre, salta, brinca y no debe llegar a tener sed, porque el niño tiene hasta $62 \%$ de agua en su organismo.

Fuente proteica, porque es importante para su crecimiento y muchas veces no se incluyen en el desayuno por la premura del tiempo en las mañanas (queso, huevo, etc.)

Fuente de semillas, que tiene proteínas, una cantidad equivalente a lo que cabe en su puño (maní, almendras, etc).

Fuente de carne, un trocito para acompañar el pan puede ser (res, pollo, etc.) Fuente energética, que brinda energía para ver, escuchar, tener actividad física, puede ser pan (por el trigo)

Fuente de verduras o frutas, para metabolizar los nutrientes necesitamos minerales y vitaminas, por mínimas porciones que podamos darle al niño será de beneficio para su organismo.

3. ¿Cómo podemos introducir hábitos saludables dentro de los gustos de los niños?

Es una lástima la cantidad de niños que tienen anemia en nuestro país y depende de los padres darles alternativas para que tengan una buena alimentación.

Un pan con pollo con trocitos de apio le da un sabor agradable al paladar del niño y también es alimenticio.

Un trozo de manzana con gotitas de limón, trocitos de naranja, debemos tratar de encontrar la comida saludable que más agrade al paladar del niño. 


\section{Consecuencias de una mala alimentación}

4. ¿Cuáles son las consecuencias en la salud de los niños si se tiene una mala alimentación?

La consecuencia más grave de una mala alimentación en los niños es que no permite desarrollar su organismo y por lo tanto no crecen como deberían. La segunda consecuencia es la anemia, ya que muchas madres no cuentan con los conocimientos sobre una alimentación balanceada y alimentan a sus niños con lo que consideran que es necesario.

5. ¿Cuáles son los factores que predisponen a la obesidad en los niños?

Cuando a un niño se le da pocas proteínas y muchas energías, nosotros no tenemos donde guardar carbohidratos (azucares y harinas), a un niño de 4 a 5 años, le encantan los dulces, pero si come más de lo que puede transformar en energía, lo transformara en grasa, por ello es importantísima la actividad física.

6. ¿Por qué cree usted que la obesidad crece y afecta principalmente a los niños entre los 6 y 10 años de edad?

Los niños entre 6 y 10años, deben aprender a comer saludable y tener mucha actividad física, jugar, correr, andar en bicicleta, ya que consumen mayor cantidad de dulces y si no realizan actividad física (como es actualmente), tienen mayor riesgo de transformar los dulces y harinas en grasas.

7. En caso de obesidad infantil ¿qué alimentos recomendaría? Frutas, verduras y proteínas porque cuando tiene un trozo de grasa que si se puede comer, esa grasa se deposita en todo nuestro organismo y esa grasa solo se elimina con proteínas.

\section{Nociones básicas de una lonchera escolar saludable}

8. ¿Por qué es importante la lonchera escolar?, ¿La lonchera reemplaza el desayuno?

La lonchera escolar es un muy importante para recuperar energías, pero definitivamente no reemplaza el desayuno, sino es un refrigerio de media mañana.

9. Desde el punto de vista nutricional ¿qué debe contener una lonchera adecuada para niños en edad escolar?

Como ya lo habíamos comentado al princio: 
Fuente de agua, el niño corre, salta, brinca y no debe llegar a tener sed, porque el niño tiene hasta $62 \%$ de agua en su organismo.

Fuente proteica, porque es importante para su crecimiento y muchas veces no se incluyen en el desayuno por la premura del tiempo en las mañanas (queso, huevo, etc.)

Fuente de semillas, que tiene proteínas, una cantidad equivalente a lo que cabe en su puño (maní, almendras, etc.).

Fuente de carne, un trocito para acompañar el pan puede ser (res, pollo, etc.) Fuente energética, que brinda energía para ver, escuchar, tener actividad física, puede ser pan (por el trigo)

Fuente de verduras o frutas, para metabolizar los nutrientes necesitamos minerales y vitaminas, por mínimas porciones que podamos darle al niño será de beneficio para su organismo. En el caso de las frutas, con gotitas de limón para evitar que se oxiden y no sean agradables a la vista del niño.

10. ¿Qué tipos de refresco o bebida recomienda?

Básicamente refrescos naturales o agua, nada industrializado. Quizás naranjada, limonada, agua de manzana, o frutas sin pepas.

11. En cuanto a la cantidad y/o porción de las loncheras, ¿Se debe tener en cuenta la edad del niño, el peso, la talla y la actividad física?

Cada niño por su edad necesita una cantidad de proteínas y vitaminas promedio, en función a sus características físicas y desarrollo de actividades.

12. ¿Las loncheras pueden variar de acuerdo con la temporada del año?, ¿Qué tipo de alimentos recomendaría para cada temporada?

Tenemos variedad de frutas durante todo el año y todas son beneficiosas para el organismo, debemos enseñar a nuestros niños, por ejemplo, a comer la manzana con cascara ya que la fibra ayuda a la digestión de los alimentos.

13. ¿Cuántas calorías al día debe consumir un niño dependiendo su edad (1-3, 4-6, 7-10)?

1600 a 1700 los alumnos del nido Hasta 2000 los niños de 4 años 
14. Para niños con enfermedades como alergias, anemia, sobrepeso etc., ¿La lonchera puede ser igual que la de un niño sano?, ¿Qué tipo de lonchera se recomienda?

Un niño con anemia debe consumir el doble de proteínas que un niño sano, en realidad de cada dos niños, uno es anémico.

15. En cuanto a la variedad, ¿Qué alimentos debemos incluir en la semana y/o a diario?

Tenemos alimentos en el Perú, que ni conocemos, los amazónicos, por ejemplo, ellos tienen proteínas, carbohidratos grasas agua macronutrientes y como micronutrientes grasos. Alimentos recomendados son, brócoli, coliflor.

16. ¿Qué tipo de alimentos no son recomendados para incluir en una lonchera saludable?

Definitivamente los alimentos procesados ya que se abusa del almidón, grasas y azucares. Normalmente de cada 10 alimentos que consumimos, 6 o 7 son procesados, un huevo frito, la leche con azúcar, el pan con mantequilla. No tenemos una chacra para tener alimentos $100 \%$ naturales.

17. ¿Cómo se consigue que los alimentos que contienen una lonchera se conserven adecuadamente?

Los Huevos por ejemplo deben ser pelados al momento de consumirlos, el niño debe aprender a pelar el huevo y eso también ayuda a su psicomotricidad, si se envía pelado no ponerlo en envase hermético porque huele.

La fruta que tiene oxidantes, con unas gotitas de limón.

18. ¿En qué tipo de recipientes debe guardarse los alimentos de la lonchera escolar?

Lo más posible evitar los envases herméticos, ya la lonchera es cerrada.

19. ¿Qué se debe considerar para el correcto transporte de los alimentos?

Evitar tener las loncheras mucho tiempo bajo el sol, para no dañar los alimentos.

20. ¿Cuáles son los beneficios de una lonchera saludable?

Que cubra los requerimientos alimenticios diarios durante la mañana, entre el desayuno y el almuerzo, ya que actualmente el desayuno es algo rápido por el tiempo y a la hora de almuerzo llegan cansados y con sueño por la actividad física realizada en el colegio. 


\section{Recomendaciones}

21. Durante el crecimiento del niño en la etapa escolar, ¿Qué recomendaciones nutricionales brindaría?

Tener en cuenta la energía, proteínas y vitaminas más que grasas.

La proteína, porque los hará crecer y les dará las enzimas que necesita para su metabolismo.

La energía le permitirá desarrollar sus actividades físicas.

Las vitaminas y minerales que le dará las frutas y verduras le permitirán hacer reacciones completas.

\section{Cierre}

22. ¿Tiene alguna recomendación o comentario adicional?

Quiero felicitarlos por su preocupación en investigar sobre el beneficio que puede brindar una lonchera saludable en el desarrollo de nuestros niños.

Muchas gracias por su tiempo Hasta luego. 
Anexo 13. Imágenes de alternativas de logo

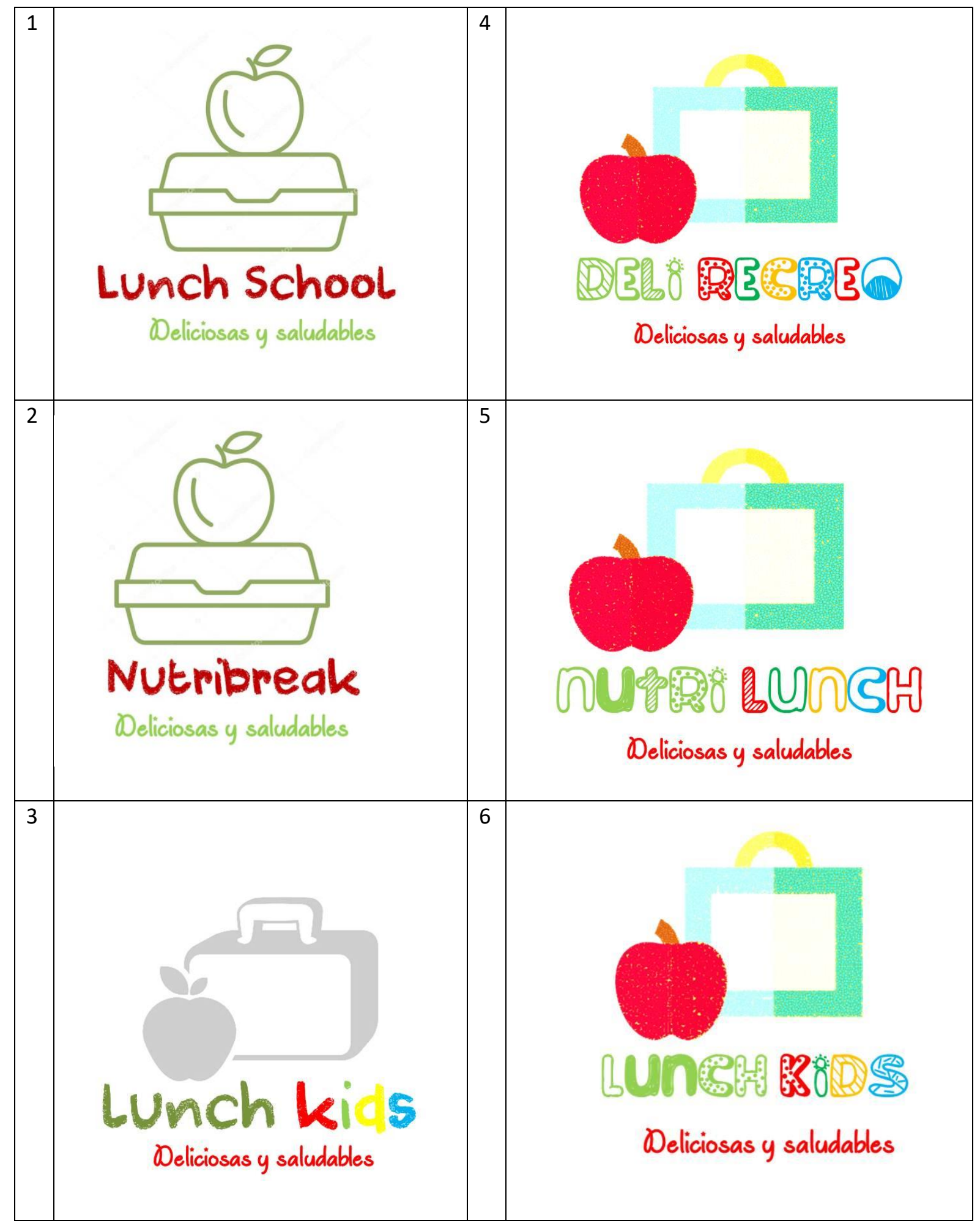




\section{Anexo 14. Cuestionario}

Estimados padres de familia, nos encontramos en la preparación de nuestra tesis por lo que estamos realizando un estudio de viabilidad sobre un plan de negocio y nos gustaría que nos puedan ayudar completando la siguiente encuesta con la mayor sinceridad posible.

Por favor marque su respuesta con una $(\mathrm{x})$

EDAD: GENERO: F ( ) M ( )

Preguntas filtro

¿Cuenta con niño(s) que actualmente se encuentren en edad escolar?

a. $\quad(\mathrm{Si})$ pase a siguiente pregunta

b. (No) fin de la encuesta

\section{¿En qué nivel educativo se encuentra su hijo?}

a. Educación Inicial

b. Educación Primaria

c. Educación Segundaria (fin de la encuesta)

¿Su hijo se encuentra estudiando en una institución educativa privada?

a. Si

b. No (fin de la encuesta)

¿En qué distrito estudia su hijo?

a. Ate

b. Santa Anita

c. La Molina

d. Otros (fin de la encuesta)

¿En qué Centro Educativo estudia su hijo?

¿En qué rango se encuentra el ingreso familiar mensual?

a. $\quad$ Más de S/ 10859 (fin de la encuesta)

b. De S/ 5606 a S/ 10859

c. De S/ 3446 a S/ 5605

d. Menos de S/ 3445 (fin de la encuesta)

¿Usted decide sobre el contenido de la lonchera de sus hijos?

a. $\mathrm{Si}$

b. No (fin de la encuesta)

¿Su hijo acostumbra llevar lonchera al colegio?

a. $\mathrm{Si}$

b. No (fin de la encuesta)

1. ¿Qué opción de alimentos predomina en la lonchera de sus hijos?

a. Galletas, snacks, chocolates, jugos procesados u otros similares

b. Embutidos, frituras u otros similares

c. Frutas frescas, frutos secos, verduras, agua

2. ¿Cuál es la principal razón por la que su hijo debería consumir una lonchera saludable? Marque del 1 al 4 según el grado de importancia, siendo 1 el más importante y 4 el menos importante.

\begin{tabular}{|l|l|l|l|l|}
\hline DETALLE & $\mathbf{1}$ & $\mathbf{2}$ & $\mathbf{3}$ & $\mathbf{4}$ \\
\hline Ayuda al correcto crecimiento de los niños & & & & \\
\hline Ayuda a prevenir enfermedades & & & & \\
\hline Ayuda en el aprendizaje y desarrollo de actividades físicas & & & & \\
\hline Evita la obesidad & & & & \\
\hline
\end{tabular}


3. ¿Conoce alguna empresa que brinde servicio de loncheras saludables estándar para niños de educación inicial o primaria?

a. Si (¿Cuál?)

b. No

Loncheras Saludables para niños de educación inicial y primaria

La propuesta de negocio consiste en la elaboración de loncheras saludables, nutritivas, balanceadas y variadas para niños en edad escolar. Cada lonchera contiene una porción de fruta, sándwich saludable y refresco o agua (hasta 500ml) presentados en un empaque reciclable con abre fácil apropiado para la manipulación de los niños.

4. Basándose en la descripción del producto, ¿Le parece interesante esta propuesta?

d. $\mathrm{Si}$

e. $\quad$ No (fin de la encuesta)

5. ¿Qué opción de bebidas le gustaría encontrar en la lonchera saludable? Marque del 1 al 4 según el grado de importancia, siendo 1 el más importante y 4 el menos importante.

\begin{tabular}{|l|l|l|l|l|}
\hline DETALLE & $\mathbf{1}$ & $\mathbf{2}$ & $\mathbf{3}$ & $\mathbf{4}$ \\
\hline $\begin{array}{l}\text { Refrescos naturales (limonada, piña, maracuyá, manzana, } \\
\text { emoliente u otros similares) }\end{array}$ & & & & \\
\hline Infusiones (manzanilla, hierba luisa, anís u otros similares) & & & & \\
\hline Jugos de fruta (naranja, piña, papaya, fresa u otros similares) & & & & \\
\hline Agua & & & & \\
\hline
\end{tabular}

6. ¿Qué opción de sándwich le gustaría encontrar dentro de nuestras opciones de loncheras saludables? Marque del 1 al 4 según el grado de importancia, siendo 1 el más importante y 4 el menos importante.

\begin{tabular}{|l|l|l|l|l|}
\hline DETALLE & $\mathbf{1}$ & $\mathbf{2}$ & $\mathbf{3}$ & $\mathbf{4}$ \\
\hline $\begin{array}{l}\text { Sándwich (pollo, atún, sangrecita, huevo, palta, queso, jamón de } \\
\text { pavita u otros similares) }\end{array}$ & & & & \\
\hline Galletas (integrales, quinua, kiwicha u otros similares) & & & & \\
\hline Huevitos de codorniz, choclo con queso & & & & \\
\hline Tortillas de verduras (brócoli, berenjena u otros similares) & & & & \\
\hline
\end{tabular}

7. ¿Qué opción de frutas le gustaría encontrar dentro de nuestras opciones de loncheras saludables? Marque del 1 al 4 según el grado de importancia, siendo 1 el más importante y 4 el menos importante.

\begin{tabular}{|l|l|l|l|l|}
\hline DETALLE & $\mathbf{1}$ & $\mathbf{2}$ & $\mathbf{3}$ & $\mathbf{4}$ \\
\hline Naranja, pepino, piña, uva, kiwi & & & & \\
\hline Mandarina, granadilla, durazno, melocotón & & & & \\
\hline Manzana, pera, melón, papaya, plátano, guayaba & & & & \\
\hline Frutos secos & & & & \\
\hline
\end{tabular}

8. Después de revisar la cartilla adjunta ¿Cuánto estaría dispuesto a pagar por una lonchera saludable que incluye refresco, sanguche y fruta?

a. Menos de $\mathrm{S} / 3$

b. $\quad$ De $\mathrm{S} / 3$ a menos de $\mathrm{S} / 5$

c. $\quad$ De $\mathrm{S} / 5$ a menos de $\mathrm{S} / 6$

d. $\quad$ De $\mathrm{S} / 6$ a menos de $\mathrm{S} / 7$

e. $\quad$ De $S / 7$ a menos de $S / 8$

f. $\quad$ De $S / 8$ a menos de $S / 9$

g. Más de S/. 9 soles

9. ¿Estaría dispuesto a comprar la lonchera saludable?

a. definitivamente si

b. probablemente si

c. me es indiferente

d. probablemente no

e. definitivamente no 
10. ¿Qué paquete de lonchera saludable compraría usted?

a. Semanal

b. Quincenal

c. Mensual

d. Eventual

11. Del periodo escolar ¿Con qué frecuencia estaría dispuesto a consumir el programa de loncheras saludables?

a. Una vez al mes.

b. Una vez cada 15 días.

c. Una vez a la semana.

d. 2 veces a la semana.

e. 3 veces a la semana.

f. 4 veces a la semana

g. 5 veces a la semana.

12. ¿Cómo preferiría realizar el pago de las loncheras saludables? Marque del 1 al 4 según su preferencia, siendo 1 el más requerido y 4 el menos requerido.

\begin{tabular}{|l|l|l|l|l|}
\hline DETALLE & $\mathbf{1}$ & $\mathbf{2}$ & $\mathbf{3}$ & $\mathbf{4}$ \\
\hline Efectivo & & & & \\
\hline Deposito/transferencia en cuenta & & & & \\
\hline POS (tarjeta de crédito/debido) & & & & \\
\hline Cargo automático en cuenta & & & & \\
\hline
\end{tabular}

13. ¿Le gustaría recibir tips sobre temas de nutrición de manera gratuita a su correo?

a. Si

b. No

14. ¿Recomendaría estas loncheras saludables con sus amistades?

a. definitivamente si

b. probablemente si

c. me es indiferente

d. probablemente no

e. definitivamente no

15. ¿Qué promoción le gustaría recibir eventualmente?, marque del 1 al 4 según su preferencia, siendo 1 el más requerido y 4 el menos requerido.

\begin{tabular}{|l|l|l|l|l|}
\hline DETALLE & $\mathbf{1}$ & $\mathbf{2}$ & $\mathbf{3}$ & $\mathbf{4}$ \\
\hline Una lonchera especial para su hijo el día de su cumpleaños & & & & \\
\hline Un descuento especial en la semana del cumpleaños de su hijo & & & & \\
\hline Una lonchera gratuita para su hijo el día de su cumpleaños & & & & \\
\hline Una lonchera gratuita para la mamá o el papá & & & & \\
\hline
\end{tabular}

16. ¿Cuál sería un nombre adecuado para este proyecto?, marque del 1 al 5 según su preferencia, siendo 1 el más requerido y 5 el menos requerido.

\begin{tabular}{|l|l|l|l|l|l|}
\hline DETALLE & $\mathbf{1}$ & $\mathbf{2}$ & $\mathbf{3}$ & $\mathbf{4}$ & $\mathbf{5}$ \\
\hline Nutribreak & & & & & \\
\hline LunchSchool & & & & & \\
\hline NutriLunch & & & & & \\
\hline LunchKids & & & & & \\
\hline Delirecreo & & & & & \\
\hline
\end{tabular}


17. ¿Cómo desearía que se realice la comunicación con usted?, marque del 1 al 4 según su preferencia, siendo 1 el más requerido y 4 el menos requerido.

\begin{tabular}{|l|l|l|l|l|}
\hline DETALLE & $\mathbf{1}$ & $\mathbf{2}$ & $\mathbf{3}$ & $\mathbf{4}$ \\
\hline Correo electrónico & & & & \\
\hline WhatsApp & & & & \\
\hline Facebook & & & & \\
\hline Teléfono & & & & \\
\hline
\end{tabular}


Anexo 15. Preguntas de control- perfil general de los niveles socioeconómicos

Preguntas de control (perfil general de los niveles socioeconómicos)

N1 ¿Cuál es el nivel de instrucción del jefe del Hogar?

1

Primaria Completa/Incompleta

2 Secundaria Incompleta

3 Secundaria Completa

4 Superior No Universitario (p. ej. Instituto Superior, otros)

$5 \quad$ Estudios Universitarios Incompletos

6

Estudios Universitarios Completos (Bachiller, Titulado)

7 Postgrado

N2 ¿A dónde acude el Jefe de Hogar para atención médica cuando él tiene algún problema de salud?

1 Posta médica / farmacia / naturista

2 Hospital del Ministerio de Salud / Hospital de la Solidaridad

3 Seguro Social / Hospital FFAA / Hospital de Policía

Médico particular en consultorio

5 Médico particular en clínica privada
N3

¿Cuál de las siguientes categorías se aproxima más al salario mensual de su casa?

$1 \quad$ Menos de 750 soles/mes aproximadamente

2 Entre $750-1000$ soles/mes aproximadamente

$3 \quad 1001-1500$ soles/mes aproximadamente

4

> 1500 soles/mes aproximadamente

N4A ¿Cuántas habitaciones tienen su hogar, exclusivamente para dormir?

N4-B ¿Cuántas personas viven permanentemente en el hogar? (sin incluir el servicio doméstico)

N5 ¿Cuál es el material predominante en los pisos de su vivienda?

1

Tierra / Arena

2 Cemento sin pulir (falso piso)

3 Cemento pulido / tapiz

4 Mayólica / loseta / cerámicos

5 Parquet / madera pulida / alfombra / mármol / terrazo

SUMAR PUNTAJES DE N1, N2, N3, N4 y N5 - ANOTAR RESULTADO Y MARCAR NSE 
Anexo 16. Modelo de convenio interinstitucional

\section{CONVENIO INTERINSTITUCIONAL}

\section{Conste por el presente documento el Convenio Interinstitucional (en adelante el Convenio) que suscriben:}

- De una parte, LUNCH KIDS S.A., con RUC. № con domicilio en

Ate-Vitarte, Lima, debidamente representada por sus Apoderados, , identificado con DNI. № -------- y Sr.

identificado con DNI. № ----------, según poderes inscritos en la Partida Electrónica № ---------- del Registro de Personas Jurídicas de Lima, a la que en adelante se denominará LUNCH,

- Y de la otra parte, , con RUC № , con domicilio en debidamente representada por su Apoderado, , según poderes inscritos en la Partida Electrónica № identificado con DNI $\mathrm{N}^{\circ}$ del Registro de Personas Jurídicas de Lima, a la que en adelante se denominará

Se deja constancia que cuando en el texto del presente Convenio se utilice el término "parte" se entenderá referido indistintamente a LUNCH o término "partes" se entenderá referido a LUNCH y en conjunto. y cuando se utilice el

El Convenio se celebra en los términos contenidos en las siguientes cláusulas:

\section{CLÁUSULA PRIMERA: ANTECEDENTES}

1.1 LUNCH es una empresa que brinda servicios de alimentación saludable a niños de nivel inicial y primaria.

1.2 (en adelante, el Colegio) es una institución educativa que desarrolla actividades académicas. Cuenta con Licenciamiento Institucional otorgado mediante la R.M. № , de fecha de de

\section{CLÁUSULA SEGUNDA: OBJETO DEL CONVENIO}

El presente Convenio tiene como finalidad que los alumnos de los colegios de inicial y primaria, puedan recibir de forma directa los productos ofrecidos por LUNCH, siempre que cumplan con las condiciones establecidas por COLEGIO, así como obtener un beneficio conforme a lo señalado en el presente Convenio.

\section{CLÁUSULA TERCERA: POR PARTE DE LA EMPRESA}

Podrán beneficiarse con el presente Convenio con los siguientes acuerdos:

a) LUNCH ofrecerá publicidad sin costo al COLEGIO a través de sus medios digitales y cualquier otra actividad de difusión masiva que la empresa realice.

b) LUNCH estará presente como auspiciador durante el desarrollo de la Kermes anual del COLEGIO. 
c) LUNCH estará presente como auspiciador durante el desarrollo de las actividades del día del maestro del COLEGIO.

CLÁUSULA CUARTA: POR PARTE DEL COLEGIO

EI COLEGIO se compromete a:

a) COLEGIO apoyará discrecionalmente en la difusión de los beneficios del presente Convenio a través de sus medios de comunicación internos (boletines internos, Intranet, e-mail, vitrinas, paneles, etc.) y a través de medios de comunicación masivos dirigidos a los padres de niños de inicial y primaria. Asimismo, LUNCH podrá realizar charlas informativas en los locales del COLEGIO, previa coordinación entre las partes.

b) COLEGIO se compromete a recibir las loncheras entregadas por LUNCH y distribuirla a los niños en sus respectivas aulas.

\section{CLÁUSULA QUINTA: COORDINADORES DEL CONVENIO}

A efectos de asegurar el logro del objeto y debido cumplimiento de los compromisos establecidos en el presente Convenio, las partes acuerdan designar como coordinadores del mismo a las siguientes personas:

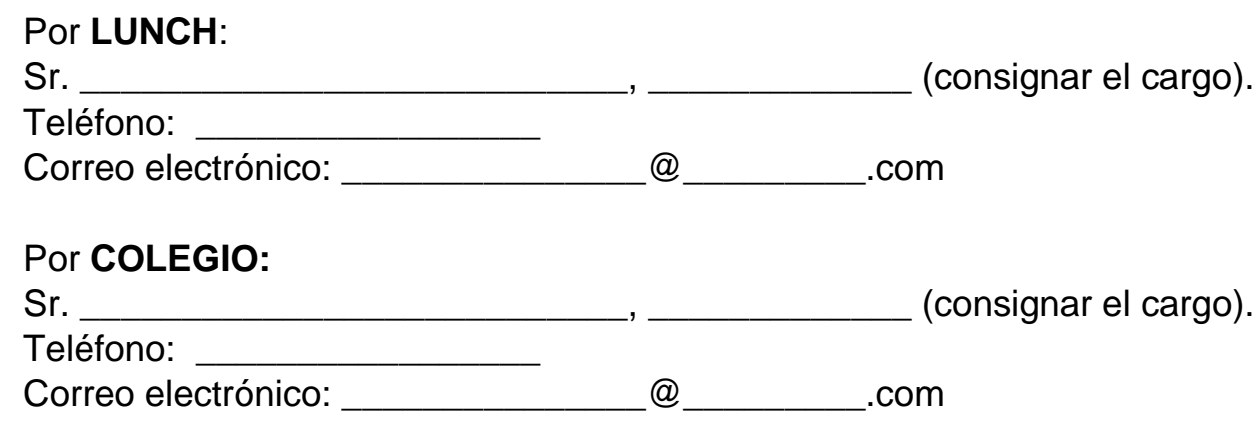

\section{CLÁUSULA SEXTA: NATURALEZA DEL VÍNCULO}

Las partes reconocen que el presente Convenio es de naturaleza civil y no genera ningún tipo de asociación o joint venture ni compromiso adicional a los expresamente establecidos en este documento. Asimismo, las relaciones laborales establecidas por cada una de las partes con su personal se mantendrán de la misma manera en que han venido existiendo, aún en los casos en que ambas instituciones realicen trabajos conjuntos que se desarrollen en las instalaciones o con los equipos de cualquiera de ellas, razón por la cual el presente acuerdo no causa vínculo laboral alguno ni da lugar a ninguna clase de prestaciones, beneficios $y / 0$ derechos sociales $y / 0$ previsionales entre el personal participante de LUNCH o COLEGIO respectivamente.

\section{CLÁUSULA SÉPTIMA: DATOS PERSONALES}

Las partes se obligan a realizar todas las actividades relacionadas que pudieran darse en virtud de las obligaciones del presente Convenio de conformidad y cumpliendo con lo dispuesto en la Ley 29733 sobre protección de Datos Personales, su reglamento y sus normas modificatorias.

Las partes se comprometen a guardar confidencialidad de los documentos que pudieran contener datos personales, incluso con posterioridad a la culminación del presente Convenio. 
Las partes se comprometen a devolver o destruir la información referida a documentos que pudieran contener datos personales que hayan obtenido en virtud al presente Convenio y sobre los cuales no se haya obtenido el consentimiento del titular para su tratamiento, salvo aquellos que por la naturaleza de las actividades y servicios a desarrollar tuvieran que ser considerada.

\section{CLÁUSULA OCTAVA: PLAZO Y RESOLUCIÓN}

El presente Convenio entrará en vigencia a partir de la fecha de su suscripción y tendrá una duración de cinco (5) años, el mismo que se renovará automáticamente y de manera sucesiva por periodos de cinco (5) años.

Cualquiera de las partes podrá resolver en cualquier momento el presente convenio sin necesidad de expresión de causa, no generando ello indemnizaciones o penalidades, bastando comunicar dicha decisión por vía notarial a la otra parte con una anticipación no menor a treinta (30) días calendario a la fecha en que se desee hacer efectiva la resolución.

\section{CLÁUSULA NOVENA: DOMICILIOS}

Las partes señalan como sus domicilios los consignados en la introducción del presente documento, a donde se les tendrá por bien notificados judicial o extrajudicialmente. Cualquier cambio de domicilio deberá ser comunicado a la otra parte por vía notarial, surtiendo efecto a partir del quinto día hábil posterior a la fecha de recepción de la comunicación.

Lima, de de 20

LUNCH KIDS S.A.

COLEGIO

$X X X X X X X X X X X$

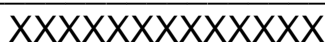

Apoderado

Apoderado 


\section{Lonchera para Primaria}
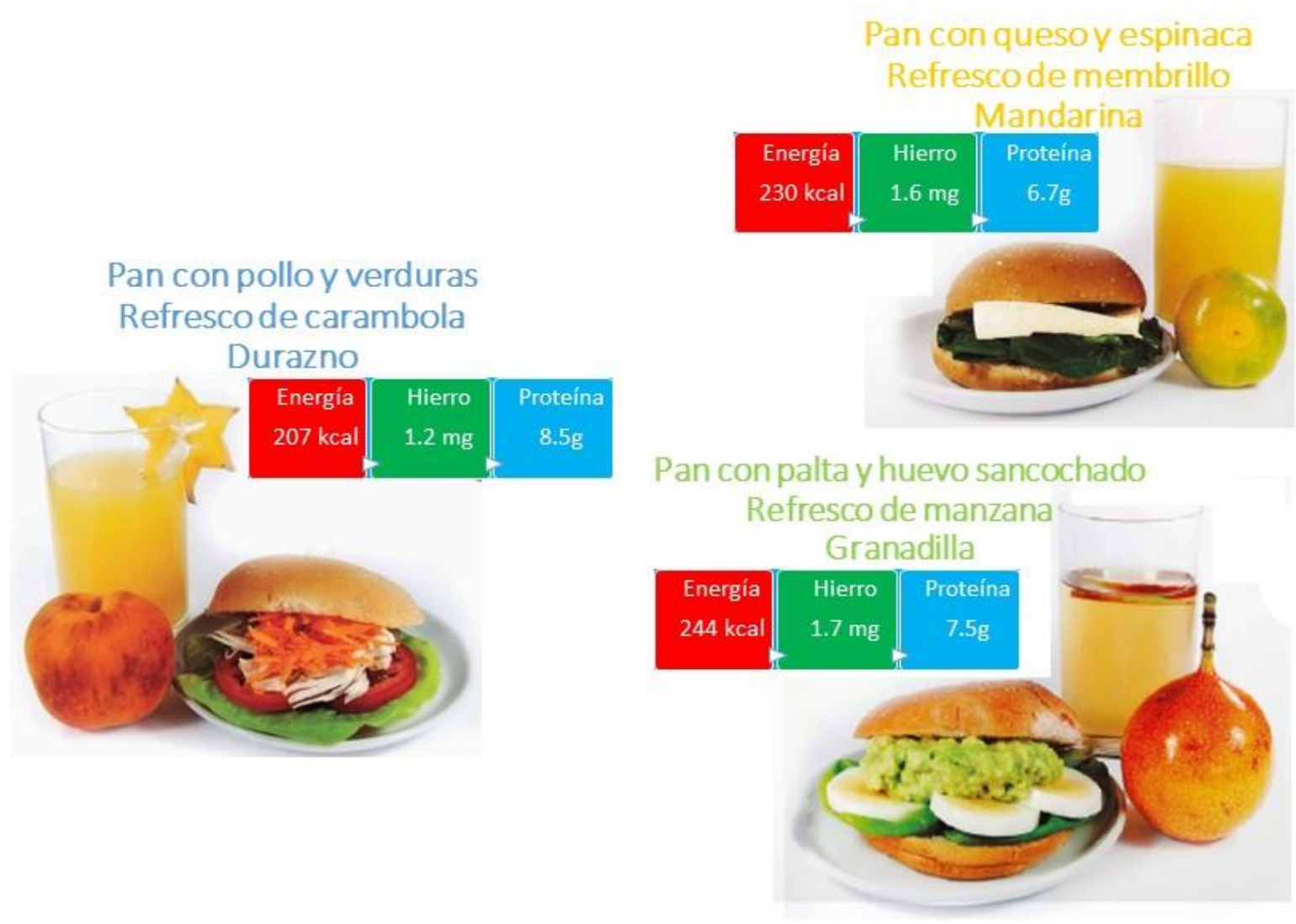

Pan con torrejita de sangrecita Jugo de durazno Naranja

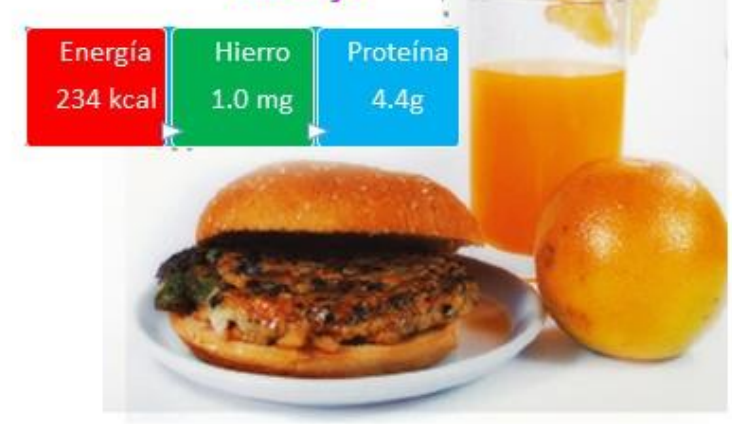

Choclo arrebozadocon huevo Refrescode cebada

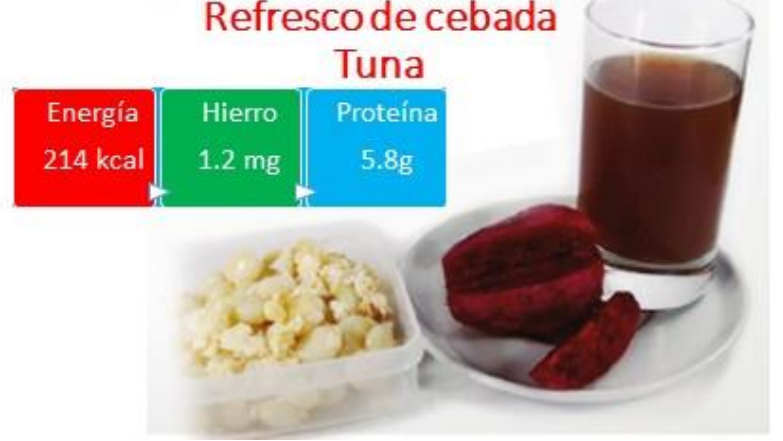


Anexo 18: Cartilla de lonchera saludable para Educación Inicial

\section{Lonchera para Inicial}

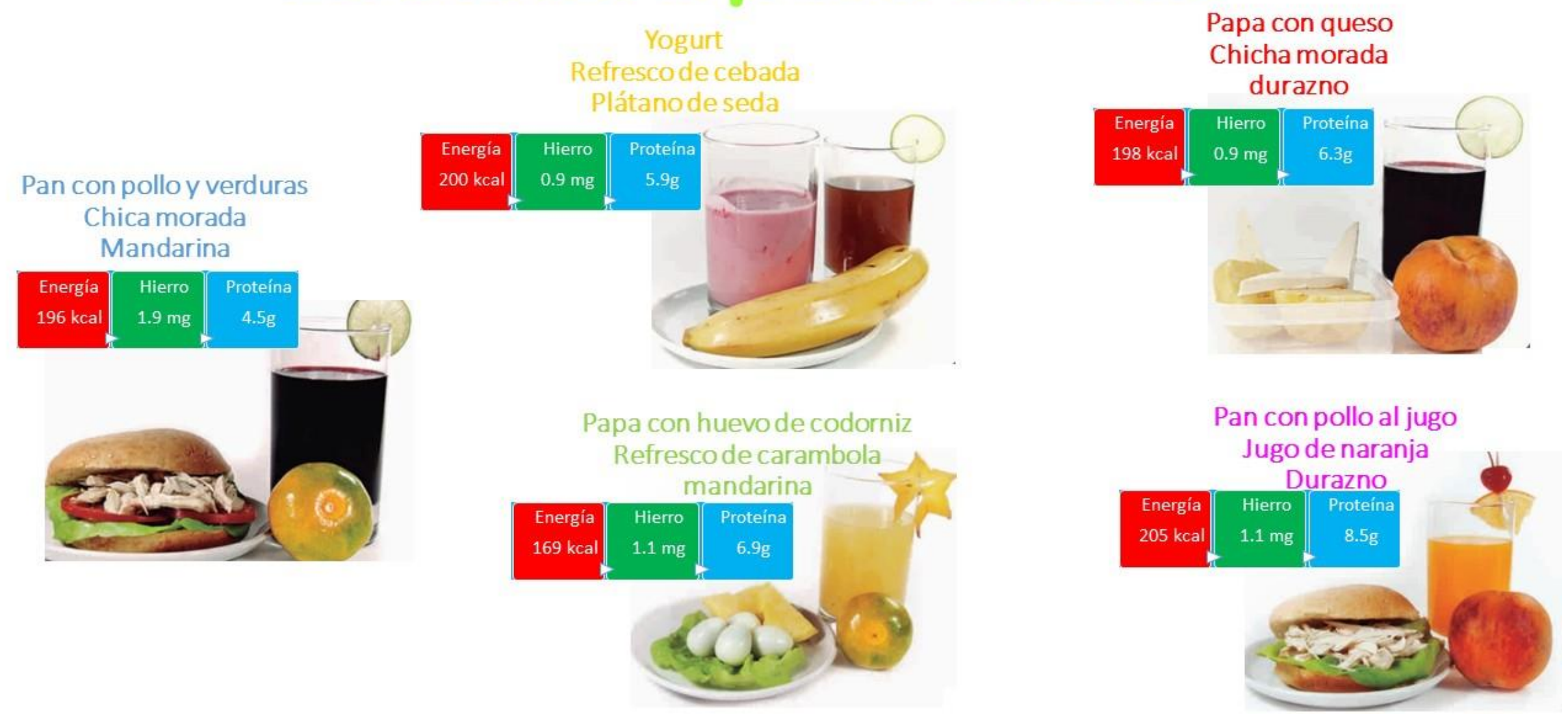




\section{Presentación y empaque de loncheras}
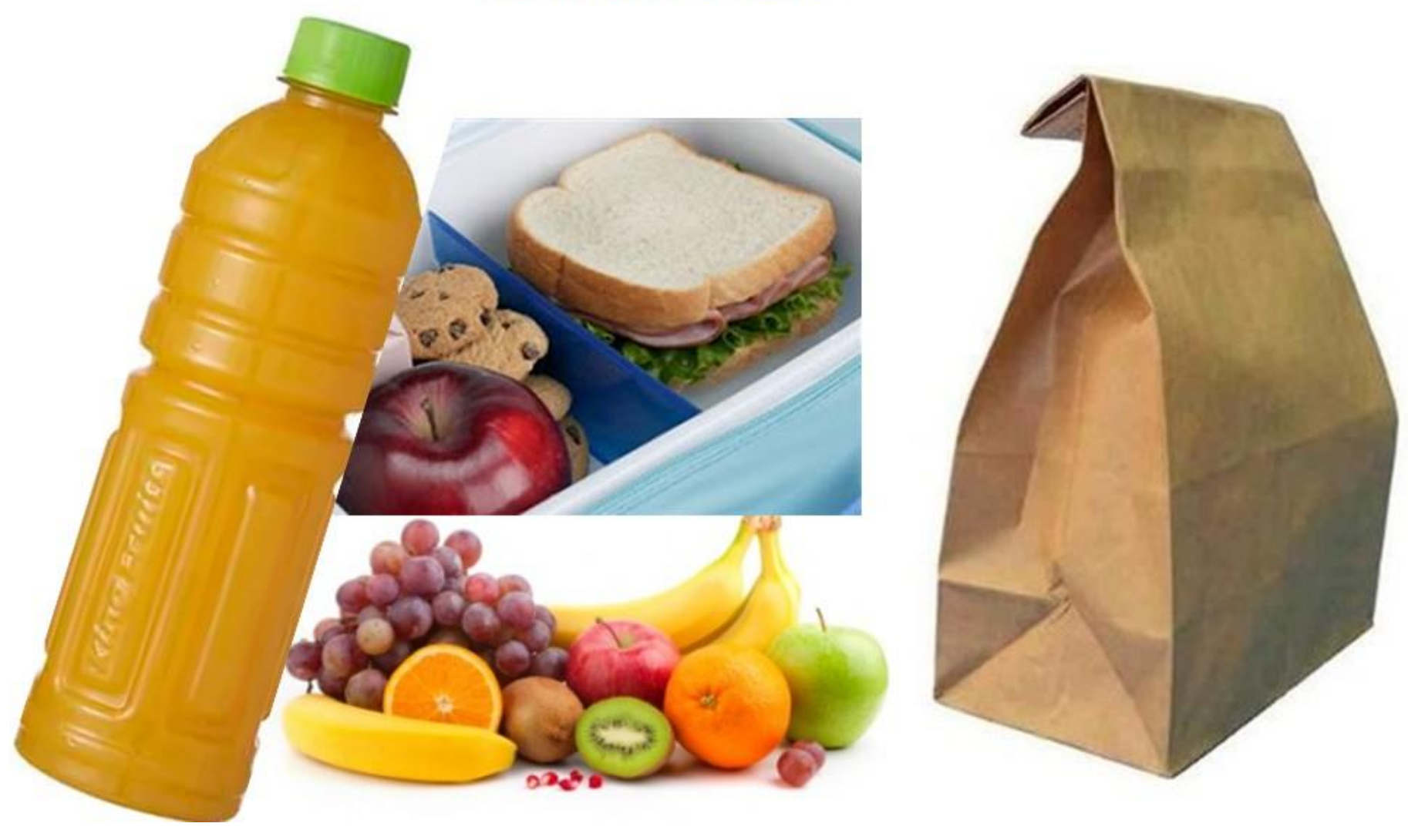